Check for updates

Cite this: RSC Adv., 2019, 9, 16606

\title{
An overview on synthetic strategies for the construction of star-shaped molecules
}

\author{
Hadeer M. Diab, Amr M. Abdelmoniem, Mohamed R. Shaaban, \\ Ismail A. Abdelhamid (D) * and Ahmed H. M. Elwahy (D)* \\ Strategies for the synthesis of star-shaped molecules have been in high demand in the last decades due to \\ the importance of those compounds in various fields. The distinctly different properties of these \\ compounds compared to their linear analogues make them versatile building blocks for the formation of \\ mesophases of interesting mesomorphic and photophysical properties. Moreover, the applications of \\ star-shaped molecules as building units for dendrimers as well as in supramolecular host-guest \\ chemistry have also been recently studied. The star-shaped molecules mentioned in this review are \\ classified according to the central core as well as the type of side arms. The properties and applications \\ of these compounds are described in the appropriate contexts. This report summarizes the recent \\ advances in this area.
}

Received 11th April 2019
Accepted 7th May 2019

DOI: 10.1039/c9ra02749a

rsc.li/rsc-advances

the synthesis of the first star-shaped polyamides. ${ }^{1}$ In 1962 , Morton et al. reported the synthesis of tetra-liked branched polystyrene through anionic polymerization. Due to its shape, this polymer was named for the first time as a star molecule. ${ }^{2}$ The name star-shaped molecules (SSMs) was then given to all structures, even small molecules, in which more than two arms are attached symmetrically to a single multifunctional core. Compared to polymer materials, small molecules offer potential advantages in terms of defined molecular structure, definite molecular weight, easy purification, and good batch-to-batch reproducibility. ${ }^{3-5}$

Some derivatives of these compounds were synthesized as promising molecules for application in optoelectronics and electrochromic devices. ${ }^{6-17}$ The structure of such molecules makes them versatile building blocks for the

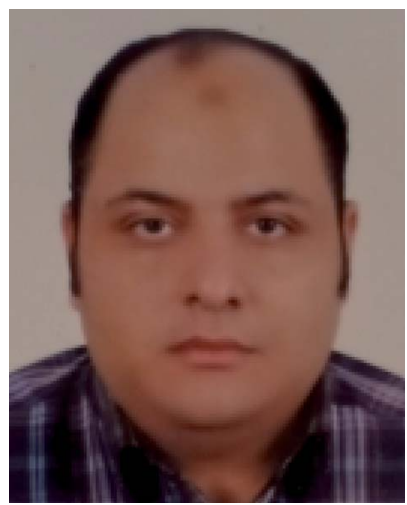

Amr M. Abdelmoniem was born Hadeer M. Diab was born in 1992 in Giza, Egypt. She graduated from Cairo University, Faculty of Science, Egypt in 2013 then she was awarded her M.Sc. degree in 2018. in Egypt in November 1984. He graduated from Cairo University, Egypt in 2005 then he obtained his M.Sc. and Ph.D. degrees in 2009 and 2014, respectively, at Cairo University in the field of organic synthesis. His M.Sc. dissertation was awarded the best thesis from Cairo University in 2009. He was awarded the Alexander von Humboldt research fellowship in 2019-2021 with Prof. Holger Butenschön, at Hannover University, Germany. In 2018 he received a Cairo University Incentive Award. 
formation of mesophases of interesting mesomorphic and photophysical properties. ${ }^{18-31}$ The applications of starshaped molecules as building units for dendrimers ${ }^{32,33}$ as well as in supramolecular host-guest chemistry have been also reported. ${ }^{\mathbf{3 4 3 5}}$ Moreover, the interesting biological activities of some diverse multivalent scaffolds adamantane have been recently investigated. ${ }^{36}$ Some of these compounds were designed to study their promising photovoltaic application in organic solar cells OSCs. ${ }^{37-55}$

The present review casts light on the main strategies for the synthesis of star-shaped molecules especially those containing heterocyclic core and/or heterocyclic arms. The star-shaped molecules mentioned in this review are classified according to the central core as well as the type of side arms.

The properties and applications of these compounds are described in the appropriate contexts.

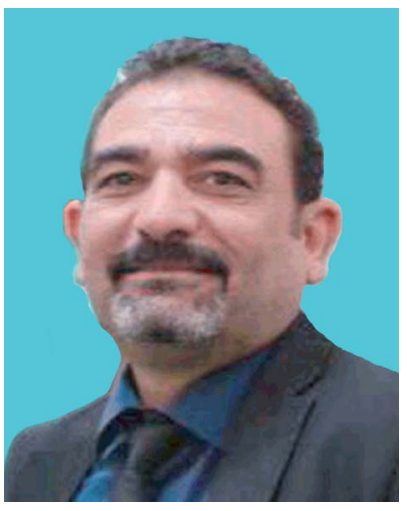

Mohamed R. Shaaban was born in 1971 in Cairo, Egypt. He graduated from Cairo University, Egypt in 1992 then he joined Professor Ahmad M. Farag's research group. He received his Ph.D. in 2001 at Tokyo, Institute of Technology, Japan. In 2001 he was promoted to a Lecturer of Organic Chemistry at Cairo University and continued his research work on organic synthesis as well as on palladium catalyzed C-C cross-couplings. In 2009 he was promoted to Associate Professor of Organic Chemistry, and in 2014 he was promoted to Professor of Organic Chemistry at the Faculty of Science, Cairo University.

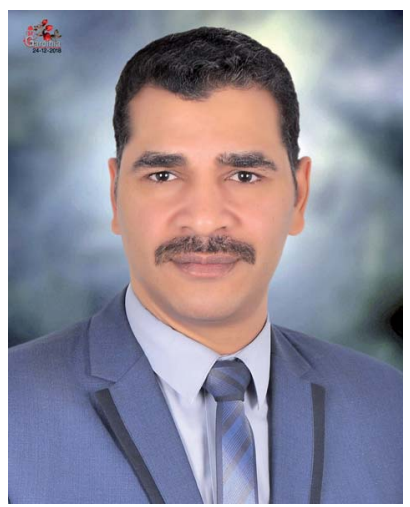

Ismail A. Abdelhamid was born in Egypt in December 1978. He graduated from Cairo University, Egypt in 2001 then he obtained his M.Sc. and Ph.D. degrees in 2005 and 2007, respectively, at Cairo University in the field of organic synthesis. In 2017 he was appointed as a full Professor of Organic Chemistry at Cairo University. He was awarded the Alexander von Humboldt research fellowship in 2008-2011 and in 2014, 2017, and 2019 with Prof. Holger Butenschön, at Hannover University, Germany. He received several research prizes; Cairo University Incentive Award (2012), Cairo University Scientific Excellence Award (2016) and State Incentive Award (2019).
To the best of our knowledge, a number of other reviews ${ }^{24,56-67}$ that have appeared, concerning the chemistry of star-shaped molecules, did not pay special attention to the synthesis of such systems in an organized manner with respect to central core as well as the type of side arms. The review will cover the literature in this area over the last decades. Starshaped molecules based on triphenylamine, truxene or other polycyclicaromatic cores have been recently reviewed and will not be mentioned in this review. ${ }^{56,61,66}$

The reported yields of the target molecules in this review are those given in the last step reaction except when an overall yield was given.

\section{Classification of star-shaped molecules}

A schematic illustration of the classification of star-shaped molecules (SSMs) is depicted in Fig. 1. The cores and the side arms are the main factors in this classification. The cores are usually an atoms (C, Si, Ge and $\mathrm{N}$ ), acyclic aliphatic (asparatic, glutamic, pentaerythritol and tris(2-aminoethyl)amine), cyclic aliphatic (cyclohexatrione and polyhedral oligomeric silsesquioxane (POSS)), aromatic (benzene, truxene, isotruxene, hexa-peri-hexabenzocoronene, hexakisfluorenylbenzene, oligofluorene and hexatriphenylene), heteroaromatic (1,3,5-triazine, pyrimidine, phenylquinoxaline, phenylcarbazole, oligothiophene, triindole, benzodifuran, benzodithiophene, benzotrithiophene, thieno[3,2- $b]$ thiophene, dithienyl naphthothiophene, tetrathienoanthracene, naphthalimide-fused pyrazinacenes, triazatrinaphthylene, pyrrolefused TTF and triazatruxene). It is worthy to mention that that benzene and 1,3,5-triazine are considered as the most popular aromatic and heterocyclic cores, respectively. Side arms may also contain aliphatic, aromatic or heterocyclic moieties. The incorporation of heterocyclic systems into the structure of the star-shaped molecules is highly useful for optical and electronic applications.

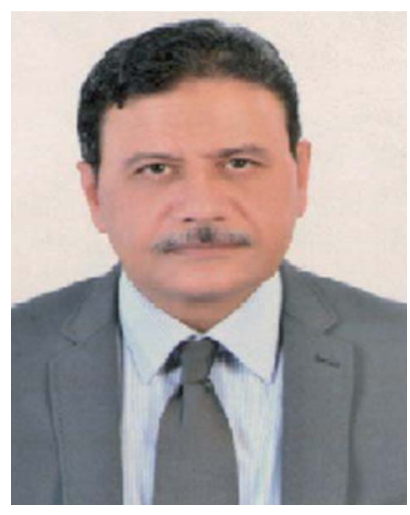

Ahmed H. M. Elwahy was born in 1963 in Giza, Egypt. He graduated from Cairo University, Egypt in 1984 then he obtained his M.Sc. and Ph.D. degrees in 1988 and 1991, respectively, at Cairo University in the field of organic synthesis. He was awarded the Alexander von Humboldt research fellowship in 1998-2000 and in 2003, 2005, 2009, 2010 and 2012 with Prof. Klaus Hafner, at TU Darmstadt, Germany. In 2002 he was appointed as a full Professor of Organic Chemistry at Cairo University. In 2001 he received the State-Award in Chemistry. He has published around 120 scientific papers in distinguished international journals. 


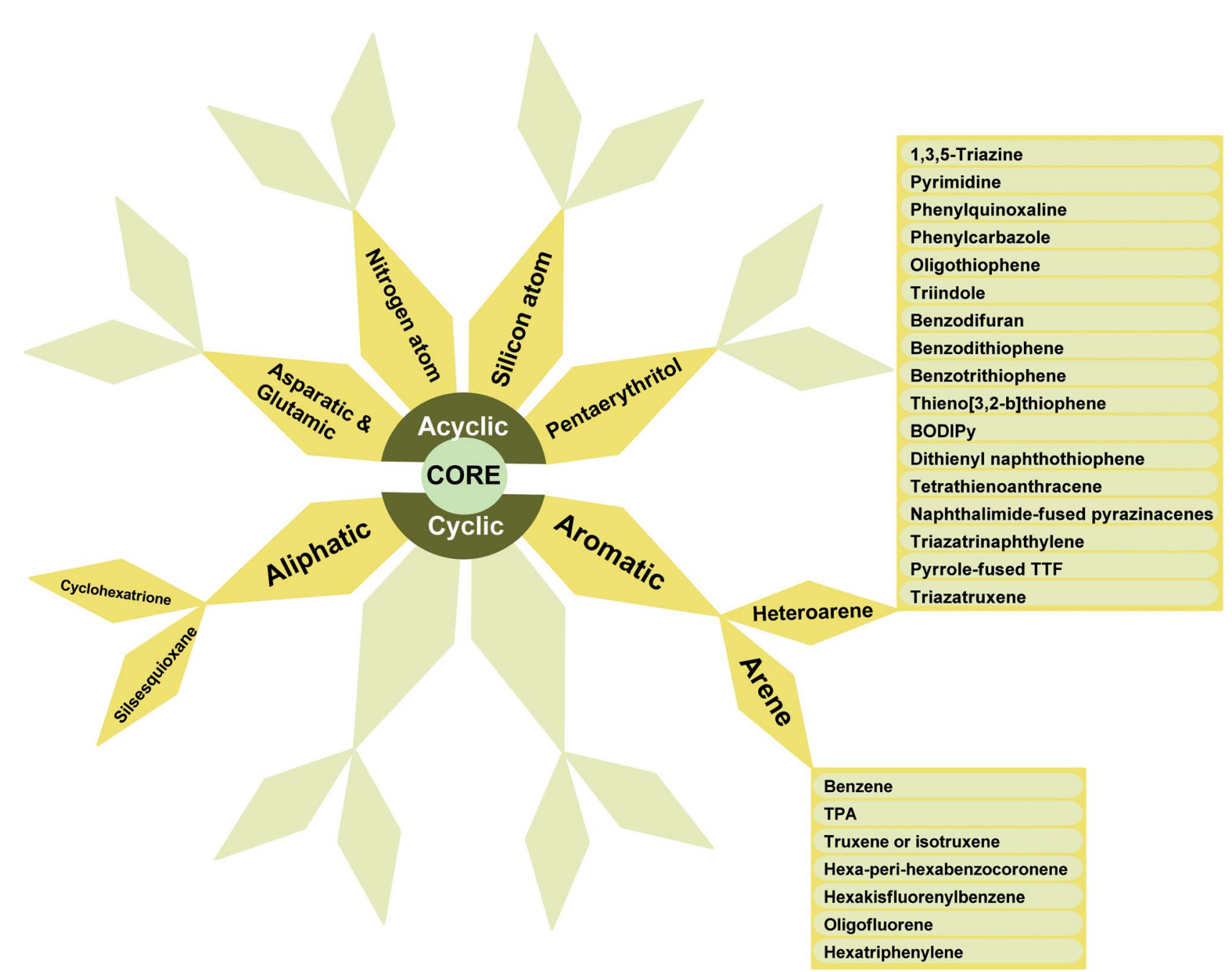

Fig. 1 Core-based classification of star-shaped molecules.

\section{General synthetic approaches for star-shaped molecules}

This section summarizes the synthetic approaches that have been developed for the synthesis of star-shaped molecules mentioned in this review. Generally, SSMs were synthesized from poly-functionalized building blocks which are then manipulated to generate the target compounds using mainly the following reactions:

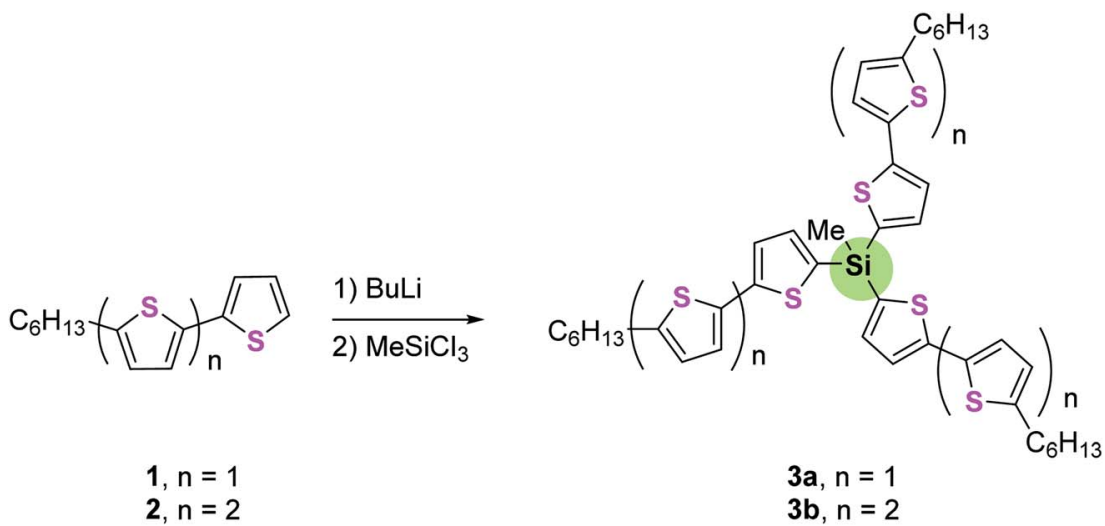

Scheme 1 Synthesis of star-shaped oligothiophenesilanes 3. 


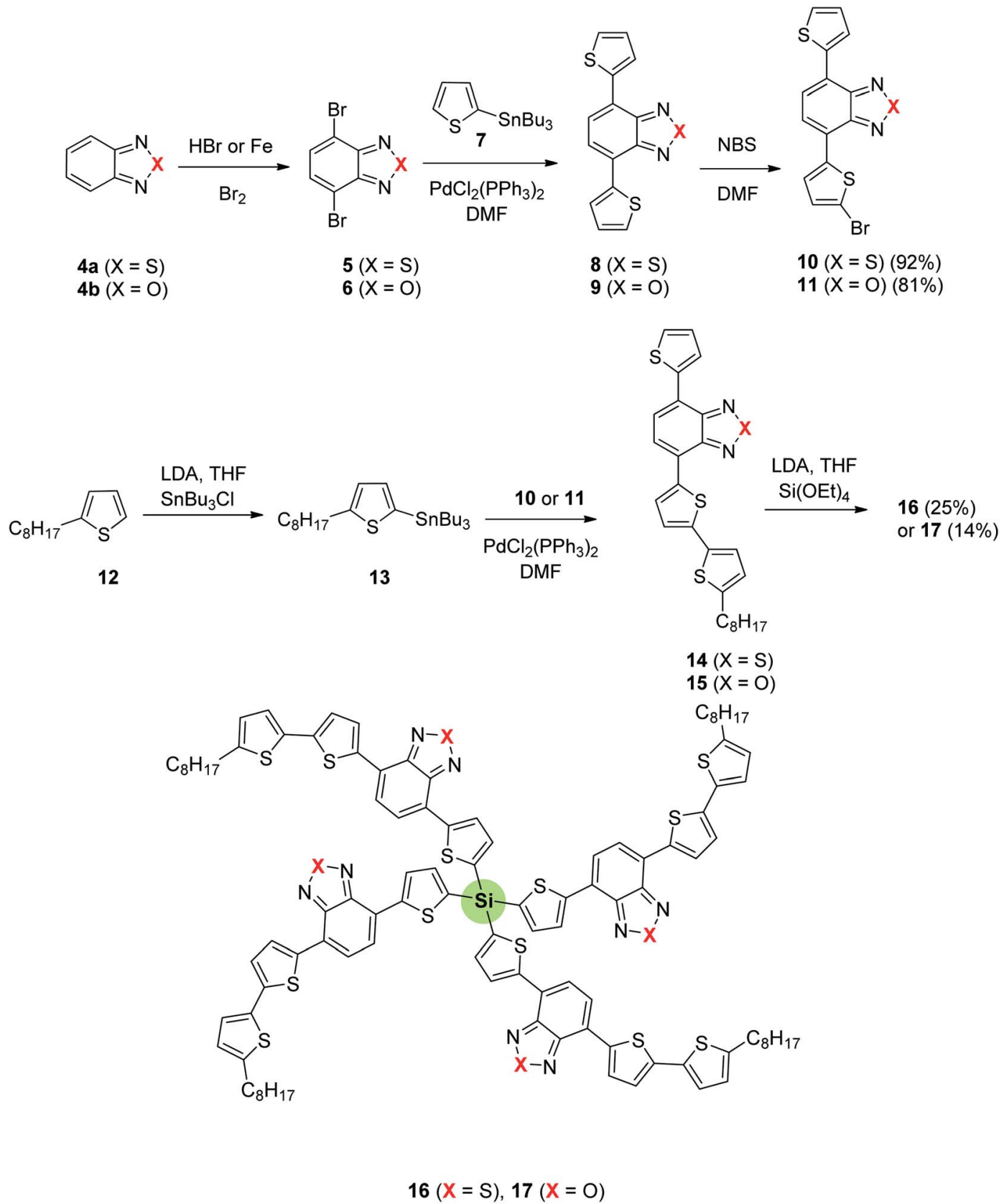

Scheme 2 Synthesis of four-armed SSMs with silicon atom-core 16 and 17.

\section{1. $O$-, $S$ - and $N$-Alkylation reactions}

The star shaped molecules were prepared in this case by polyalkylation of the appropriate alcohol, phenols, heterocyclic thiol, aromatic or heteraromatic amines with a variety of alkyl or aryl halides. The reactions are fast, operationally simple, and allows rapid access to a variety of poly(heterocyclic) derivatives. Achieving selectivity in these reactions or prediction of the site of the alkylation remains a challenging point for substrates with more nucleophilic centers.

\subsection{Cyclocondensation reactions}

SSMs prepared using this strategy depends mainly on the formation of polychalcones and subsequent reaction with hydrazine derivatives to give the corresponding polydihydropyrazoles. Polythiazoles can also prepared by cyclocondensation of polythiosemicarbazones with the appropriate $\alpha$-haloketones. Moreover, cyclization of polybenzoylhydrazides with $\mathrm{POCl}_{3}$ was reported to give polyoxadiazole derivatives. Furthermore, cyclocondensation of 3-aminobut-2-enenitrile with polyaldehydes represent one of the most interesting 


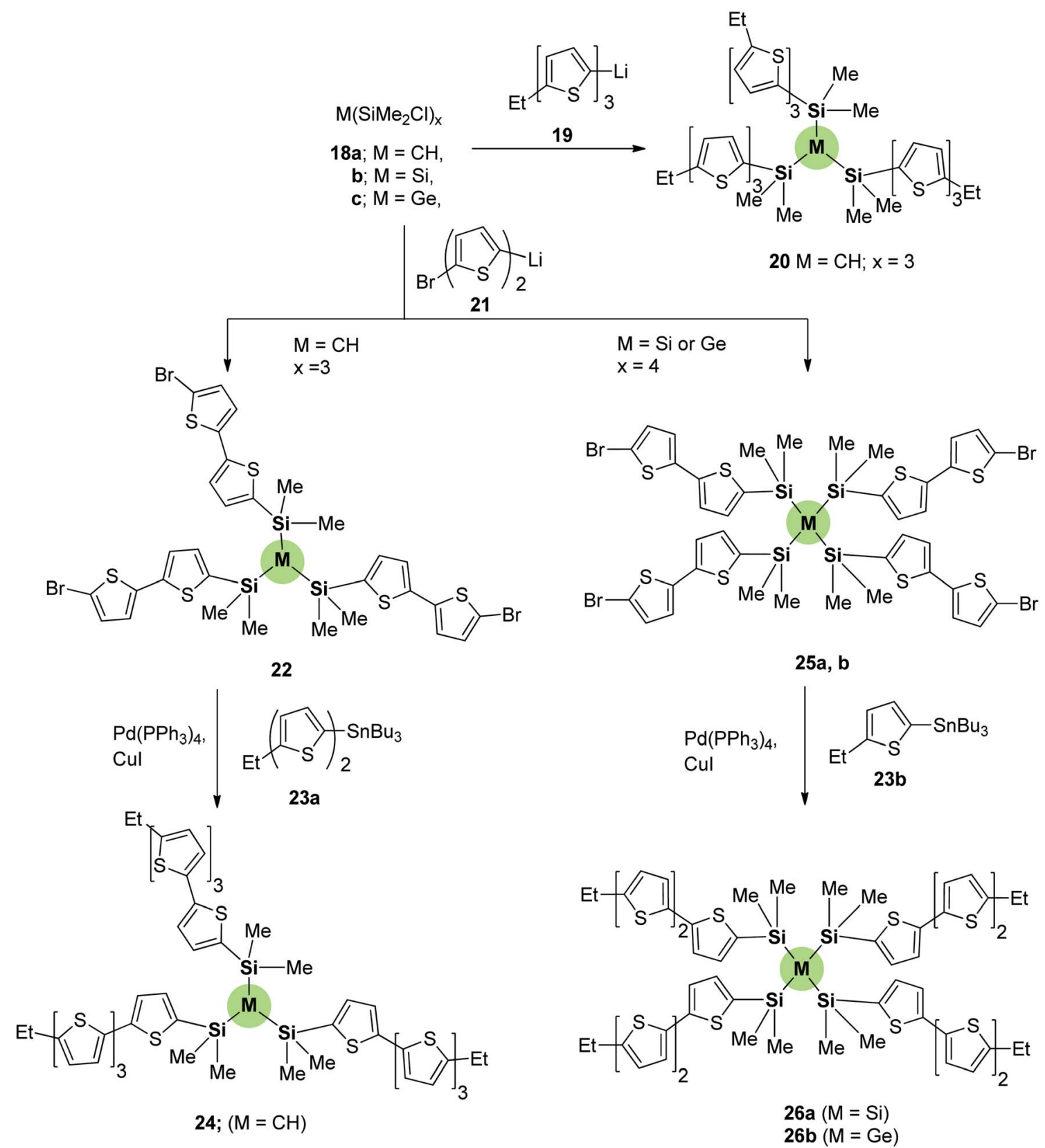

Scheme 3 Synthesis of silicon-cored SSMs 20, 24, 26a and 26b.

approaches which led to the formation of polydihydropyridines. Although the overall yields of these reactions are moderate, only a small library of poly(heterocycles) prepared by this strategy are available.

\subsection{Cyclotrimerization reactions}

This reaction was used to prepare tris(thiophenyl)benzenes via cyclotrimerization of 2-acetylylthiophene derivatives upon treatment with $\mathrm{SiCl}_{4}$. Tris(4-(thiophenyl)phenyl)-1,3,5triazines can also obtained via cyclotrimerization of (thiophenyl)benzonitriles in the presence of $\mathrm{CF}_{3} \mathrm{SO}_{3} \mathrm{H}$. Hexaheteroarylbenzene derivatives were prepared by cobaltcatalyzed cyclotrimerization reaction of different alkyne precursors. The scope of this reaction in this area is limited and the overall yields of the products are moderate.

\subsection{1,3-Dipolar cycloaddition reactions}

This strategy was mainly used to synthesize star-shaped molecules with pyrrolidine side arms via the reaction of chalcones with sarcosine and paraformaldehyde.

\subsection{Imidization via cleavage-cyclization reactions}

Star-shaped molecules with cyclic imide structure were synthesized by imidization reaction of 1,3,5-triamino benzene with cyclic carboxylic anhydride in the presence of $\mathrm{Zn}(\mathrm{OAc})_{2}$. 


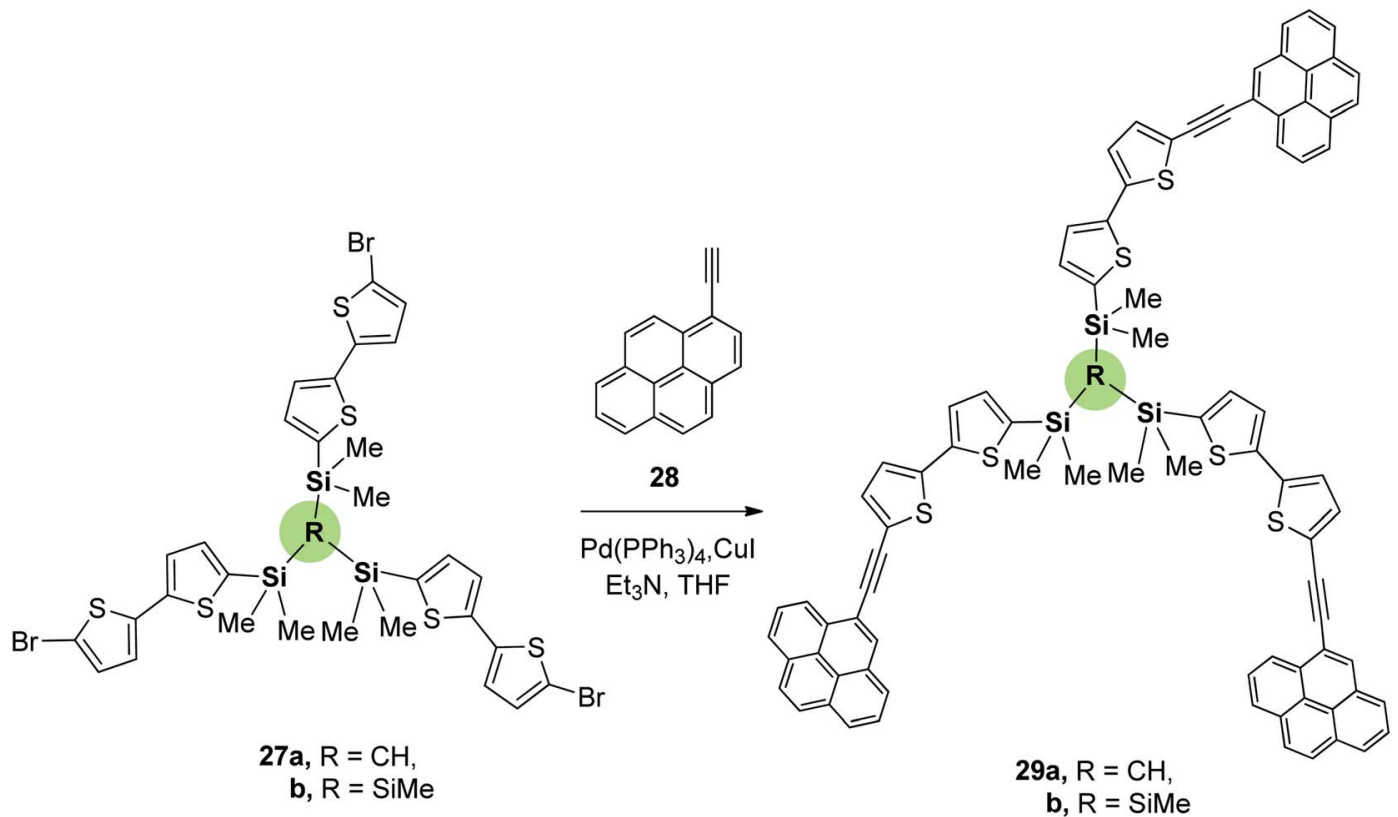

Scheme 4 Synthesis of silicon-cored SSMs 29a,b.<smiles>Cc1ccc(-c2ccc(C#Cc3cc4cccc5ccc6cccc3c4c56)s2)s1</smiles>

30

Fig. 2 Structure of linear (hexylbithiophenyl)pyrenylacetylene 30.

3.6. Palladium-catalyzed $\mathrm{C}-\mathrm{C}$ and $\mathrm{C}-\mathrm{N}$ bond formation via Heck, Negishi, Sonogashira, Stille and Suzuki cross-coupling reactions

A variety of metal-catalyzed reactions, such as Suzuki, Stille, Sonogashira, Heck, and Negishi cross-coupling reactions have been employed to functionalize a range of star-shaped molecules.

3.6.1. Suzuki-Miyaura reaction. This reaction led to the formation of SSMs with biphenyl, thiophene, bithiophene, trithiophene, pyrrolo[3,4-c]pyrrole, quinolone carbazole or fluorine arms by cross-coupling reaction of boronic acid derivatives with the appropriate polyhalo compounds in the presence of palladium catalyst. Aryl-/alkylboronic acids or boronate esters, used in this reaction, very often suffer from a few limitations associated with their preparation, purification, and handling.

3.6.2. Sonogashira reaction. Sonogashira cross-coupling between the appropriate halo compounds with the corresponding alkyne derivatives in the presence Pd catalyst furnished star-shaped molecules with thiophene, pyrene, carbazole or fluorene side arms attached to the core via ethylenic linkages.

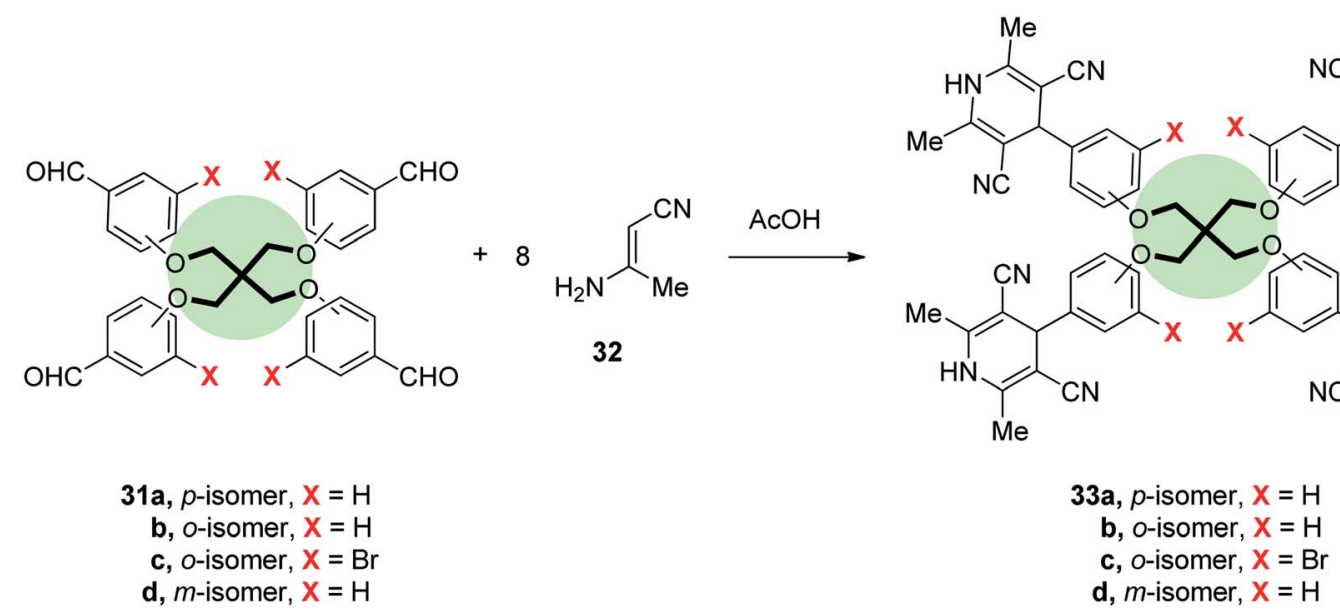

Scheme 5 Synthesis of tetrakis(2,6-dimethyl-4-phenyl-1,4-dihydropyridinyl)methanes 33a-d. 


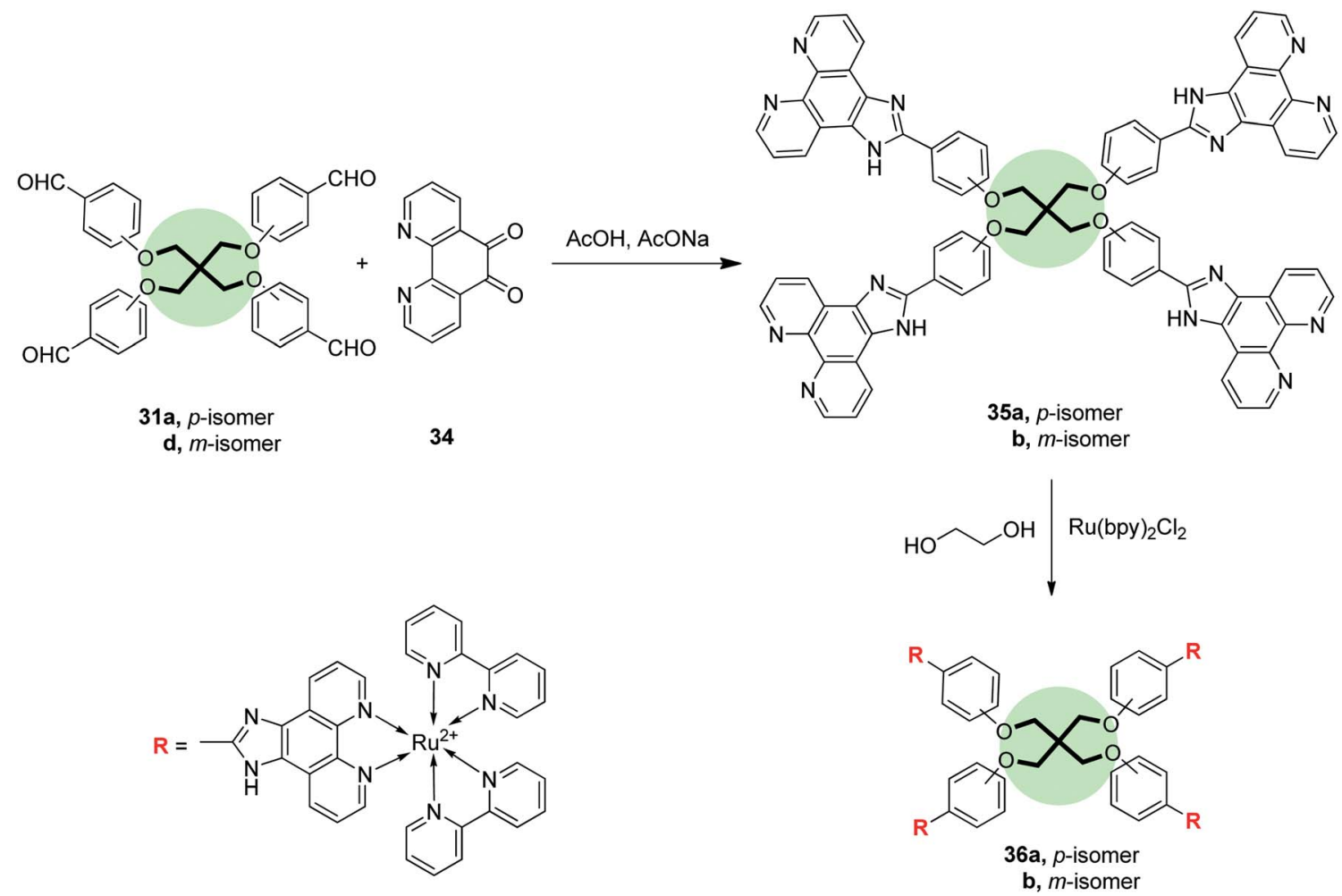

Scheme 6 Synthesis of tetrapodal ligands 35a,b and their ruthenium complexes 36a,b

3.6.3. Stille cross-coupling reactions. A Stille crosscoupling reaction between halo compounds and tributylstannyl derivatives in the presence of Pd catalyst afforded mainly thiophene-containing SSMs liked to benzothiadiazole, benzooxadiazole, pyrrolopyrrole or thiadiazolo[3,4-c]pyridine arms. One of the disadvantage of this reaction is the possible development of organotin by-products in reaction products.

3.6.4. Negishi cross-coupling reaction. This approach was used to prepare thiophene, thieno[3,2- $b]$ thiophene, arylethynyl containing triphenylamine, fluorene, and/or carbazole-based SSMs by Pd-catalysed cross-coupling reaction of the appropriate halides with the corresponding organozinc compounds. The scope of the reactions could be significantly extended to the synthesis of a variety of SSMs using electron deficient heteroaromatic aryl bromides or chloride and acyclic zinc reagents as coupling partners.

3.6.5. Heck coupling reaction. Heck coupling reaction was utilized for the synthesis of vinylbithiophene-based SSMs via coupling of haloarenes with vinylbithiophene in the presence of $\mathrm{Pd}(\mathrm{OAc})_{2}$.

\section{7. van Leusen oxazoles synthesis}

This reaction was used to prepare oxazole-containing starshaped molecules by the reaction of tris-aldehydes with $p$-toluenesulfonylmethyl isocyanide (TosMIC).

The scope of this method is rather low and applied only for the synthesis of very few systems of tris((oxazolyl)thiophenyl) benzene.

\subsection{Ullmann reactions}

Benzimidazole-based SSMs were synthesized using this carbon-nitrogen bond-forming reaction through coupling of benzimidazole with tribromobenzene using $\mathrm{CuSO}_{4}$ in the presence of a base catalyst. The applications of Ullmann reaction in this area are limited due to some limitations like harsh reaction conditions, high copper catalyst loading, poor functional group tolerance and generally the low yield of the products.

\subsection{Click reaction}

This reaction was used mainly to synthesize 1,2,3-triazole-based SSMs by the classic copper-catalyzed click reaction of the appropriate azide with the corresponding alkyne. Some important limitations of Click reaction are the stability of some azides in addition to the use of copper catalyst and the possible of alkyne homocoupling under the reaction conditions.

\subsection{Diels-Alder reactions}

Diels-Alder reaction was used to prepare star-shaped molecules with hexakis(fluoren-2-yl)benzene by heating of cyclopentadienone with the appropriate acetylene derivatives. A significant limitation of this reaction is the poor reactivity associated with cis-dienes as well as prolonged reaction time. 


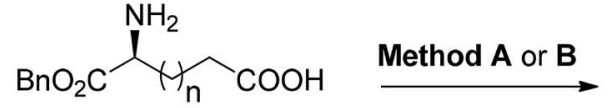

$$
\begin{array}{r}
37 a, n=0(\text { Asp) } \\
\text { b, } n=1(\text { Glu) }
\end{array}
$$

Method A: for Cbz-based starting materials $\mathrm{DMT}$, dioxane, $\mathrm{AcOH}, \mathrm{HCl}$, reflux $\rightarrow \mathrm{rt}, 24 \mathrm{~h}$ Method B: for Pyr-basd starting materials) DMT, $\mathrm{NaOAc}, \mathrm{AcOH}, \mathrm{H}_{2} \mathrm{O}, 75^{\circ} \mathrm{C}, 2 \mathrm{~h}$

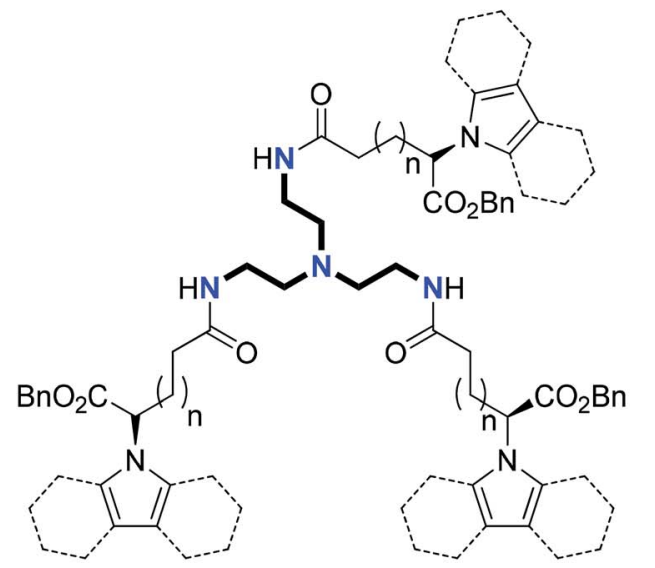

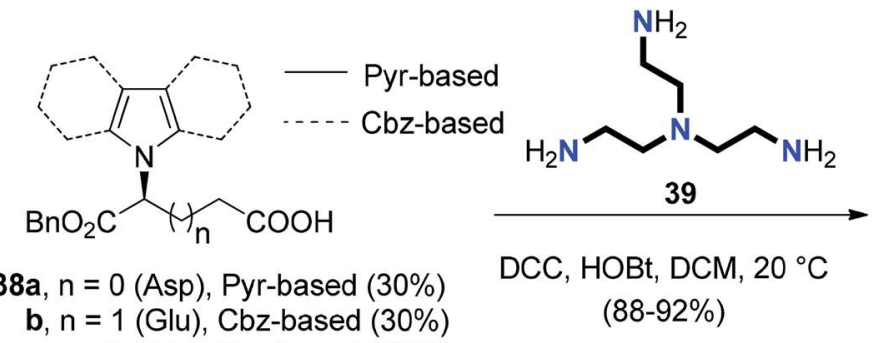

c, $n=1(\mathrm{Glu})$, Cbz-based $(50 \%)$

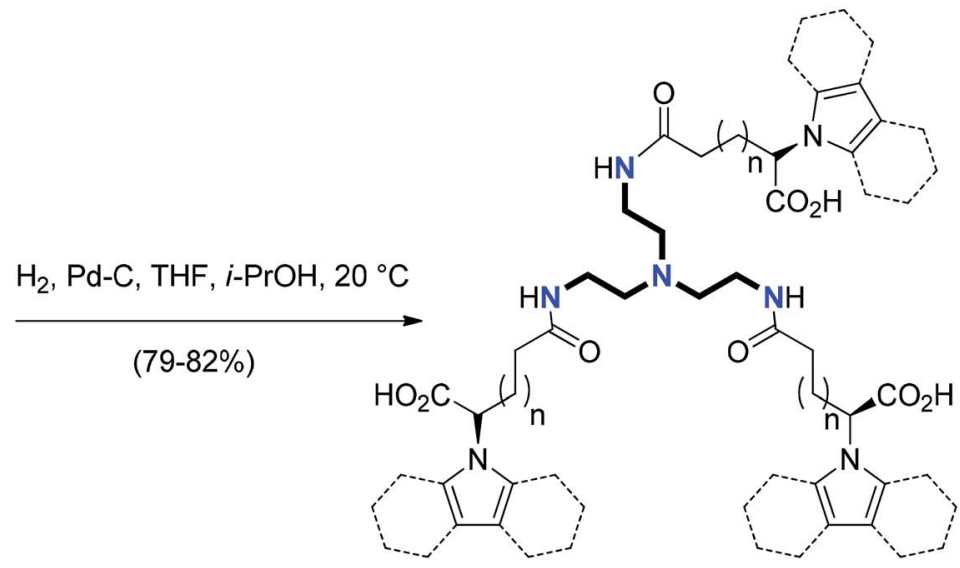

41a, $n=0$ (Asp), Pyr-based b, $n=1$ (Glu), Cbz-based c, $n=1(\mathrm{Glu})$, Cbz-based

Scheme 7 Synthesis of homochiral C3-symmetrical dendritic carboxylic acids 41a-c.<smiles>C[SiH](C)O[Si]12O[Si]3(O[SiH](C)C)O[Si]4(O[SiH](C)C)O[Si](O[SiH](C)C)(O1)O[Si]1(O[SiH](C)C)O[Si](O[SiH](C)C)(O2)O[Si](O[SiH](C)C)(O3)O[Si](O[SiH](C)C)(O4)O1</smiles>

42
$+8$<smiles>Cn1c2ccccc2c2ccccc21</smiles>
$\underset{\text { Toluene, } \mathrm{Ar}, 24 \mathrm{~h} \text {. }}{\stackrel{\text { Pt-dvs catalyst }}{\longrightarrow}}$ 43 Pt-dvs = platinum-1,3-divinyltetramethyldisiloxane

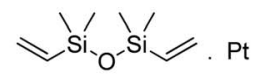

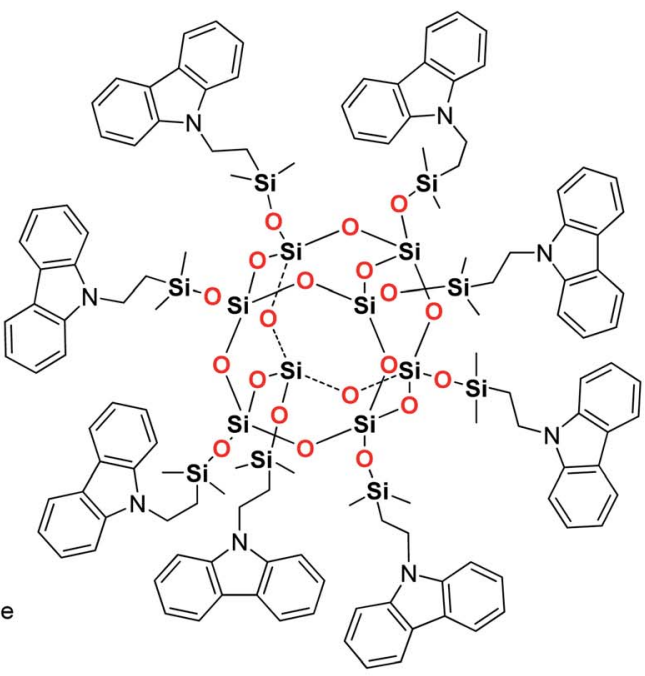

44, $(84.7 \%)$ 


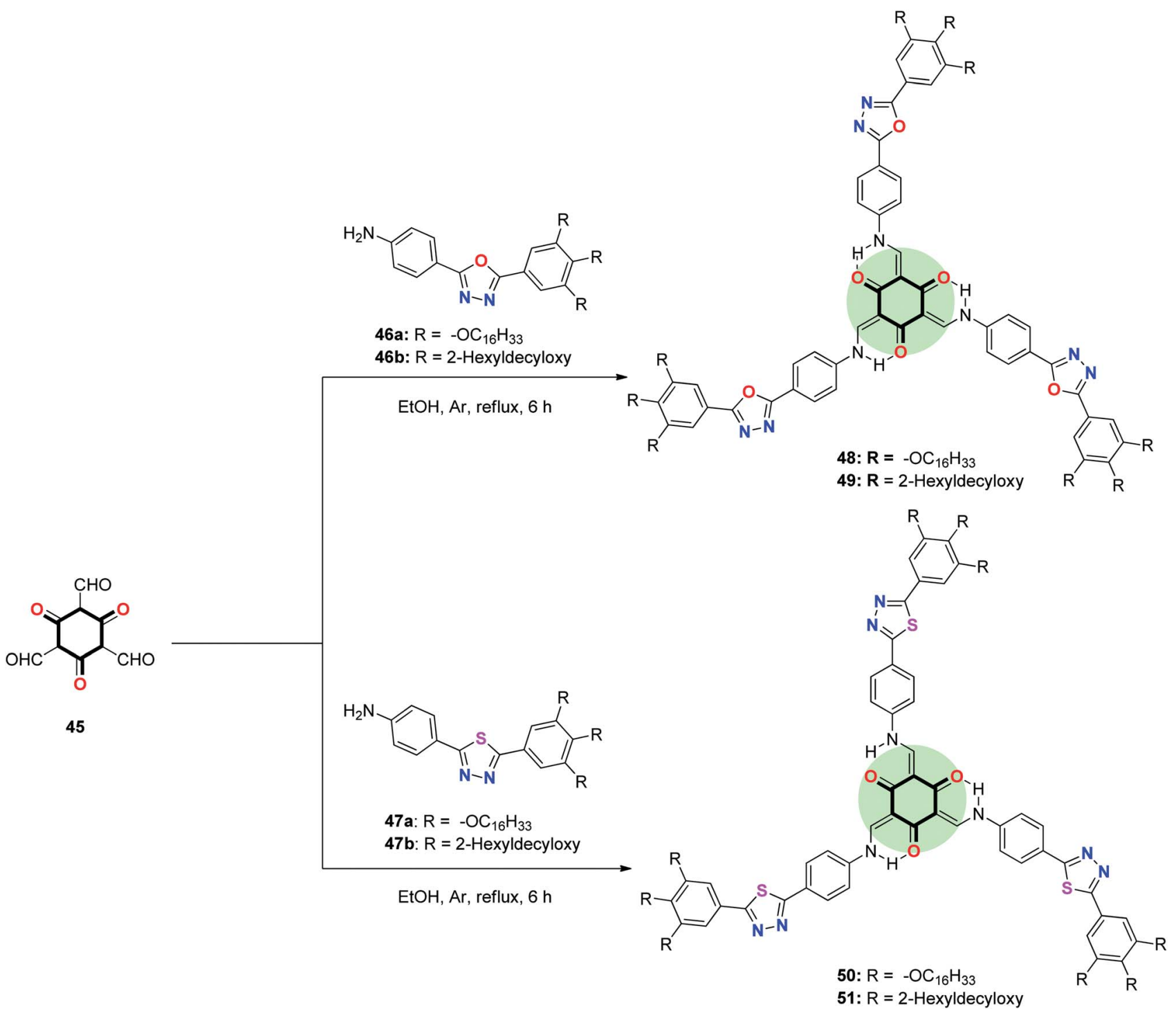

Scheme 9 Synthesis of star-shaped tris( $N$-salicylideneanilines incorporated azoles) $48-51$.

\subsection{Wittig reaction}

Using this strategy tris- and tetrakis(2-(benzofuran-2-yl)vinyl) benzene as well as tris- and tetrakis[2-(benzo[ $b]$ thien-2-yl)vinyl] benzene were prepared by the reaction of the appropriate carbaldehyde with benzene-cored phosphonates. The reaction may be slow and give low yields in addition to the labile nature of aldehydes which can oxidize, polymerize or decompose.

\section{Specific synthesis of star-shaped molecules}

\subsection{SSMs with acyclic cores}

This class of star-shaped molecules comprises compounds with $\mathrm{Si}$, Ge or carbon atoms as cores.

4.1.1. Silicon, germanium or carbon atom cores. Starthiophene derivatives with one central silicon atom linked to three oligothiophene units has attracted a considerable interest since a discovery of strong fluorescence of the star-like molecules that have a regular arrangement of $\mathrm{Si}-\mathrm{Si}$ bonds and bithienylene units. ${ }^{68}$

Luponosov et al. ${ }^{69}$ synthesized star-shaped oligothiophenesilanes $3 \mathbf{a}, \mathbf{b}$ by firstly lithiation of 5-hexyl-2,2'-bithiophene 1 or 5-hexyl-2,2' $: 5^{\prime}, 2^{\prime \prime}$-terthiophene 2 , respectively, followed by reaction with methyltrichlorosilane (Scheme 1). This work was extended to the synthesis of some different dentritic oligothiophenes, via Suzuki coupling reaction. ${ }^{70-72}$

These compounds showed very effective energy transfer from the outer bithiophene to the internal terthiophenesilane units. Some of these compounds show efficient photoluminescence in the violet-blue region, the quantum yield of which is 5-15 times higher than that for the parent bithiophene or bithiophenesilanes.

The synthesis of four-armed SSMs with silicon atom-core 16 and 17 starting from benzothiadiazole or benzooxadiazole is outlined in Scheme 2. Bromination of $\mathbf{4 a}$ and $\mathbf{4 b}$ 


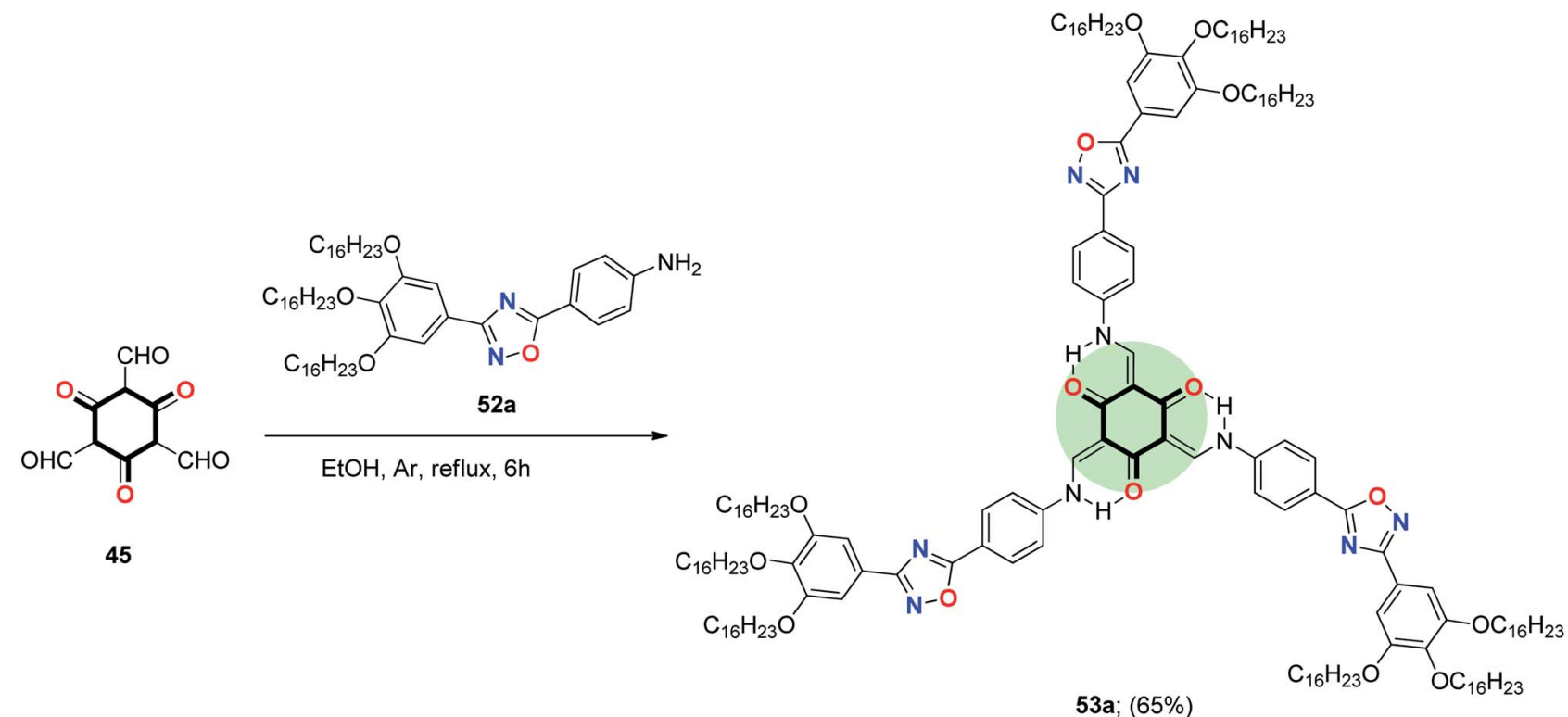

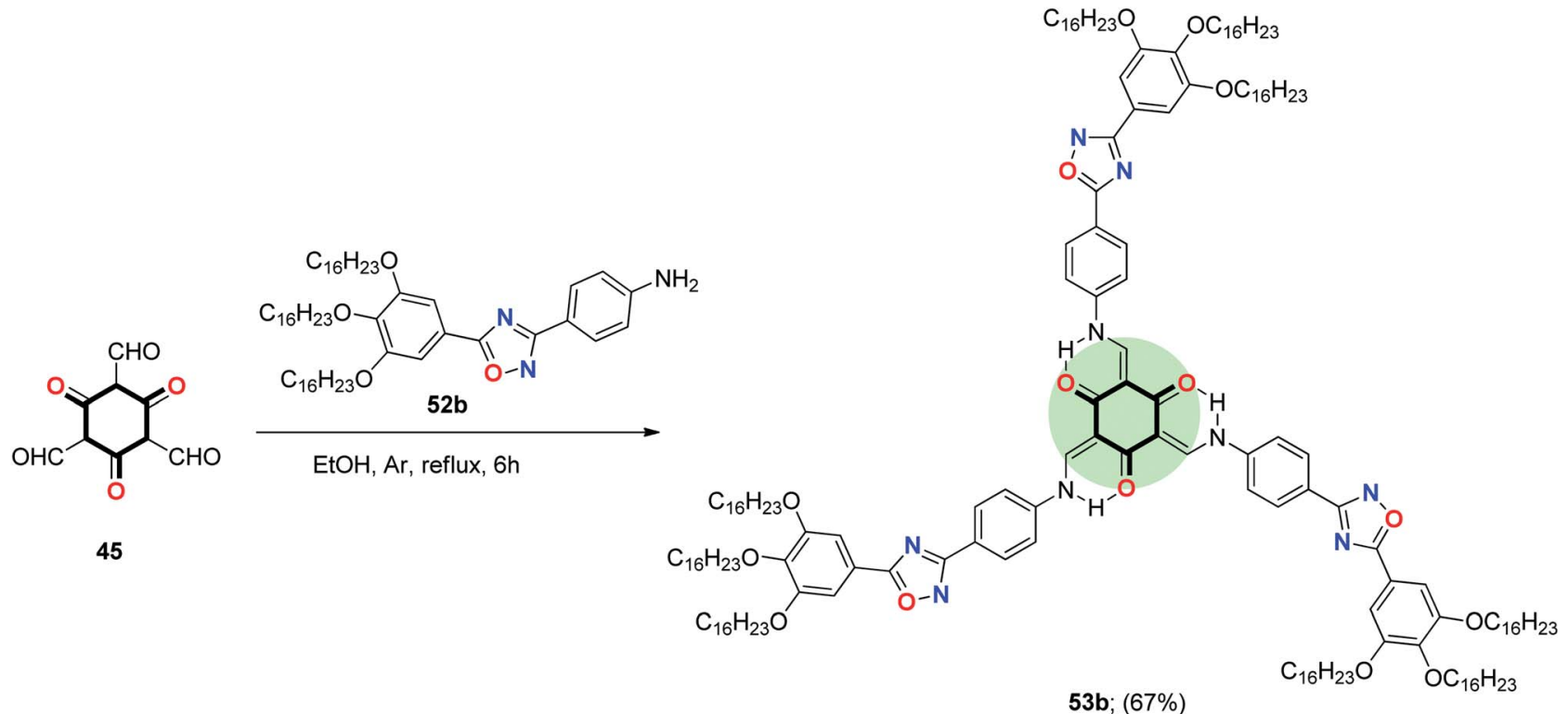

Scheme 10 Synthesis of star-shaped tris( $N$-salicylideneanilines incorporated 1,2,4-oxadiazole) 53a,b.

afforded the 4,7-dibromo derivatives 5 and 6 , respectively. Stille coupling of 5 or 6 with 2-tributylstannylthiophene 7 resulted in the formation of 4,7-bis(2-thienyl) derivative 8 or
9 which underwent a single bromination to yield $\mathbf{1 0}$ or 11, respectively. Another Stille coupling of $\mathbf{1 0}$ or $\mathbf{1 1}$ with 2tributylstannyl-5-octylthiophene $\mathbf{1 3}$ (obtained from 2-<smiles>Ic1cc(I)cc(I)c1</smiles>

54

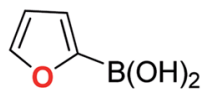

55<smiles>c1coc(-c2cc(-c3ccco3)cc(-c3ccco3)c2)c1</smiles>

56; $(66 \%)$

Scheme 11 Synthesis of 1,3,5-tris(2-furyl)benzene 56 . 


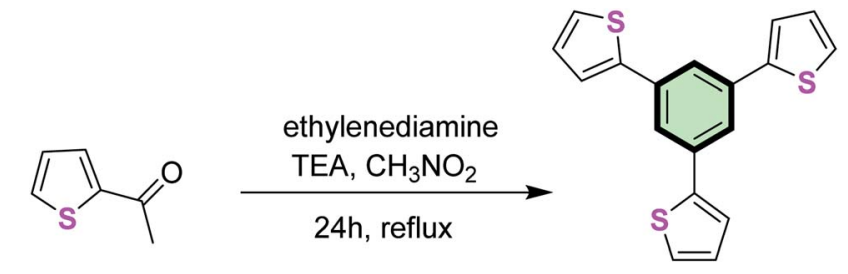

57

58; $(65 \%)$

Scheme 12 Synthesis of 1,3,5-tri(thiophen-2-yl)benzene 58.

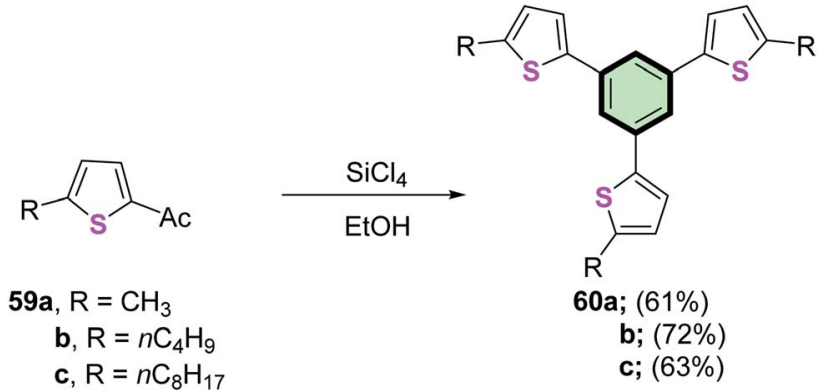

Scheme 13 Synthesis of 1,3,5-tris(5-alkylthiophen-2-yl)benzenes $60 a-c$.

octylthiophene 12 upon treatment with tributylstannyl chloride) affords the arm 14 or 15 in $92 \%$ and $81 \%$, respectively. Lithiation of compounds 14 and 15 followed by reaction with tetraethoxysilane led to SSMs 16 and 17 in low isolated yields of $25 \%$ and $14 \%$, respectively, presumably due to aggregation and solubility issues. SSMs 16 and 17 were synthesized as low band gap compounds for applications in organic photovoltaic devices. Generally, benzothiazdiazole SSM 16 showed a better photovoltaic performance than benzooxadiazole SSM 17. The energy band gaps, $E_{\mathrm{g}}$ of $16(1.83 \mathrm{eV})$ and $17(2.05 \mathrm{eV})$ were found to be higher than $1.5 \mathrm{eV}$ (ideal organic photovoltaics). The energy gap values reflect that the electron-attracting ability of benzooxadiazole is higher than that of benzothiazdiazole moiety. ${ }^{73}$

Silicon-cored SSMs 20, 24, 26a and 26b were synthesized as shown in Scheme $3 .^{74}$ The three-armed thiophene-containing SSM 20 was prepared by nucleophilic substitution of tris(chlorodimethylsilyl)methane $\mathbf{1 8 a}$ by ethylthienyllithium $\mathbf{1 9}$. SSM 24 is prepared in two steps: the first is nucleophilic substitution of 18a with bromobithienyllithium 21 and the second is a Stille coupling with tributyl(ethyl)stannylbithiophene 23a. Similarly, the four-armed silicon- or germaniumcentered SSMs 26a and 26b were synthesized starting from $18 \mathrm{~b}$ and 18c, respectively, by firstly reaction with 21 to give tetrabromoderivative $\mathbf{2 5}$ and subsequent Stille coupling reaction with $\mathbf{2 3 b}$. These compounds have been studied as holetransporting materials for the sake of use as thin film transistor and TFT-active materials.

Pyrene-containing SSMs 29a,b with high potential as photovoltaic materials were synthesized in 41 and $39 \%$

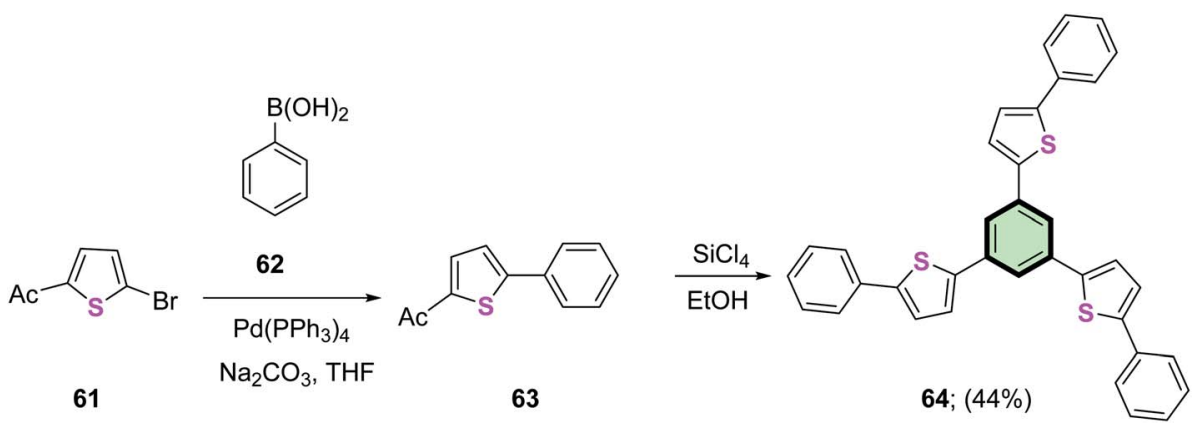

Scheme 14 Synthesis of 1,3,5-tris(5-phenylthiophen-2-yl)benzene 64.

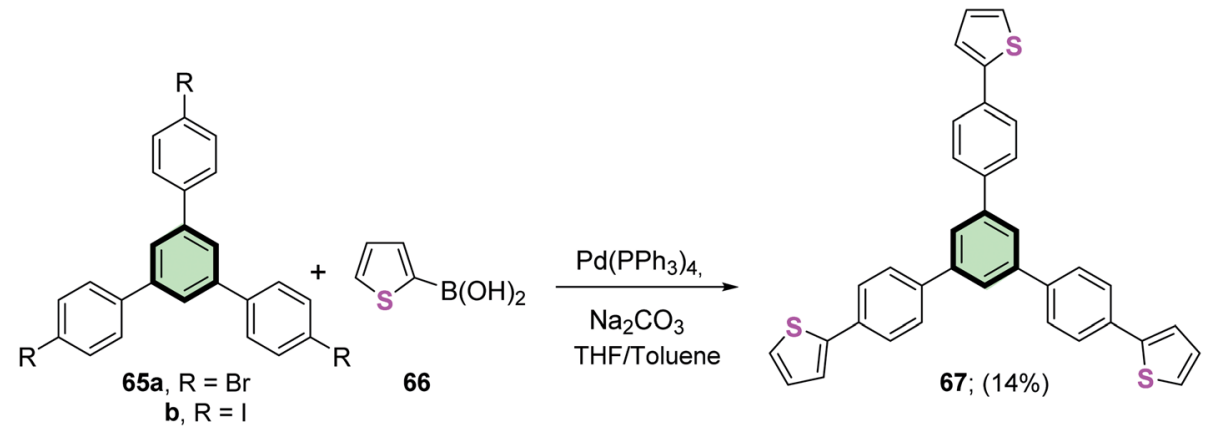

Scheme 15 Synthesis of 1,3,5-tris[4-(2'-thienyl)phenyl]benzene 67. 


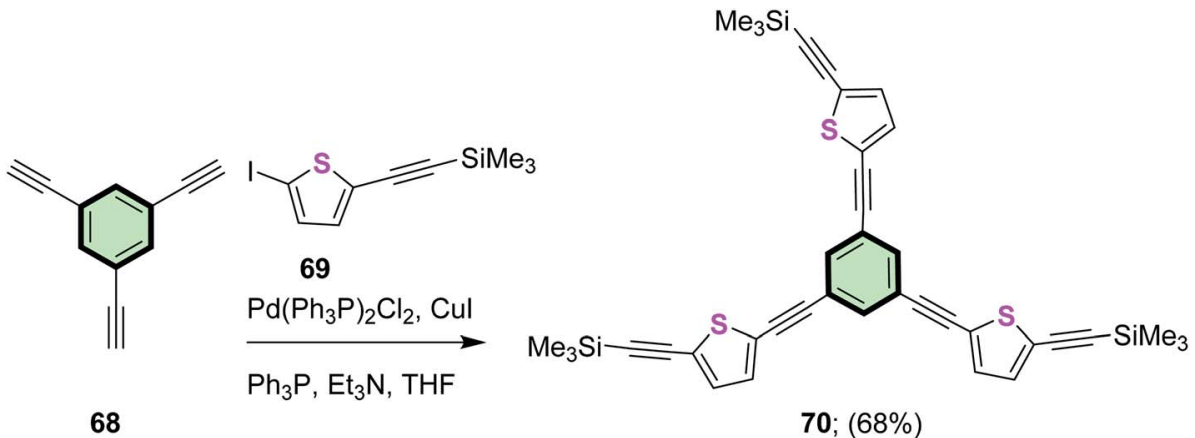

Scheme 16 Synthesis of 1,3,5-tris((5-((trimethylsilyl)ethynyl)thiophen-2-yl)ethynyl)benzene 70.

yields by Sonogashira coupling of tris[(bromobithiophenyl) dimethylsilyl]methylsilane $\mathbf{2 7 a}$ or tris[(bromobithiophenyl) dimethylsilyl]methane $\mathbf{2 7 b}$, respectively, with ethynylpyrene 28 (Scheme 4). ${ }^{75}$ These compounds showed good solubility in common organic solvents; presumably due to the flexible organosilicon core that reduces the intermolecular $\pi$ stacking. Comparison of the UV spectra of compounds 29a $\left(\lambda_{\max }=404 \mathrm{~nm}\right), 29 \mathrm{~b}\left(\lambda_{\max }=407 \mathrm{~nm}\right)$ and 30 (linear<smiles>Nc1ccc(-c2ccc(/N=C/c3ccc(-c4cc(/C=N/c5ccc(/N=C/c6ccc[nH]6)cc5)cc(-c5ccc(-c6cc(-c7ccc(N)cc7)cc(-c7ccc(N)cc7)c6)cc5)c4)cc3)cc2)cc1</smiles>

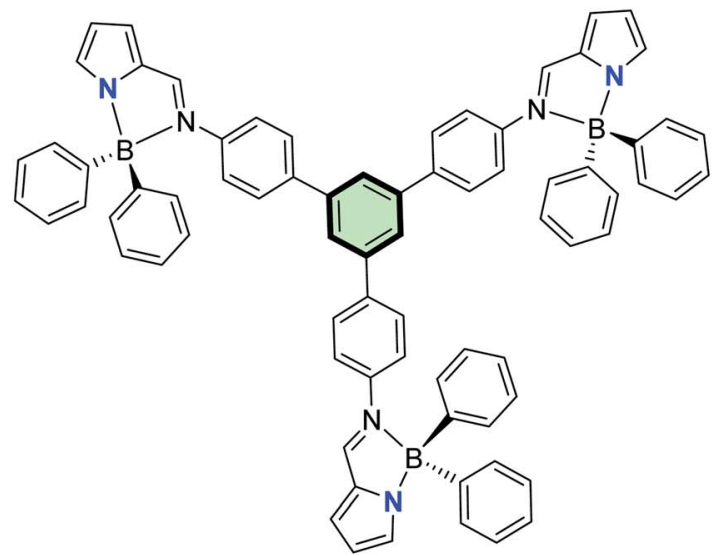




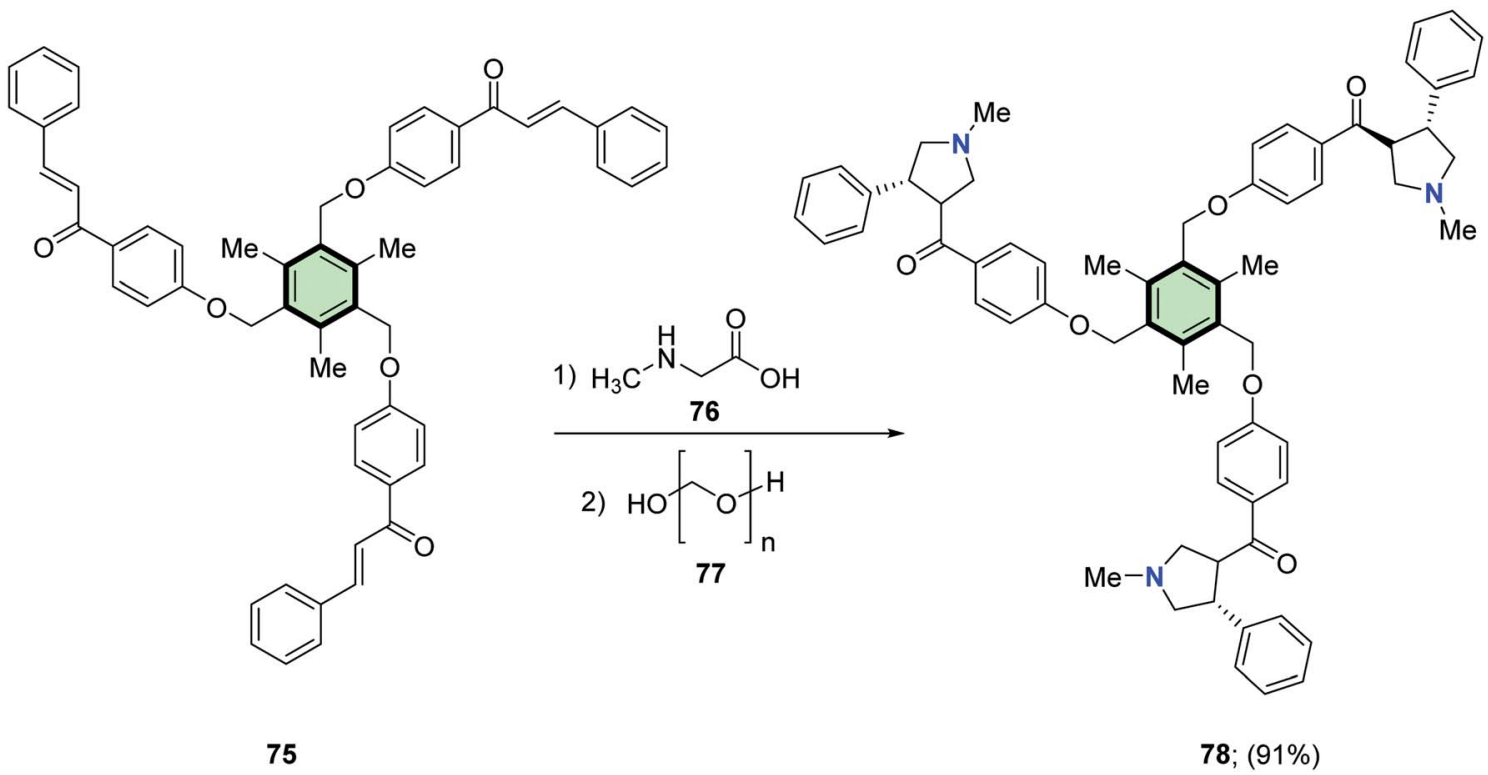

Scheme 18 Synthesis of star-shaped molecule with pyrrolidine side arms 78.

(hexylbithiophenyl)pyrenylacetylene, $\lambda_{\max }=404 \mathrm{~nm}$ which is depicted in Fig. 2) showed a negligible effect of the bridging core. However, UV spectra of spin-coated films of 29a,b showed a red shift $\left(\lambda_{\max }=440 \mathrm{~nm}\right)$ apparently due to $\pi$-stacking in the solid state.

4.1.2. Pentaerythritol core. Mohamed et al. ${ }^{76}$ reported the synthesis of tetrakis(2,6-dimethyl-4-phenyl-1,4dihydropyridinyl)methanes $\quad \mathbf{3 3 a}-\mathbf{d}$ by acid-catalyzed condensation of tetrakis-aldehydes 31a-d with eight equivalents of 3-aminobut-2-enenitrile 32 in acetic acid. These tetrapodal 1,4-dihydropyridines, especially 33 , revealed high antiproliferative effect in vitro studies against human tumor cell lines (A549, HCT116, and MCF7) (Scheme 5).

Cheng et al. $^{77}$ reported the synthesis of tetrapodal ligands with imidazo[4,5-f][1,10]phenanthroline units $\mathbf{3 5 a} \mathbf{a}, \mathbf{b}$ in good yields by the reaction of 1,10-phenanthroline-5,6-dione $\mathbf{3 4}$

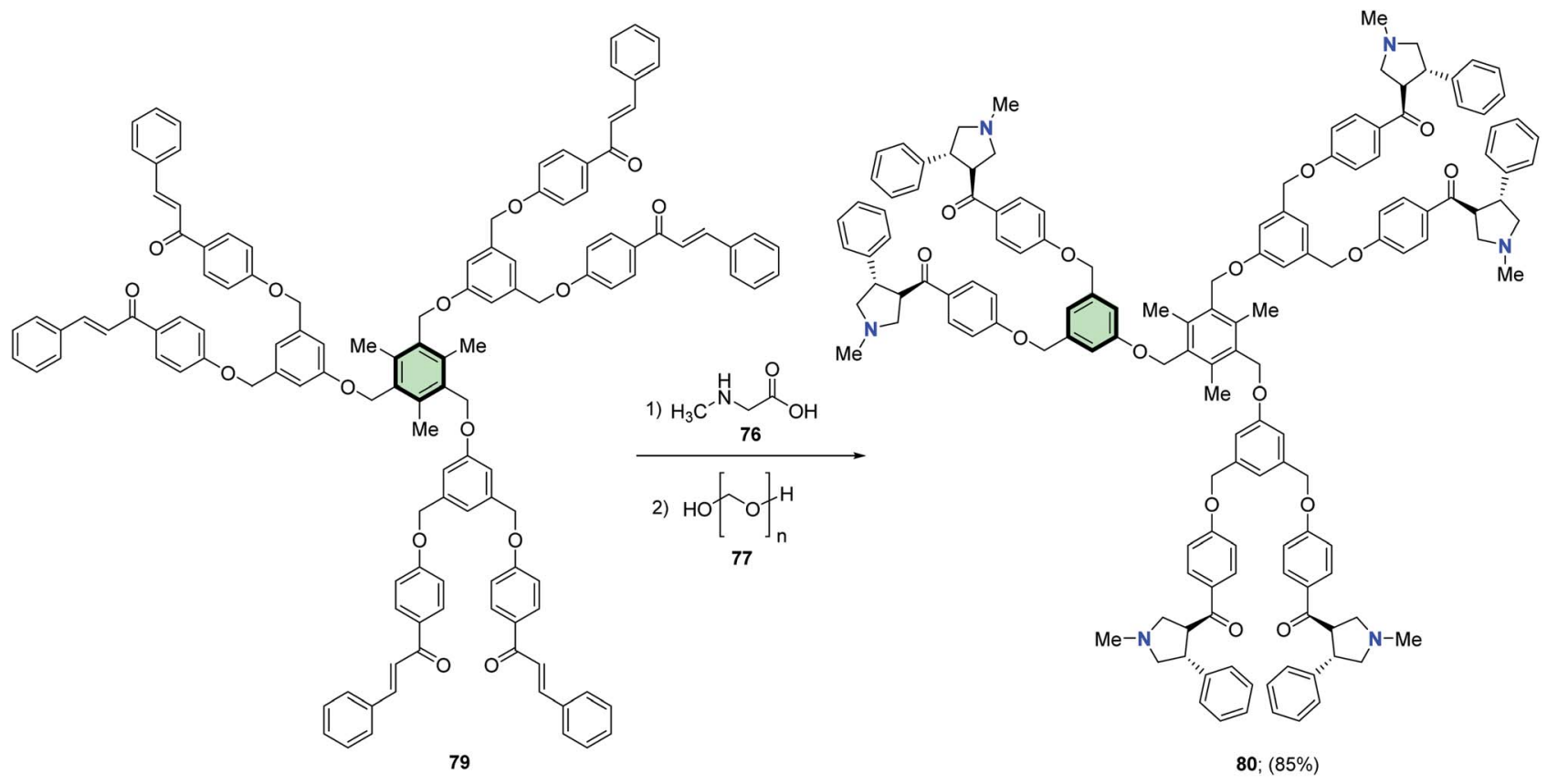

Scheme 19 Synthesis of star-shaped molecule with pyrrolidine side arms 80 . 
<smiles>O=C(/C=C/c1ccccc1)c1ccc(OCc2c(COc3ccc(C(=O)/C=C/c4ccccc4)cc3)c(COc3ccc(C(=O)/C=C/c4ccccc4)cc3)c(COc3ccc(C(=O)/C=C/c4ccccc4)cc3)c(COc3ccc(C(=O)/C=C/c4ccccc4)cc3)c2COc2ccc(C(=O)/C=C/c3ccccc3)cc2)cc1</smiles>

81

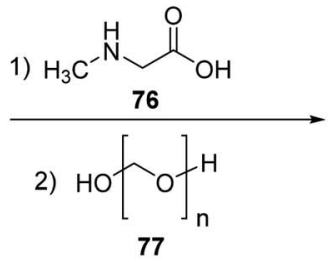

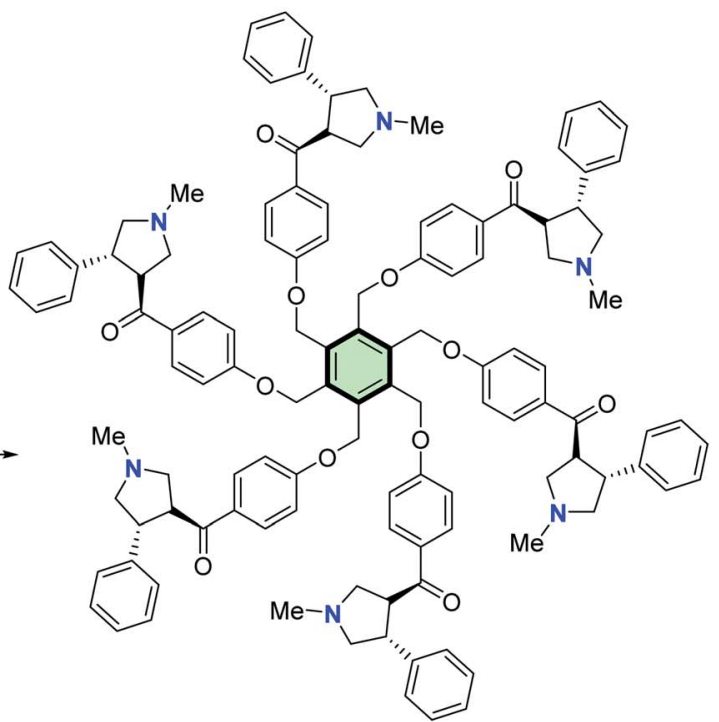

82; $(89 \%)$

Scheme 20 Synthesis of star-shaped molecule with pyrrolidine side arms $\mathbf{8 2}$.

with each of tetrakis[(4-formylphenoxy)methyl]methane 31a, and tetrakis[(3-formylphenoxy)methyl]methane 31d, respectively, in acetic acid at reflux. The corresponding $\mathrm{Ru}(\mathrm{II})$ complexes $\mathbf{3 6} \mathbf{a}, \mathbf{b}$ were prepared by heating $\mathbf{3 5 a} \mathbf{a}, \mathbf{b}$ with $\mathrm{Ru}(\mathrm{bpy})_{2} \mathrm{Cl}_{2} \cdot 2 \mathrm{H}_{2} \mathrm{O}$ in ethylene glycol solution at reflux (Scheme 6). It is worth-mentioning that these complexes are possible $\mathrm{pH}$ indicators because of their $\mathrm{pH}$-dependent photophysical properties. For instance, the UV-vis spectra of $\mathrm{Ru}(\mathrm{II})$ complex 36a showed three distinct bands at 458 , $318,286 \mathrm{~nm}$ corresponding to metal-to-ligand charge transfer, centered ligand $\pi \rightarrow \pi^{*}$, and bipyridyl $\pi \rightarrow \pi^{*}$, respectively. On the other hand, fluorescence emission spectrum of 36a showed a characteristic peak at $592 \mathrm{~nm}$ for metal-to-ligand charge transfer, $\mathrm{Ru}(\mathrm{II}) \mathrm{dn} \rightarrow \mathrm{d} \pi^{*}$. The $\mathrm{pH}$ alteration $1.82 \rightarrow 6.22$ caused a blue shift to $598 \mathrm{~nm}$ with a $25 \%$ increase in the intensity while $\mathrm{pH}$ change $6.22 \rightarrow$

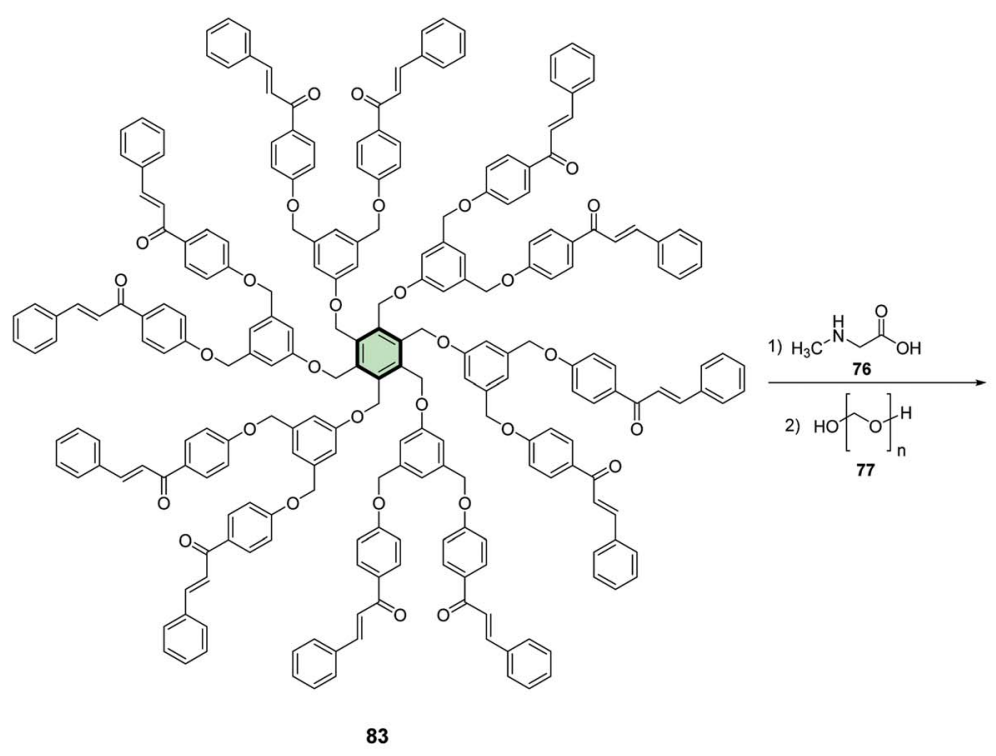

83

Scheme 21 Synthesis of star-shaped molecule with pyrrolidine side arms 84 .

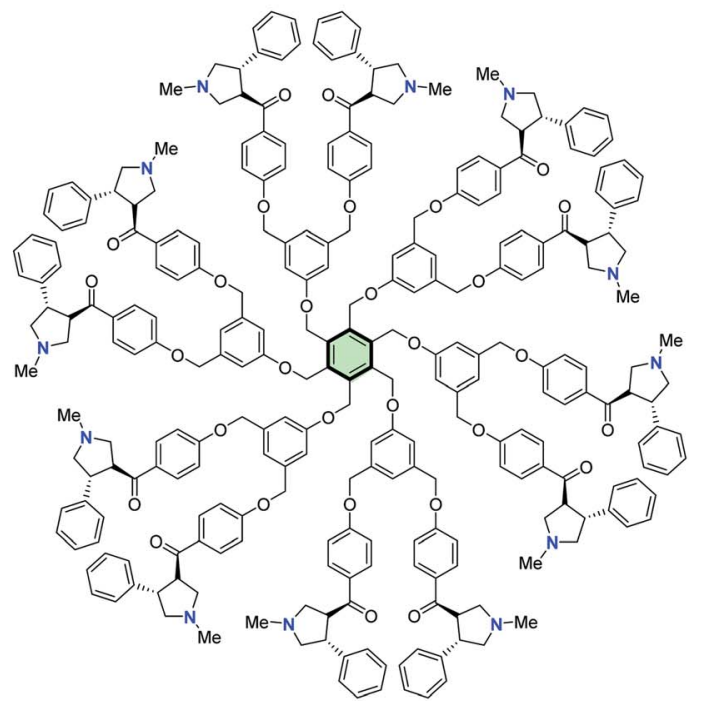

84; $(79 \%)$ 
<smiles>NC(=S)NN=Cc1ccccc1OCc1cc(COc2ccccc2)cc(COc2ccc(NN=C(N)C(=S)NN=Cc3ccccc3)cc2)c1</smiles>

85a; $p$-isomer b; o-isomer

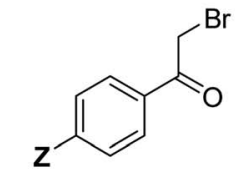

86; $\mathrm{Z}=\mathrm{H}$ $87 ; \mathbf{Z}=\mathrm{Cl}$

EtOH, TEA

Reflux, 3-5hr

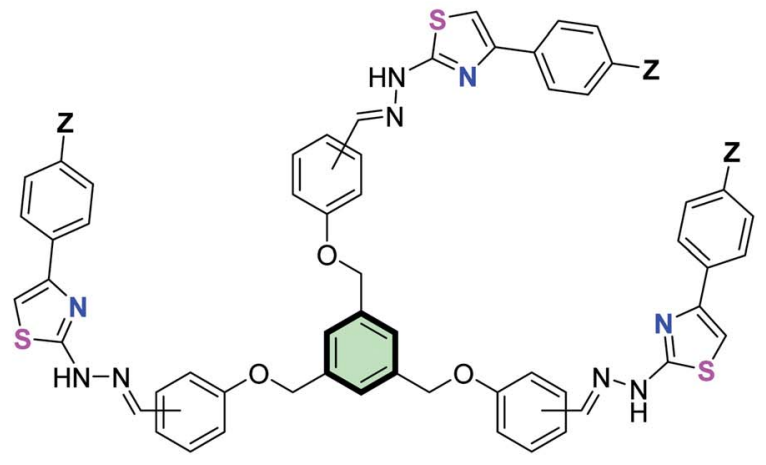

88a; $p$-isomer, $\mathbf{Z}=\mathrm{H}$; $(67 \%)$

b; o-isomer, $\mathbf{Z}=\mathrm{Cl} ;(69 \%)$

Scheme 22 Synthesis of multi-armed thiazole derivatives $88 \mathrm{a}$ and $88 \mathrm{~b}$

12.04 resulted in a red-shift to $606 \mathrm{~nm}$ with a remarkable quenching to $78 \%$. Thus, complex 36a acts as off-on-off fluorescence $\mathrm{pH}$ switch.

4.1.3. Tris(2-aminoethyl)amine core. Homochiral C3symmetrical dendritic compounds 41a-c were synthesized as shown in Scheme 7. The protected $(S)$-L-aspartic acid (Asp) 37a and (S)-L-glutamic acid (Glu) 37b underwent modified Clauson-Kaas ring closure reaction with 2,5dimethoxytetrahydrofuran (DMT) under acidic condition to form pyrrolyl and carbazolyl derivatives $\mathbf{3 8 a}-\mathbf{c}$. The amidation reactions of these compounds with tris(2-aminoethyl) amine 39 in presence of a mixture of dicyclohexylcarbodiimide (DCC) and 1-hydroxybenzotriazole (HOBt) afforded the protected dentritic compound 40a-c. Palladium-deprotection of the latter compound gave the dentritic carboxylic acids $41 a-c{ }^{78}$ It should be noted that SSMs 41b and 41c with peripheral carbazole groups underwent an oxidative electropolymerization to form a stable electroactive polymer films which might find application for stereoselective recognition of biomolecules.

\subsection{SSMs with alicyclic cores}

4.2.1. Polyhedral oligomeric silsesquioxane core. Polyhedral oligomeric silsesquioxane, POSS-cored SSMs are examples of organic-inorganic hydrid materials which have interesting optoelectronic properties. Incorporating POSS core in place of traditional hole transport materials in organic light emitting devices (OLEDs) could improve both their brightness and efficiencies. $\mathrm{Xu}$ et al. ${ }^{79}$ reported the synthesis of POSS-cored SSM 44 with incorporated carbazole moiety in excellent yield

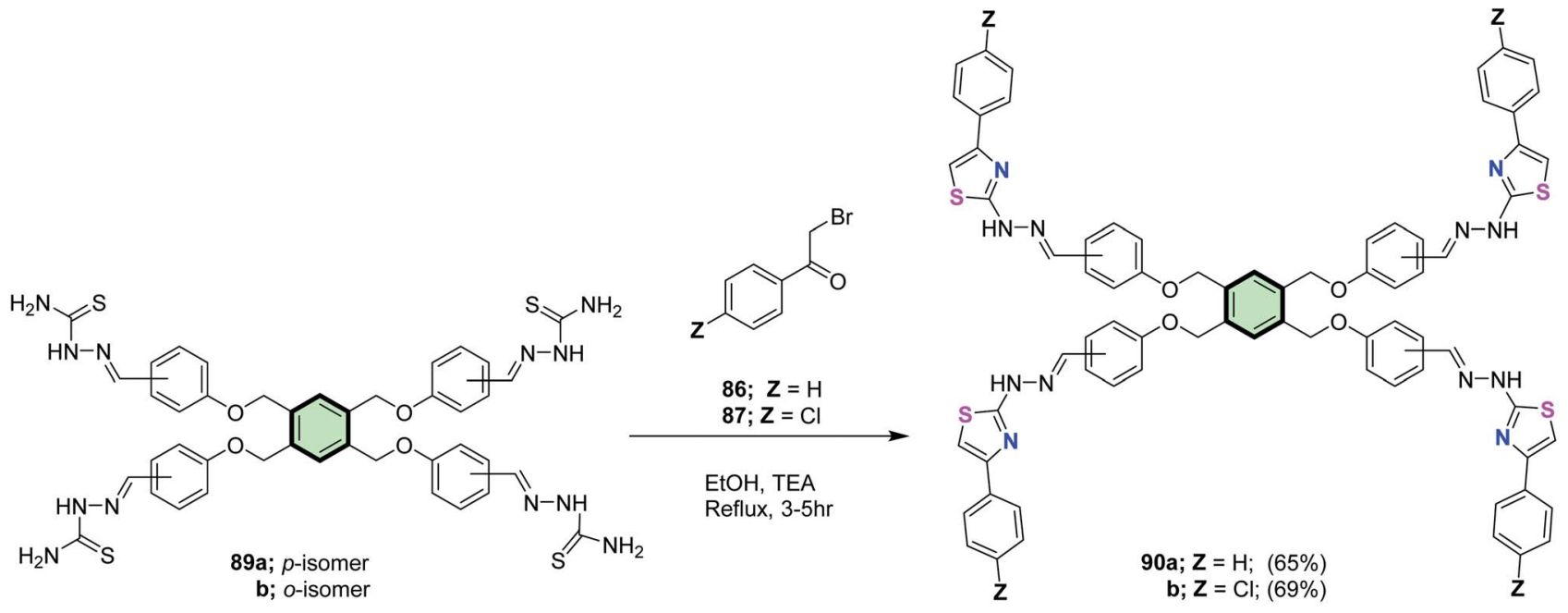

Scheme 23 Synthesis of tetrakis(thiazoles) $90 \mathrm{a}$ and $90 \mathrm{~b}$. 


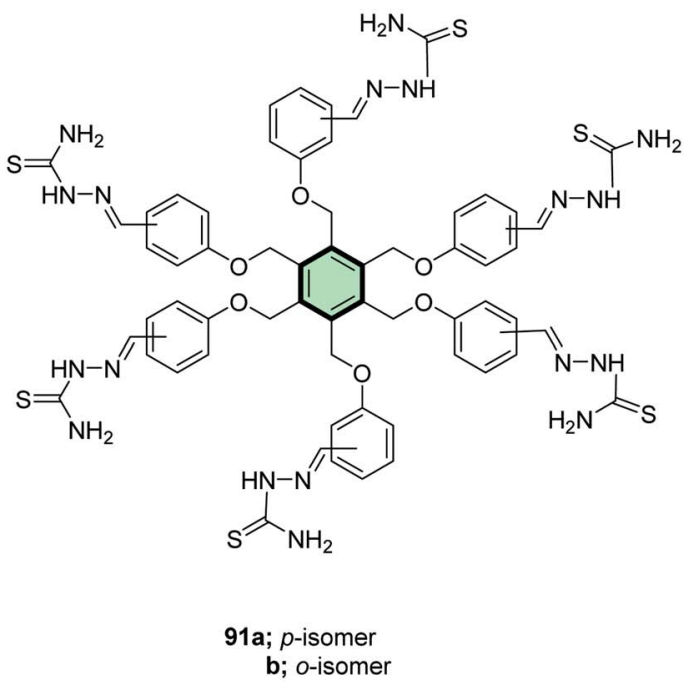

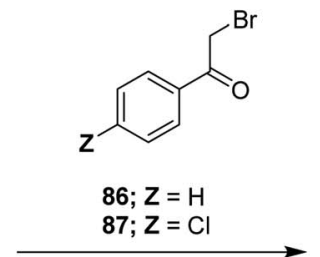

EtOH, TEA

Reflux, 3-5hr

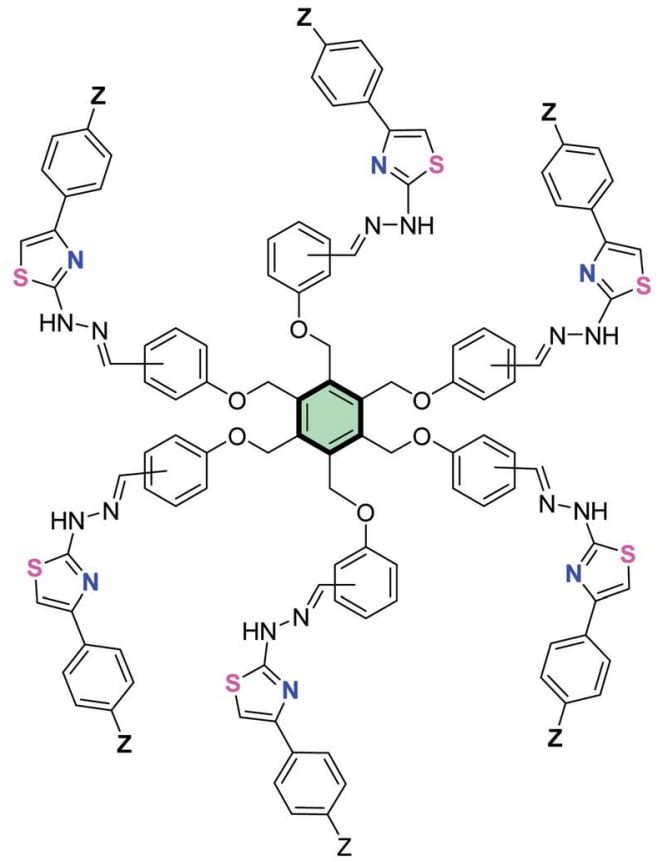

92a; $\mathbf{Z}=\mathrm{H} ;(63 \%)$

b; $\mathbf{Z}=\mathrm{Cl} ;(65 \%)$

Scheme 24 Synthesis of hexakis(thiazoles) 92a and 92b.

(85\%) via the hydrosilylation reaction of 9 -allylcarbazole 43 by the action of POSS $\mathbf{4 2}$ in the presence of platinum(0)-1,3-divinyl1,1,3,3-tetramethyldisiloxane (Pt-dvs) catalyst (Scheme 8). POSScored SSM 44 showed thermal stability with no aggregation in either solution or solid film probably due to the short POSS spacer. The UV and photoluminescence spectra showed a blue emission in both cases.

4.2.2. Cyclohexatrione core. Pathak et al. ${ }^{19}$ reported the synthesis of star-shaped tris( $N$-salicylideneanilines) (TSANs) containing 1,3,4-oxadiazole $\mathbf{4 8}$ and $\mathbf{4 9}$, as well as 1,3,4- thiadiazole based arms $\mathbf{5 0}$ and $\mathbf{5 1}$ in $65-80 \%$ yields by the reaction of 1,3,5-triformylphloroglucinol 45 with the appropriate amine derivatives $\mathbf{4 6 a}, \mathbf{b}$ and $\mathbf{4 7 a}, \mathbf{b}$, respectively, in EtOH at reflux (Scheme 9).

A similar approach was used to synthesize a star-shaped molecule 53a,b with 1,3,5-cyclohexatrione as a core and 1,2,4oxadiazole as arms in good yield by the reaction of $\mathbf{4 5}$ with the respective 4-(3-aryl-1,2,4-oxadiazol-5-yl)aniline 52a and 4-(5-aryl1,2,4-oxadiazol-3-yl)aniline 52b in ethanol at reflux (Scheme $10)^{30}$

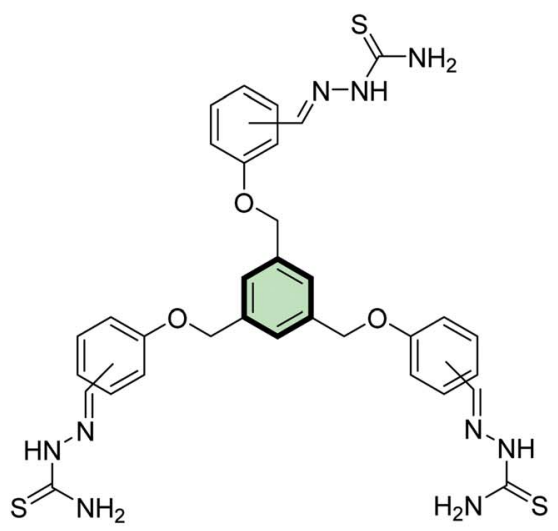

85a; $p$-isomer b; o-isomer

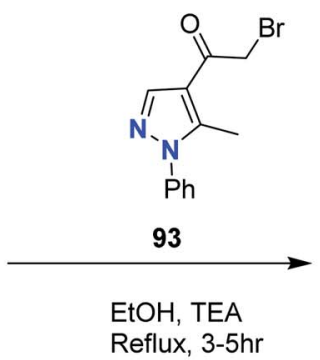

Reflux, 3-5hr<smiles></smiles>

94a; $p$-isomer $(70 \%)$

b; o-isomer (64\%)

Scheme 25 Synthesis of star-shaped molecules with benzene core and (pyrazolyl)thiazole side arm 94a and 94b. 


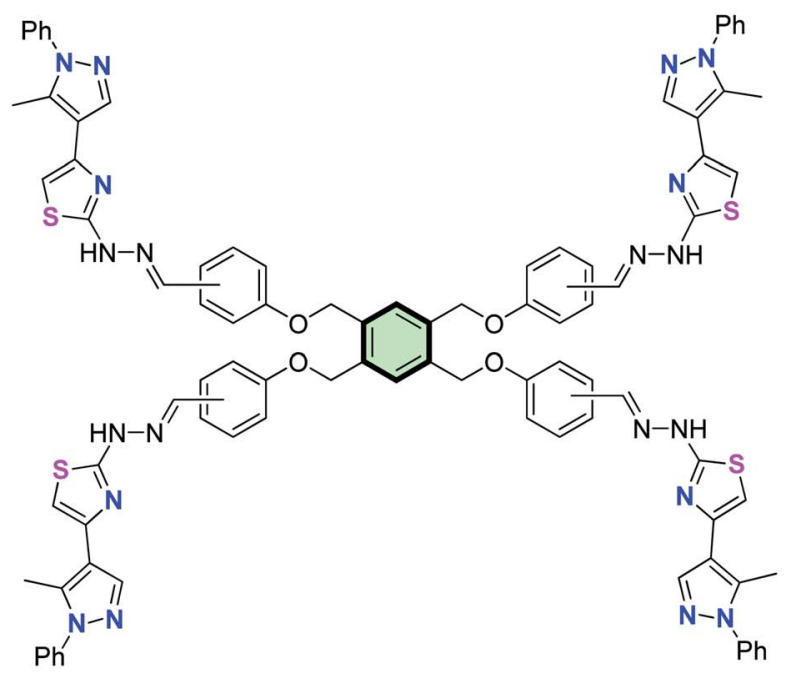

95a; $(66 \%)$

b; $(68 \%)$

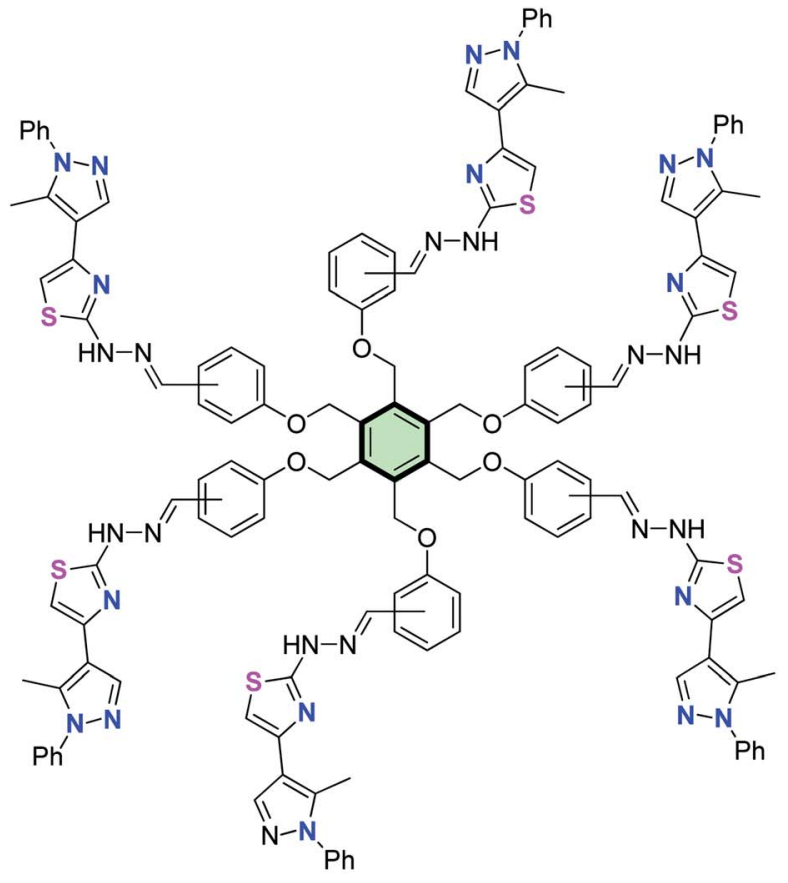

96a; $(66 \%)$

b; $(67 \%)$

Fig. 3 Structures of tetrakis(pyrazolyl)thiazoles $95 \mathrm{a}$ and $95 \mathrm{~b}$ and hexakis(pyrazolyl)thiazoles $96 \mathrm{a}$ and $96 \mathrm{~b}$.

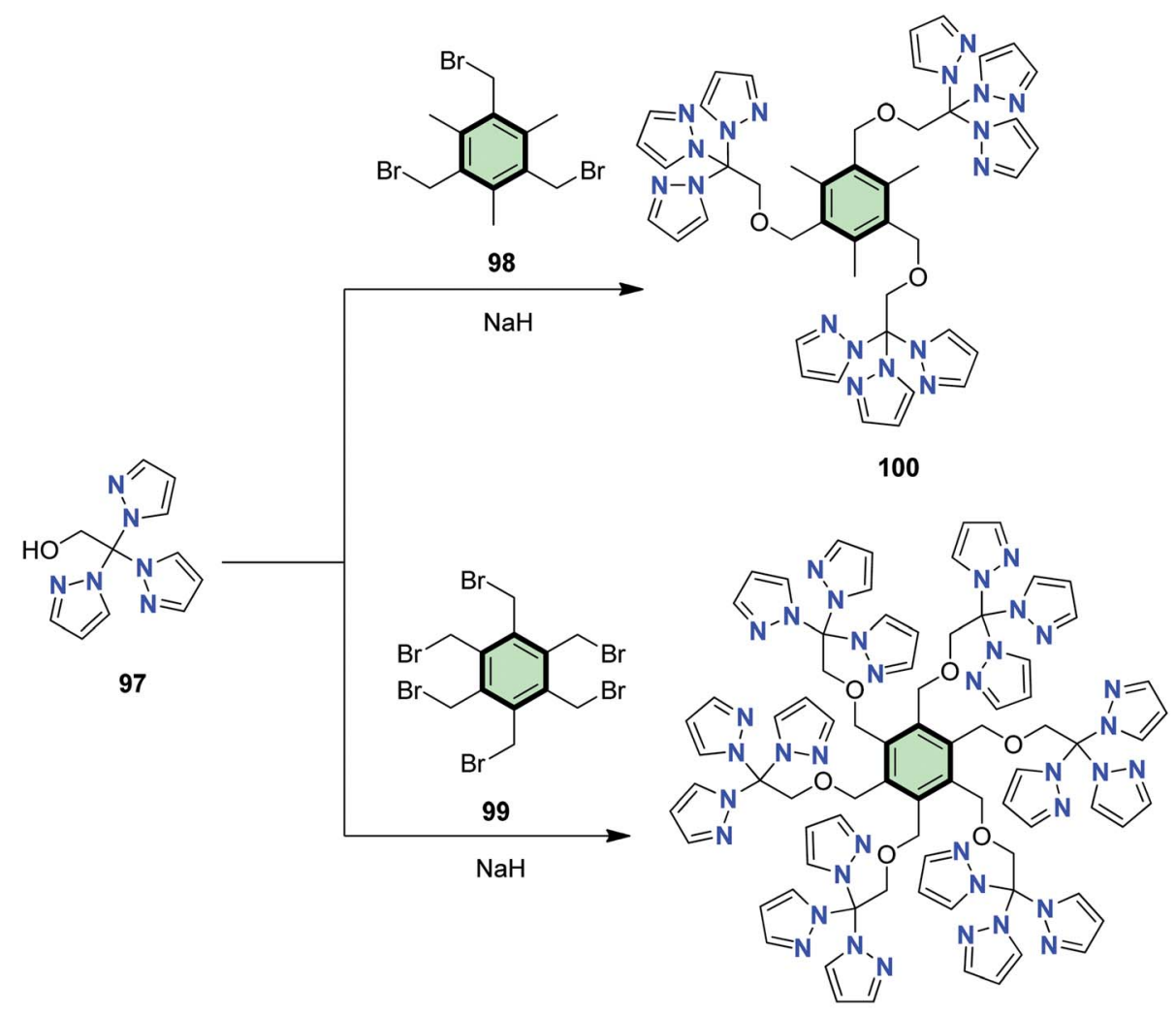



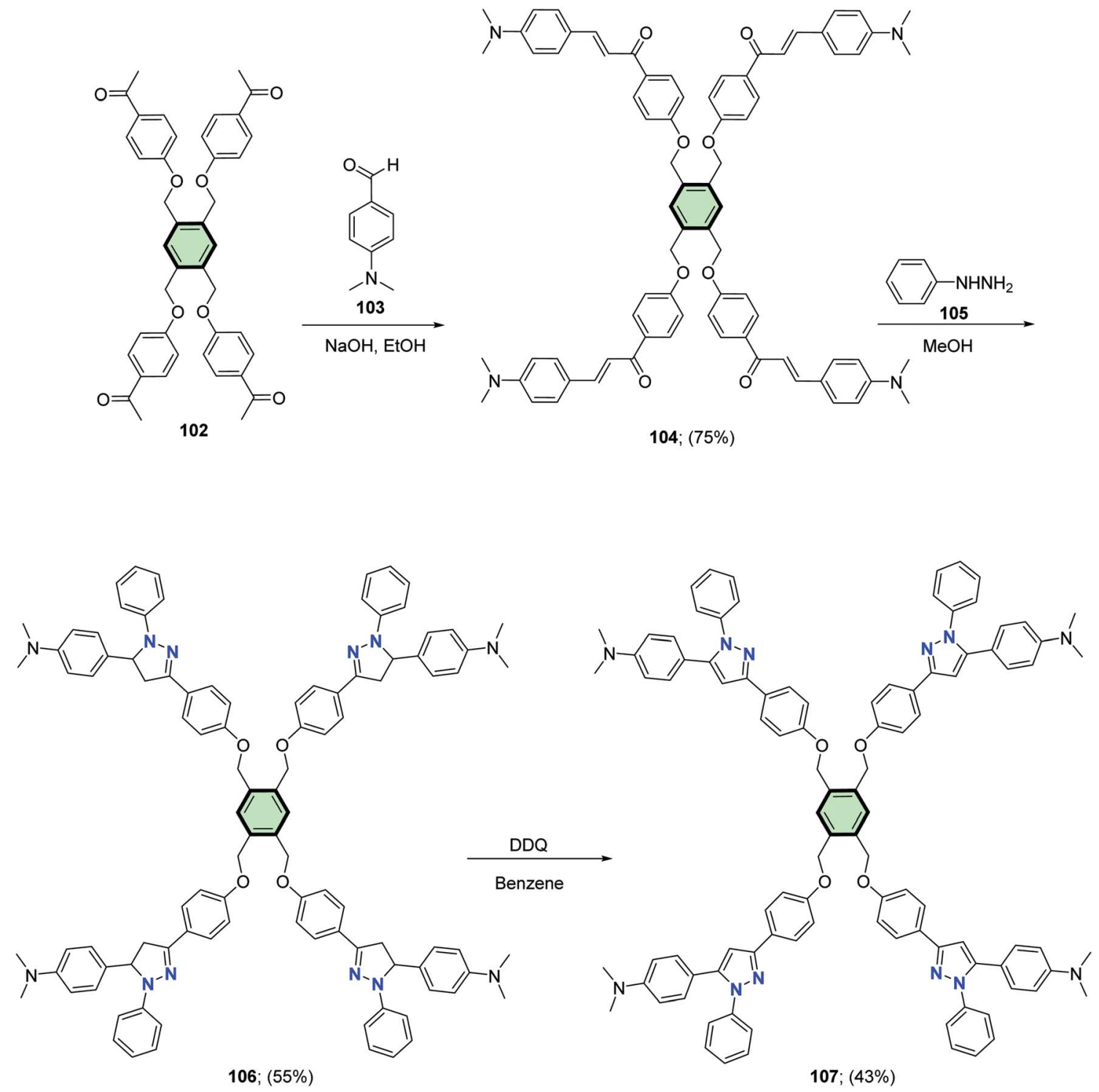

Scheme 27 Synthesis of SSMs containing four pendant pyrazole rings 107.<smiles>[R]c1cc(/C(N)=N/O)cc([R])c1[R]</smiles><smiles>O=C(O)c1cc(C(=O)Cl)cc(C(=O)Cl)c1</smiles>

$$
\begin{gathered}
\text { 108a; } \mathrm{R}^{1}=\mathrm{R}^{3}=\mathrm{H}, \mathrm{R}^{2}=n-\mathrm{OC}_{10} \mathrm{H}_{21} \\
\text { b; } \mathrm{R}^{1}=\mathrm{R}^{2}=n-\mathrm{OC}_{10} \mathrm{H}_{21}, \mathrm{R}^{3}=\mathrm{H} \\
\mathbf{c} ; \mathrm{R}^{1}=\mathrm{R}^{2}=\mathrm{R}^{3}=n-\mathrm{OC}_{10} \mathrm{H}_{21} \\
\text { d; } \mathrm{R}^{1}=\mathrm{R}^{2}=\mathrm{R}^{3}=n-\mathrm{OC}_{12} \mathrm{H}_{25}
\end{gathered}
$$<smiles>[R]c1cc(-c2noc(-c3cc(-c4nc(-c5cc([R])c([R])c([R])c5)no4)cc(-c4nc(-c5cc([R])c([R])c([R])c5)no4)c3)n2)cc([R])c1[R]</smiles>

$110 a-d(55-60 \%)$

Scheme 28 Synthesis of 1,2,4-oxadiazole-based benzene-cored SSMs 110a-d. 
<smiles>[R][R2]c1c([R2])cc(-c2nnc(-c3cc(-c4nnc(-c5cc([R20])c([R])c([R])c5)o4)cc(-c4nnc(-c5cc([R20])c([R2])c([R])c5)o4)c3)o2)cc1O[R]</smiles>

$117-120(31-36 \%)$

117: $\mathrm{R}^{1}=\mathrm{R}^{3}=\mathrm{H}, \mathrm{R}^{2}=n-\mathrm{C}_{10} \mathrm{H}_{21}$

118: $\mathrm{R}^{1}=\mathrm{R}^{2}=n-\mathrm{C}_{10} \mathrm{H}_{21}, \mathrm{R}^{3}=\mathrm{H}$

119: $\mathrm{R}^{1}=\mathrm{R}^{2}=\mathrm{R}^{3}=n-\mathrm{C}_{10} \mathrm{H}_{21}$

120: $R^{1}=R^{2}=R^{3}=2$-Ethyl hexyl

Fig. 4 SSMs with three pendant 1,3,4-oxadiazole moieties 117-120.

It should be mentioned that replacing oxygen in the fivemembered ring (in star-shaped TSANs 48 and 49) by a more voluminous and more basic sulfur atom (in star-shaped TSANs 50 and 51) has a pronounced effect on bent angle and electron distribution. It caused a larger longitudinal/lateral dipole moment and attractive $S \cdots S$ interactions in the condensed state as well. Tuning the peripheral groups from straight to branched chains affected the transition temperature, self-assembly and photophysical behavior in the solid state. The 1,3,4-oxadiazole based TSANs with branched tails 49 stabilized a columnar rectangular $\mathrm{Col}_{\mathrm{r}}$ phase at room temperature, while the straight chain analogue 48 showed a columnar hexagonal $\mathrm{Col}_{\mathrm{h}}$ phase at a high temperature. In contrast to 48 and 49, 1,3,4-thiadiazole
TSAN with straight peripheral tail 50 showed a $\mathrm{Col}_{\mathrm{r}}$ phase (presumably because of intermolecular attraction of 1,3,4-thiadiazole rings) while that with the bulkier branched tail $\mathbf{5 1}$ became a non-crystalline viscous liquid. ${ }^{19}$ 1,2,4-Oxadiazolebased TSANs 53a,b, on the other hand, showed lower melting, clearing points and wider mesophase range than 1,3,4oxadiazole-based TSANs 50 and 51. The position of trialkoxyphenyl group at the heterocycle has a prominent effect on the self-assembly properties; 53a with a trialkoxyphenyl group at 5position showed $\mathrm{Col}_{\mathrm{r}}$ phase while $\mathbf{5 3 b}$ with a trialkoxyphenyl group at 3-position exhibited $\mathrm{Col}_{\mathrm{h}}$ phase. Both compounds 53a and 53b emitted green light in solution with quantum yield (0.27-0.31) and red-shifted compared to 1,3,4-oxadiazole derivatives in thin film. ${ }^{30}$

\subsection{SSMs with aromatic or heterocyclic cores}

4.3.1. Benzene-cored SSMs. This class of SSMs are characterized by the presence of a central benzene core connected to different arms.

4.3.1.1. Benzene-cored SSMs with five-membered heterocyclic arms

4.3.1.1.1. Five-membered heterocyclic arms containing one heteroatom. 4.3.1.1.1.1. Furan. Kotha et al. ${ }^{80}$ reported the synthesis of 1,3,5-tris(2-furyl)benzene 56 in $66 \%$ yield by heating a mixture of 1,3,5-triiodobenzene $\mathbf{5 4}$ and furan-2-boronic acid 55 in $\mathrm{THF} /$ toluene mixture in the presence of $\mathrm{Pd}\left(\mathrm{PPh}_{3}\right)_{4}$ (Scheme 11).

4.3.1.1.1.2. Thiophene. A star-shaped molecule 1,3,5tri(thiophen-2-yl)benzene $\mathbf{5 8}$ was synthesized in 65\% yield, via trimerization of 2-acetyl thiophene 57 in the presence of TEA (Scheme 12)..$^{\mathbf{1 1}}$

2-Acetyl-5-alkylthiophenes 59a-c underwent cyclotrimerization reaction upon treatment with $\mathrm{SiCl}_{4}$ to give 1,3,5tris(5-alkylthiophenyl)benzenes 60a-c in 61, 72 and $63 \%$ yields, respectively (Scheme 13). ${ }^{\mathbf{8 0}}$<smiles>Brc1ccc(-c2nnn[nH]2)cc1</smiles>

111

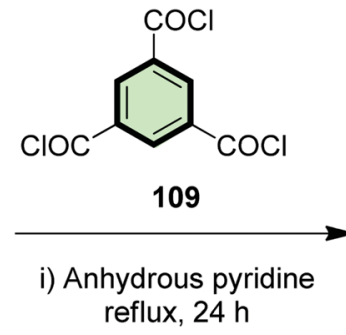

reflux, $24 \mathrm{~h}$

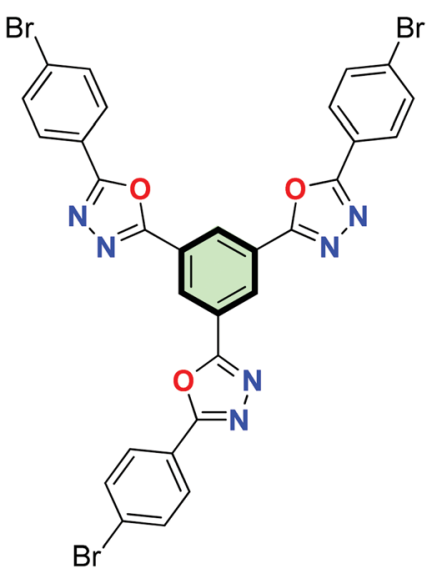

$112 ;(75 \%)$ 


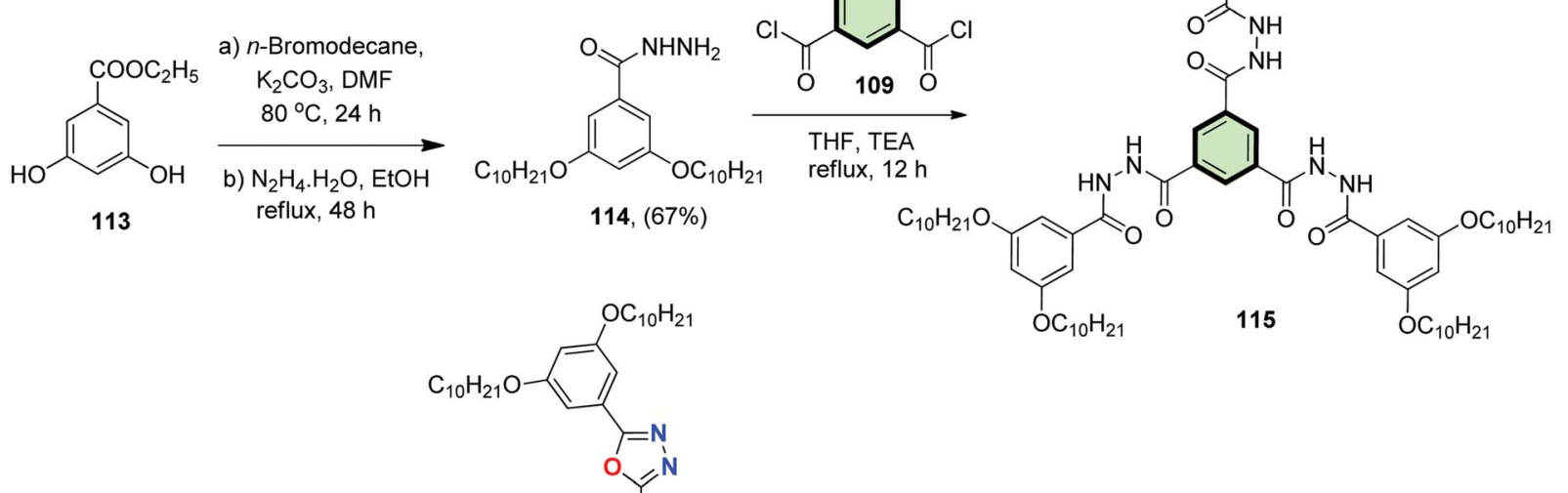

$\mathrm{POCl}_{3}, 100^{\circ} \mathrm{C}, 24 \mathrm{~h}$

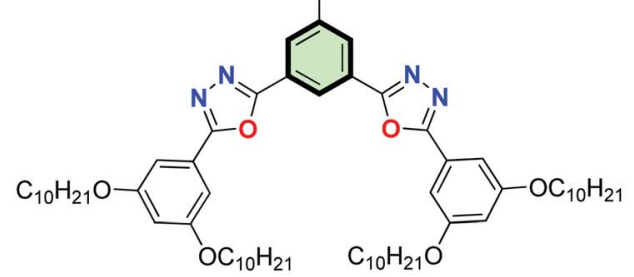

116

Scheme 30 Synthesis of SSMs with three pendant 1,3,4-oxadiazole moieties 116.

1,3,5-Tris(5-phenylthiophen-2-yl)benzene 64 was synthesized in $44 \%$ yield via the reaction of 2-acetyl-5phenylthiophene 63 with $\mathrm{SiCl}_{4}$ in ethanol. Compound 63 was synthesized from the reaction of 2-acetyl-5- bromothiophene 61 with phenylboronic acid 62 in the presence of $\mathrm{Pd}\left(\mathrm{PPh}_{3}\right)_{4}$ (Scheme 14). ${ }^{\mathbf{8 0}}$

1,3,5-Tris[4-(2'-thienyl)phenyl]benzene 67 was obtained in $14 \%$ yield by the reaction of 1,3,5-tris(4-halophenyl)benzenes

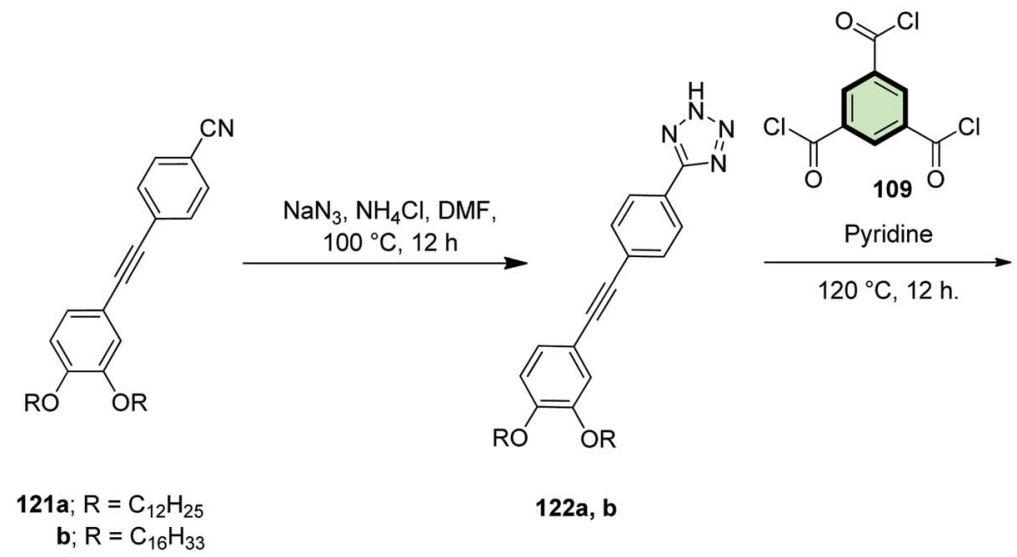

b; $\mathrm{R}=\mathrm{C}_{16} \mathrm{H}_{33}$

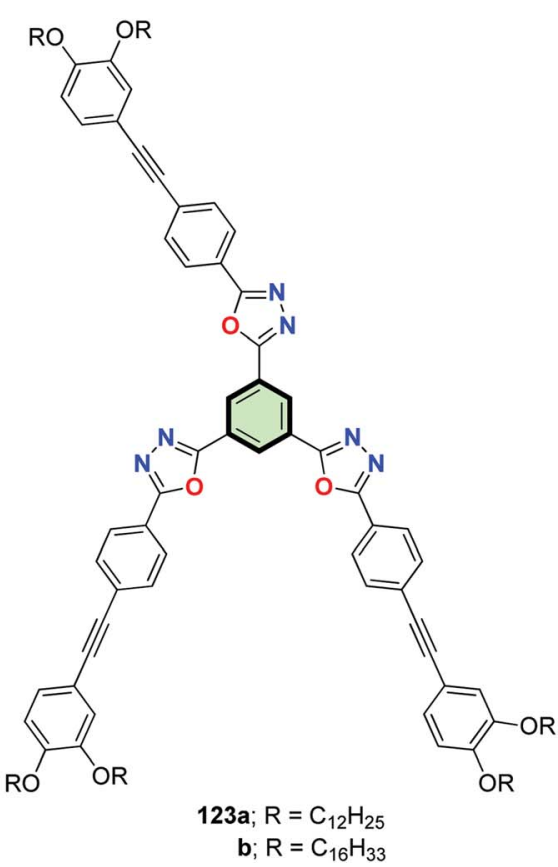

Scheme 31 Synthesis of 1,3,4-oxadiazole-based SSM 123a and 123b. 


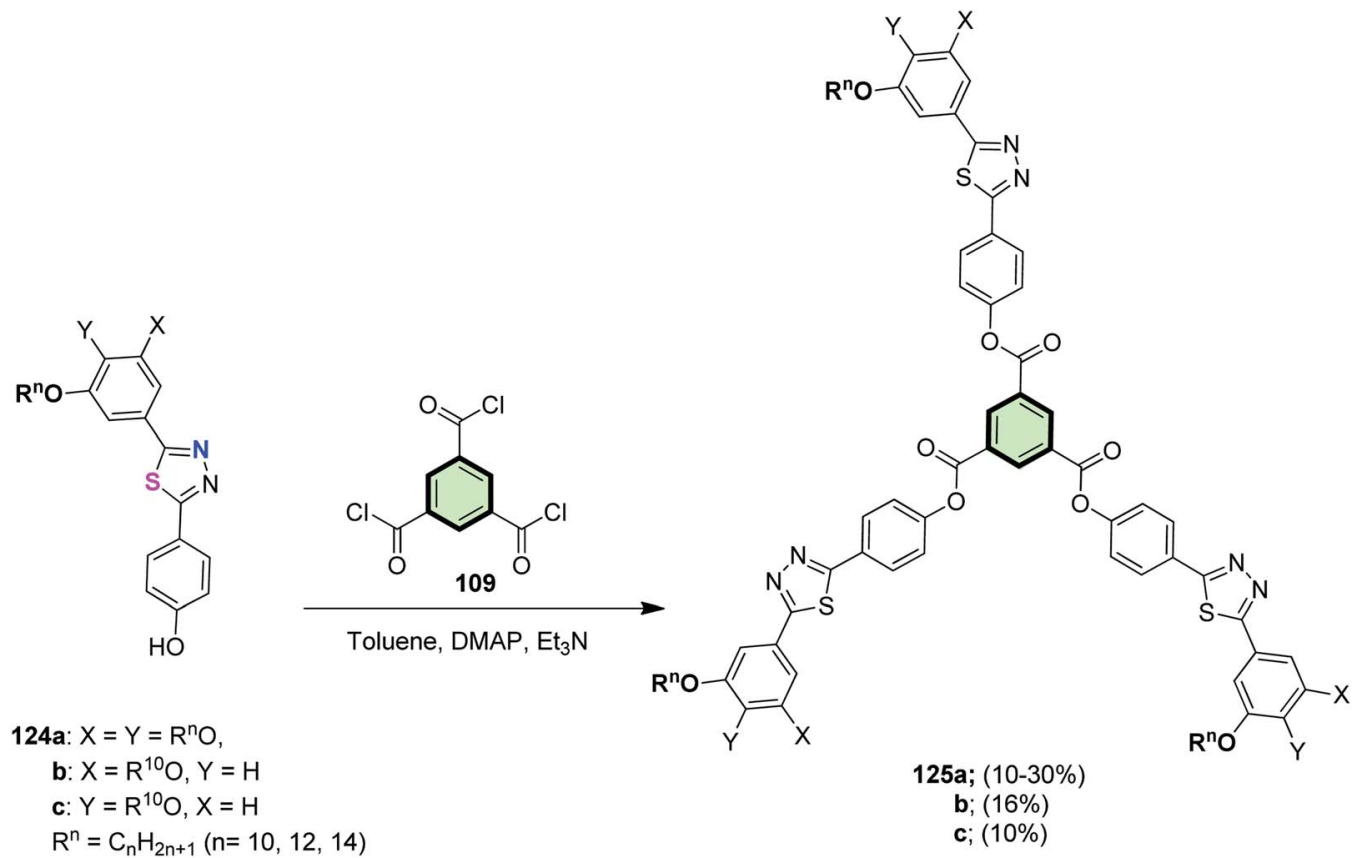

Scheme 32 Synthesis of SSMs with pendant 1,3,4-thiadiazole rings 125a-c.

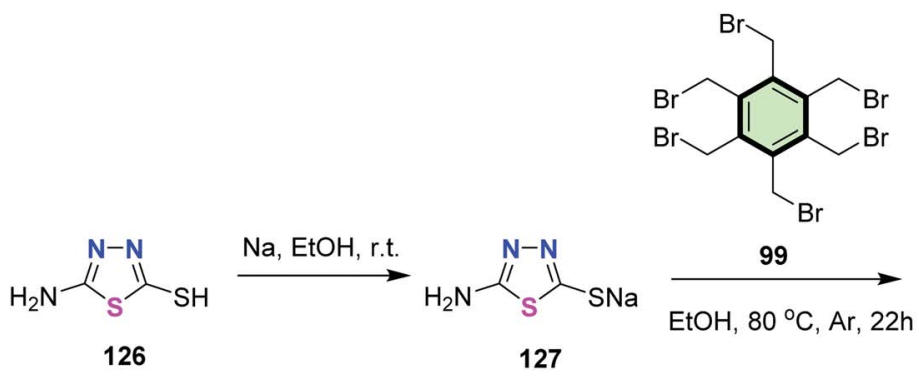<smiles>Nc1nnc(SCc2c(CSc3nnc(N)s3)c(CSc3nnc(N)s3)c(CSc3nnc(N)s3)c(CSc3nnc(N)s3)c2CSc2nnc(N)s2)s1</smiles>

128; (93\%)

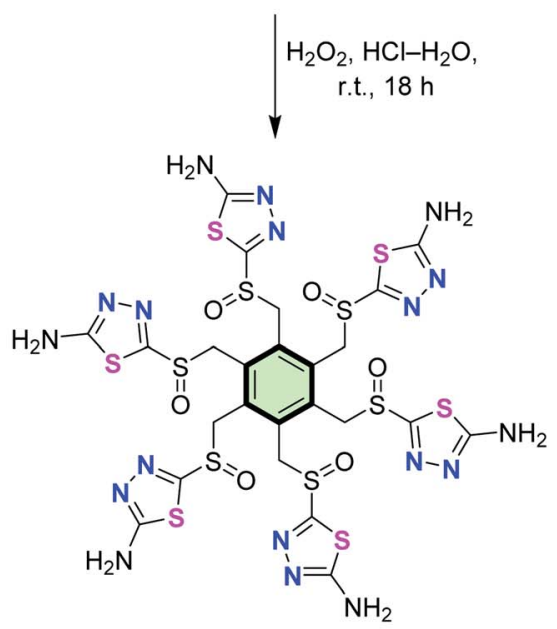

129; $(90 \%)$ 
Review

View Article Online

RSC Advances<smiles>NC(=S)N/N=C/c1ccccc1OCc1cc(COc2ccccc2/C=N/NC(N)=S)cc(COc2ccccc2/C=N/NC(N)=S)c1</smiles>

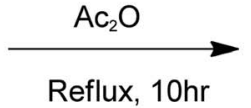

$85 b$<smiles>CC(=O)NC1=NN(C(C)=O)C(c2ccccc2OCc2cc(COc3ccccc3C3SC(NC(C)=O)=NN3C(C)=O)cc(COc3ccccc3C3SC(NC(C)=O)=NN3C(C)=O)c2)S1</smiles>

130; $(64 \%)$

Scheme 34 Synthesis of SMM with benzene core and 1,3,4-thiadiazole side arm 130.

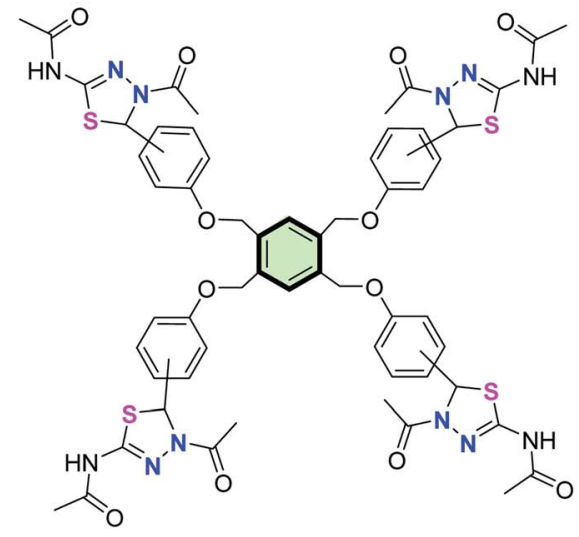

$131 \mathrm{a} ;$ p-isomer; $(68 \%)$

b; o-isomer; $(66 \%)$<smiles>COCc1c(COC)c(COc2ccc(C3SC(NC(C)=O)=NN3C(C)=O)cc2)c(COc2ccc(C3SC(NC(C)=O)=NN3C(C)=O)cc2)c(COc2ccc(C3SC(NC(C)=O)=NN3C(C)=O)cc2)c1COc1ccc(C2SC(NC(C)=O)=NN2C(C)=O)cc1</smiles>

$132 ;(67 \%)$

Fig. 5 Tetra- and hexakis(4,5-dihydro-1,3,4-thiadiazolyl) derivatives 131a, 131b and 132.

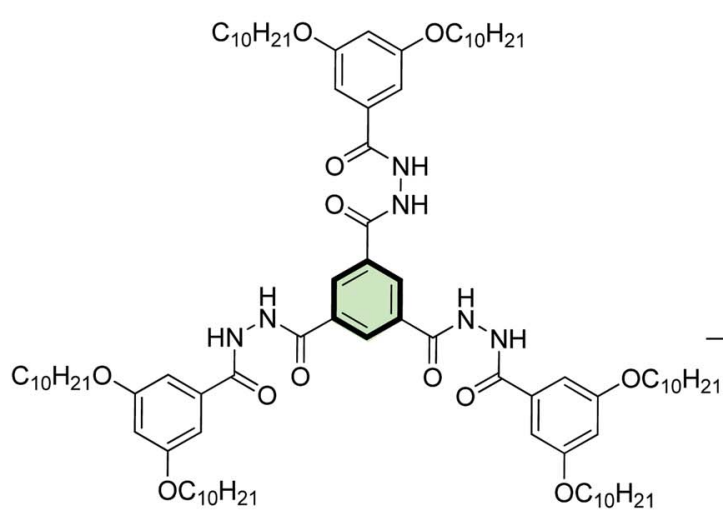

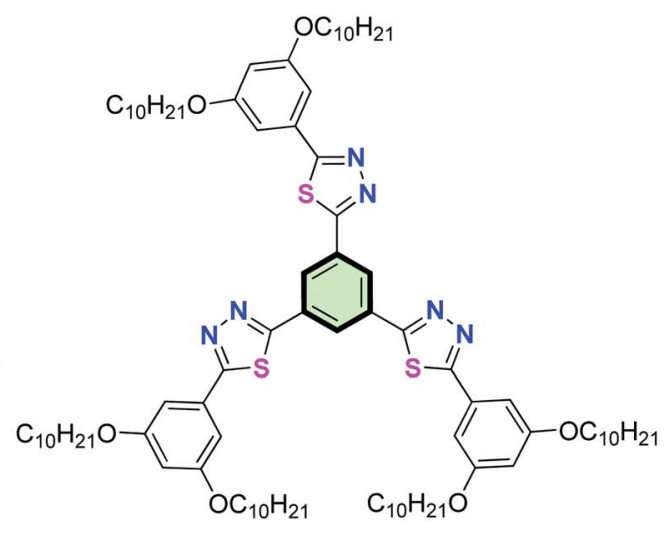

115

$133(50 \%)$

Scheme 35 Synthesis of SSM 133 with three pendant 1,3,4-thiadiazole moieties.

This journal is (c) The Royal Society of Chemistry 2019

RSC Adv., 2019, 9, 16606-16682 | 16627 
<smiles>[R][R2]c1c([R2])cc(-c2nnc(-c3cc(-c4nnc(-c5cc([R2])c([R2])c([R])c5)s4)cc(-c4nnc(-c5cc([R2])c([R])c(O[R])c5)s4)c3)s2)cc1O[R]</smiles>

134a-d (31-36\%)

134a: $\mathrm{R}^{1}=\mathrm{R}^{3}=\mathrm{H}, \mathrm{R}^{2}=n-\mathrm{C}_{10} \mathrm{H}_{21}$

134b: $\mathrm{R}^{1}=\mathrm{R}^{2}=n-\mathrm{C}_{10} \mathrm{H}_{21}, \mathrm{R}^{3}=\mathrm{H}$

134c: $\mathrm{R}^{1}=\mathrm{R}^{2}=\mathrm{R}^{3}=n-\mathrm{C}_{10} \mathrm{H}_{21}$

134d: $R^{1}=R^{2}=R^{3}=2$-Ethyl hexyl

Fig. 6 SSMs 134a-d with three pendant 1,3,4-thiadiazole moieties.

65a or 65b with thiophene-2-boronic acid 66 in the presence of $\mathrm{Pd}\left(\mathrm{PPh}_{3}\right)_{4}$ in refluxing THF/toluene mixture (Scheme 15). ${ }^{\mathbf{8 0}}$

Sonogashira coupling of ((5-iodothiophen-2-yl)ethynyl) trimethylsilane 69 and 1,3,5-triethynylbenzene 68 afforded 1,3,5-tris((5-((trimethylsilyl)ethynyl)thiophen-2-yl)ethynyl) benzene 70 in good yield (68\%) (Scheme 16). Star-shaped molecule 70 showed excellent luminescent properties. The fluorescence emission spectrum of $\mathbf{7 0}$ indicated four peaks at $375,390,418$ and $446 \mathrm{~nm}$, respectively, and the emission maximum peak at $375 \mathrm{~nm}$. The fluorescence intensities of 70 showed a dramatic change in chloroform relative to concentration; it increased (from 1235 to 6714 a.u.) with the concentration (from $5.0 \times 10^{-4}$ to $5.0 \times 10^{-6} \mathrm{M}$ ), while it decreased (from 5364 to 2042 a.u.) with the concentration (from $1.0 \times 10^{-6}$ to $1.0 \times 10^{-7} \mathrm{M}$ ). This behavior was attributed to the concentration aggregate-enhanced emission (AEE) effect ${ }^{82}$ and aggregation-caused quenching (ACQ) effect. Increasing the polarity of solvent from toluene to acetonitrile resulted in a blue shift of the peaks. ${ }^{83}$

4.3.1.1.1.3. Pyrrole. Suresh et al. ${ }^{84}$ reported the synthesis of star-shaped molecule with benzene core and pyrrole side arms 73 in $72 \%$ yield, through the reaction of $4^{\prime}, 4^{\prime \prime}, 4^{\prime \prime \prime}$-triamino-1,3,5triphenyl-benzene $\mathbf{7 1}$ with three equivalents of $1 \mathrm{H}$-pyrrole-2carbaldehyde $\mathbf{7 2}$ in the presence of ( $p$-TSA) in EtOH at reflux (Scheme 17). The ligand molecule 73 itself is non-emissive; however, its boron complex $\mathbf{7 4}$ acted as a blue emitter (510 $\mathrm{nm}$ ) with a fluorescence quantum yield of 0.46 . DFT calculations explained that in the singlet excited state, only one iminopyrrolyl group remains planar while the two others remain at their original geometries.

4.3.1.1.1.4. Pyrrolidine. Rajakumar et $a .^{85}$ reported the synthesis of some novel star-shaped molecules with pyrrolidine side arms 78, 80, 82 and 84 in high yields through 1,3-dipolar
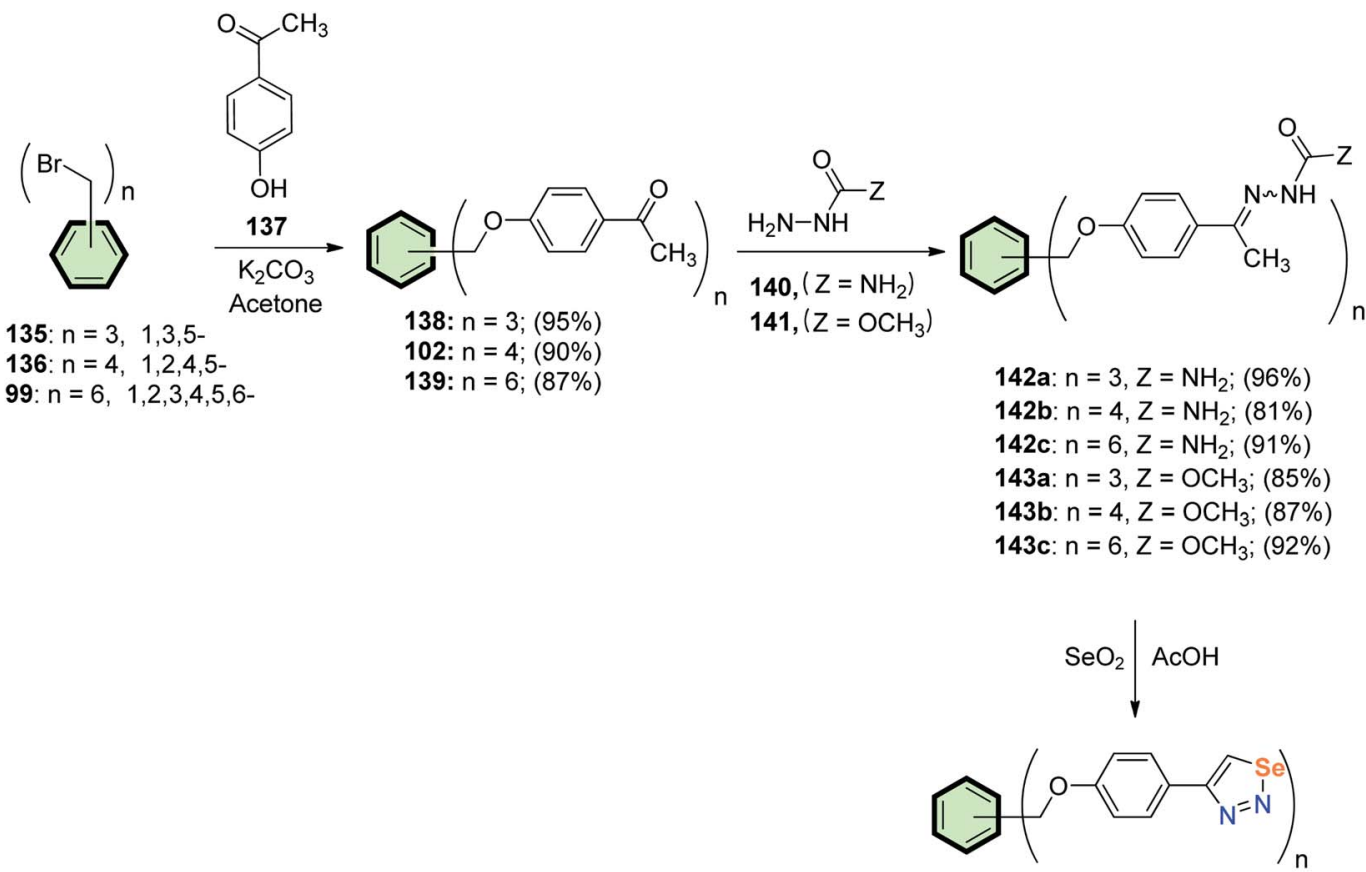

$144 a ;(87 \%)$

$144 b ;(92 \%)$

$144 \mathrm{c} ;(96 \%)$ 

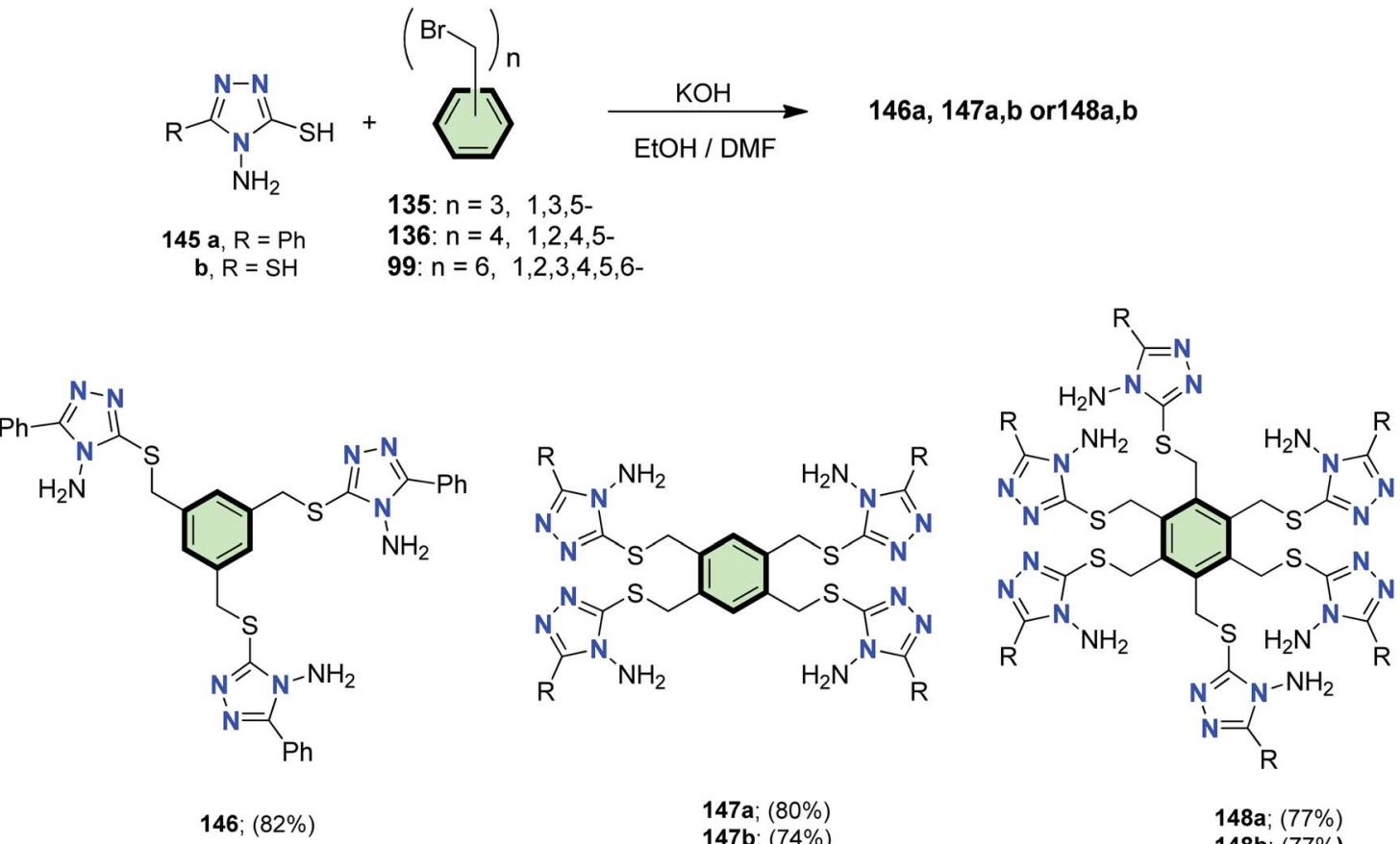

$147 a ;(80 \%)$

$147 \mathrm{~b} ;(74 \%)$

Scheme 37 Synthesis of SSMs with benzene core and 1,2,4-triazole side arms.

cycloaddition reaction of the respective chalcones 75, 79, 81 and 83 with sarcosine 76 and paraformaldehyde 77 in toluene at reflux (Schemes 18-21).

4.3.1.1.2. Five-membered heterocyclic arms containing two heteroatoms. 4.3.1.1.2.1. Thiazole and its derivatives. Salem et $a l .{ }^{86}$ reported the synthesis of multi-armed thiazole derivatives $\mathbf{8 8 a}$ and $\mathbf{8 8 b}$ in 67 and $69 \%$ yields, respectively, by the reaction of tris(aldehyde thiosemicarbazones) $85 \mathrm{a}$ and $\mathbf{8 5 b}$ with each of 2-bromo-1-phenyl ethanone 86 and 2-bromo-1-(4chlorophenyl)ethanone $\mathbf{8 7}$ in ethanol at reflux in the presence of TEA (Scheme 22). The same methodology was extended to the preparation of tetrakis- and hexakis(thiazoles) 90a, 90b, 92a and 92b in good yields from the corresponding poly(aldehyde thiosemicarbazones) 89a, 89b, 91a and 91b (Schemes 23 and 24).

Star-shaped molecules with benzene core and (pyrazolyl) thiazole side arm 94a and 94b were synthesized in 70 and 64\% yields, upon reaction each of tris(aldehyde thiosemicarbazones) 85a and 85b with 2-bromo-1-(5-methyl-1-phenyl-1 $H$-pyrazol-4-yl) ethanone 93 in ethanol at reflux in the presence of TEA (Scheme 25). ${ }^{86}$

In analogy, tetrakis(pyrazolyl)thiazoles 95a and 95b and hexakis(pyrazolyl)thiazoles $\mathbf{9 6 a}$ and $\mathbf{9 6 b}$ were synthesized by the reaction of the appropriate poly(thiosemicarbazones) $\mathbf{8 9 a} \mathbf{b} \mathbf{b}$ and 91a,b with 4-bromoacetylpyrazole 93 under the same condition (Fig. 3). ${ }^{86}$

4.3.1.1.2.2. Pyrazole. Reger et al. ${ }^{34}$ reported the synthesis of ligands with tris(pyrazolyl)methane units 100 and hexakis(pyrazolyl)methane units $\mathbf{1 0 1}$ in good yields by the reaction of tris-2,2,2-(1-pyrazolyl)ethanol 97 with each of 2,4,6-tris(bromomethyl)mesitylene $\mathbf{9 8}$ and 1,2,3,4,5,6- hexakis(bromomethyl)benzene 99, respectively, in the presence of $\mathrm{NaH}$ (Scheme 26). These star-shaped ligands have been used to synthesize interesting metallacage complexes via symmetry-interaction approach. The ligands showed a semi-flexible coordination behavior depending on the central metal mode of bonding, i.e. closed metallacage of high thermal stability at $200{ }^{\circ} \mathrm{C}$ was formed in case of $\mathrm{Ag}$ (I) while in case of $\mathrm{Cd}$ (II) open cage was produced.

Al-Smadi et al. ${ }^{87}$ reported the synthesis of multi-armed aromatic chalcone $\mathbf{1 0 4}$ in $\mathbf{7 5 \%}$ yield through cross-aldol condensation reaction between multi-armed aromatic ketone 102 and 4-(dimethylamino)benzaldehyde 103 in basic medium. The multi-armed aromatic chalcone $\mathbf{1 0 4}$ underwent cyclization reactions upon treatment with phenyl hydrazine $\mathbf{1 0 5}$ to yield the corresponding multiarmed pyrazoline derivatives 106 in 55\% yield. Aromatization of the pyrazoline rings of the latter compound with 2,3dichloro-5,6-dicyano-1,4-benzoquinone (DDQ) in benzene gave the corresponding multi-armed compound 107 in $43 \%$ yield (Scheme 27).

4.3.1.1.3. Five-membered heterocyclic arms containing three heteroatoms. 4.3.1.1.3.1. 1,2,4-Oxadiazole. Heating benzamidoxime derivatives $\mathbf{1 0 8}$ (prepared form ethyl gallate via a multistep procedure) with trimesic acid chloride 109 (prepared by heating benzene-1,3,5-tricarboxylic acid 4 with thionyl chloride in DMF) in pyridine at reflux afforded 1,2,4oxadiazole-based benzene-cored SSMs 110 in moderate yields (55-60\%) (Scheme 28). The number and length of the peripheral tails altered greatly the mesophase stability and the thermal range. Single crystal XRD analysis indicated that 110a (with 


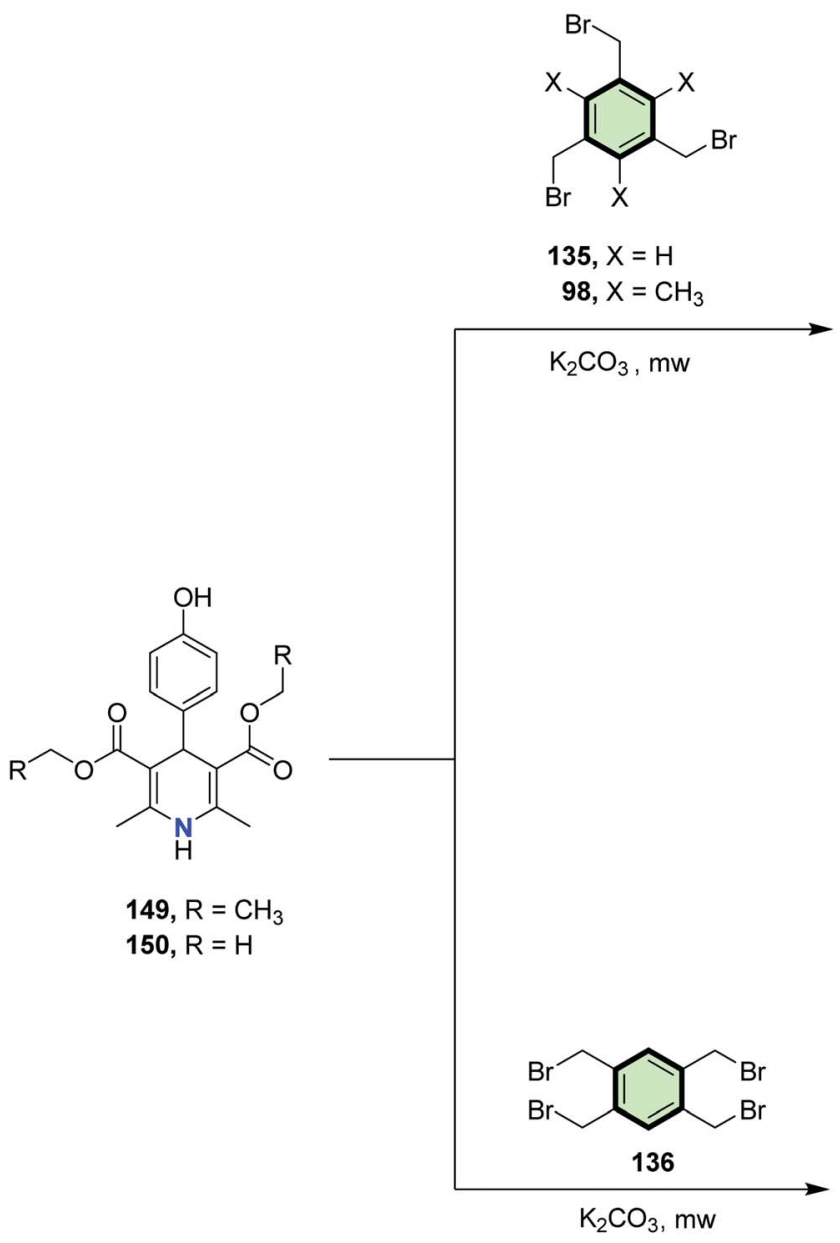<smiles>[R]COC(=O)C1=C(C)NC(C)=C(C(=O)OC[R])C1c1ccc(OCc2c([X])c(COc3ccc(C4C(C(=O)OC[R])=C(C)NC(C)=C4C(=O)OC[R])cc3)c([X])c(COc3ccc(C4C(C(=O)OC[R])=C(C)NC(C)=C4C(=O)OC[R])cc3)c2[X])cc1</smiles>

151, $\mathrm{R}=\mathrm{CH}_{3} ; \mathrm{X}=\mathrm{H}$; thermal: $67 \%$; MW: $82 \%$

152, $\mathrm{R}=\mathrm{CH}_{3} ; \mathrm{X}=\mathrm{CH}_{3}$; thermal: $50 \% ; \mathrm{MW}: 77 \%$

153, $\mathrm{R}=\mathrm{H} ; \mathrm{X}=\mathrm{H}$; thermal: $69 \%$; MW: $85 \%$

154, $\mathrm{R}=\mathrm{H} ; \mathrm{X}=\mathrm{CH}_{3}$; thermal: $63 \%$; MW: $79 \%$<smiles>[R]COC(=O)C1=C(C)NC(C)=C(C(=O)OC[R])C1c1ccc(OCc2cc(COc3ccc(C4C(C(=O)OC[R])=C(C)NC(C)=C4C(=O)OC[R])cc3)c(COc3ccc(C4C(C(=O)OC[R])=C(C)NC(C)=C4C(=O)OC[R])cc3)cc2COc2ccc(C3C(C(=O)OC[R])=C(C)NC(C)=C3C(=O)OC[R])cc2)cc1</smiles>

155, $\mathrm{R}=\mathrm{CH}_{3}$; thermal: $49 \% ; \mathrm{MW}: 72 \%$

156, $\mathrm{R}=\mathrm{H}$; thermal: $54 \%$; $M W: 80 \%$

Scheme 38 Synthesis of tripodal and tetrapodal(1,4-dihydropyridines) 151-156<smiles>O=Cc1ccc(OCc2cc(COc3ccc(C=O)cc3)cc(COc3cccc(C=O)c3)c2)cc1</smiles>

157a, $p$-isomer

b, o-isomer<smiles>C[C+](N)/C=C\C#N</smiles>

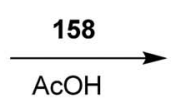<smiles>[1H]</smiles><smiles>C/C(N)=C\C#N</smiles>

Scheme 39 Synthesis of tris(1,4-dihydropyridines) 159a and 159b. 


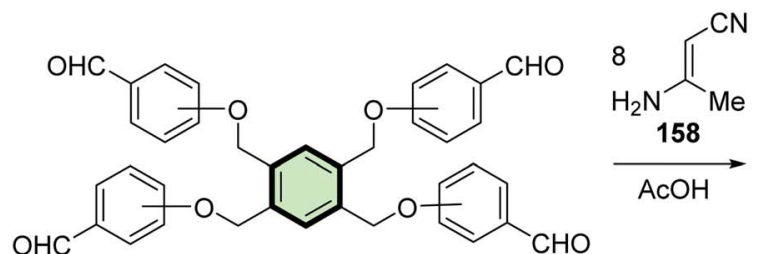

160a, $p$-isomer

b, o-isomer

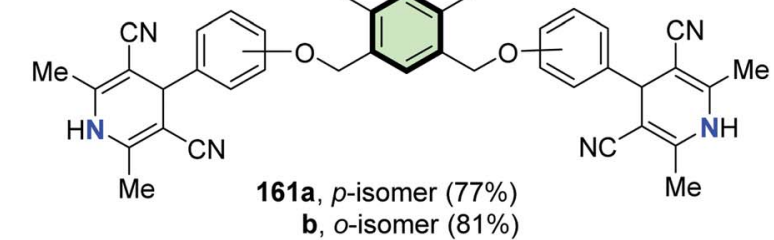

Scheme 40 Synthesis of tetrakis(1,4-dihydropyridines) $161 \mathrm{a}$ and $161 \mathrm{~b}$

three peripheral chains) was crystalline and lamellar. The starshaped compound has to contain at least six peripheral alkyl groups to attain a $\mathrm{Col}_{h}$ phase. The thermal range is direct proportional to the number of peripheral alkyl tails. Furthermore, increasing the length of alkyl chain led to a reduction of $\mathrm{Col}_{\mathrm{h}}$ phase. Although all hekates 110a-d exhibited weak fluorescence in solution, they have a strong emission in solid state and exhibited a red shift upon increasing the number of alkyl tails. The energy gap $\Delta E_{\mathrm{g}}^{\text {opt }}$ values of 110a-d are $4.21-4.23 \mathrm{eV}$ which is higher than that of 1,3,4-oxadiazole analogues 117-120 (3.35-3.48 eV, ${ }^{31} c f$. Fig. 4). The emission spectra of 110a-d displayed maxima centered at 299-314 $\mathrm{nm}$ which were red-shifted on increasing the number of peripheral groups. In particular, Hekate 110b acted as a supergelator forming gel in non-polar solvent (which is so rare). At higher concentration, it formed a stable gel which could be molded. Compound 110b exhibited aggregation-induced blue light emission twelve times higher than that of the monomer. Photophysical studies showed that 110b forms $\mathrm{J}$-aggregate in thin film while $\mathrm{H}$-aggregate in gel. XRD of 110b clarified a $\mathrm{Col}_{\mathrm{r}}$ assembly in the xerogel state. ${ }^{25}$

4.3.1.1.3.2. 1,3,4-Oxadiazole. $\quad 5$-(4-Bromophenyl)- $1 H$-tetrazole 111 underwent cleavage-cyclization reaction upon treatment with benzene-1,3,5-tricarbonyl trichloride 109 in anhydrous pyridine to give 1,3,5-tris(5-(4-bromophenyl)-1,3,4oxadiazol-2-yl)benzene 112 in $75 \%$ yield (Scheme 29). ${ }^{88}$

Williamson's $O$-alkylation of ethyl 3,5-dihydroxybenzoate 113 with $n$-bromodecane followed by reaction with hydrazine hydrate gave 3,5-bis(decyloxy)benzohydrazide $\mathbf{1 1 4}$ in moderate yield (67\%). The acylation of $\mathbf{1 1 4}$ with benzene-1,3,5-tricarbonyl trichloride 109 in THF in the presence of triethylamine at reflux resulted in the formation of tris(aroyl)benzene-1,3,5tricarbohydrazide 115. Cyclization of $\mathbf{1 1 5}$ was affected by treatment with phosphorus oxychloride to form SSMs with three pendant 1,3,4-oxadiazole moieties 116 (Scheme 30). Compound 116 stabilized a $\mathrm{Col}_{\mathrm{h}}$ phase and showed supergelation property due to $\pi-\pi$ interactions. It also showed many fold hyperchromic increase in photoluminescence. ${ }^{89}$<smiles>O=Cc1ccc(OCc2c(COc3ccc(C=O)cc3)c(COc3ccc(C=O)cc3)c(COc3ccc(C=O)cc3)c(COc3ccc(C=O)cc3)c2COc2ccc(C=O)cc2)cc1</smiles>

162a, $p$-isomer b, $O$-isomer

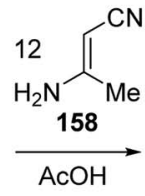

Scheme 41 Synthesis of hexakis(1,4-dihydropyridines) 163a and 163b.

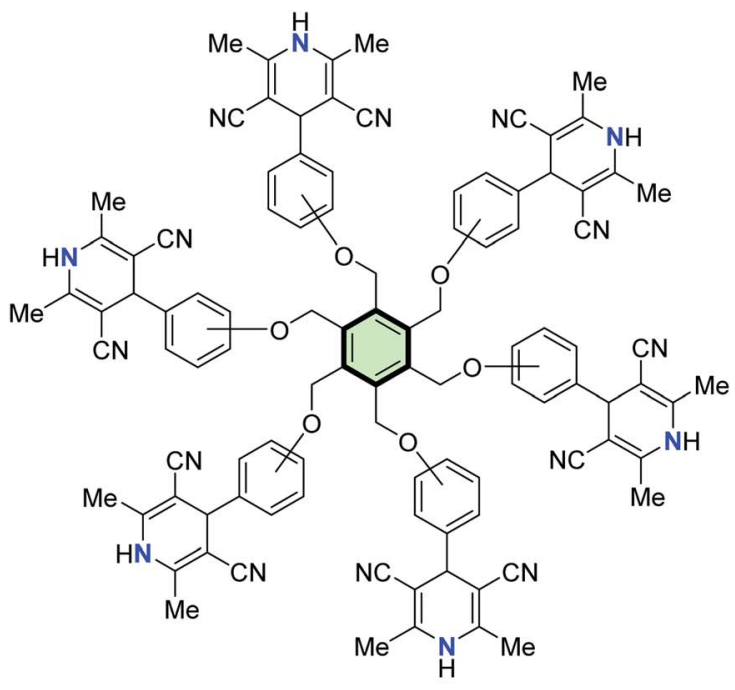

163a, $p$-isomer $(74 \%)$ b, o-isomer ( $82 \%)$ 


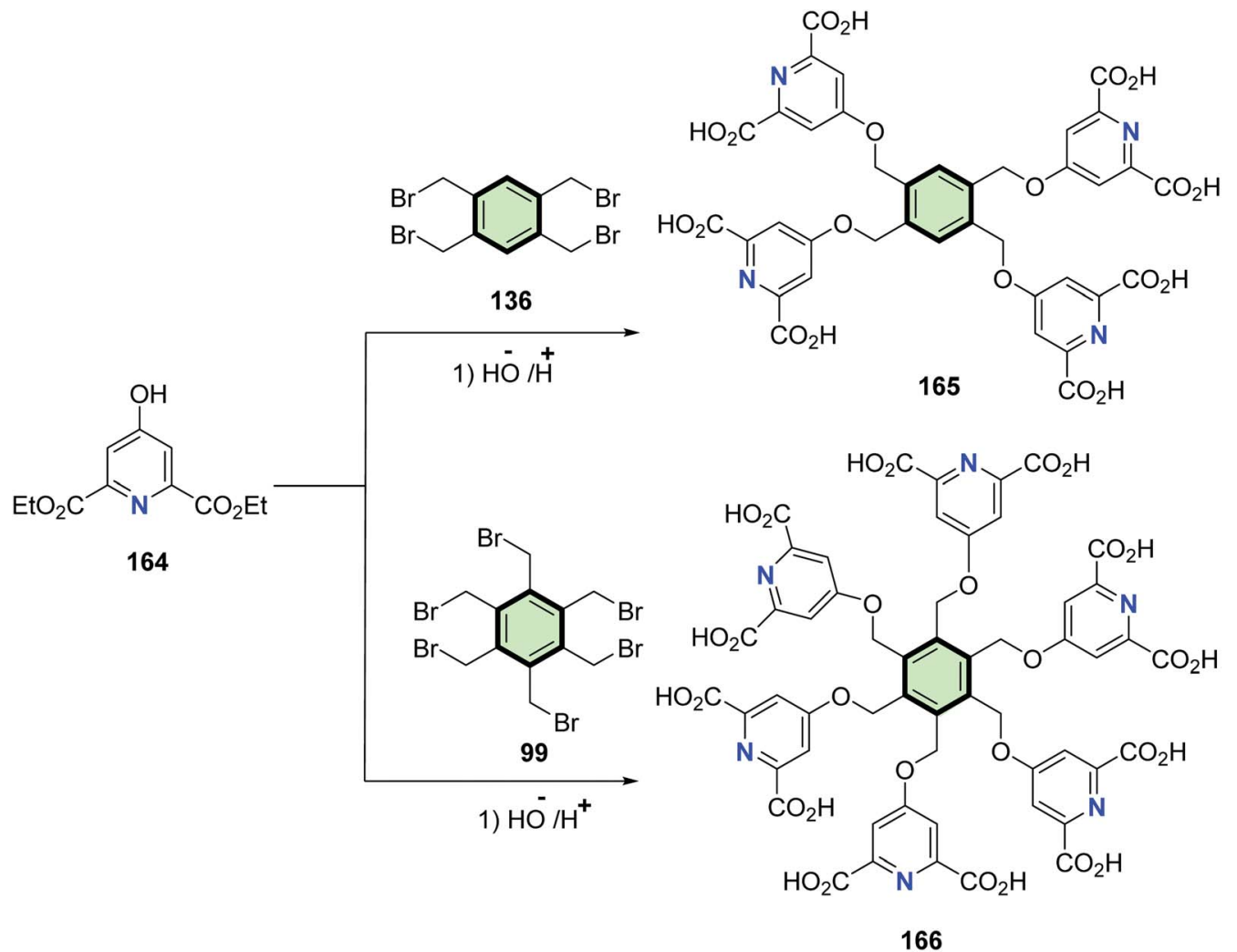

Scheme 42 Synthesis of SMM 165 and 166 with benzene core and pyridine-2,6-dicarboxylic acid side arm.

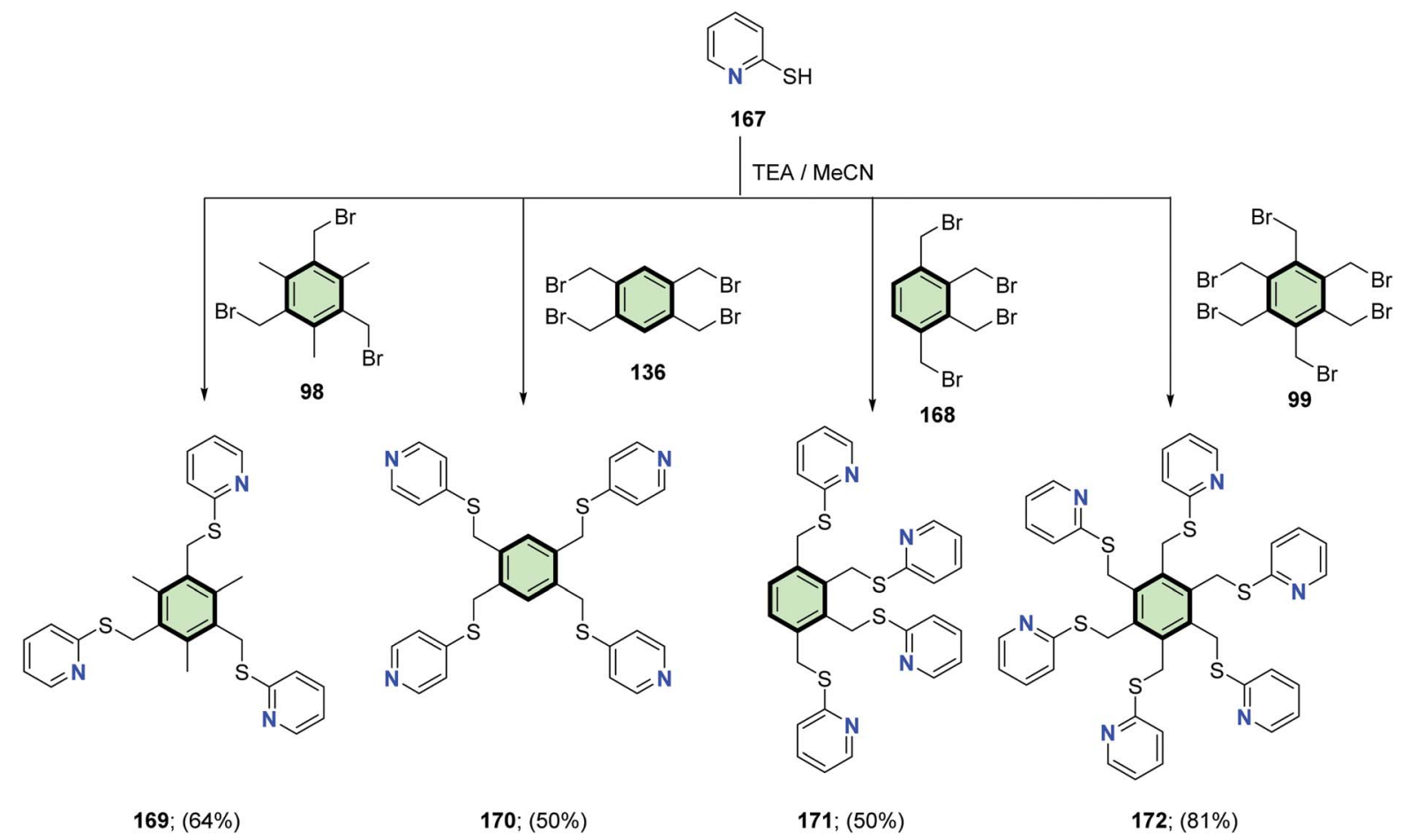

Scheme 43 Synthesis of poly(pyridylsulfanylmethyl)arenes 169-172. 


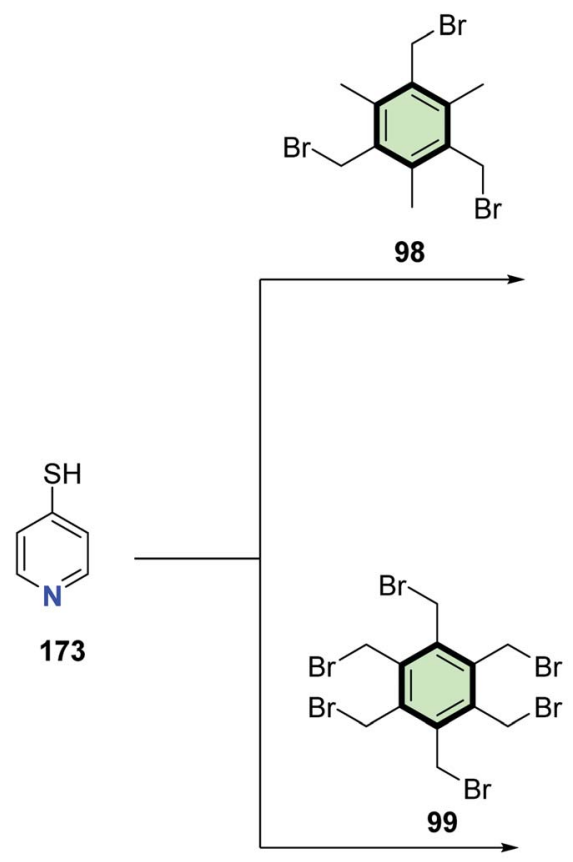<smiles>Cc1c(CSc2ccncc2)c(C)c(CSc2ccncc2)c(C)c1CSc1ccncc1</smiles>

$174 ;(72 \%)$<smiles>c1cc(SCc2c(CSc3ccncc3)c(CSc3ccncc3)c(CSc3ccncc3)c(CSc3ccncc3)c2CSc2ccncc2)ccn1</smiles>

$175 ;(90 \%)$

Scheme 44 Synthesis of poly(pyridylsulfanylmethyl)arenes 174 and 175

In a similar reaction sequence, SSMs 117-120 were synthesized in 31-36\% yields starting from ethyl gallate (Fig. 4). ${ }^{31}$

1,3,4-Oxadiazole-based SSMs 123a,b were synthesized as outlined in Scheme 31 via firstly reaction of 4-((3,4-bis(alkoxy) phenyl)ethynyl)benzonitrile $\mathbf{1 2 1 a}$ or $\mathbf{1 2 1 b}$ with sodium azide to afford tetrazole derivatives $\mathbf{1 2 2 a}$ and $\mathbf{1 2 2 b}$, respectively, in excellent yields (85-90\%). Synthesis of 123a and 123b was then achieved via treating 122a and $\mathbf{1 2 2 b}$, respectively, with trimesic acid chloride 109 by a typical Huisgen reaction mechanism. 1,3,4-Oxadiazole-SSMs 123a and 123b exhibited enantiotropic columnar mesophases over a wide temperature range, with the liquid crystalline phases exhibiting strong blue fluorescence. On cooling, 123a transformed into a transparent glass at room temperature wherein the liquid crystalline texture was retained. The glassy film remained stable over a period of one year and exhibited blue luminescence with an absolute quantum yield of $26 \%$.

The length of the alkyl substituent was observed to have a significant effect on the absorption and fluorescence properties of the gels, which was attributable to the role of the alkyl substituents in controlling the nature of the molecular packing within the self-assembled fibers of the gels. The optical properties of these derivatives in gel state were found to be alkyl chain dependent. The gel derived from 123a exhibited blue emission whereas 123b exhibited bluish-green emission in decane.
The extent of aggregation was found to be higher in $\mathbf{1 2 3 b}$ which is evident from their large red shift observed in absorption and emission spectra compared to the other derivative. These observations clearly demonstrate that perturbation of molecular structure has remarkable influence on their bulk macroscopic properties. ${ }^{85}$

4.3.1.1.3.3. 1,3,4-Thiadiazole. A series of star-shaped molecules based on benzene as the central core and three pendant 2phenyl-5-(di-, and/or tri- $n$-alkoxyphenyl)-1,3,4-thiadiazole arms 125a-c were synthesized by the reaction of 1,3,5-benzenetricarbonyl trichloride 109 with the corresponding phenolic1,3,4-thiadiazole precursors 124a-c, respectively, in the presence of dimethylaminopyridine (DMAP) and triethylamine in dry toluene (Scheme 32). ${ }^{18}$ The position and number of alkoxy substituents was found to affect the photophysical and liquid crystalline properties of SSMs 125. Of the synthesized SSMs, 125a and 125b showed enantiotopic liquid crystalline properties adopting hexagonal columnar phase on cooling the isotropic liquid to room temperature. These mesogens were luminescent at room temperature either in solid or in film. The cyclic voltammetry data of $\mathbf{1 2 5 b}$ indicated that it can act as hole-blockers.

Yang et $a{ }^{90}{ }^{90}$ reported that heating hexakis(bromomethyl) benzene 99 with the sodium salt of 2-amino-5-sulfanyl-1,3,4thiadiazole 127 (obtained upon treatment of $\mathbf{1 2 6}$ with sodium ethoxide) in ethanol at reflux gave hexakis(1,3,4-thiadiazol-2amine) 128 bonded to benzene core via methylenesulfinyl 


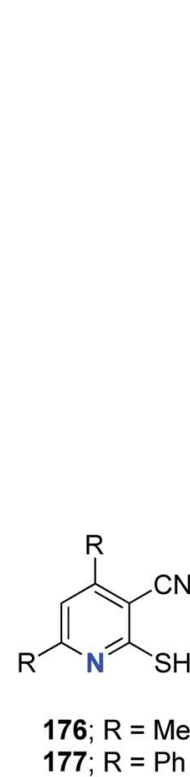

$\mathrm{KOH}, \mathrm{EtOH}$, reflux, $1 \mathrm{hr}$ $\mathrm{MW}: \mathrm{KOH}, \mathrm{DMF}, 1 \mathrm{~min}$ $160^{\circ} \mathrm{C}, 250 \mathrm{~W}$
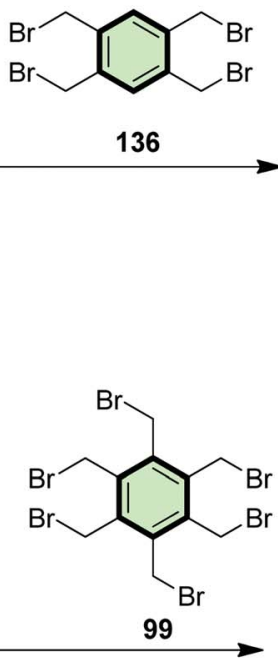<smiles>[R]c1cc([R])c(C#N)c(SCc2cc(CSc3nc([R])cc([R])c3C#N)cc(CSc3nc([R])cc([R])c3C#N)c2)n1</smiles>

178; $\mathrm{R}=\mathrm{Me}$; thermal: $74 \% ; \mathrm{MW}: 75 \%$ 179; $\mathrm{R}=\mathrm{Ph}$; thermal: $82 \%$; $\mathrm{MW}: 89 \%$<smiles>[R]c1cc([R])c(C#N)c(SCc2cc(CSc3nc([R])cc([R])c3C#N)c(CSc3nc([R])cc([R])c3C#N)cc2CSc2nc([R])cc([R])c2C#N)n1</smiles>

180; $R=$ Me; thermal: $65 \% ; M W: 69 \%$ 181; $\mathrm{R}=\mathrm{Ph}$; thermal: $72 \% ; \mathrm{MW}: 78 \%$<smiles>[R]c1cc([R])c(C#N)c(SCc2c(CSc3nc([R])cc([R])c3C#N)c(CSc3nc([R])cc([R])c3C#N)c(CSc3nc([R])cc([R])c3C#N)c(CSc3nc([R])cc([R])c3C#N)c2CSc2nc([R])cc([R])c2C#N)n1</smiles>

182; $\mathrm{R}=\mathrm{Me}$; thermal: $73 \% ; \mathrm{MW}: 77 \%$

183; $\mathrm{R}=\mathrm{Ph}$; thermal: $50 \% ; \mathrm{MW}: 64 \%$

Scheme 45 Synthesis of SMM with benzene core and nicotinonitrile side arm 178-183.

$\left(\mathrm{CH}_{2}-\mathrm{S}\right)$ linkages in $93 \%$ yield. The latter compound underwent oxidation upon treatment with hydrogen peroxide to give hexakis(methylenesulfinyl)hexakis(1,3,4-thiadiazol-2-amine) 129 in $90 \%$ yield (Scheme 33). Three arms of compound 129 could successfully encapsulate one or two copper(II) ions.

A star-shaped molecule with benzene core and 1,3,4-thiadiazole side arm 130 was synthesized in 64\% yield by refluxing tris(aldehyde thiosemicarbazone) $\mathbf{8 5 b}$ in acetic anhydride (Scheme 34). ${ }^{86}$

Similarly, tetrakis(4,5-dihydro-1,3,4-thiadiazolyl) derivatives 131a and 131b as well as hexakis(4,5-dihydro-1,3,4-thiadiazolyl) 132 have been synthesized in good yields from the corresponding tetra- and hexa(aldehyde thiosemicarbazone) (Fig. 5). ${ }^{86}$
Heating of tris(aroyl)benzene-1,3,5-tricarbohydrazide 115 with Lawesson's reagent in dry toluene furnished SSM 133 with three pendant 1,3,4-thiadiazole moieties (Scheme 35). ${ }^{89}$

In a similar reaction sequence, SSMs $134 a-d$ were synthesized in $30-49 \%$ yields starting from ethyl gallate (Fig. 6). ${ }^{31}$

4.3.1.1.3.4. 1,2,3-Selenadiazole. Al-Smadi and Ratrout ${ }^{91}$ reported a multi-step procedure for the synthesis of multi-armed benzene derivatives 144a-c containing two, three, four and six 1,2,3-selenadiazole side arms as outlined in scheme 36 . The poly ketones 138, 102 and 139 were prepared by reacting bromomethyl benzene derivatives 135, 136 and 99, respectively, with 4-hydroxyacetophenone $\mathbf{1 3 7}$ in acetone in the presence of $\mathrm{K}_{2} \mathrm{CO}_{3}$. Condensation of 138, 102 and 139 with semicarbazide 140 or methyl hydrazine carboxylate 141 afforded the corresponding semicarbazones 142a-c or the ethoxycarbonyl 


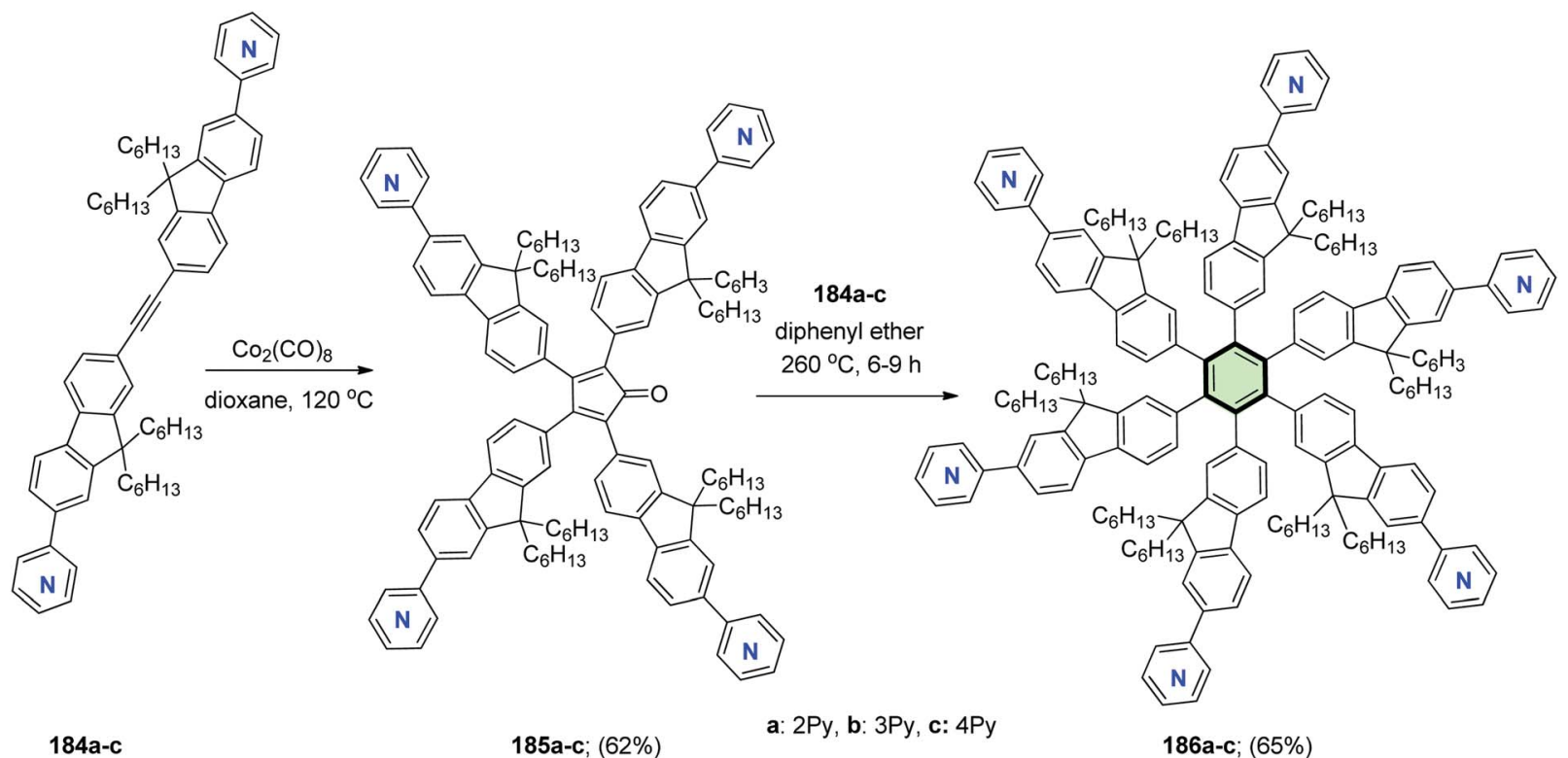

a: $2 \mathrm{Py} ; 38 \%$, b: $3 \mathrm{Py} ; 63 \%$, c: $4 \mathrm{Py} ; 62 \%$

a: $2 \mathrm{Py} ; 61 \%$, b: $3 \mathrm{Py} ; 17 \%, \mathrm{c}: 4 \mathrm{Py} ; 65 \%$

Scheme 46 Synthesis of hexakis(9,9-dihexyl-7-(pyridin-4-yl)-9H-fluoren-2-yl)benzene 186a-c.

hydrazones 143a-c, respectively. Subsequent treatment of the latter compounds with selenium dioxide in acetic acid gave compounds 144a-c in good yields (Scheme 36).

4.3.1.1.3.5. 1,2,4-Triazole. Elwahy et al. ${ }^{92}$ reported the synthesis of 1,3,5-tris(4-amino-5-phenyl-4H-3-sulfanylmethyl) benzene 146 in $82 \%$ yield by the reaction of tris(bromomethyl) benzene 135 with 4-amino-5-phenyl-4H-1,2,4-triazole-3-thiol 145a in refluxing EtOH/DMF mixture containing $\mathrm{KOH}$. Under similar conditions, tetrakis- and hexakis(4-amino-5-phenyl$4 H$-3-sulfanyl methyl)benzenes $147 \mathbf{a}, \mathbf{b}$ and $148 \mathbf{a}, \mathbf{b}$ were prepared in $74-80 \%$ yields, respectively, upon treatment of the

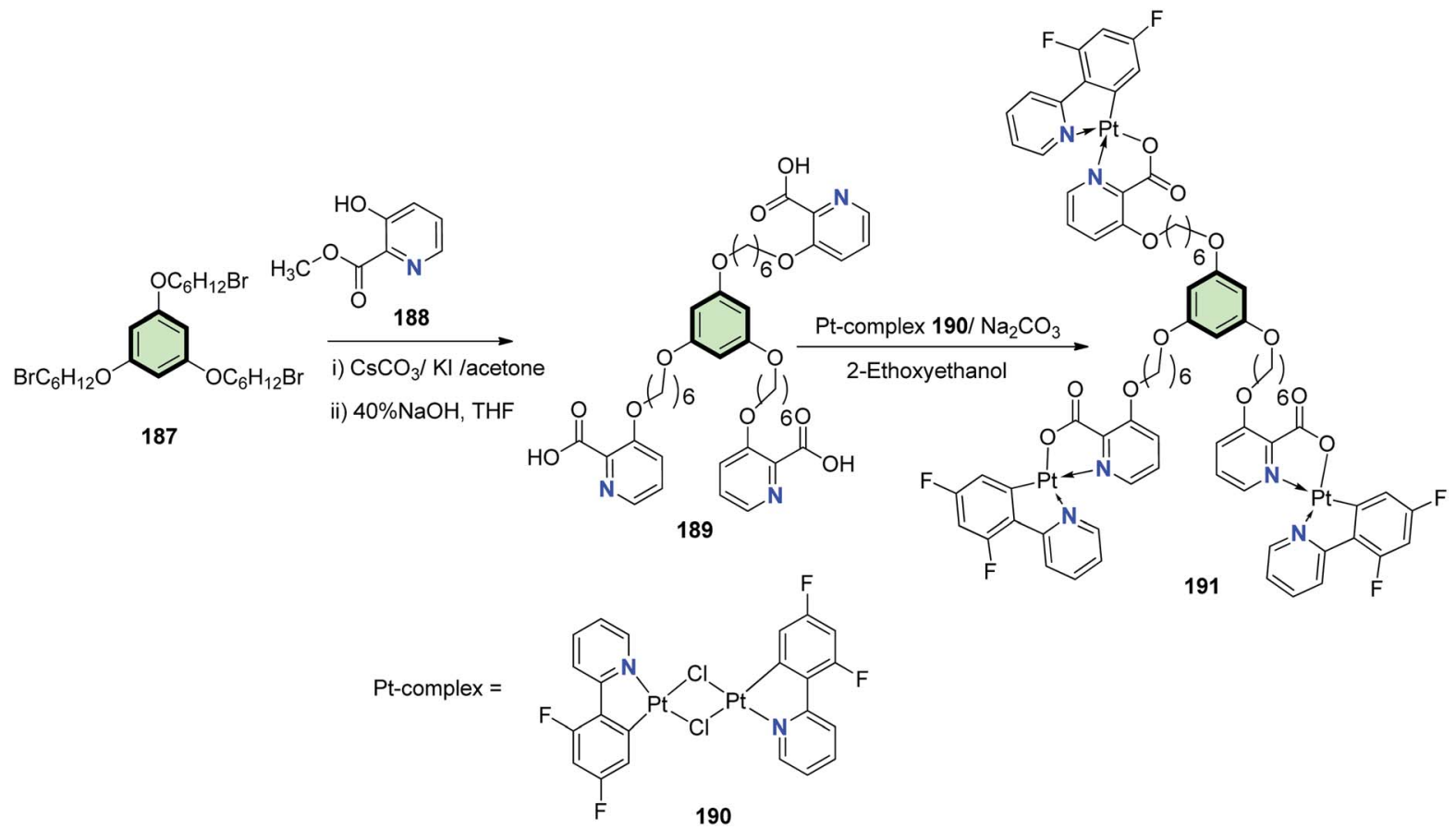

Scheme 47 Synthesis of cyclometalated platinum(II) complexes 191. 


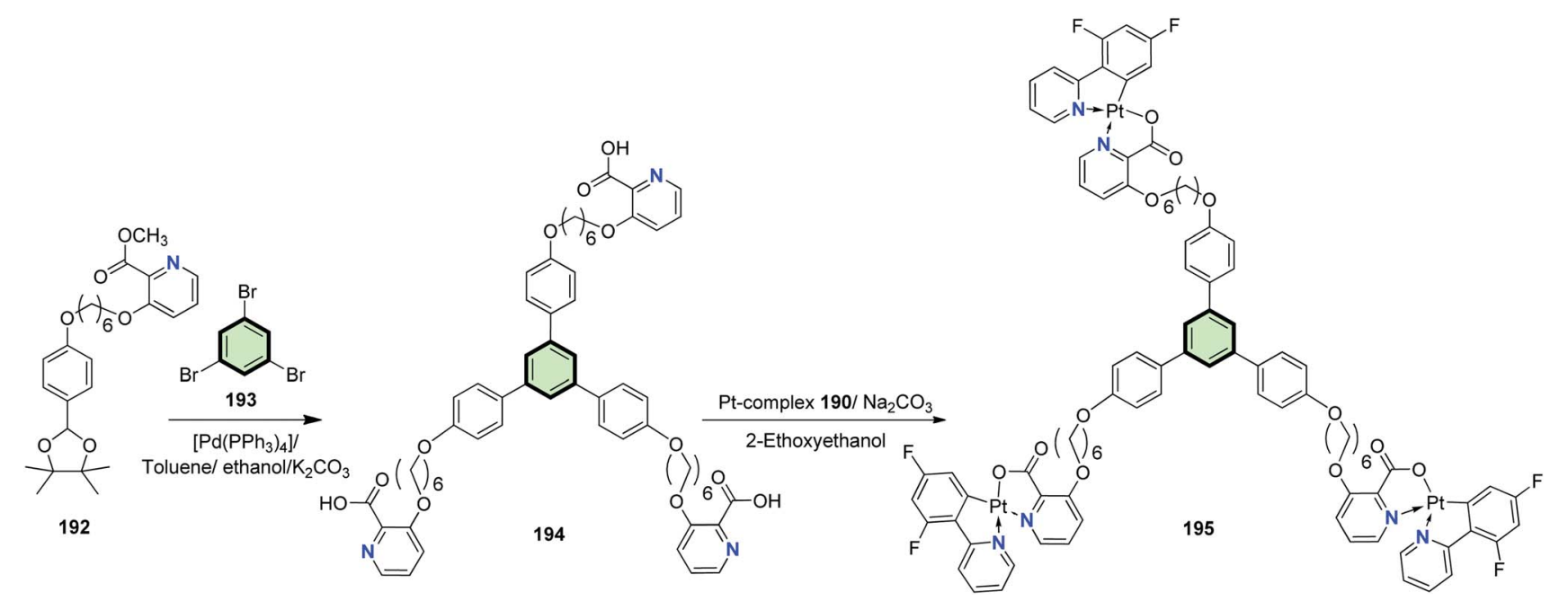

Scheme 48 Synthesis of cyclometalated platinum(॥) complexes 195.

aminotriazoles 145a,b with the corresponding tetrakis(bromomethyl)benzene $\mathbf{1 3 6}$ and hexakis (bromomethyl) benzene 99 in refluxing EtOH/DMF mixture containing $\mathrm{KOH}$ (Scheme 37).

4.3.1.2. Benzene-cored SSMs with six-membered heterocyclic arms

4.3.1.2.1. Six-membered heterocyclic arms containing one heteroatom. 4.3.1.2.1.1. 1,4-Dihydropyridine. Rajesh et al. ${ }^{\mathbf{9 3}}$ reported the synthesis of tripodal and tetrapodal 1,4-dihydropyridines (DHP) 151-156 by the reaction of monofunctional 1,4-DHP 149 and 150 with the appropriate tribromomethylbenzenes 135 and $\mathbf{9 8}$ or tetra-bromomethyl benzene 136, respectively, in the presence of $\mathrm{K}_{2} \mathrm{CO}_{3}$ as a base. The reactions were performed under conventional heating (49$69 \%$ yields) as well as under microwave irradiation (72-85\% yields) (Scheme 38).

Abdelhamid et $a .^{94}$ reported the synthesis of poly(2,6dimethyl-4-phenyl-1,4-dihydropyridinyl)arenes 159a, 159b, 161a, 161b, 163a and 163b in good yields through reaction of tris-, tetrakis-, and hexakis(formylphenoxy methyl)benzenes 157a, 157b, 160a, 160b, 162a and 162b, respectively, with 3aminobut-2-enenitrile $\mathbf{1 5 8}$ in acetic acid at reflux (Schemes 3941).<smiles>Oc1ccc(Sc2c(Sc3ccc(O)cc3)c(Sc3ccc(O)cc3)c(Sc3ccc(O)cc3)c(Sc3ccc(O)cc3)c2Sc2ccc(O)cc2)cc1</smiles><smiles>CC(C)C1COC(c2cc(Cl)cc(C3=N[C@@H](C(C)C)CO3)n2)=N1</smiles>

$\mathrm{Cs}_{2} \mathrm{Co}_{3}$ DMSO, $80^{\circ} \mathrm{C}$

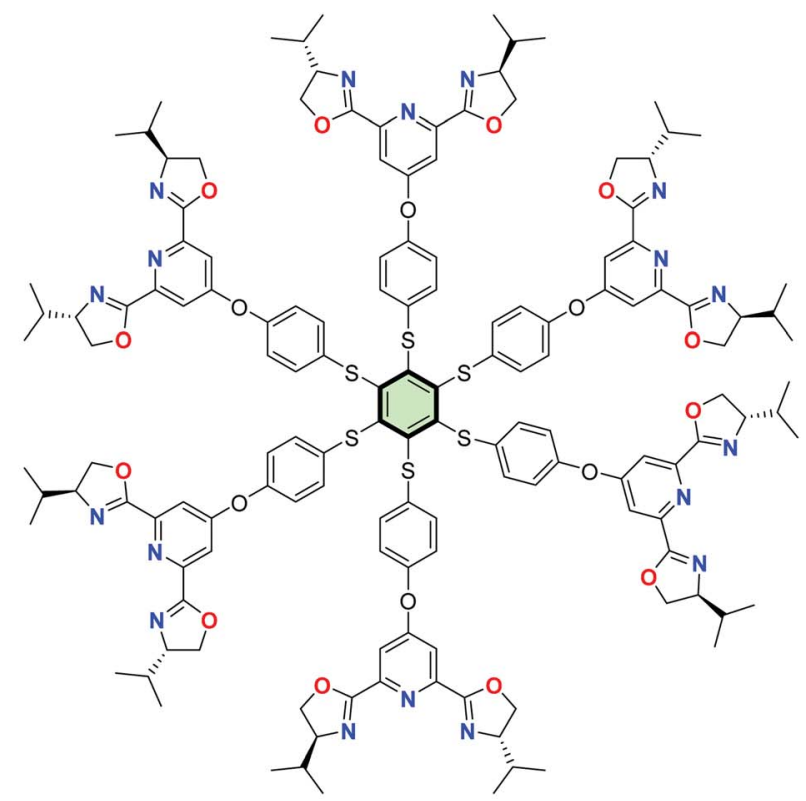

198; $(94 \%)$

Scheme 49 Synthesis of SSMs with (phenylthio)benzene core and 2,6-bis(4,5-dihydrooxazol-2-yl)pyridine side arms 198. 


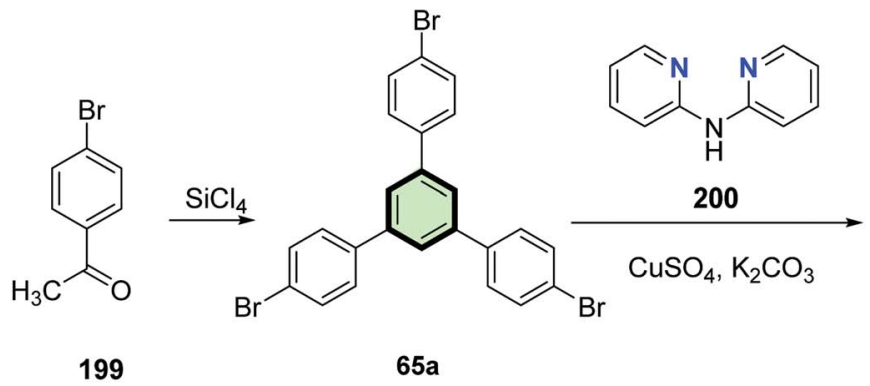

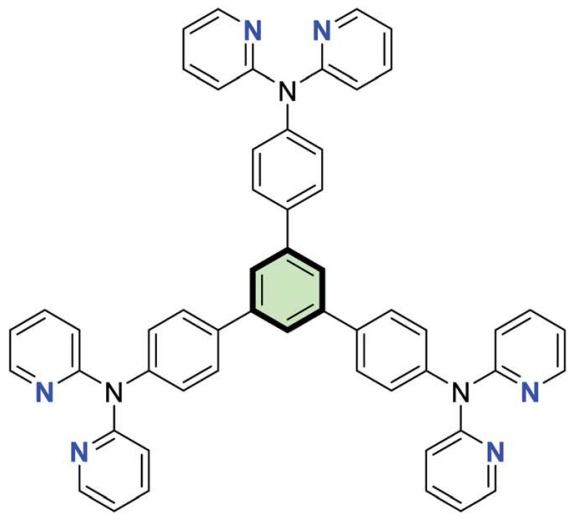

$201 ;(85 \%)$

Scheme 50 Synthesis of 1,3,5-tris( $p$-(2,2'-dipyridylamino) phenyl) benzene 201.

4.3.1.2.1.2. Pyridine and its derivatives. Yin and $\operatorname{Tan}^{95}$ reported the synthesis of multifunctional pyridine-2,6dicarboxylic acid derivatives 165 and 166 by coupling of diethyl 4-hydroxypyridine-2,6-dicarboxylate 164 with tetrakis(bromomethyl)benzene $\mathbf{1 3 6}$ and hexakis(bromomethyl)benzene $\mathbf{9 9}$, respectively, in basic medium (Scheme 42).

McMorran and Steel ${ }^{96}$ reported the synthesis of a series of poly(pyridylsulfanylmethyl)arenes 169-172, 174 and 175 in

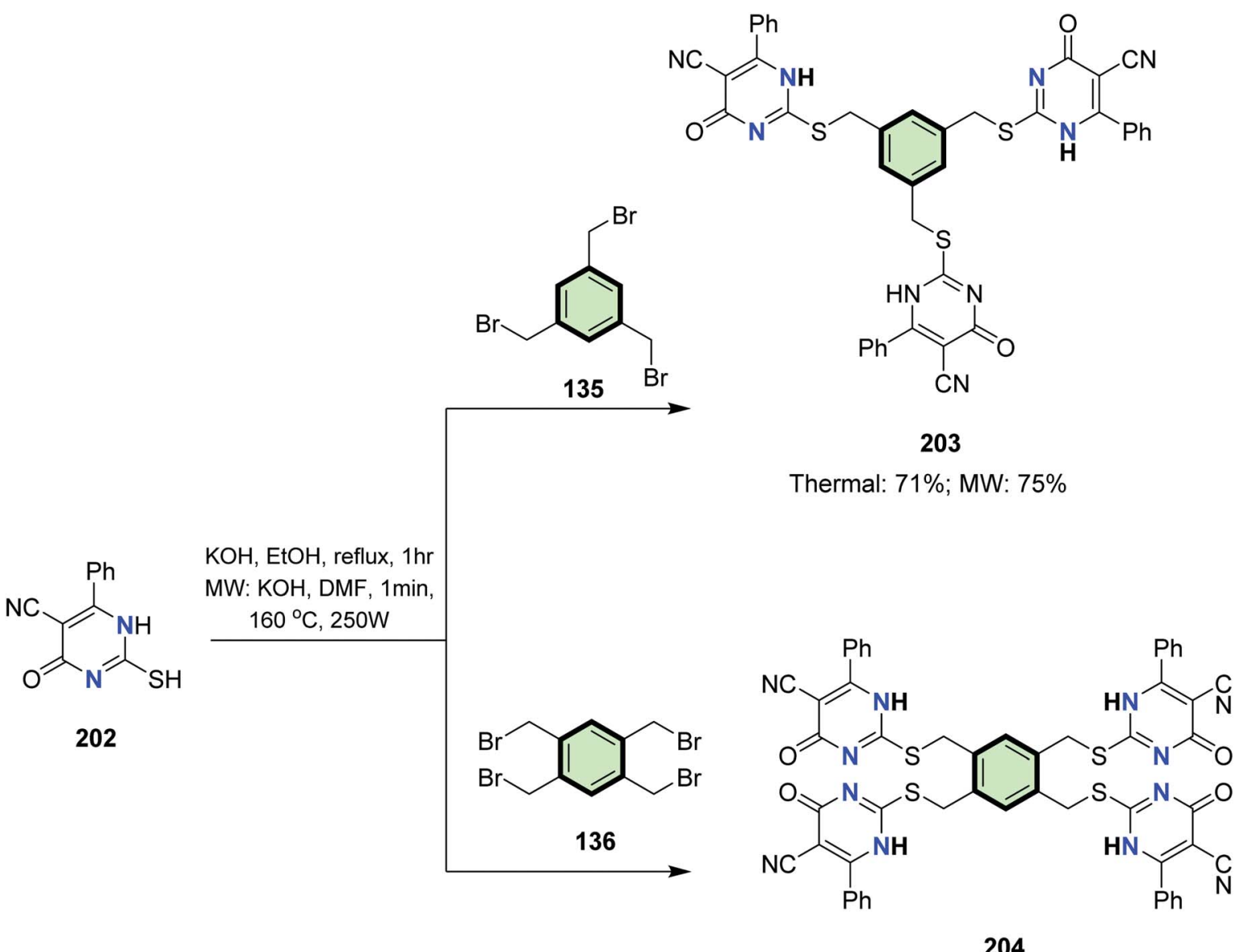

204

Thermal: $78 \%$; MW: $88 \%$

Scheme 51 Synthesis of tris- and tetrakispyrimidine derivatives 203 and 204 


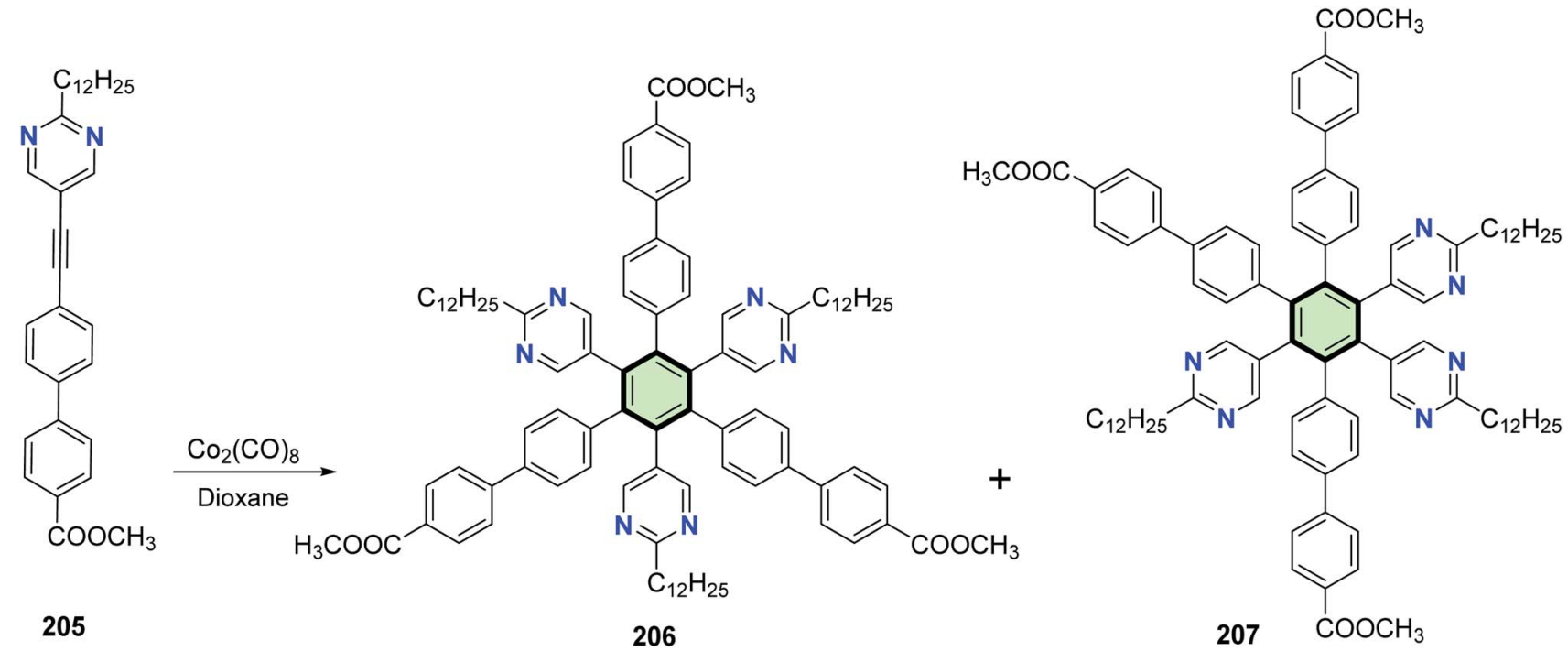<smiles>COC(C)(C)C(C)F</smiles>

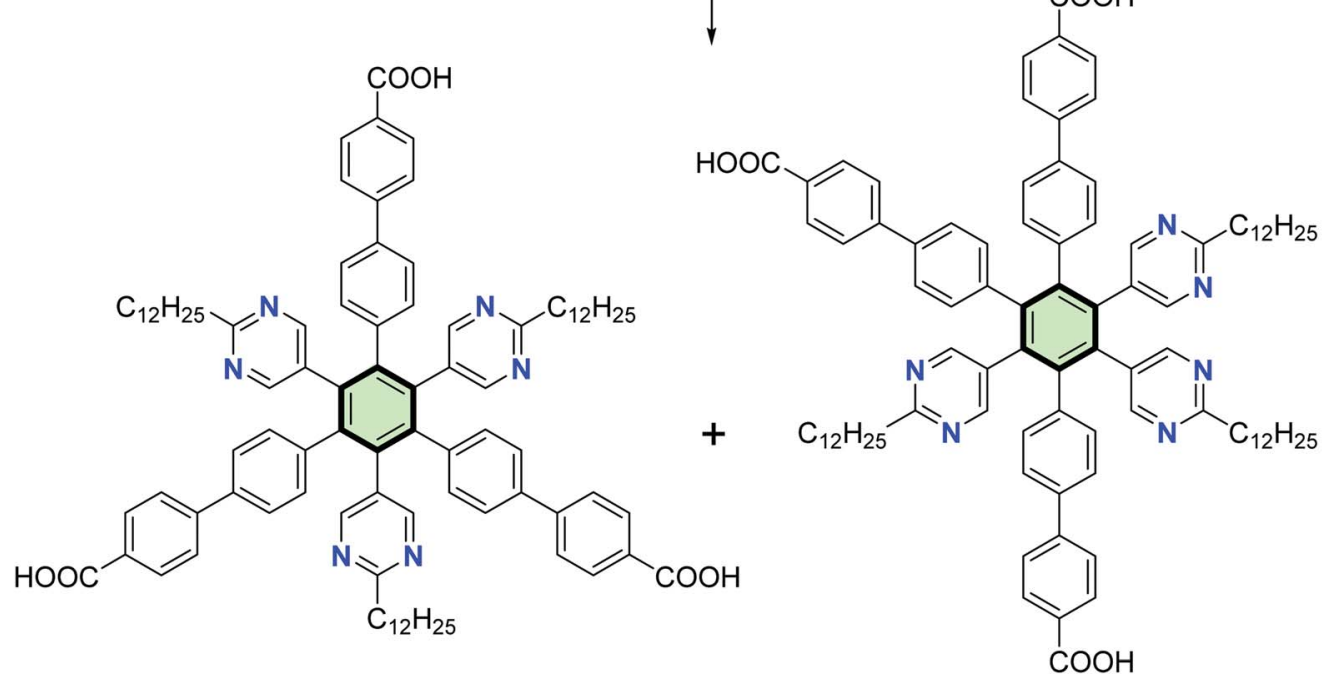

Scheme 52 Synthesis of hexaheteroaryl benzene derivatives 206-209 containing three pyrimidylbenzene side arms.

good yields from the reaction of either 2- or 4-mercaptopyridine 167 and 173 with the corresponding poly(bromomethyl)arene 98, 136, 168 and 99 in the presence of triethylamine (Schemes 43 and 44$)$.

Reaction of 2-mercaptonicotinonitriles 176 and 177 with poly(bromomethyl) benzenes 135, 136 and 99 in ethanolic $\mathrm{KOH}$ under conventional heating as well as under microwave irradiation, afforded the corresponding polypyridines 178-183 in good yields (Scheme 45). ${ }^{97}$

Yin et al. ${ }^{98}$ reported the synthesis of star-shaped macromolecules 186a-c with hexakis(fluoren-2-yl)benzene as the core and pyridine as the periphery. The synthetic strategy includes octacarbonyldicobalt-catalyzed cycloaddition reaction for different alkyne precursors 184a-c. The coordination interaction between the pyridine ring of alkyne precursor and the cobalt catalyst may result in very low yield of the cyclotrimerization product. However, with the increase of the catalyst loading, the yields of the intermediates cyclopentadienone 185a-c are more likely to generate via cycloaddition reactions presumably due to the electron-deficient property of the alkyne precursors. The desired cyclotrimerization products can be obtained by the Diels-Alder reactions of cyclopentadienone 185a-c with acetylene 184a-c in good yield (Scheme 46). Under the initial catalyst loading $10 \%$, the desired cyclotrimerization product 186a was exceptionally obtained from the precursor of 184a with a good yield of $61 \%$. These compounds exhibit good thermal stability and favorable electron affinity. By using these compounds as electron-transporting materials, all-solutionprocessed phosphorescent organic light-emitting devices (OLEDs) show good performance with a maximum current 

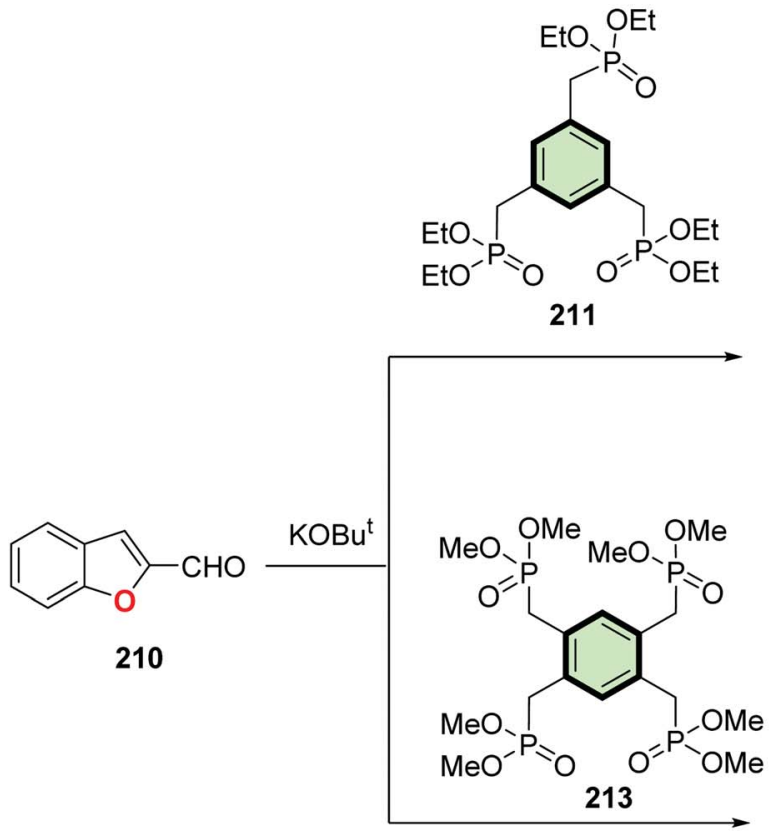
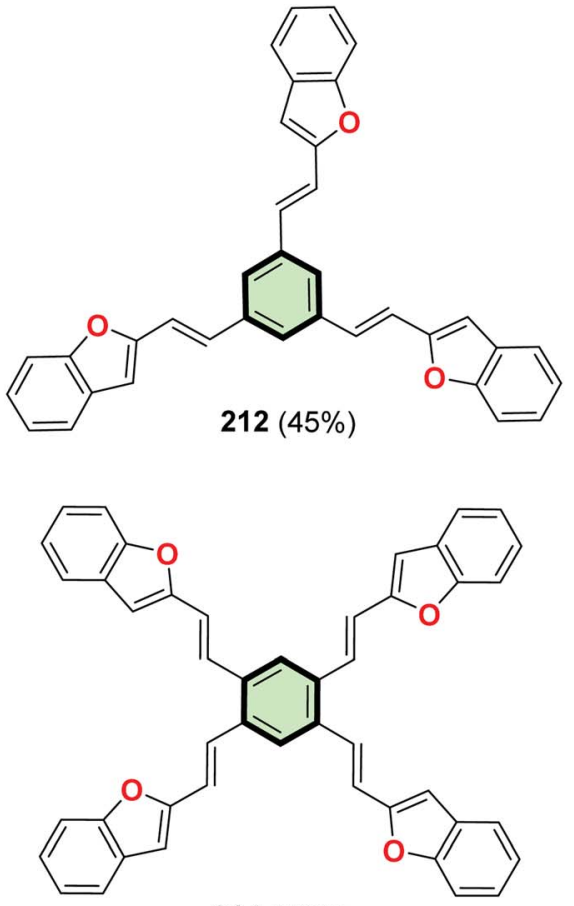

$214(58 \%)$

Scheme 53 Synthesis of tris- and tetrakis(2-(benzofuran-2-yl)vinyl)benzene 212 and 214.

efficiency of $5.6 \mathrm{~cd} \mathrm{~A}^{-1}$ and maximum external quantum efficiency of $4.68 \%$.

The synthesis of cyclometalated platinum(II) complexes 191 and 195 for the application as single emitters in polymeric white emitting diodes (WPLED) is described in Schemes 47 and 48. The starting SSMs containing picolinic acid residues 189 and 194 were prepared by either of the following procedures: (a) tris(bromohexyl)phloroglucinol 187 reacts with methyl 3-

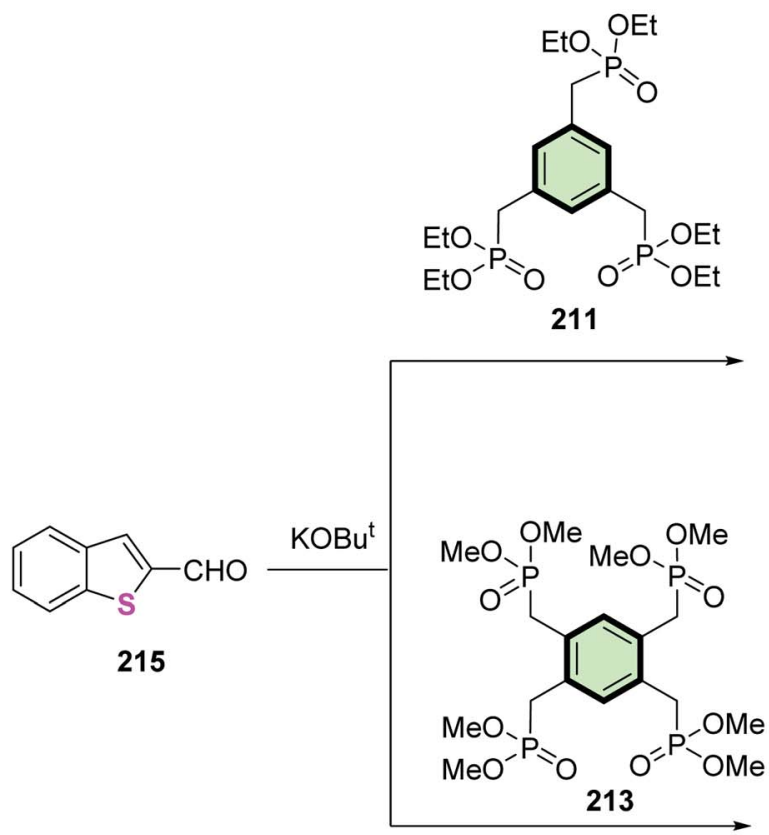

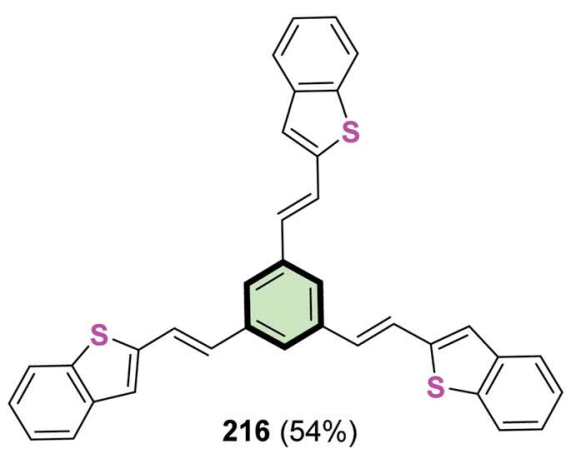

$216(54 \%)$<smiles>C(=C/c1cc(/C=C/c2cc3ccccc3s2)c(/C=C/c2cc3ccccc3s2)cc1/C=C/c1cc2ccccc2s1)\c1cc2ccccc2s1</smiles>

$217(30 \%)$

Scheme 54 Synthesis of tris and tetra[2-(benzo[b]thien-2-yl)vinyl]benzene 216 and 217. 


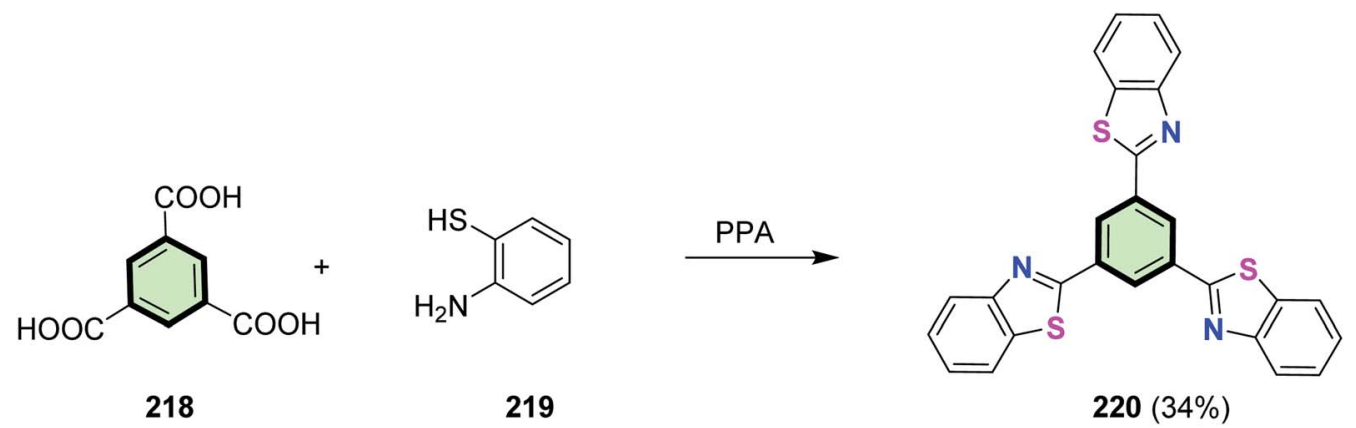

Scheme 55 Synthesis of tris(benzo[d]thiazol-2-yl)benzene 220.

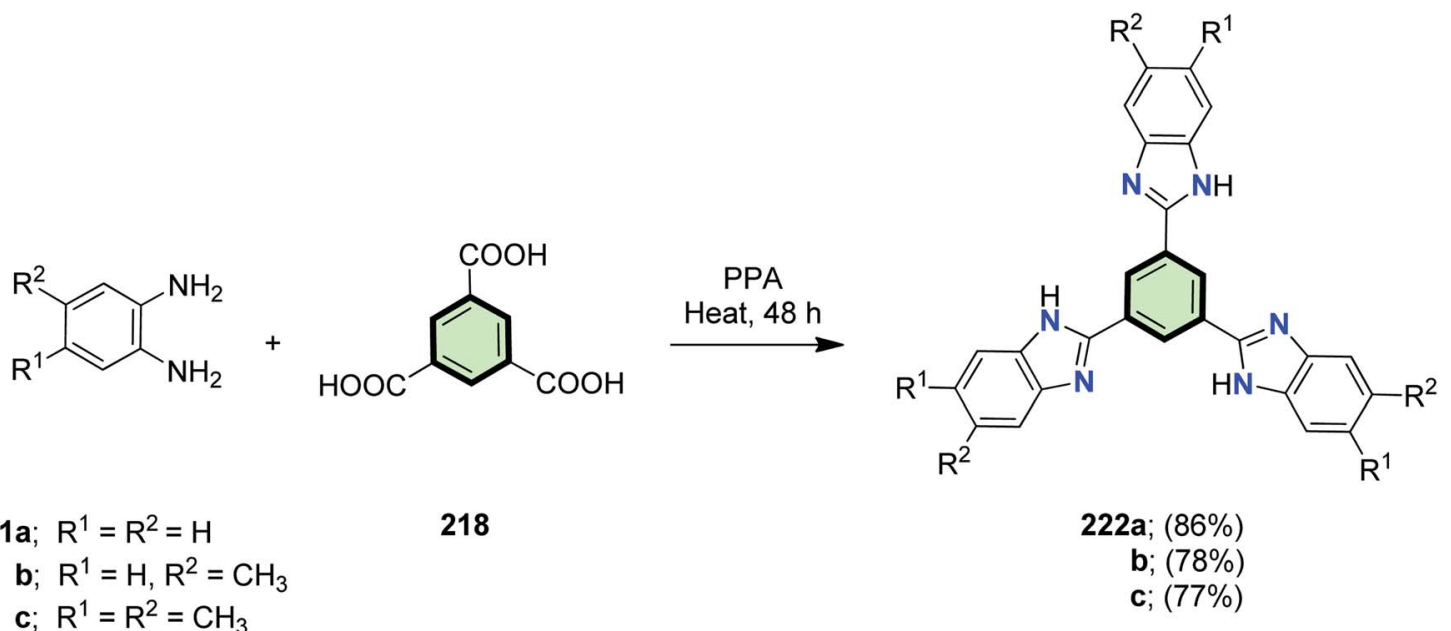

Scheme 56 Synthesis of SSMs with benzene core and benzimidazole side arms 222a-c.

hydroxypicolinate $\mathbf{1 8 8}$ in the presence of cesium carbonate as a base followed by basic hydrolysis by sodium hydroxide in THF to yield 189, or (b) the Suzuki coupling reaction of boronic acid bearing methyl picolinate residue 192 with 1,3,5-tribromobenzene 193 followed by basic hydrolysis to give 194. The cyclometalated complexes 191 and 195 was then synthesized by the reaction of SSMs 189 with dimer 194 in 2-ethoxyethanol in the presence of sodium carbonate as a base. ${ }^{99}$

The UV/Vis absorption data of 191 showed an intense high-lying absorption band (around $240 \mathrm{~nm}$ ) for ligandcentered $\pi-\pi^{*}$ electron transition and two moderate lowlying absorption peaks (about $324 \mathrm{~nm}$ and $352 \mathrm{~nm}$ ) for spin-allowed and spin-forbidden metal-to-ligand charge transfer transitions. Considering 195, a fourth intense absorption band at $266 \mathrm{~nm}$ owing to the effect of the 1,3,5-(4oxytriphenyl)benzene core. Thus, modifying the aryl core has small effect on the electron transition. The photoluminescence spectra of 191 and 195 showed a clear similarity. Increasing the concentration led to gradual redshifted emissions. In thin film, significant difference in photoluminescence: two intense high-lying bands (425-485 $\mathrm{nm})$ and a moderately intense, low-lying band $(600 \mathrm{~nm})$ are exhibited by 191. Complex 195 showed a much weaker lowlying emission. In general, the Pt(II) complexes 195 displayed lower aggregation with a controllable excimer emission.

Aubert et al. ${ }^{\mathbf{1 0 0}}$ described the synthesis of star shaped compound with (phenylthio)benzene core 198 in 94\% overall yield, via coupling of $\left(4 S, 4^{\prime} S\right)-2,2^{\prime}$-(4-chloropyridine-2,6diyl)bis(4-isopropyl-4,5-dihydrooxazole) 197 with hexakis(4-hydroxyphenylthio)benzene 196 in the presence of $\mathrm{Cs}_{2} \mathrm{CO}_{3}$ as a base (Scheme 49). Star compound 198 acted as a catalyst for Rh-catalyzed hydrosilylation of acetophenone.

4.3.1.2.1.3. Dipyridylamine. Pang et al. ${ }^{101}$ reported the synthesis of 1,3,5-tris ( $p$-(2,2'-dipyridylamino)phenyl) benzene 201 in $85 \%$ yield, by the reaction of 1,3,5-tris- $(p$ bromo phenyl)benzene 65a [obtained from trimerization of 1-(4-bromophenyl)ethanone 199 with $\mathrm{SiCl}_{4}$ ] with 2,2'-dipyridylamine 200 in the presence of $\mathrm{K}_{2} \mathrm{CO}_{3}$ and $\mathrm{CuSO}_{4}$ (Scheme 50). Zinc(II) complex of 201 was synthesized and its application as fluorescent sensor for detection of benzene vapors was investigated. 


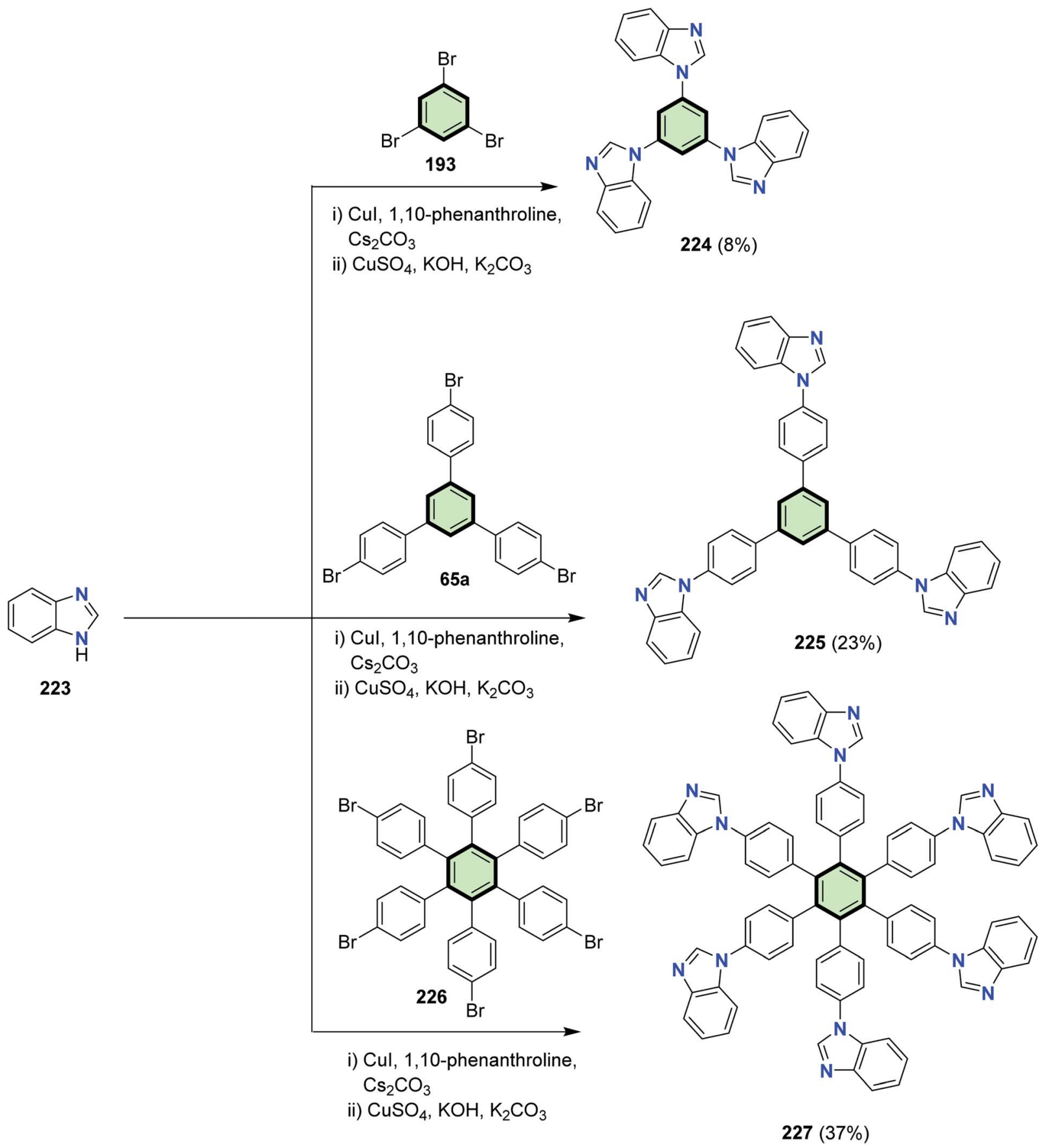

Scheme 57 Synthesis of SSMs with benzene core and benzimidazole side arms 224, 225 and 227 .

4.3.1.2.2. Six-membered heterocyclic arms containing two heteroatoms. 4.3.1.2.2.1. Pyrimidine. Tris- and tetrakispyrimidine derivatives 203 and $\mathbf{2 0 4}$ were synthesized in good yields via alkylation of 2-mercapto-4-oxo-6-phenyl-1,4dihydropyrimidine-5-carbonitrile 202 with 135 and 136, respectively (Scheme 51). ${ }^{97}$

Xiang et al. ${ }^{\mathbf{1 0 2}}$ reported the synthesis of electron-deficient hexaheteroarylbenzene derivatives containing three pyrimidine rings 208 and 209 through multi-step reactions including the cobalt-catalyzed cyclotrimerization reaction of methyl $4^{\prime}$-((2-dodecylpyrimidin-5-yl)ethynyl)-[1,1'biphenyl]-4-carboxylate 205 to yield isomeric carboxylated hexaheteroarylbenzene derivatives 206 and 207 which were then hydrolyzed to the corresponding acids 208 and 209, respectively, upon treatment with methanolic $\mathrm{KOH}$ (Scheme 52).

\subsubsection{Benzene-cored SSMs with benzofused arms}




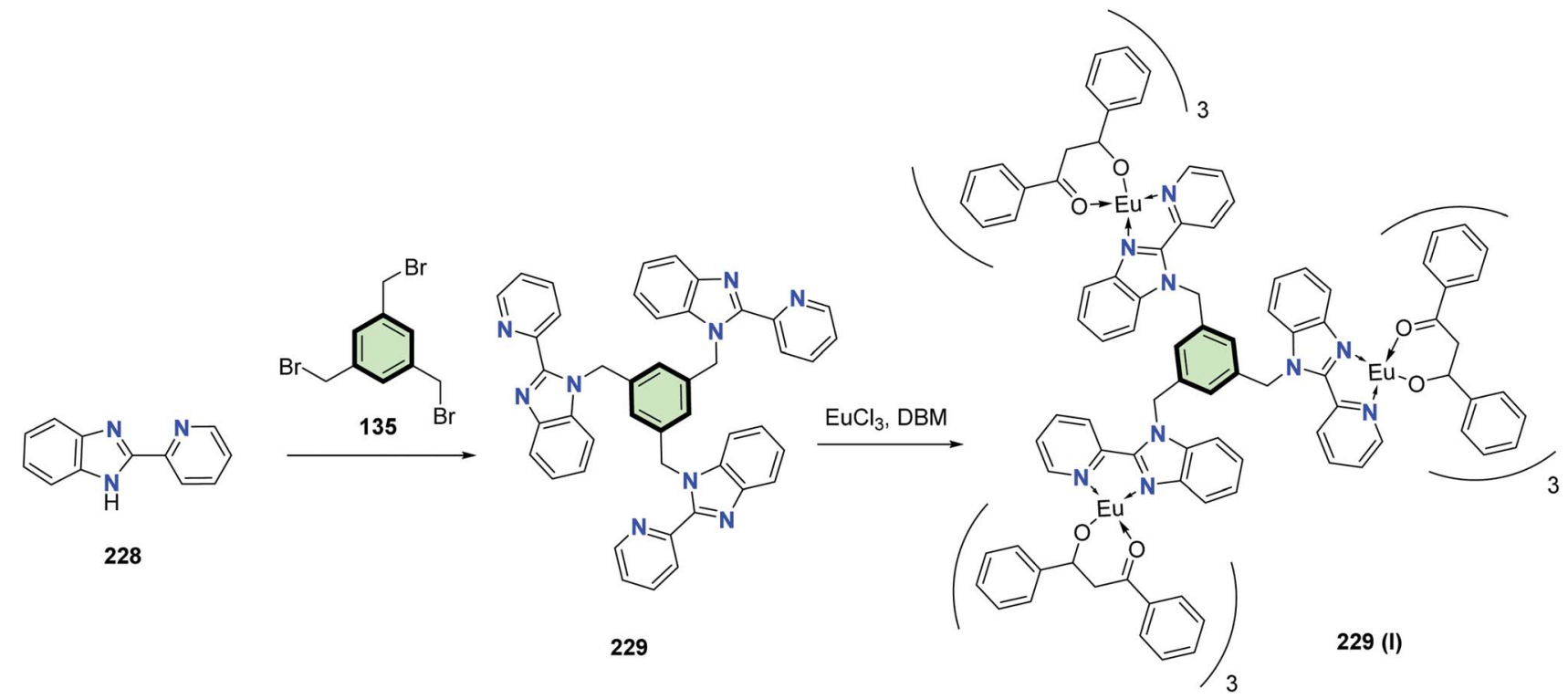

Scheme 58 Synthesis of (1,3,5-tris((2-(pyridin-2-yl)-1H-benzo[d]imidazol-1-yl)methyl)benzene) 229 and its Eu ${ }^{3+}$-complex 229 (I).

4.3.1.3.1. Benzofused five-membered heterocyclic ring arms. 4.3.1.3.1.1. Benzo[b]furan. The Wittig reaction of benzo[b] furan-2-carbaldehyde $\mathbf{2 1 0}$ with benzene-cored tris- and tetrakis(phosphonate) $\mathbf{2 1 1}$ or $\mathbf{2 1 3}$ afforded the corresponding tris- and tetrakis(2-(benzofuran-2-yl)vinyl)benzene $\mathbf{2 1 2}$ and 214 in moderate yields of (Scheme 53). Compound 212 is sensitive to the crystallization condition involving two phases $(\alpha, \beta)$ in solution and one phase in thin film. ( $\beta$ phase) Molecule of 212 pack into a three-dimensional cofacial herringbone structure (H-aggregate). It has moderate emission efficiency with quantum yield of $34 \%$ (solution), $16 \%$ ( $\alpha$-phase) and $22 \%$ ( $\beta$-phase). On the other hand, compound $\mathbf{2 1 4}$ decomposed before melting. It adopts an inter-inserted two-dimensional hexagonal packing structure and can be considered as $2 \mathrm{D}$-semiconductor. It has quantum yield of $53 \%$ (solution) and $16 \%$ (solid). Compound 212 exhibited hole-mobility and its amorphous film performance is similar to its crystalline film, which should simplify device fabrication. ${ }^{103}$

4.3.1.3.1.2. Benzo[b]thiophene. Reaction of benzo[b] thiophene-2-carbaldehyde 215 with 1,3,5-tris(diethoxy phosphorylmethyl)benzene 211 and 1,2,4,5-tetra(dimethoxyphosphoryl methyl)benzene 213 in THF in the presence of $t$ BuOK afforded the corresponding 1,3,5-tris [2-(benzo[b]thien-2yl)vinyl]benzene 216 and 1,2,4,5-tetra[2-(benzo[b]thien-2-yl) vinyl]benzene 217, respectively, in good yields (Scheme 54). ${ }^{104}$ Similar to SSMs with benzo[b]furan arms 212 and 214, compound 216 showed 3D-cofacial herringbone structure. Absorption and emission spectra of $\mathbf{2 1 6}$ showed a more efficient hypsochromic shift than $\mathbf{2 1 7}$, due to discontinued $\pi$-conjugation of meta-substitution.

4.3.1.3.1.3. Benzo[d]thiazole. The polyphosphoric acid PPAcatalyzed cyclocondensation of trimesic acid (benzene-1,3,5- tricarboxylic acid) 218 with 2-aminothiophenol 219 affords tris(benzo[ $d]$ thiazol-2-yl)benzene $\mathbf{2 2 0}$ in low yield (34\%) (Scheme 55). Compound 220 is an efficient iron(III) fluorescent probe with fast response of $50 \mathrm{~s}$. The dynamic quenching mechanism was proven by time-correlated single photon counting (TCSPC) experiment. The probe $\mathbf{2 2 0}$ can be used to detect rapidly iron(III) ions in aqueous solutions at $\mathrm{pH}$ range (312). It can be efficiently employed for detection of iron(III) ions in real water. ${ }^{105}$

4.3.1.3.1.4. Benzo[b]imidazole. Star-shaped molecules with benzene core and benzimidazole side arms 222a-c were synthesized in 86,78 and $77 \%$ yields, by the simple condensation of $o$-phenylenediamine derivatives 221a-c with trimesic acid 218 in the presence of polyphosphoric acid as a catalyst (Scheme 56). Compounds 221a-c could be successfully utilized as chemosensors for fluoride ions with good selectivity, high sensitivity, and fast response. The effect of addition of fluoride ion to the chemosensors 222a-c led to a distinct color change from blue to light cyan in either solution or solid state (with TLC or solution-coated strips) under UV irradiation. Compounds 222a-c were efficiently applied to the detection of fluoride ion from inorganic origin and commercial toothpaste samples. ${ }^{106}$

Different benzimidazole-based SSMs 224, 225 and 227 were synthesized via a modified Ullmann aromatic C-N coupling of benzimidazole 223 with tribromobenzene 193, 1,3,5-tris(4bromophenyl)benzene 65a, and hexakis(4-bromophenyl) benzene 226, respectively (Scheme 57). These SSMs 224, 225 and 227 showed all deep LUMO and HOMO-LUMO energy gap of 3.45-3.95 eV. They are fluorescent ion the UV regions and possess highly stable thermal and morphological features. They have an obvious fluorescent response to silver(I) and zinc(II) ions in solution. ${ }^{107}$ 


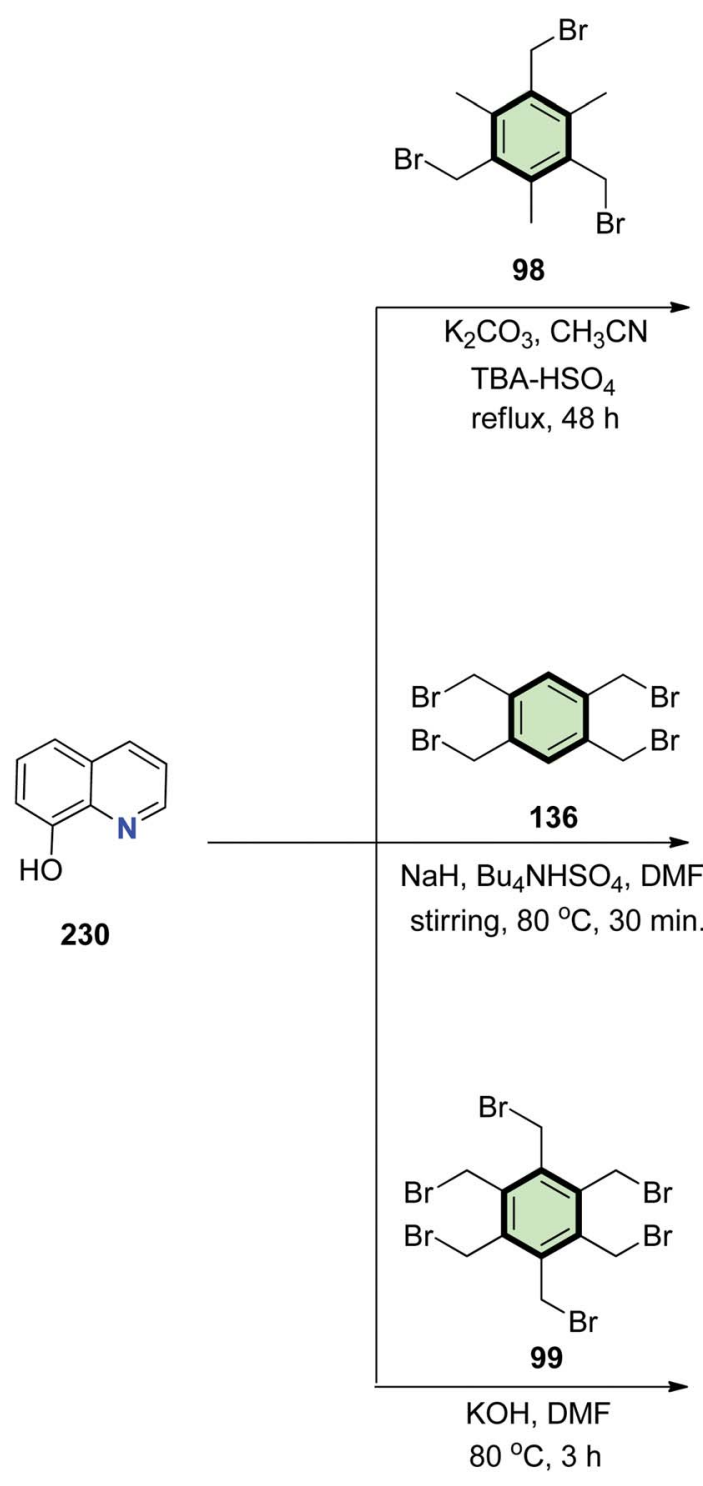<smiles>Cc1c(COc2cccc3cccnc23)c(C)c(COc2cccc3cccnc23)c(C)c1COc1cccc2cccnc12</smiles><smiles>c1cnc2c(OCc3cc(COc4cccc5cccnc45)c(COc4cccc5cccnc45)cc3COc3cccc4cccnc34)cccc2c1</smiles>

232; $(53 \%)$<smiles>c1cnc2c(OCc3c(COc4cccc5cccnc45)c(COc4cccc5cccnc45)c(COc4cccc5cccnc45)c(COc4cccc5cccnc45)c3COc3cccc4cccnc34)cccc2c1</smiles>

233; $(56 \%)$

Scheme 59 Synthesis of SSMs with benzene core and quinoline side arms 231-233.

The reaction of 1,3,5-tris(bromomethyl)benzene 135 with 2pyridylbenzimidazole 228 in DMF in the presence of sodium hydroxide at reflux afforded hexadentate ligand $(1,3,5$-tris $((2-$ (pyridin-2-yl)-1 $H$-benzo[d]imidazol-1-yl)methyl)benzene) 229 in good yield (62\%). Heating 229 with europium chloride/ dibenzoylmethane (DBM) in ethanol at reflux in the presence of sodium hydroxide yielded the $\mathrm{Eu}^{3+}$-complex 229 (I) (Scheme 58). Europium(III) complex 229 (I) was found to be promising red emitter in view of its structural and photophysical properties. It showed high photoluminescence yield (0.64) with a short lifetime of excited state $(120 \mu \mathrm{s})$. It is thermally stable to high temperature $\left(315^{\circ} \mathrm{C}\right)$. The HOMO-LUMO energy gap $(2.5 \mathrm{eV})$ of 229 (I) is suitable for organic functional devices.
Electroluminescence and photovoltaic devices of 229 (I) led to a white emission (maximum luminance of $168 \mathrm{~cd} \mathrm{~m}^{-2}$ ) and a maximum power conversion efficiency of $1.05 \%$, respectively. ${ }^{108}$

4.3.1.3.2. Benzofused six-membered heterocyclic ring arms. 4.3.1.3.2.1. Quinoline. Reaction of 8-hydroxyquinoline 230 with the appropriate bromomethyl benzenes 98,136 and 99 afforded tris-, tetrakis-, and hexakis(8-quinolinoxymethyl) benzene derivatives 231,232 and 233 , respectively, in good yields (Scheme 59). SSM 231 exhibited selective fluorescence quenching with copper(II) and could be used for estimation of copper(II) (1-6 ppm) even in the presence of nickel(II), 


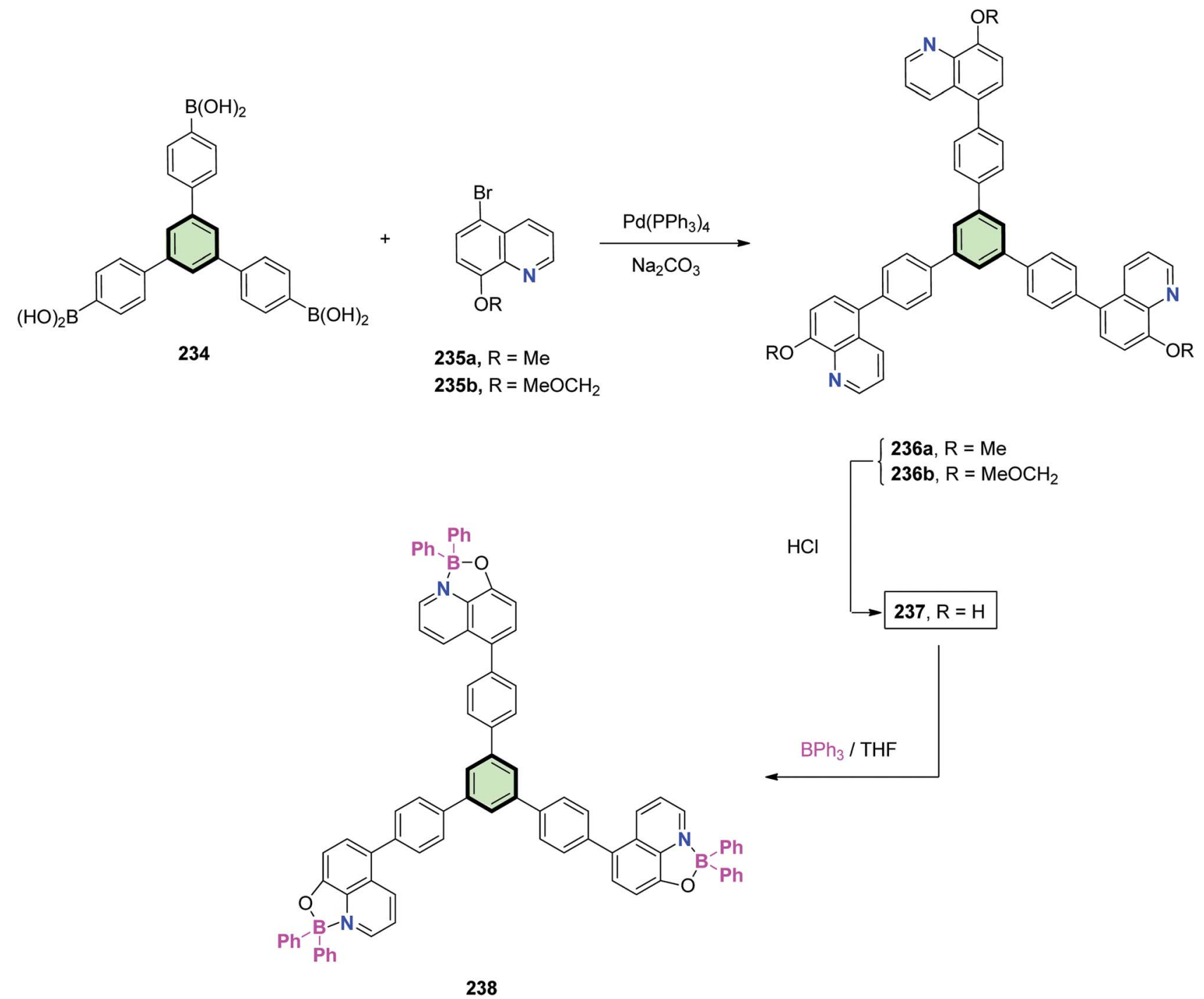

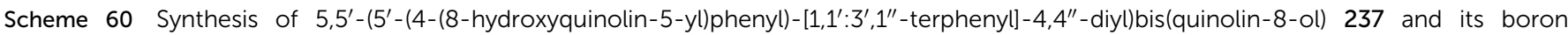

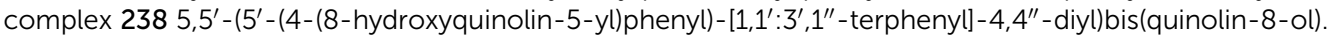

cadmium(II), zinc(II) (1000 ppm), or silver(II) (100 ppm). Different coordination modes of 232 (with silver(I) and copper(I)) and 233 (with cobalt(II) and palladium(II)) were studied. SSMs 231 and 232 displayed different fluorescence perturbation with change in the concentration of silver(I). Compound 231 showed a simultaneous fluorescence quenching with addition of silver(I). Compound 232, on the other hand, introduced "ONOFF-ON switching" involving two fluorescence perturbations

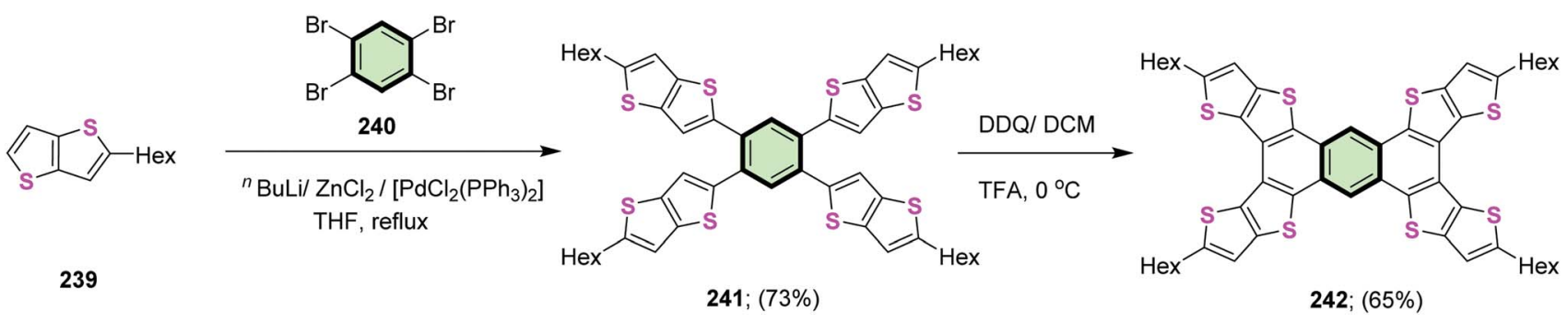

Scheme 61 Synthesis of tetra(5-hexyl)thieno([3,2-b]thieno)anthracene 242. 
<smiles>Brc1ccc(-c2cc(-c3ccc(Br)s3)cc(-c3ccc(Br)s3)c2)s1</smiles>

243<smiles>[R4][Hg]c1ccco1</smiles>
$\underset{\text { THF/toluene/ } \mathrm{H}_{2} \mathrm{O}}{\stackrel{\mathrm{Pd}\left(\mathrm{PPh}_{3}\right)_{4}, \mathrm{~K}_{2} \mathrm{CO}_{3}}{\longrightarrow}}$<smiles>[R16]c1ccc(-c2cc(-c3ccc(-c4ccco4)s3)cc(-c3ccc(-c4ccco4)s3)c2)s1</smiles>

Scheme 62 Synthesis of 1,3,5-tris(5-(furan-2-yl)thiophen-2-yl)benzene 245.<smiles>Brc1ccc(-c2cc(-c3ccc(Br)o3)cc(-c3ccc(Br)o3)c2)o1</smiles>

246<smiles>Oc1cccs1</smiles>

247

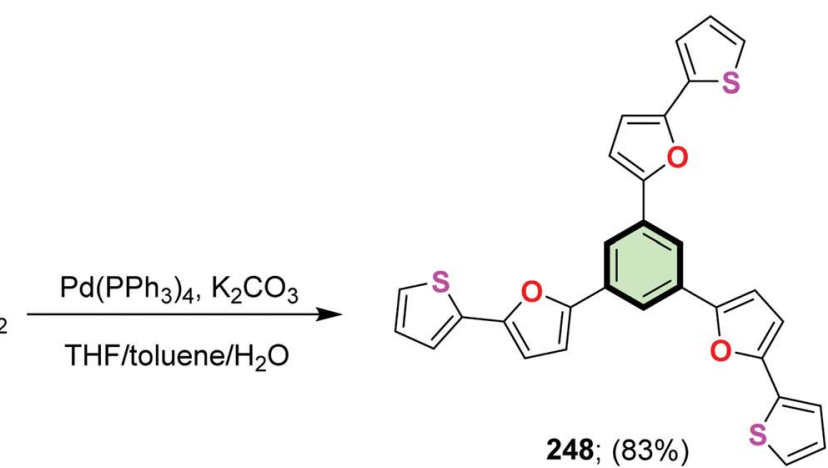

Scheme 63 Synthesis of 1,3,5-tris(5-(thiophen-2-yl)furan-2-yl)benzene 248.

with incremental increase of silver(I) concentration: the first fluorescence quenching (with $<1.0$ equiv. of $\mathrm{Ag}^{+}$, at $\lambda_{\max }=395$ $\mathrm{nm}$ ) and the second is fluorescence enhancement (at $\lambda_{\max }=$ $500 \mathrm{~nm}$, with $>3$ equiv. of $\left.\mathrm{Ag}^{+}\right) .{ }^{109-111}$

Cui and Wang ${ }^{112}$ reported the synthesis of star-shaped conjugated molecules 236a and 236b in good yields using Suzuki-Miyaura coupling reaction of boronic acid derivatives 234 with 5-bromo-8-methoxyquinoline 235a and 5-bromo-8methoxy-2-methylquinoline $\mathbf{2 3 5 b}$, respectively, in the presence of $\mathrm{Na}_{2} \mathrm{CO}_{3}$ and $\mathrm{Pd}\left(\mathrm{PPh}_{3}\right)_{4}$ (Scheme 60). The starburst compounds 236a,b were found to act as blue emitters with excellent thermal stabilities $\left(\sim 300{ }^{\circ} \mathrm{C}\right)$ and layered arrangements in solid state. Treatment of SSMs 236a,b with $\mathrm{HCl}$ gave the 8-hydroxyquinoline derivative 237. Chelation of the latter compound with triphenylborane in THF at reflux afforded the boron complex 238 which exhibited green emissions.

\subsubsection{Miscellaneous arms}

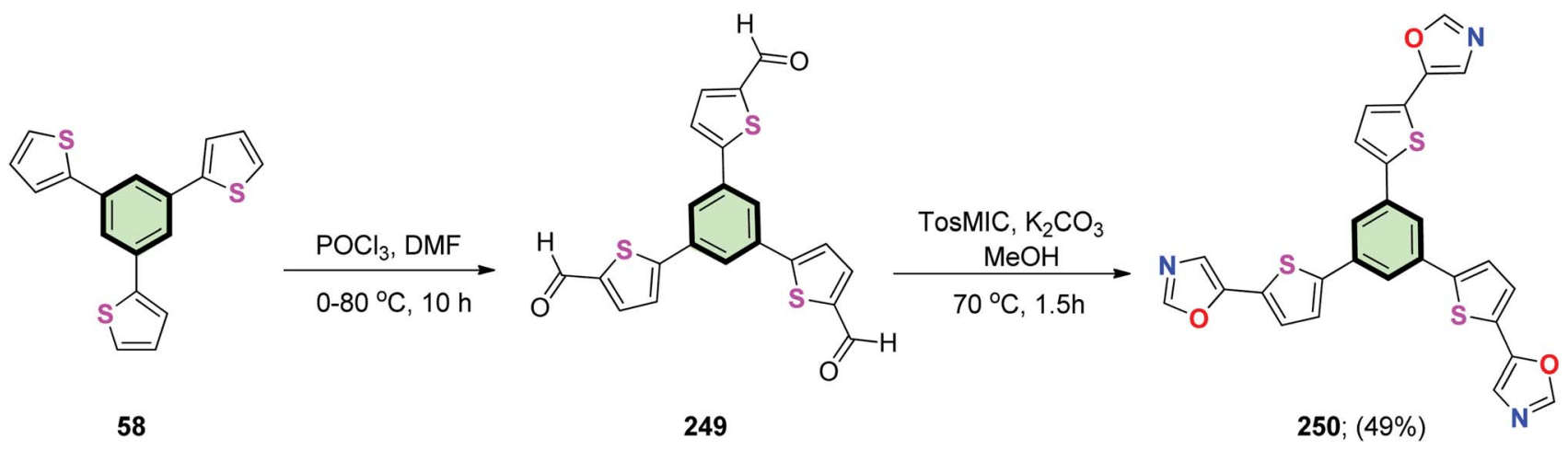

Scheme 64 Synthesis of 1,3,5-tris(5-(oxazol-5-yl)thiophen-2-yl)benzene 250. 


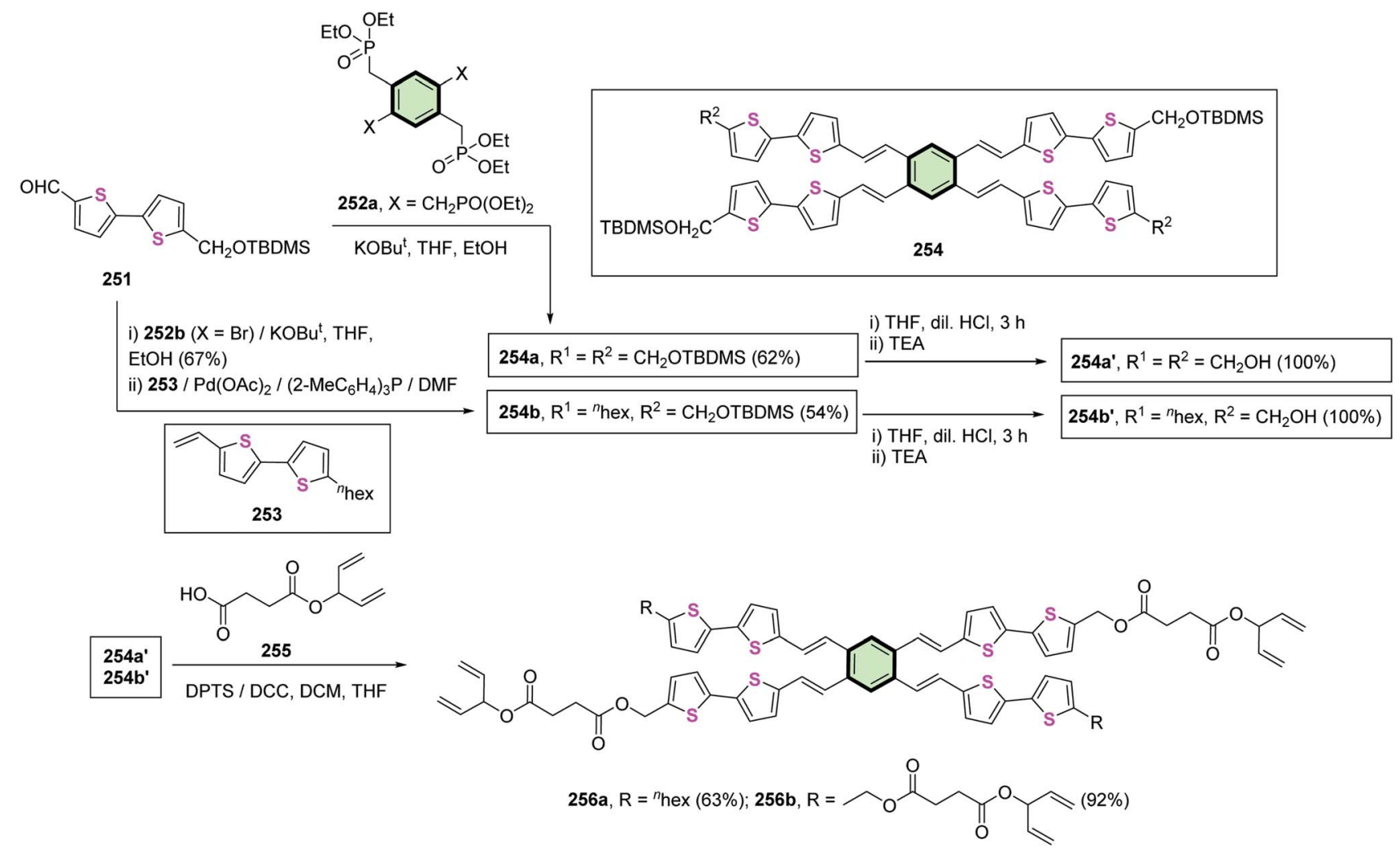

Scheme 65 Synthesis of bithiophene SSMs side arms 254 and 256.

4.3.1.4.1. Thieno[3,2-b]thiophene. Magnan et al. ${ }^{113}$ reported the synthesis of star-shaped compounds 241 in $73 \%$ yields by four-fold Negishi coupling between 1,2,4,5-tetrabromobenzene 240 with 2-hexylthieno[3,2-b]thiophene 239 in the presence of ${ }^{n} \mathrm{BuLi}$ and anhydrous $\mathrm{ZnCl}_{2}$. Subsequent oxidative cyclodehydrogenation of the latter compound in chlorobenzene using anhydrous ferric chloride gave tetra(5-hexyl)thieno([3,2- $b]$ thieno)anthracene $\mathbf{2 4 2}$ in $65 \%$ yield (Scheme 61). It was found that cyclization of $\mathbf{2 4 1}$ to $\mathbf{2 4 2}$ led a red shift of the absorption due to decrease of HOMO-LUMO energy gap affected by an efficient $\pi$-conjugation.

4.3.1.4.2. 2-(Thiophen-2-yl)furan. 1,3,5-Tris(5-(furan-2-yl) thiophen-2-yl)benzene $\mathbf{2 4 5}$ was synthesized in $78 \%$ yield by the reaction of 1,3,5-tris(5-bromothiophen-2-yl) benzene 243 with 2-furanyl boronic acid $\mathbf{2 4 4}$ in the presence of $\mathrm{Pd}\left(\mathrm{PPh}_{3}\right)_{4}$. Similarly, 1,3,5-tris(5-(thiophen-2-yl)furan-2-yl) benzene 248 was synthesized in $83 \%$ yield by the reaction of 1,3,5-tris(5-bromofuran-2-yl)benzene 246 with 2-thiophenylboronic acid 247 (Schemes 62 and 63). ${ }^{81}$ SSM 248 (containing peripheral thiophene moieties) was found to be better fluorophore than $\mathbf{2 4 5}$ (containing peripheral furan) as evident from the fluorescence quantum yield values of 0.15 and 0.06 , respectively.

4.3.1.4.3. 2-(Thiophen-2-yl)oxazole. Kotha et al. ${ }^{81}$ reported the synthesis of a star-shaped molecule with benzene core and (thiophen-2-yl)oxazole as arms $\mathbf{2 5 0}$ by firstly treatment of 1,3,5- tri(thiophen-2-yl)benzene 58 with $\mathrm{POCl}_{3}$ in DMF to give $5,5^{\prime}, 5^{\prime \prime}$ (benzene-1,3,5-triyl)tris(thiophene-2-carbaldehyde) 249. The latter compound underwent van Leusen reaction upon treatment with toluene sulfonylmethyl isocyanide (TosMIC) $/ \mathrm{K}_{2} \mathrm{CO}_{3}$ in methanol under reflux to afford 1,3,5-tris(5-(oxazol-5-yl) thiophen-2-yl)benzene 250 in $49 \%$ yield (Scheme 64).

4.3.1.4.4. 2,2'-Bithiophene and 2-([2,2'-bithiophen $]-5-y l)-1,3,4-$ oxa(thia)diazole. The synthesis of SSMs 256a,b is represented in Scheme 65. Star-shaped tetrapod 256a was synthesized via the Horner-Emmons coupling of $5^{\prime}$-(( (tert-butyldimethylsilyl)oxy) methyl)-[2,2'-bithiophene]-5-carbaldehyde 251 and octaethyl (benzene-1,2,4,5-tetrayltetrakis(methylene)) tetrakis(phosphonate) 252a. Deprotection of TBDMS proceeded to

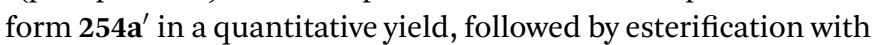
4-oxo-4-(penta-1,4-dien-3-yloxy)butanoic acid 255 furnished SSMs 256a with four pentadiene tails in good yield (63\%). Other SSM 256b (with two pentadiene tails) was synthesized similarly but with a slight modification. It employed the HornerEmmons coupling of 251 with tetraethyl (2,5-dibromo-1,4phenylenebis(methylene))bis(phosphonate) 252b followed by Heck coupling of the resulting dibromo product with 5-hexyl-5'vinyl-2,2'-bithiophene 253 to yield $\mathbf{2 5 4 b}$ in moderate yield (54\%). Deprotection of $254 \mathbf{b}$ to $254 \mathbf{b}^{\prime}$ followed by reaction of 254b with 255 afforded SSM 256b in excellent yield (92\%). The SSMs 256a and 256b acted as photopatternable organic semiconductors due to their ability to photopolymerize enabled by 


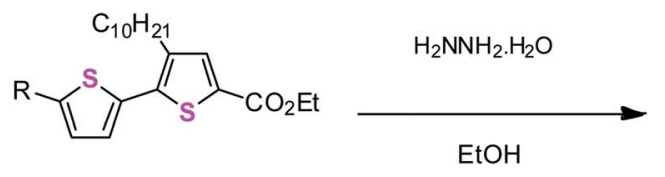<smiles>[R]c1ccc(-c2sc(C(N)=O)cc2[14CH2][2H])s1</smiles>

257a, $\mathrm{R}=\mathrm{H}$

b, $\mathrm{R}=\mathrm{C}_{6} \mathrm{H}_{13}$
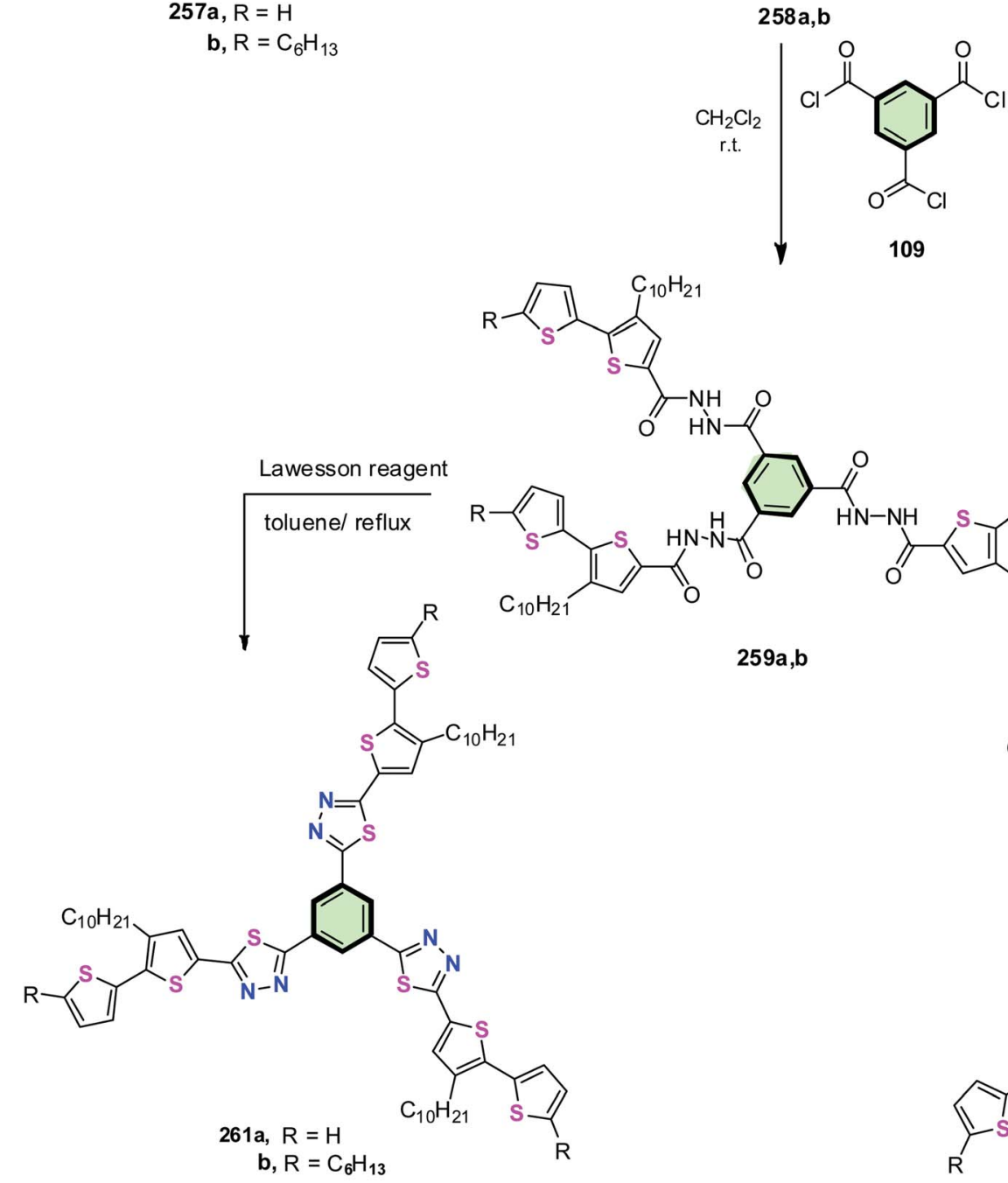

Scheme 66 Synthesis of SSMs containing either oxadiazole or thiadiazole side arms 260 and 261.

the reactive pentadiene tails. The transistor devices based on 256a and 256b exhibited a field-effect mobility of $1.3( \pm 0.2) \times$ $10^{-3}$ to $3.7( \pm 0.5) \times 10^{-3} \mathrm{~cm}^{2} \mathrm{~V}^{-1} \mathrm{~s}^{-1}, I_{\text {on/off }}$ value $\left(>10^{3}\right)$, and a small threshold voltage $(-16 \mathrm{~V})$. The field-effect mobility of SSM 256b persisted even after being cross-linked during photopolymerization. This was explained on the basis of the strong intermolecular interaction of conjugated structure which may freeze the molecular axis under push-pull force during the cross-linking and is accompanied by a highly lamella-ordered in two directions. ${ }^{\mathbf{1 1 4}}$

Kotwica et al. ${ }^{\mathbf{1 1 5}}$ reported the synthesis of star-shaped molecules containing either oxadiazole or thiadiazole side arms each connected by bithiophene moiety 260a, 260b, 261a and 261 b. Thus, the esters $257 \mathbf{a}$ and $257 \mathbf{b}$ were converted into the corresponding hydrazide derivatives 258 a and 258 b, respectively, by heating with hydrazine hydrate. Treatment of 258 a and $258 b$ with benzene-1,3,5-tricarbonyl trichloride 109 gave alkylsubstituted $N^{\prime} 1, N^{\prime} 3, N^{\prime} 5$-tris[(3-decyl-2,2'-bithien-5-yl)carbonyl] benzene-1,3,5-tricarbohydrazides 259a and 259b, respectively. The latter compounds were converted into the oxadiazole bithiophene series 260a and 260b upon treatment with phosphorus oxychloride. On the other hand, treatment of 259a and 259b with Lawesson's reagent led to the formation of the corresponding thiadiazole bithiophene series 261a and 261b, respectively, in good yields (Scheme 66). The HOMO-LUMO energy gap of oxadiazole SSMs 260a,b were found to be just below $3 \mathrm{eV}$ and higher than that of thiadiazole SSMs 261a,b by $0.2 \mathrm{eV}$. Substitutions were shown to affect further reduction of energy gap. SSMs 260 and 261 displayed an excellent electroluminescence in guest/host LEDs. Unsubstituted SSMs 260 and 


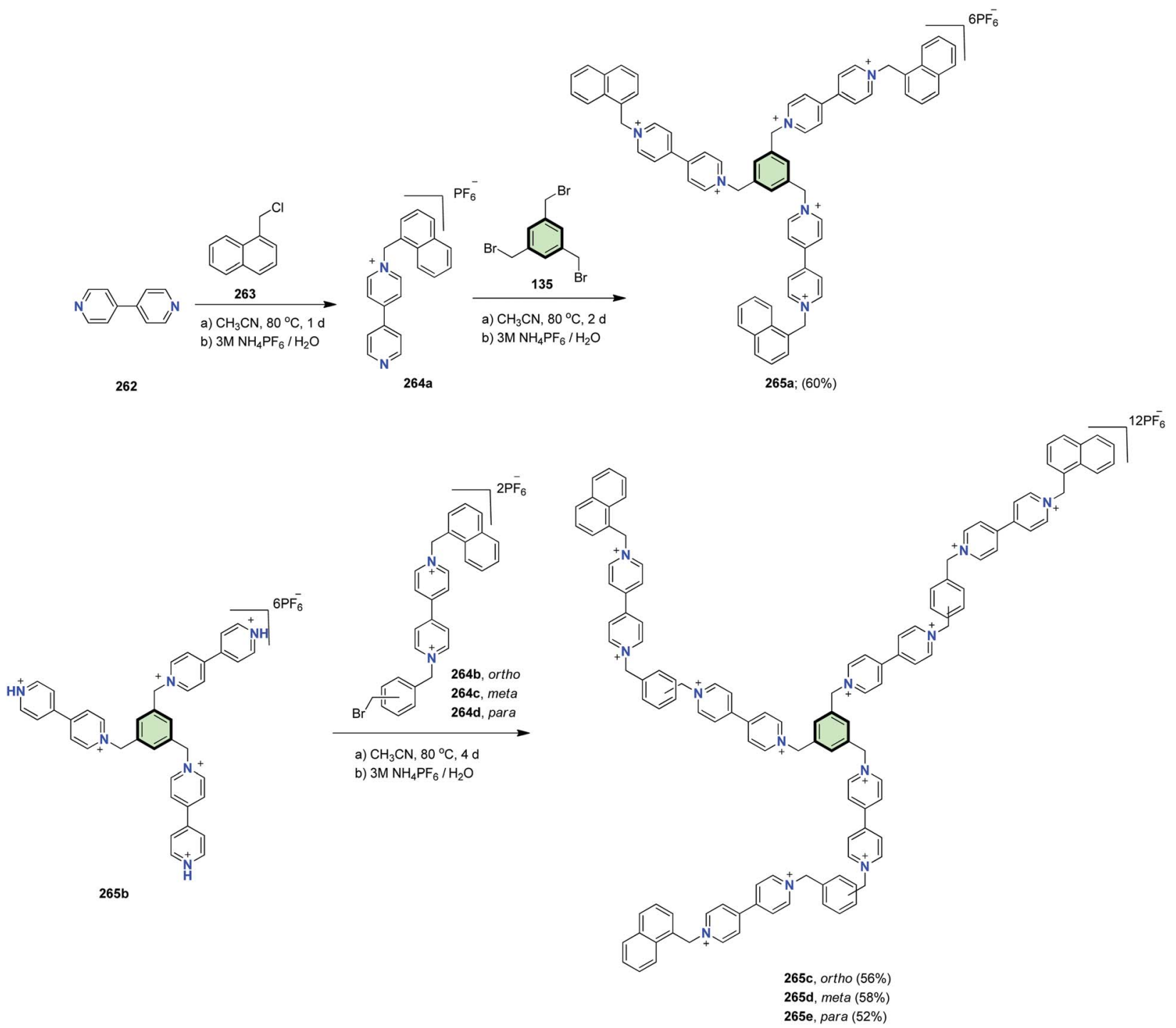

Scheme 67 Synthesis of SSMs containing 4,4'-bipyridyl naphthalene side arms 265

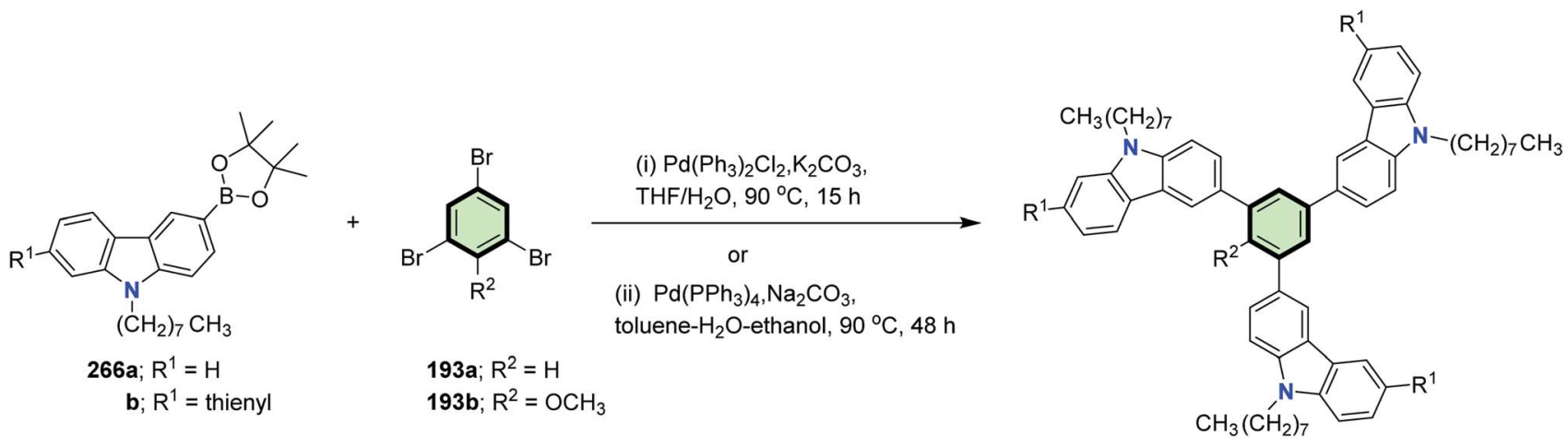

267a; $R^{1}=H, R^{2}=H ;(42 \%)$

b; $\mathrm{R}^{1}=\mathrm{H}, \mathrm{R}^{2}=\mathrm{OCH}_{3} ;(49 \%)$

c; $\mathrm{R}^{1}=$ thienyl, $\mathrm{R}^{2}=\mathrm{H} ;(58 \%)$

Scheme 68 Synthesis of SSMs 267a-c with 1,3,5-tris(9-octyl-9H-carbazol-3-yl)benzene side arms. 


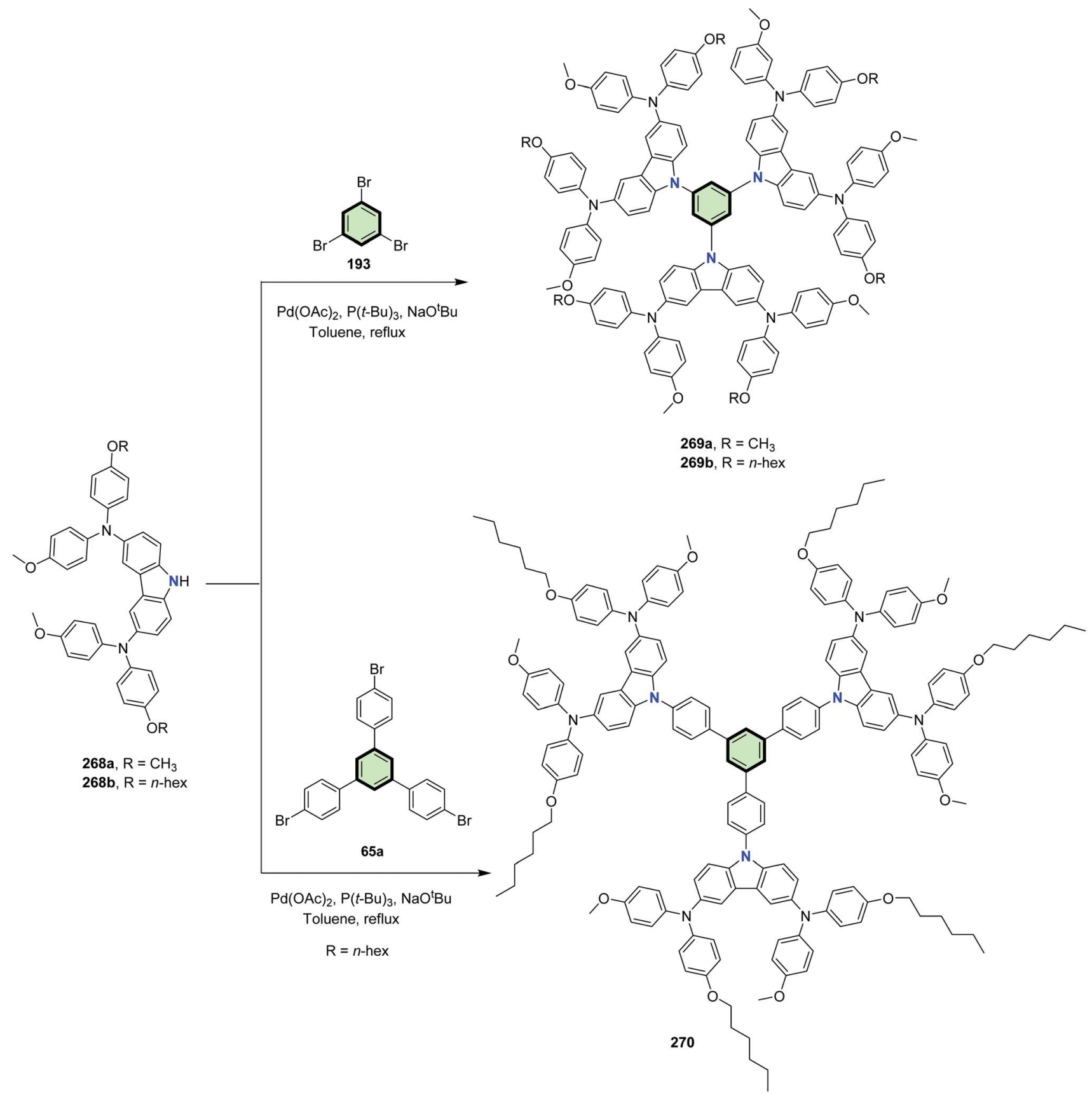

Scheme 69 Synthesis of SSMs 269a,b and 270.

$261(\mathrm{R}=\mathrm{H})$ were electropolymerizable. The macromolecules based on SSMs 260 and 261 retained a reversible electrochromism on the oxidation and reduction modes.

4.3.1.4.5. 4,4'-Bipyridine. Madasamy et al. ${ }^{116}$ reported the synthesis of viologen (4,4'-bipyridinium) star shaped molecule with benzene core and naphthalene tails $265 \mathrm{a}$ in $60 \%$ yields upon reaction of 1,3,5-tris(bromomethyl)benzene 135 with the key intermediate 264a. The latter compound was obtained from alkylation of 4,4'-bipyridine 262 with 1-chloromethylnaphthalene 263 (Scheme 67). In addition, several dendritic viologin molecules 265c-e were synthesized via a similar strategy incorporating the dealkylated star-shaped derivative $265 \mathbf{b}$ and bromoxylyl viologins 264b-d. Cyclic voltammetry showed that among the different viologen SSMs 265a-e, only 265c (ortho) exhibited the most positive reduction potential due to both intermolecular and intramolecular charge transfer. The absorption spectra of $265 \mathrm{c}$ as well indicated absorption of radical monocation and pimer while 265a,e (meta and para) revealed absorption for radical monocation only. This suggested that the intramolecular charge transfer is evident only in 

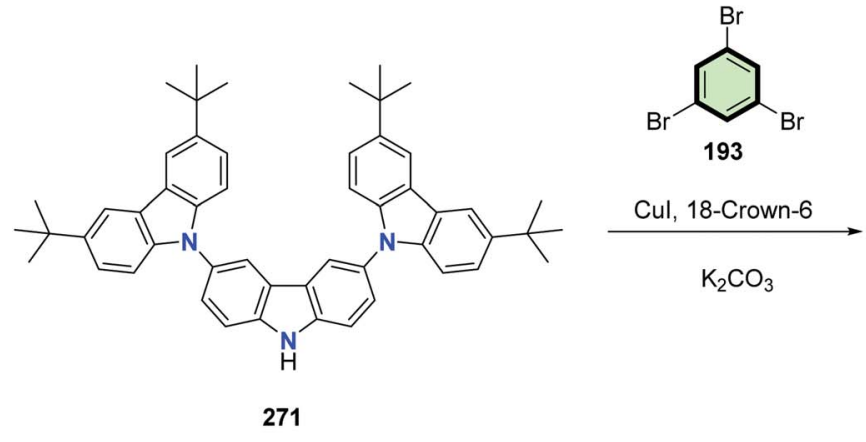

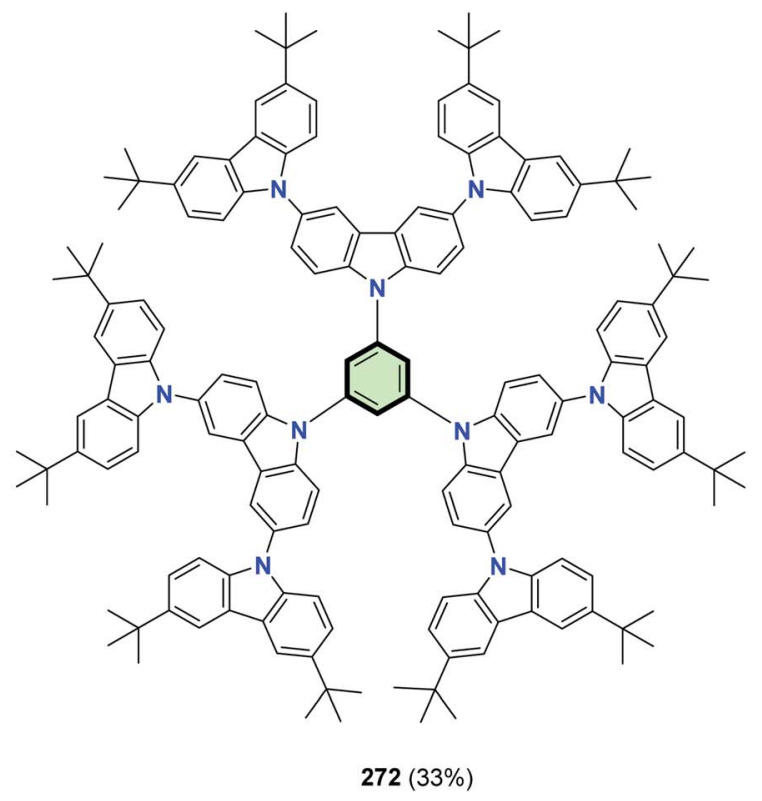

Scheme 70 Synthesis of dendritic tercarbazole-based SSM 272.

the ortho derivative $265 \mathrm{c}$. It should be mentioned that the viologen SSMs could form $(1: 1)$ inclusion complexes with $\beta$ cyclodextrin. In these complexes, $\beta$-cyclodextrin capped the hydrophobic part of $\mathbf{2 6 5} \mathbf{c}-\mathbf{e}$ as detected from NMR measurements. This capping was solvent-dependent. In polar aprotic solvents, no capping was observed as the solvent molecules were capped more efficiently to $\beta$-cyclodextrin. In aqueous media, a partial capping of naphthalene tails of 265c-e to $\beta$ cyclodextrin was noticed.
Madasamy et al. ${ }^{116}$ reported the synthesis of viologen $\left(4,4^{\prime}\right.$ bipyridinium) star shaped molecule with benzene core and naphthalene tails 265 in $60 \%$ yield upon reaction of 1,3,5-tris(bromomethyl)benzene 135 with the key intermediate 264. The latter compound was obtained from alkylation of 4,4'-bipyridine 262 with 1-chloro methylnaphthalene 263 (Scheme 67).

4.3.1.4.6. Carbazole and its derivatives. Brzeczek et al. ${ }^{117}$ reported the synthesis of star-shaped molecules 1,3,5-tris(9-octyl-

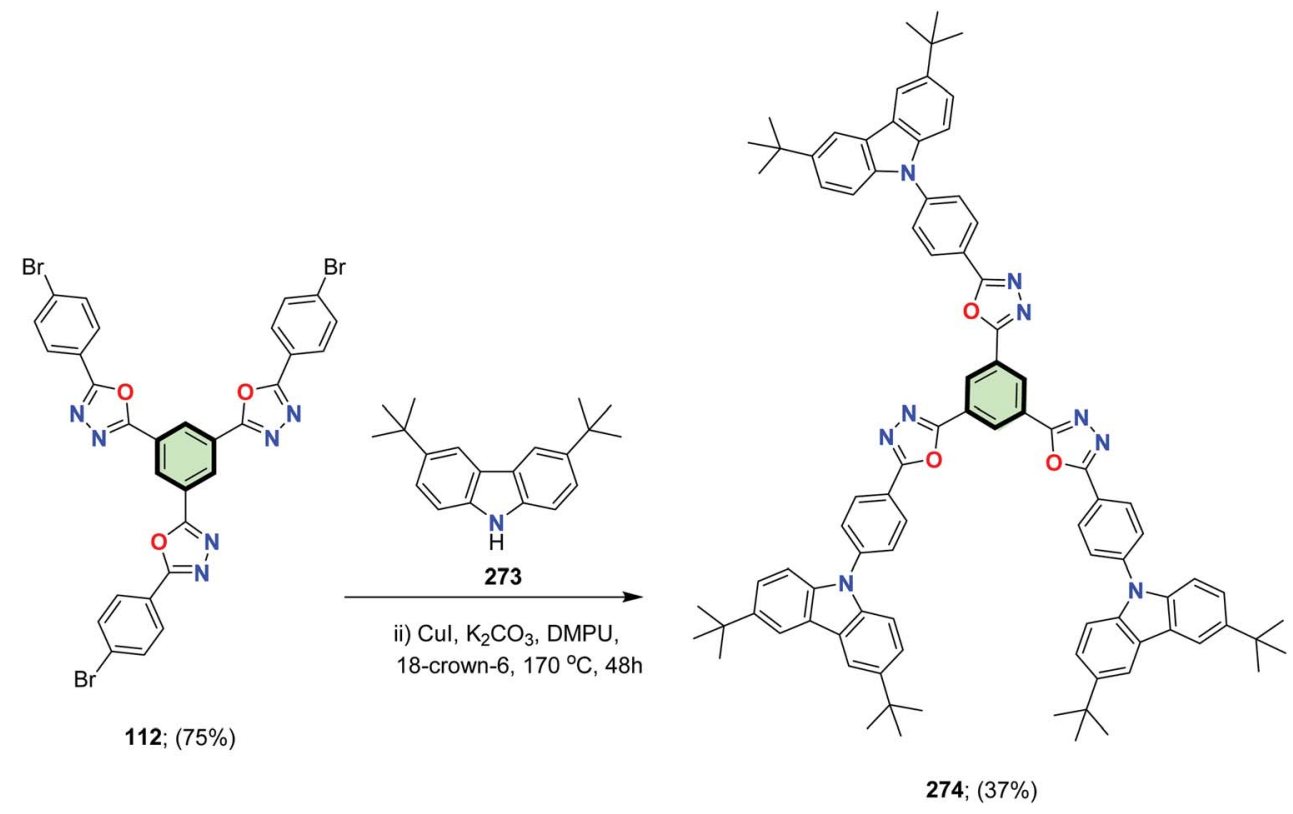

Scheme 71 Synthesis of 1,3,5-tris(5-(4-(3,6-di-tert-butylcarbazol-9-yl)phenyl)-1,3,4-oxadiazol-2-yl)benzene 274. 
<smiles>O=C1OC(=O)c2ccc3c4c(ccc1c24)C(=O)OC3=O</smiles>

\section{$\mathrm{R}-\mathrm{NH}_{2}$ \\ 276}

275<smiles>[R]N1C(=O)c2ccc3c4c(ccc(c24)C1=O)C(=O)OC3=O</smiles>

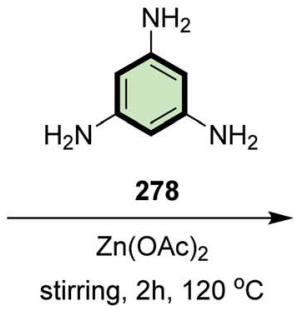

277a; $\mathrm{R}=n-\mathrm{C}_{4} \mathrm{H}_{9} \quad,(20 \%)$ b; $\mathrm{R}=\mathrm{CH}\left(\mathrm{CH}_{2} \mathrm{CH}_{3}\right)_{2},(30 \%)$<smiles></smiles>

279a: $10 \%$ $279 b ; 20 \%$

Scheme 72 Synthesis of SSMs with benzene core and three naphthalene diimide side arms 279 .

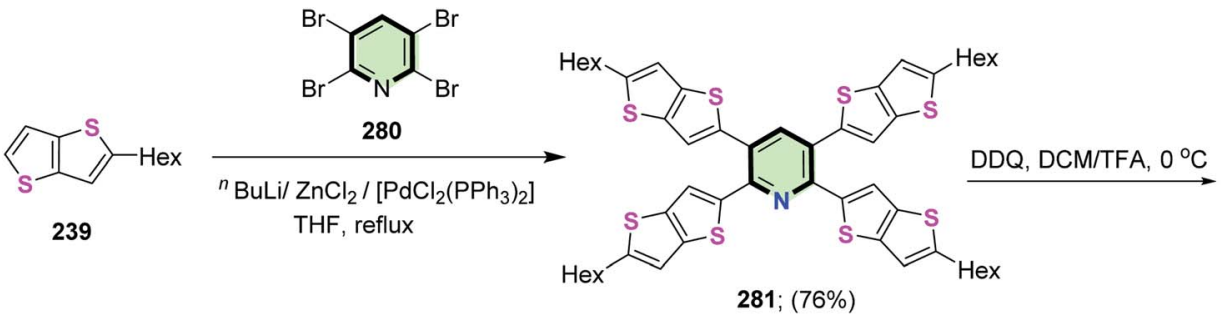

281; $(76 \%)$

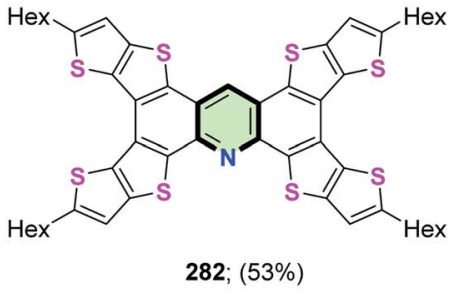

Scheme 73 Synthesis of star-shaped compound with pyrimidine core 281 and tetra(5-hexylthieno[3,2-b]thieno)acridine 282.

9H-carbazol-3-yl)benzene 267a, 2-methoxy-1,3,5-tris(9-octyl-9Hcarbazol-3-yl)benzene 267b and 1,3,5-tris(9-octyl-6-(thiophen-2yl)-9H-carbazol-3-yl)benzene 267c in 42, 49 and 58\% yields, respectively, via Suzuki-Miyaura coupling reaction between the appropriate carbazolyl boronic acid pinacol esters 266a and 266b with the corresponding 1,3,5-tribromobenzene derivatives 193a and 193b (Scheme 68). The star-shaped compounds 267ac were shown to be promising p-types semiconducting materials for application in OLEDs and OFETs in view of their HOMO energies ( -5.5 to $-5.3 \mathrm{eV})$, energy gaps $\left(E_{\mathrm{g}} 3.20\right.$ to $\left.3.38 \mathrm{eV}\right)$, and IP values $(5.5 \mathrm{eV})$. Presence of thiophene ring caused a red shift of both the UV and fluorescence spectra due to extra conjugation.

Star-shaped molecules 269a,b and 270 were synthesized in good yields, via $\mathrm{C}-\mathrm{N}$ palladium catalyzed coupling of 1,3,5-tribromobenzene 193 or 4,4"-dibromo-5'-(4-bromophenyl)-1, $1^{\prime}: 3^{\prime}, 1^{\prime \prime}$-terphenyl 65a with $N 3, N 6$-bis(4-(alkyloxy) phenyl)-N3,N6-bis(4-methoxyphenyl)-9H-carbazole-3,6-

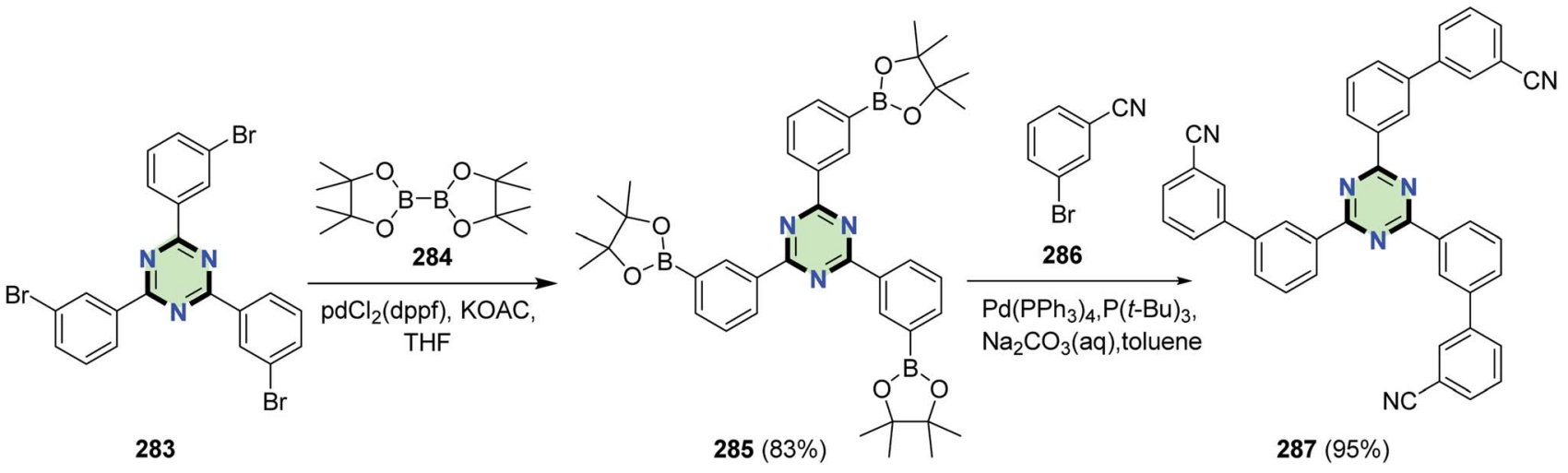

Scheme 74 Synthesis of SSM containing 1,3,5-triazine core and biphenyl arms 287. 


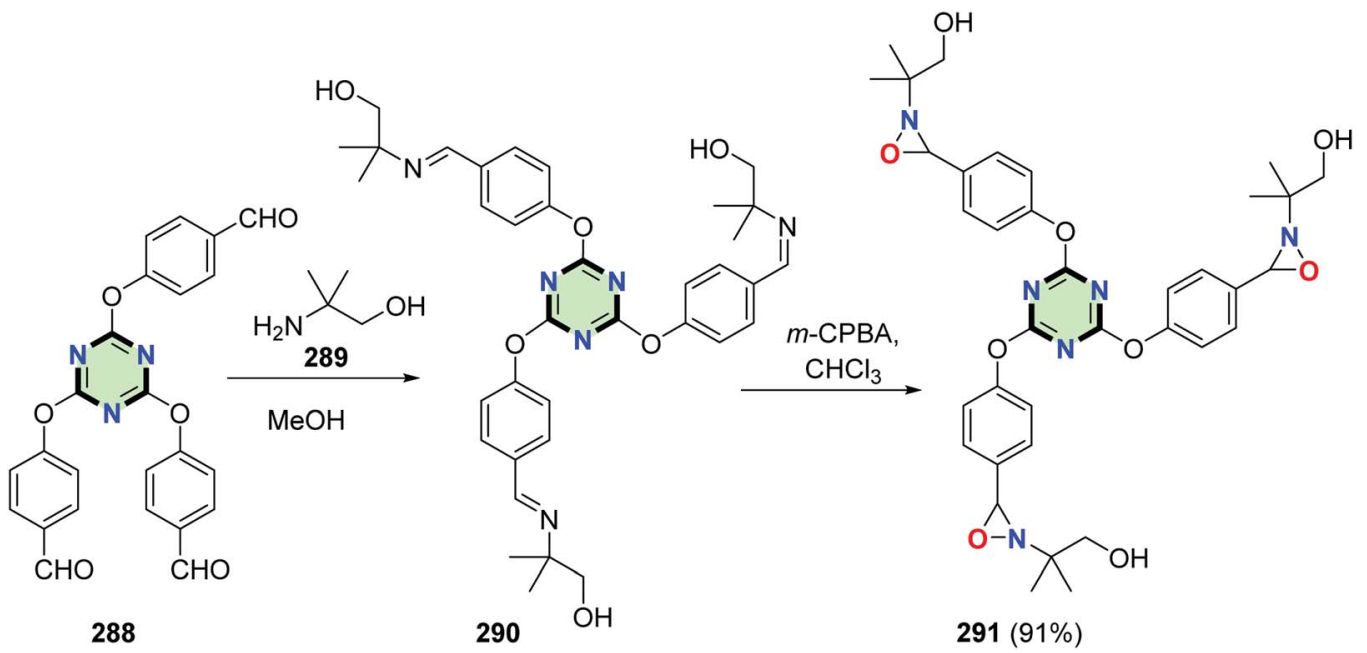

Scheme 75 Synthesis of a star-shaped molecule with triazine core and oxaziridine side arm 291.

diamine 268a,b in toluene at reflux in the presence of $\mathrm{Pd}(\mathrm{OAc})_{2}$ (Scheme 69). ${ }^{40}$ Among the synthesized starburst molecules, 269a possessed the best hole-transporting properties. Mesoporous perovskite solar cells incorporating 269a showed excellent power conversion efficiency PCE $18.87 \%$ which even higher than that of the common photovoltaic devices based on spiro-OMeTAD as a hole-transporting material with PCE $17.71 \%$.

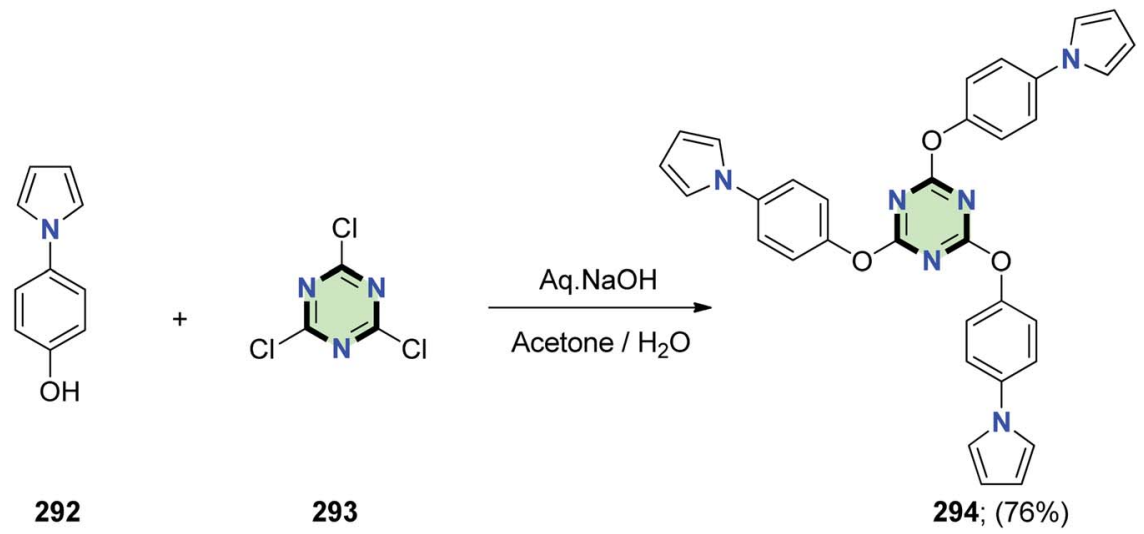

Scheme 76 Synthesis of 2,4,6-tris(4-(1H-pyrrol-1-yl)phenoxy)-1,3,5-triazine 294.<smiles>CC(C)(C)C(C)(C)C(=O)N1C(=O)C=CC1=O</smiles>

Scheme 77 Synthesis of triazine-cored compound 296 


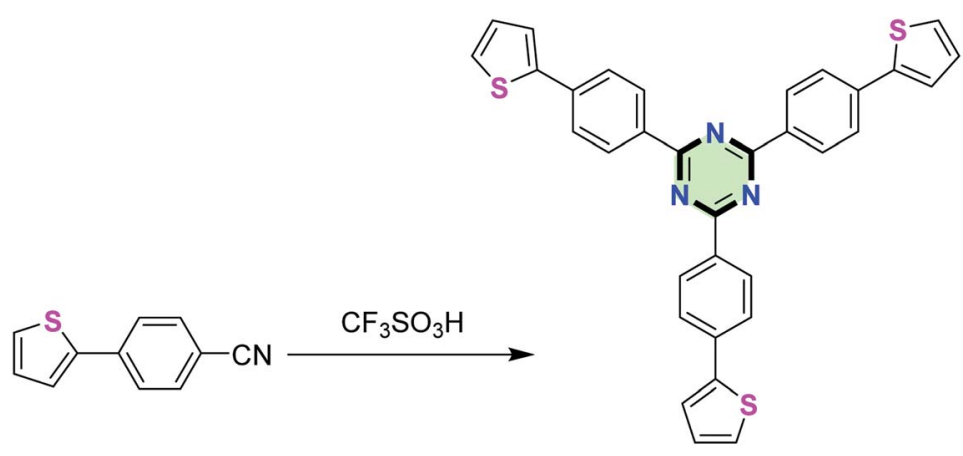

297

298; $(15 \%)$

Scheme 78 Synthesis of 2,4,6-tris(4-(thiophen-2-yl)phenyl)-1,3,5-triazine 298.<smiles>Clc1nc(Cl)nc(Cl)n1</smiles>

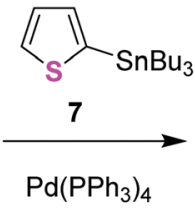

293

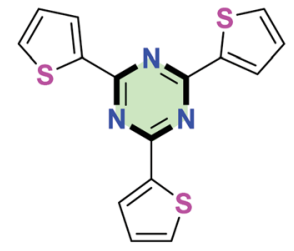

299; $(80 \%)$
Scheme 79 Synthesis of 2,4,6-tri(thiophen-2-yl)-1,3,5-triazine 299.
The aromatic C-N coupling of 1,3,5-tribromobenzene 193 with $3,3^{\prime \prime}, 6,6^{\prime \prime}$-tetra-tert-butyl-9' $\mathrm{H}-9,3^{\prime}: 6^{\prime}, 9^{\prime \prime}$-tercarbazole 271 in 18-crown-6 ether in the presence of copper(I) iodide and potassium carbonate resulted in the formation of dendritic tercarbazole-based SSM 272 in acceptable yield (33\%) (Scheme 70). The non-planar twisted starburst configuration of 272 resulted in excellent thermal stability and morphological stabilities. It retain the triplet state energy high at $2.86 \mathrm{eV}$ (compared to 1,3,5-tri( $N$-carbazolyl)benzene (TCB), $3.01 \mathrm{eV}$ ) showing the inefficient conjugation of the additional carbazole

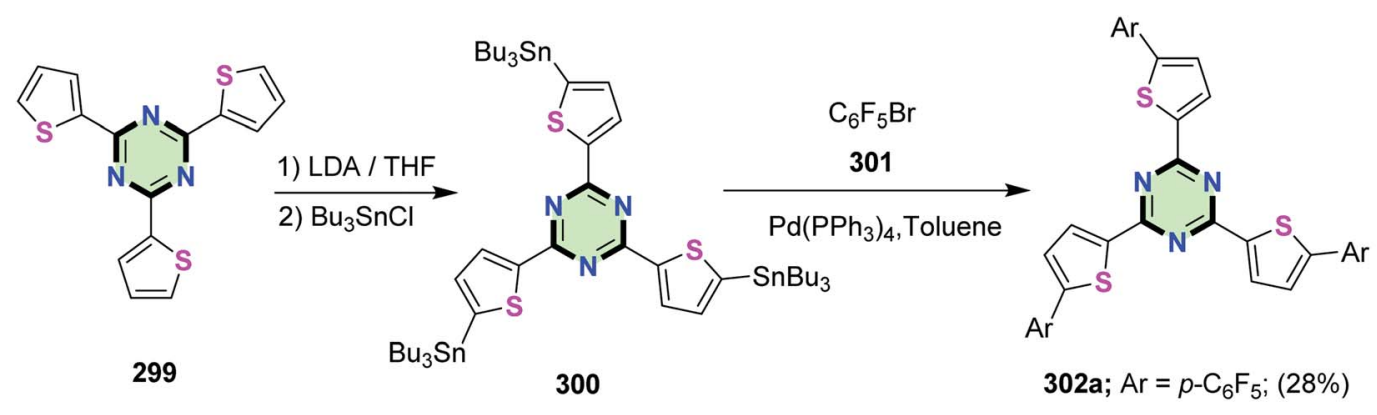

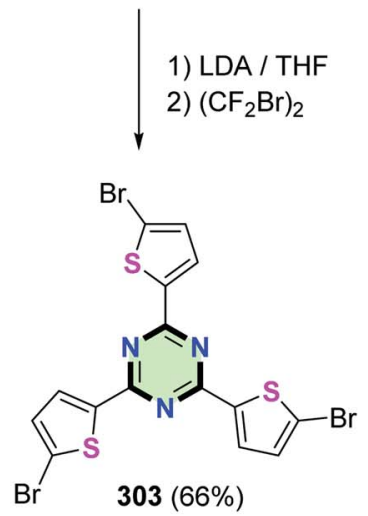<smiles>CCCCC(C)c1ccc(-c2nc(-c3ccc(Br)s3)nc(-c3ccc(Br)s3)n2)s1</smiles>

302b; $\mathrm{Ar}=\mathrm{Ph}(87 \%)$

302c; $\mathrm{Ar}=4-\mathrm{BuC}_{6} \mathrm{H}_{4}(90 \%)$

302d; $\mathrm{Ar}=4-\mathrm{BuOC}_{6} \mathrm{H}_{4}(62 \%)$

302e; $\mathrm{Ar}=4-\mathrm{Bu}_{2} \mathrm{NC}_{6} \mathrm{H}_{4}(88 \%)$

302f; $\mathrm{Ar}=4-\mathrm{CF}_{3} \mathrm{C}_{6} \mathrm{H}_{4}(61 \%)$ 


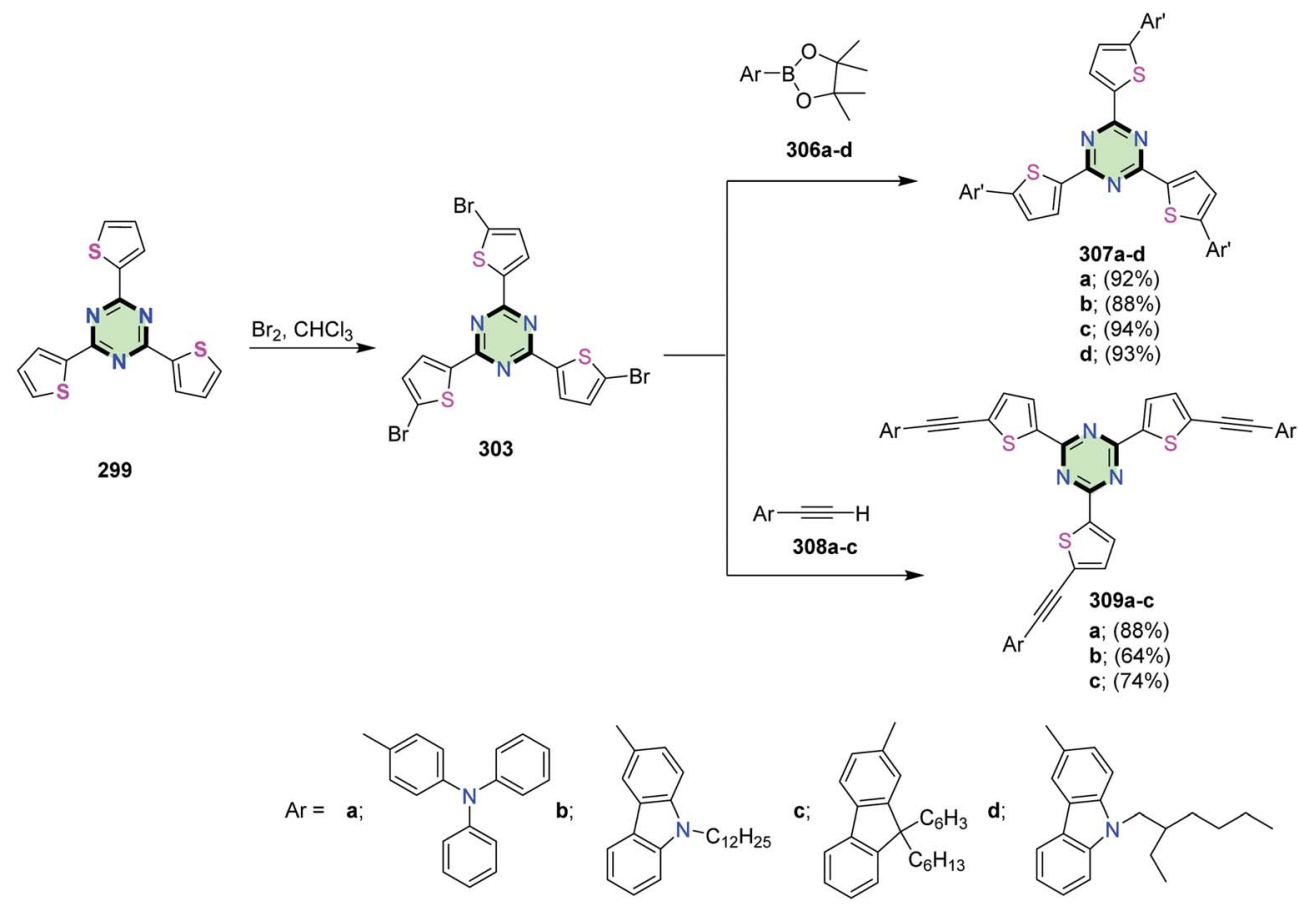

Scheme 81 Synthesis of SSMs with 1,3,5-triazine core and thiophene side arms 307 and 309

moieties due to lack of planarity. The application of 272 as a dendritic host material in solution-processed phosphorescent blue OLEDs was investigated and found to be far better than TCB. ${ }^{118}$

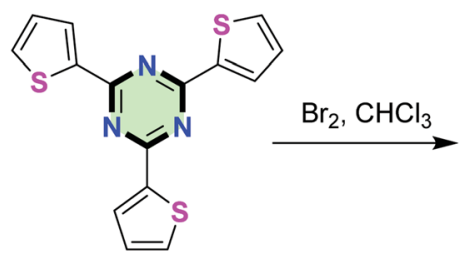

299

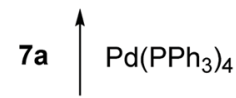<smiles>Clc1nc(Cl)nc(Cl)n1</smiles>

260<smiles>Brc1ccc(-c2nc(-c3ccc(Br)s3)nc(-c3ccc(Br)s3)n2)s1</smiles>

$303(74 \%)$

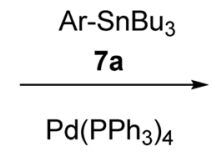

$310 \mathrm{a}(80 \%)$

$\mathrm{Ar}=\mathrm{a})$<smiles>Ic1cccs1</smiles>

b)

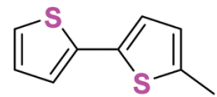

Scheme 82 Synthesis of star-shaped 1,3,5-triazines 310a,b with thiophene or bithiophene end groups.

He et al. ${ }^{88}$ reported the synthesis of 1,3,5-tris(5-(4-(3,6-di-tertbutylcarbazol-9-yl)phenyl)-1,3,4-oxadiazol-2-yl)benzene 274 in $37 \%$ yield, upon reaction of 1,3,5-tris(5-(4-bromophenyl)-1,3,4oxadiazol-2-yl)benzene 112 with 3,6-di-tert-butyl-9H-carbazole 273 in the presence of $\mathrm{CuI}$ and $\mathrm{K}_{2} \mathrm{CO}_{3}$ (Scheme 71). The donor$\pi$-acceptor (D- $\pi-\mathrm{A})$ structured SSM 274 emitted a blue color at $424 \mathrm{~nm}$ with an excellent quantum efficiency $\Phi_{\mathrm{f}}=93 \%$ in dilute toluene and $\Phi_{\mathrm{f}}=72 \%$ in thin film. The photoluminescence spectrum of 274 persisted even at elevated temperature $150{ }^{\circ} \mathrm{C}$ for 220 hours in air which permits an ease of applicability. Nondoped electroluminescent blue-emitting device based on $\mathbf{2 7 4}$ displayed a turn-on voltage of $3.7 \mathrm{~V}$ because of its bipolar structure. Excellent current efficiency (CE) and external quantum efficiency (EQE) were $4.22 \mathrm{~cd} \mathrm{~A}^{-1}$ and $3.37 \%$, respectively.

4.3.1.4.7. Naphthalene diimide. Two star-shaped molecules with benzene core and three naphthalene diimide side arms 279a and 279b were synthesized by imidization reaction of 1,3,5-triamino benzene 278 with naphthalene derivatives 277 a and $277 \mathbf{b}$. The latter compounds were obtained by treatment of 1,4,5,8-naphthalenetetracarboxylic dianhydride 275 with amine derivatives 276 in the presence of $\mathrm{Zn}(\mathrm{OAc})_{2}$ (Scheme 72). ${ }^{119}$ These star-shaped compounds 279a and 279b showed a bathochromic shift in the film state compared to solution which reflects the aggregation in the solid state. Also, these compounds were characterized by low-lying LUMO levels at -3.83 and $-3.87 \mathrm{eV}$, respectively, which indicates the applicability of these compounds as n-type semi-conductors.

4.3.2. Pyridine-cored SSMs. Magnan et al. ${ }^{113}$ reported the synthesis of star-shaped compound with pyrimidine core 281 in 
<smiles>O=Cc1ccc(Oc2nc(Oc3ccc(C=O)cc3)nc(Oc3ccc(C=O)cc3)n2)cc1</smiles>

288

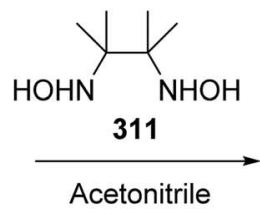<smiles>COc1ccc(C2N(O)C(C)(C)C(C)(C)N2O)cc1</smiles>

\section{Scheme 83 Synthesis of star-shaped molecule with triazine core and imidazolidine side arms 312.}

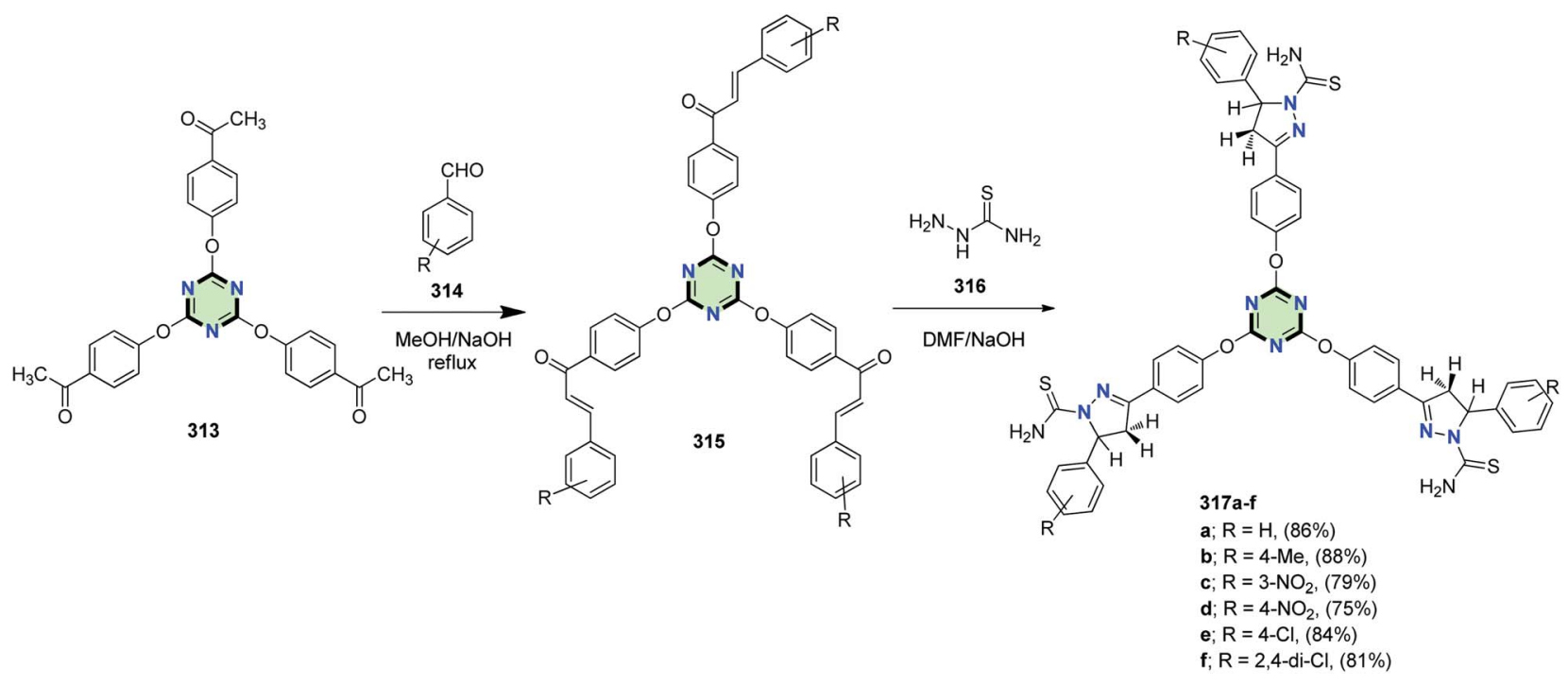

Scheme 84 Synthesis of tris-pyrazoline $317 a-f$.

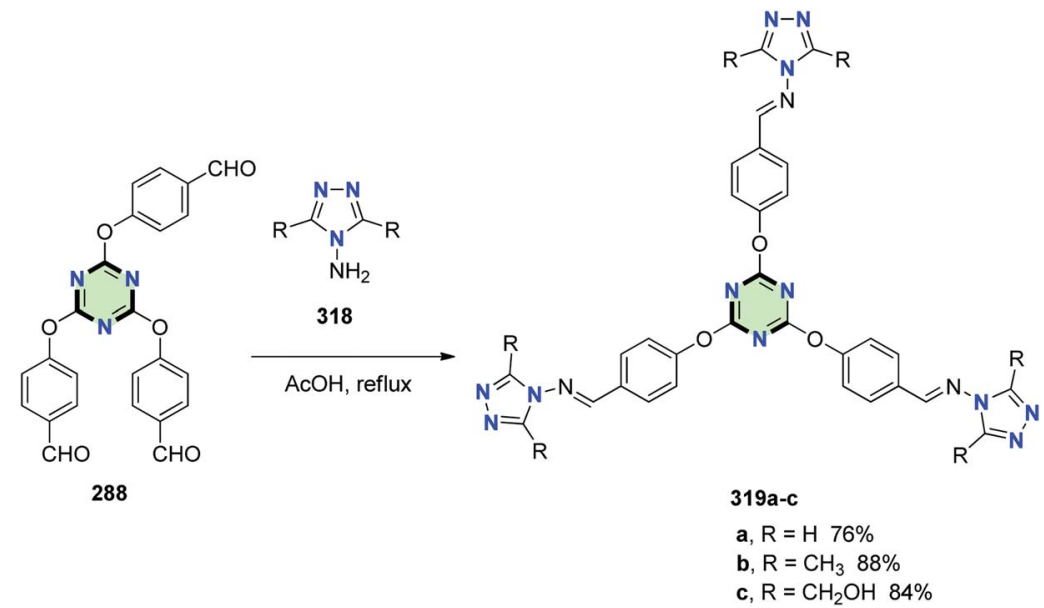

Scheme 85 Synthesis of star-shaped Schiff bases 319a-c. 


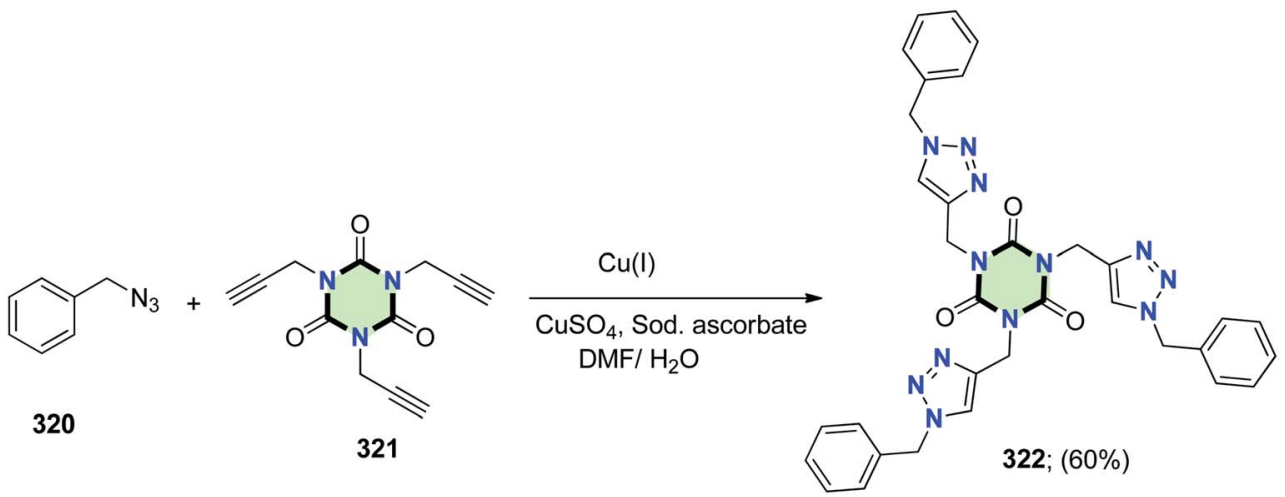

Scheme 86 Synthesis of tris(triazole) derivative 322.

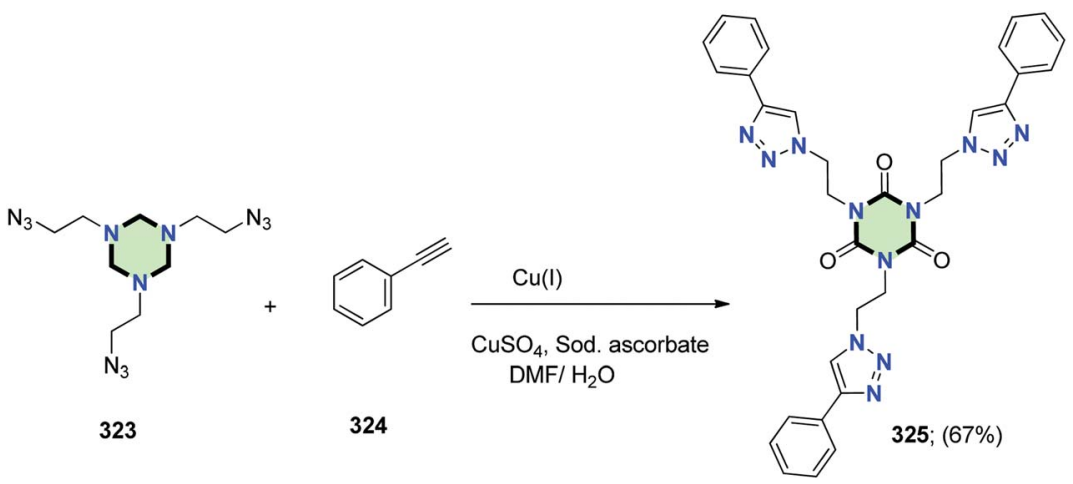

Scheme 87 Synthesis of tris(triazole) derivative 325.

76\% yield by four-fold Negishi coupling between 2,3,5,6-tetrabromopyridine 280 with 2-hexylthieno[3,2- $b]$ thiophene 239 in the presence of ${ }^{n} \mathrm{BuLi}$ and anhydrous $\mathrm{ZnCl}_{2}$. Subsequent oxidative cyclodehydrogenation of the latter compound in chlorobenzene using anhydrous ferric chloride gave tetra(5-hexylthieno[3,2- $b]$ thieno)acridine 282 in $53 \%$ yield (Scheme 73 ). Changing the benzene core in compound $\mathbf{2 4 2}$ ( $c f$. Scheme 61) with the electrondeficient pyridine ring in $\mathbf{2 8 2}$ resulted in a red shift from 468 to<smiles>CC(C)(C)C#CC#Cc1nc(C#CC(C)(C)C)nc(C#CS(C)(=O)=O)n1</smiles>

326<smiles>[R]c1cc(N)cc([R])c1[R]</smiles>

327

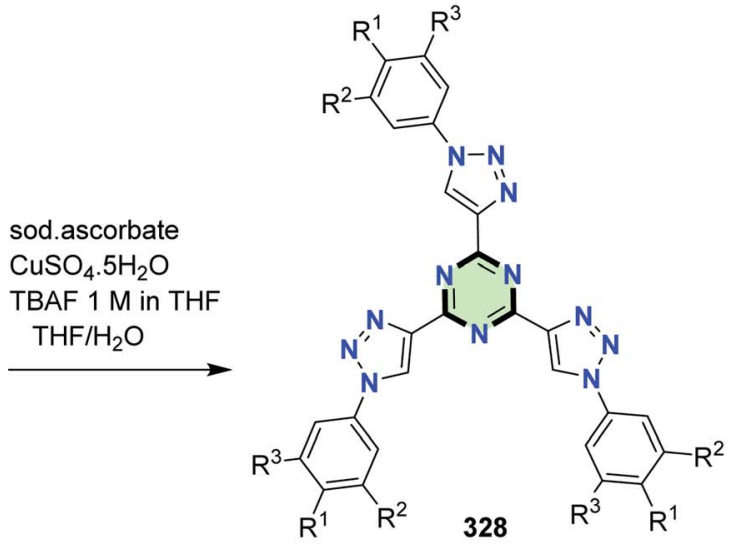

a; $\mathrm{R}^{1}=\mathrm{OC}_{10} \mathrm{H}_{21}, \mathrm{R}^{2}=\mathrm{R}^{3}=\mathrm{H}(45 \%)$

b; $R^{1}=R^{2}=O_{10} \mathrm{H}_{21}, R^{3}=\mathrm{H}(51 \%)$

c; $R^{1}=R^{2}=R^{3}=O C_{10} H_{21}(48 \%)$

Scheme 88 Synthesis of SSMs with triazine core and phenyltriazole side arms 328 . 

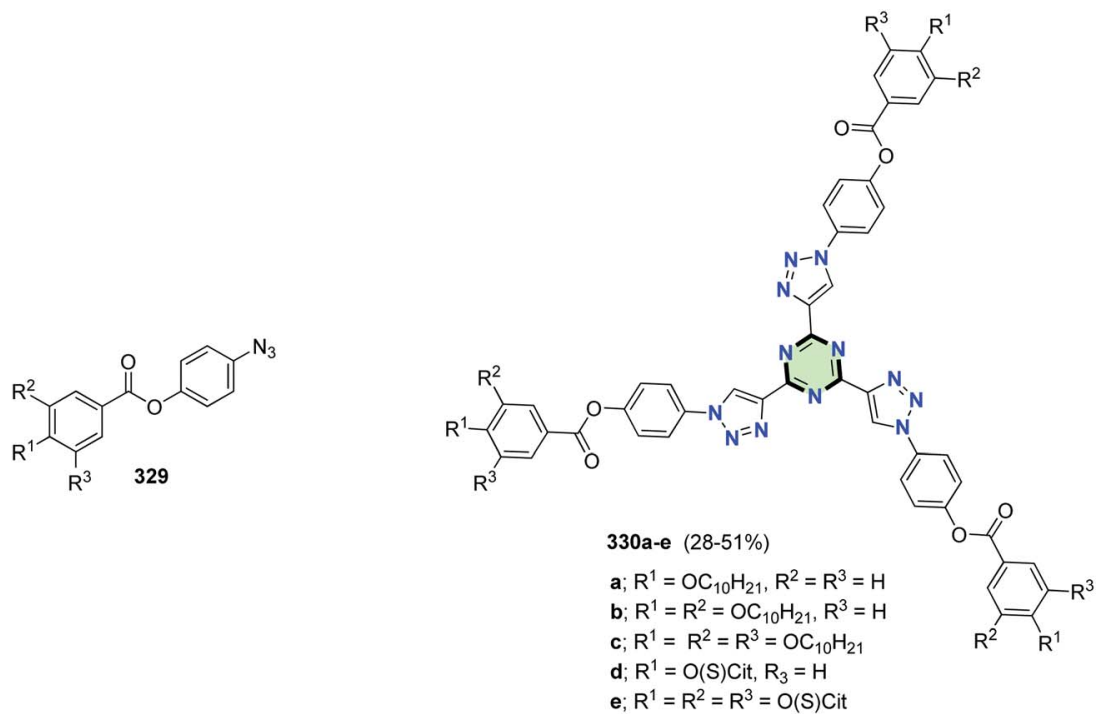

Fig. 7 Structures of 4-azidophenyl benzoate 329 and SSMs 330a-e.

$494 \mathrm{~nm}$, respectively. This may be attributed to the presence of the electronegative nitrogen atom which lowers the energy of the LUMO of 282 and thus, decreases the energy gap.

\subsection{3. $\quad s$-Triazine-cored SSMs with different arms}

4.3.3.1. Biphenyl. SSM containing 1,3,5-triazine core and biphenyl arms 287 was synthesized in an excellent yield (95\%) via Suzuki cross-coupling of 2,4,6-tris(3-(4,4,5,5-tetramethyl1,3,2-dioxaborolan-2-yl)phenyl)-1,3,5-triazine 285 with 3-bromobenzonitrile 286 in the presence of $\mathrm{Pd}\left(\mathrm{PPh}_{3}\right)_{4}$ catalyst and $\mathrm{P}(t-\mathrm{Bu})_{3}$ as co-catalyst. Compound 285 was obtained in $83 \%$ yield by the reaction of 1,3,5-tris(bromophenyl)triazine 283 with octamethyl-2,2'-bi(1,3,2-dioxaborolane) 284 in the presence of Pd catalyst (Scheme 74). ${ }^{\mathbf{1 2 0}}$

4.3.3.2. Oxaziridine. Peng et al. ${ }^{121}$ reported the synthesis of a star-shaped molecule with triazine core and oxaziridine side arm 291 in 91\% yield by reaction of 2,4,6-tris ( $p$-formylphenoxy)1,3,5-triazine 288 with 2-amino-2-methyl-1-propanol 289 to give tris(imine) 290 followed by oxidation using $m$-CPBA in chloroform (Scheme 75).

4.3.3.3. Pyrrole. 2,4,6-Tris(4-(1H-pyrrol-1-yl)phenoxy)-1,3,5triazine 294 was synthesized in $76 \%$ yield upon treatment of 4-(1H-pyrrol-1-yl)phenol 292 with 2,4,6-trichloro-1,3,5-triazine 293 under basic condition (Scheme 76). Electropolymerization of the star-shaped molecule $\mathbf{2 9 4}$ was then conducted and the resulting polymer was studied spectroelectrochemically. Three bands were shown at 346, 508 and 665 for $\pi-\pi^{*}$ transition, polaron and bipolaron formation, respectively. The switching ability of this polymer was examined by means of chronoabsorptometry and the optical contrast was $20 \%$ with a switching time of $1.1 \mathrm{~s}$. A dual complementary-colored electrochromic device was designed for both of the latter polymer and poly(3,4ethylenedioxythiophene) (PEDOT) in a sandwich configuration. It switched between dark blue and red colors within $2.2 \mathrm{~s}$ and with an optical contrast of $25 \% .^{122}$

Triazine-cored compound 296 was synthesized in 91\% yield through reaction of cyanuric chloride 293 with 1-(4-
hydroxyphenyl)-1H-pyrrole-2,5-dione 295 in the presence of TEA (Scheme 77).

4.3.3.4. Thiophene and bithiophene. Li et al. ${ }^{15}$ reported the synthesis of 2,4,6-tris(4-(thiophen-2-yl)phenyl)-1,3,5-triazine 298 in 15\% yield through cyclotrimerization of 4-(thiophen-2yl)benzonitrile 297 in the presence of $\mathrm{CF}_{3} \mathrm{SO}_{3} \mathrm{H}$ (Scheme 78). Electropolymerization of $\mathbf{2 9 8}$ resulted in the formation of a polymer of insignificant electrochromic properties. However, the copolymerization of this polymer with (a polymer of low ionization potential) PEDOT improved greatly the electrochromic properties.

2,4,6-Tri(thiophen-2-yl)-1,3,5-triazine 299 was synthesized in $80 \%$ yield by the reaction of 2-tributylstannylthiophene 7 with cyanuric chloride 293 in the presence of $\mathrm{Pd}\left(\mathrm{PPh}_{3}\right)_{4}$ (Scheme 79). ${ }^{6,123}$

A selective lithiation of 299 and subsequent stannylation gave 2,4,6-tris(5-tributylstannyl-2-thienyl)-1,3,5-triazine $\mathbf{3 0 0}$. The latter compound underwent Stille coupling reaction with pentafluorophenylbromide $\mathbf{3 0 1}$ in the presence of $\mathrm{Pd}\left(\mathrm{PPh}_{3}\right)_{4}$ to give 2,4,6-tris(5-pentafluorophenyl-2-thienyl)-1,3,5-triazine 302a in $28 \%$ yield. On the other hand, 2,4,6-tri(5-aryl-thiophen-2-yl)1,3,5-triazines 302b-f were synthesized via Suzuki-Miyaura cross-coupling reactions of 2,4,6-tri(5-bromo-2-thienyl)-1,3,5triazine 303 with arylboronic acids $\mathbf{3 0 4}$ or tetramethyl-2-aryl1,3,2-dioxaborolane 305 in the presence of cesium carbonate and Pd catalyst (Scheme 80). ${ }^{6}$ The effect of tuning the electronic nature of aryl groups connected to thiophene peripheral of SSMs 302 was found to be consistent with the electronaccepting or electron-attracting capabilities of these molecules as deduced from their UV absorption and fluorescence emission spectra. Moreover, compound 302e having $\mathrm{Bu}_{2} \mathrm{~N}-$ group showed both absorption and emission solvatochromism (due to internal charge transfer), as well as colorimetric and luminescence proton-sensing properties in view of the visually observed changes in the color of the solution and emission related to the two-step protonation of the $\mathrm{Bu}_{2} \mathrm{~N}$ - groups and the nitrogen 
<smiles>[R]c1cc(C(=O)OCC)cc([R])c1[R]</smiles>

331a: $\mathrm{R}^{1}=\mathrm{R}^{3}=\mathrm{H}, \mathrm{R}^{2}=n-\mathrm{OC}_{16} \mathrm{H}_{33}$ 331b: $\mathrm{R}^{1}=\mathrm{H}, \mathrm{R}^{2}=\mathrm{R}^{3}=n-\mathrm{OC}_{16} \mathrm{H}_{33}$ 331c: $\mathrm{R}^{1}=\mathrm{R}^{3}=n-\mathrm{OC}_{16} \mathrm{H}_{33}, \mathrm{R}^{2}=\mathrm{H}$ 331d: $R^{1}=R^{2}=R^{3}=n-O_{16} \mathrm{H}_{33}$ 331e: $\mathrm{R}^{1}=\mathrm{R}^{3}=\mathrm{H}, \mathrm{R}^{2}=n-\mathrm{OC}_{12} \mathrm{H}_{25}$ 331f: $R^{1}=H, R^{2}=R^{3}=n-O_{12} \mathrm{H}_{25}$ 331g: $\mathrm{R}^{1}=\mathrm{R}^{3}=n-\mathrm{OC}_{12} \mathrm{H}_{25}, \mathrm{R}^{2}=\mathrm{H}$ 331h: $\mathrm{R}^{1}=\mathrm{R}^{2}=\mathrm{R}^{3}=n-\mathrm{OC}_{12} \mathrm{H}_{25}$

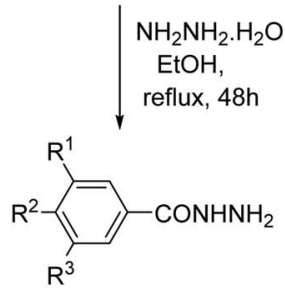

332a-h $(65-75 \%)$<smiles>[R]c1cc(C(=O)NNC(=O)c2ccc(-c3nc(-c4ccc(C(=O)NNC(=O)c5cc([R])c([R])c([R])c5)cc4)nc(-c4ccc(C(=O)NNC(=O)c5cc([R])c([R])c([R])c5)cc4)n3)cc2)cc([R])c1[R1]</smiles>

337a-h<smiles>CC(C)(C)C(=O)OC(=O)c1ccc(-c2nc(-c3ccc(C(=O)O)cc3)nc(-c3ccc(C(=O)O)cc3)n2)cc1</smiles>

335<smiles>[R]c1cc(-c2nnc(-c3ccc(C4=NC(c5ccc(-c6nnc(-c7cc([R])c([R])c([R])c7)o6)cc5)NC(c5ccc(-c6nnc(-c7cc([R])c([R])c([R])c7)o6)cc5)=N4)cc3)o2)cc([R])c1[R]</smiles>

338a-h (45-50\%)

Scheme 89 Synthesis of SSMs with a central triazine core appended with three 1,3,4-oxadiazole arms 338a-h.

atoms on the 1,3,5-triazine moiety. This makes compound 302e to be a promising polarity or $\mathrm{pH}$ sensors.

A series of SSMs with 1,3,5-triazine core and thiophene attached directly or via ethylenic linkages to triphenylamine, carbazole or fluorene moieties as side arms 307 and 309 could be synthesized starting from the 2,4,6-tri(5-bromo-2-thienyl)1,3,5-triazine 303 through Suzuki-Miyaura and Sonogashira cross-coupling reactions involving arylboronates 306a-d or ethynylarenes 308a-c, respectively, in moderate-to-excellent yields (64-93\%). Compound 303 was obtained by bromination of tris-2,4,6-thienyl-1,3,5-triazine 299 in the presence of bromine in chloroform at reflux (Scheme 81). The UV-vis spectra of compounds 307 and 309 showed that the absorption maximum was affected not only by the electron-donating 
<smiles>O=Cc1ccc(Oc2nc(Oc3cccc(C=O)c3)nc(Oc3cccc(C=O)c3)n2)cc1</smiles>

288; $p$-isomer

339; $m$-isomer

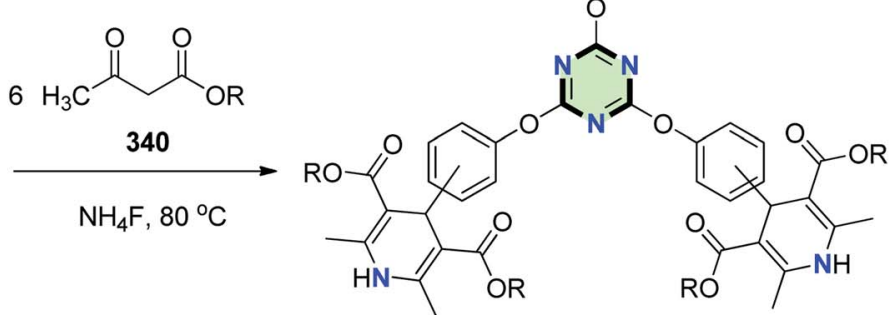

341a; $p$-isomer, $\mathrm{R}=\mathrm{Et}, 90 \%$

341b; $p$-isomer, $\mathrm{R}=\mathrm{CH}_{3}, 87 \%$

341c; $m$-isomer, $\mathrm{R}=\mathrm{Et}, 80 \%$

341d; $m$-isomer, $\mathrm{R}=\mathrm{CH}_{3}, 86 \%$

Scheme 90 Synthesis of tripodal 1,4-dihydropyridines 341a-d.

strength of the peripheral group or introduction of an ethynyl spacer, but on the position of the same electron-donating substituent as well (as in case of $\mathbf{3 0 7 b}$ and $\mathbf{3 0 7 d}$ ). The electrochemical data of these compounds displayed a reversible or a quasi-reversible redox behavior due to their donor-acceptor properties. In addition, these compounds indicated large twophoton absorption cross-sections at $720-880 \mathrm{~nm}$, greatly

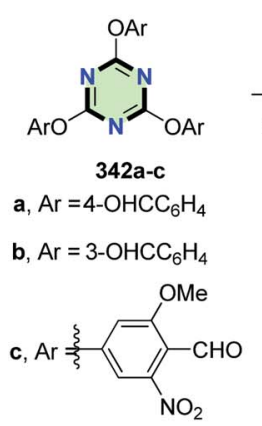

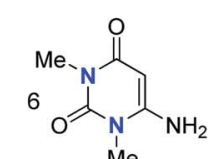

343
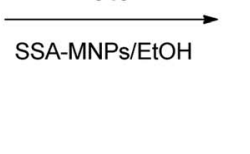

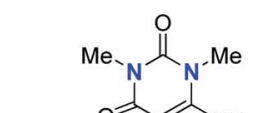

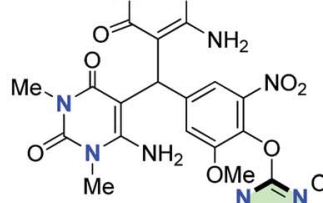<smiles>Cn1c(N)cc(=O)n([14CH3])c1=O</smiles>

$\mathrm{Me}$<smiles>COc1nc(Oc2c(OC)cc(C(C)c3c(N)n(C)c(=O)n(C)c3=O)cc2OC)nc(Oc2c(OC)cc(C(c3c(N)n(C)c(=O)n(C)c3=O)c3c(N)n(C)c(=O)n(C)c3=O)cc2[N+](=O)[O-])n1</smiles>

$344(88 \%)$<smiles>Cn1c(N)c(C(C=CN)c2cccc(Oc3nc(Oc4cccc(C(c5c(N)n(C)c(=O)n(C)c5=O)c5c(N)n(C)c(=O)n(C)c5=O)c4)nc(Oc4cccc(C(c5c(N)n(C)c(=O)n(C)c5=O)c5c(N)n(C)c(=O)n(C)c5=O)c4)n3)c2)c(=O)n(C)c1=O</smiles>

$346(87 \%)$ 
<smiles>O=Cc1cccc(O)c1</smiles>

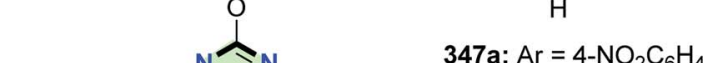<smiles>Cc1ccc(Oc2ncnc(Oc3ccc(C=O)cc3)n2)cc1</smiles>

288; $p$-isomer 339; $m$-isomer

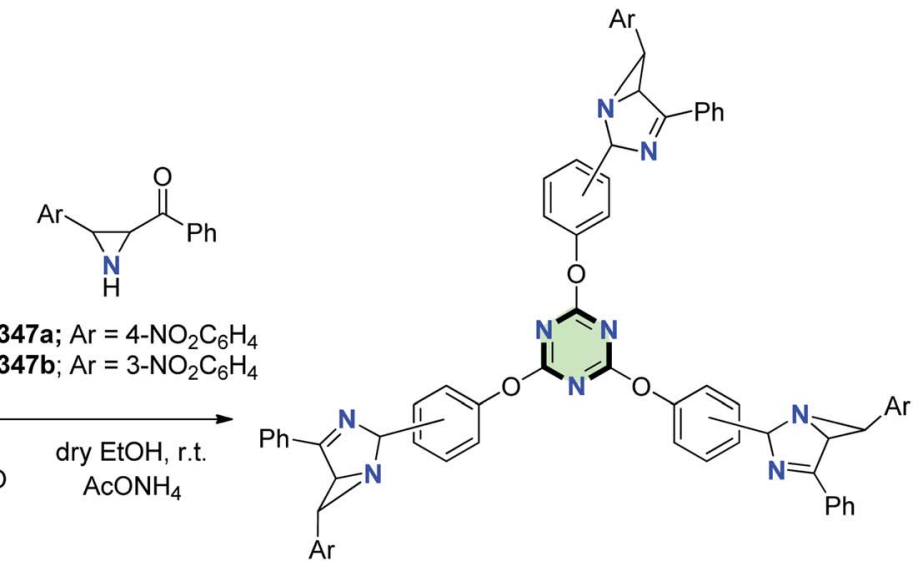

348; $p$-isomer, $\mathrm{Ar}=4-\mathrm{NO}_{2} \mathrm{C}_{6} \mathrm{H}_{4} ;(72 \%)$

349; $m$-isomer, $\mathrm{Ar}=3-\mathrm{NO}_{2} \mathrm{C}_{6} \mathrm{H}_{4} ;(70 \%)$

Scheme 92 Synthesis of SSMs with 1,3-diazabicyclo[3.1.0]hex-3-enes side arms 348 and 349.

affected by the intramolecular charge transfer and the extent of $\pi$-conjugation. ${ }^{124}$

Leriche et al. ${ }^{123}$ reported the synthesis of star-shaped 1,3,5triazine molecules 310a,b with thiophene or bithiophene tails in 80 and $60 \%$ yields, respectively, by the reaction of cyanuryl chloride $\mathbf{2 6 0}$ with tributylstannylarenes $7 \mathrm{a}$ or by the reaction of 2,4,6-tris(5-bromothiophen-2-yl)-1,3,5-triazine 303 with 2-tributylstannylthiophene $\mathbf{7 b}$ in the presence of $\mathrm{Pd}\left(\mathrm{PPh}_{3}\right)_{4}(\mathrm{Scheme}$ 82). It was shown that enlargement of thiophene tail resulted in a bathochromic shift in their UV-vis absorption spectra and a reduction in their oxidation potential as shown from their cyclic voltammograms.

4.3.3.5. Imidazolidine. Condensation of trisaldehyde $\mathbf{2 8 8}$ with 2,3-dihydroxyamino-2,3-dimethylbutane 311 in acetonitrile afforded a star-shaped molecule with triazine core and 4,4,5,5-tetramethyl-2-phenylimidazolidine-1,3-diol side arms 312 in $45 \%$ yield (Scheme 83 ).

4.3.3.6. 4,5-Dihydro-1H-pyrazole. A series of tris-pyrazoline 317a-f were synthesized in good yields by tris-cyclization of trischalcones 315 with thiosemicarbazide 316 under basic conditions in DMF. The chalcones $\mathbf{3 1 5}$ were prepared by condensation of tris-acetophenone 313 with the appropriate aldehydes 314 in $\mathrm{MeOH}$ in the presence of $\mathrm{NaOH}$ (Scheme 84). ${ }^{125}$

4.3.3.7. 1,2,4-Triazole. Star-shaped Schiff bases 319a-c with triazine core and 1,2,4-triazole side arms were synthesized in good yields through condensation of 2,4,6-tris $(p-$ formylphenoxy)-1,3,5-triazine $\mathbf{2 8 8}$ with the appropriate aminotriazole 318 in glacial acetic acid at reflux (Scheme 85). ${ }^{126}$<smiles>O=Cc1ccc(Oc2nc(Oc3ccc(CO)cc3)nc(Oc3ccc(CO)cc3)n2)cc1</smiles><smiles>[R]c1ccc(N)c(N)c1</smiles><smiles></smiles>

Scheme 93 Synthesis of tripodal-benzimidazole derivatives 351a-d 


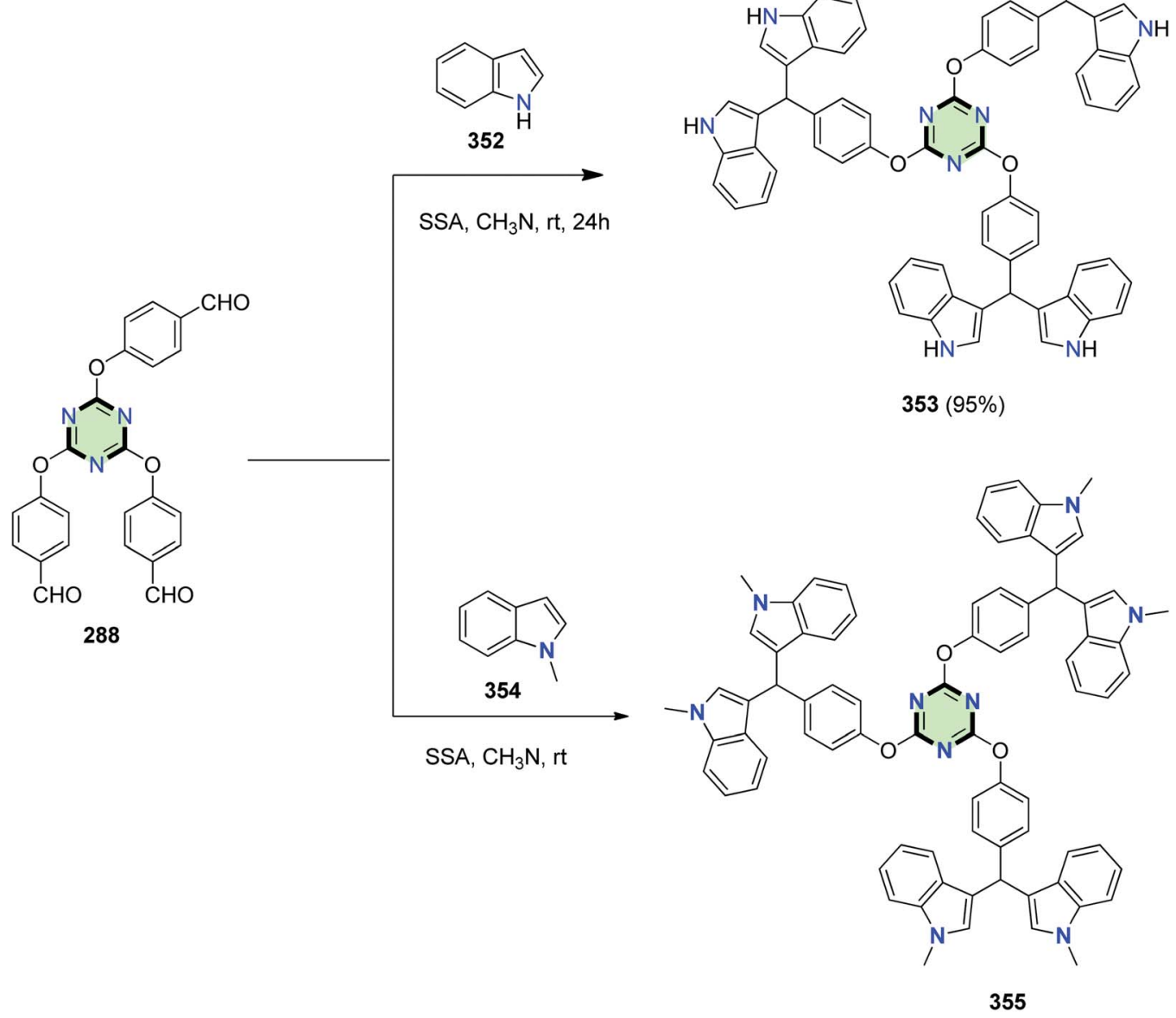

Scheme 94 Synthesis of tris(bis(indolyl)methanes) compounds 353 and 355.

4.3.3.8. 1,2,3-Triazole. The synthesis of tripodal 322 with 1,2,3-triazole side arms were performed using a copper catalyzed Huisgen's reaction. Thus, reaction of a mixture of alkyne
321 and benzylazide 320 in DMF afforded tris[(1-benzyl-1 $H$ 1,2,3-triazole-4-yl)methyl]-1,3,5-triazinane-2,4,6-trione 322 in $60 \%$ yield (Scheme 86$).{ }^{127}$<smiles>O=Cc1cccc(Oc2nc(Oc3cccc(C=O)c3)nc(Oc3cccc(C=O)c3)n2)c1</smiles>

339

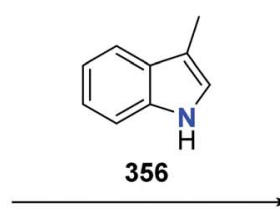

SSA, $\mathrm{CH}_{3} \mathrm{~N}, \mathrm{rt}$<smiles></smiles>

Scheme 95 Synthesis of 2,4,6-tris((bis(indol-2-yl)methyl)phenoxy)-1,3,5-triazine 357. 
<smiles></smiles>

Scheme 96 Synthesis of tris-dihydrotetrazolo[1,5-a]pyrimidines 360a and 360b<smiles>Clc1nc(Cl)nc(Cl)n1</smiles>

293

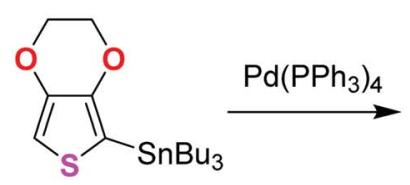

361<smiles>c1nc(-c2scc3c2OCCO3)nc(-c2scc3c2OCCO3)n1</smiles>

Scheme 97 Synthesis of 2,4,6-tris(2,3-dihydrothieno[3,4-b][1,4]dioxin-5-yl)-1,3,5-triazine 362.

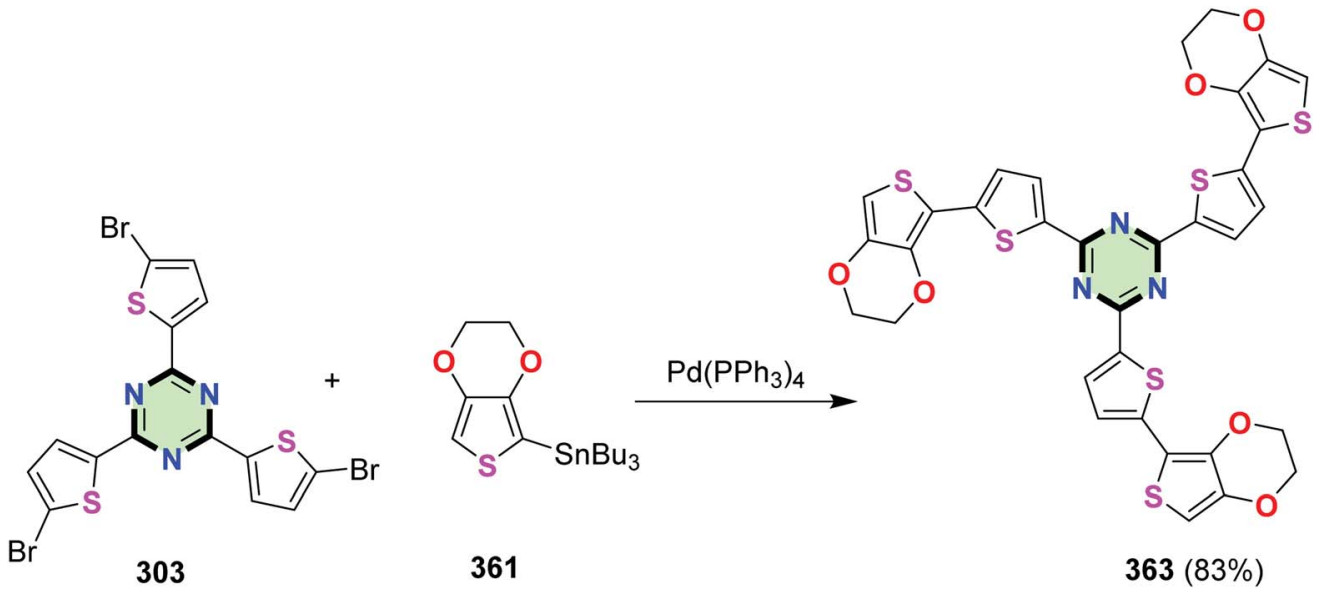

Scheme 98 Synthesis of SSM with triazine core linked to thieno[3,4-b][1,4]dioxine. 


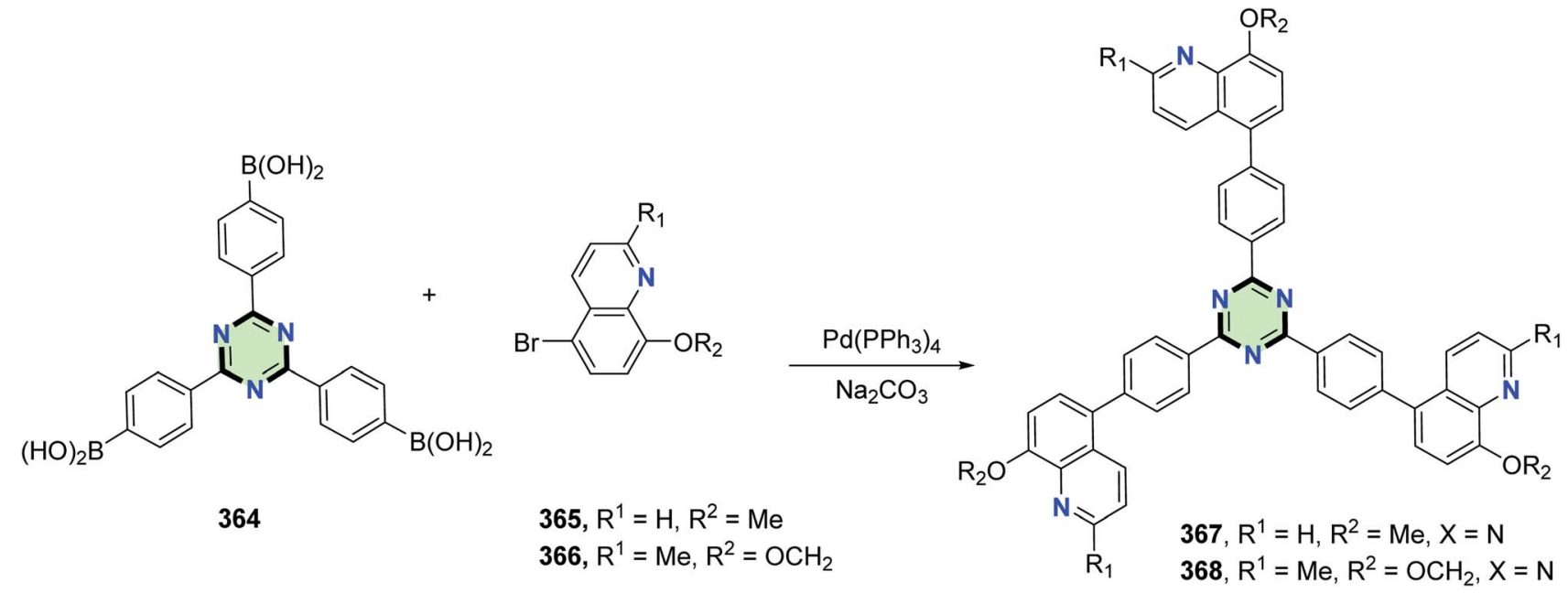

Scheme 99 Synthesis of SSMs with quinolone side arms 367 and 368.

The same method was applied to synthesize the triazole derivative 325 in $67 \%$ yield, using the tris azide 323 and phenylacetylene 324 (Scheme 87). ${ }^{127}$

The click copper-catalyzed cycloaddition reaction of tris [(trimethylsilyl)ethynyl]-1,3,5-triazine 326 with azide derivatives 327 afforded SSMs 328 with triazine core and phenyltriazole side arms containing mono-, di-, and trialkoxy groups (Scheme 88). The star-shaped materials 328 showed ordered columnar mesophases. They displayed luminescence from the blue to green light depending on the peripheral substitution. Electrochemical behavior of these compounds was good correlated to their electron-deficient nature and their potential for electron transport. ${ }^{128}$

In a similar fashion, SSMs 330a-e with triazine core and arms containing triazole moieties and aroyloxy groups could be synthesized in moderate yields $(28-51 \%)$ starting from the appropriate 4-azidophenyl benzoate $\mathbf{3 2 9}$ (Fig. 7). It has been found that inclusion of long alkoxy chains in compounds $\mathbf{3 3 0}$ decreases both solvatofluorochromism and electron-accepting properties. ${ }^{129}$

4.3.3.9. Oxadiazole. Pradhan et al. ${ }^{130}$ reported the synthesis of star-shaped molecules with a central triazine core appended with three 1,3,4-oxadiazole arms 338a-h through multi-step reactions including, firstly the transformation of alkoxy esters 331a-h into their respective hydrazides 332a-h upon treatment with hydrazine hydrate in ethanol. Reaction of the hydrazides with $4,4^{\prime}, 4^{\prime \prime}$-(1,3,5-triazine-2,4,6-triyl)tribenzoyl chloride 336 (obtained upon treatment of 4,4',4"-(1,3,5-triazine-2,4,6-triyl) tribenzoic acid 335 with $\left.\mathrm{POCl}_{3}\right)$ in THF in the presence of triethylamine yielded tri- $N$-benzoylbenzohydrazides $337 \mathbf{a}-\mathbf{h}$. These compounds were heated with $\mathrm{POCl}_{3}$ to give the target molecules 338a-h. The key intermediate $4,4^{\prime}, 4^{\prime \prime}$-(1,3,5-triazine-2,4,6-triyl) tribenzoic acid 335 was prepared in good yield from $p$-tolunitrile 333 by firstly triflic acid catalyzed trimerization to give<smiles>O=Cc1ccc(Oc2nc(Oc3ccc(C=O)cc3)nc(Oc3ccc(C=O)cc3)n2)cc1</smiles>
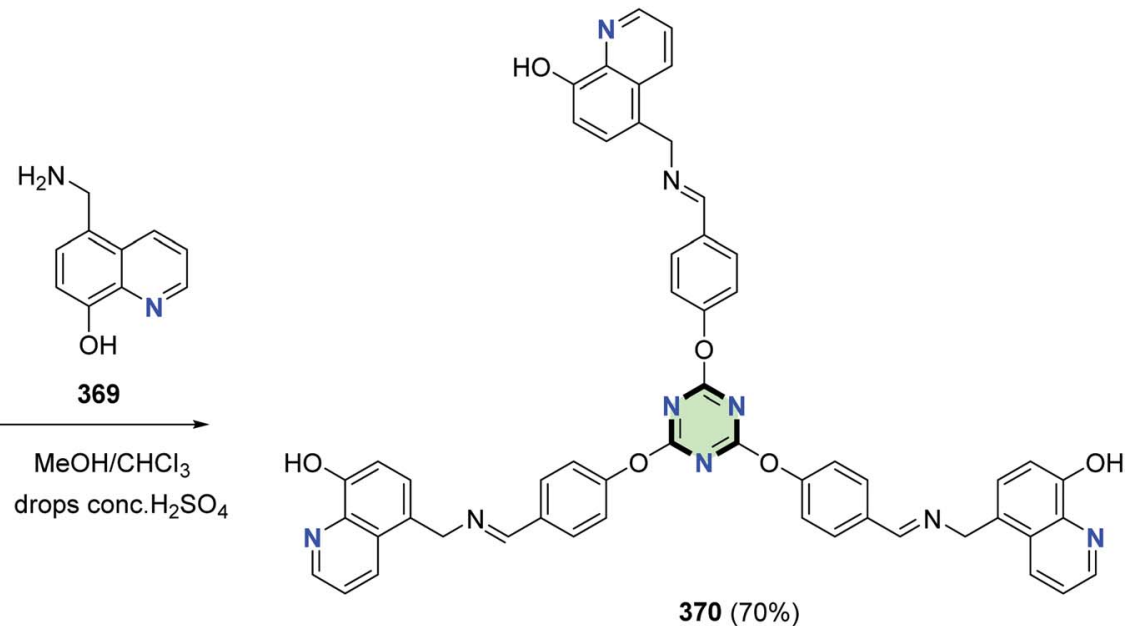

Scheme 100 Synthesis of tripodal Schiff base with triazine core and quinoline side arms 370 . 
<smiles>O=c1cc(O)c2ccccc2o1</smiles>

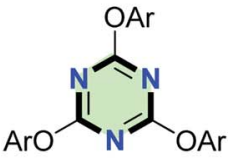

288; $\mathrm{Ar}=4-\mathrm{OHCC}_{6} \mathrm{H}_{4}$

$339 ; \mathrm{Ar}=3-\mathrm{OHCC}_{6} \mathrm{H}_{4}$

$371 ; \mathrm{Ar}=3-\mathrm{MeO}-4-\mathrm{OHCC}_{6} \mathrm{H}_{4}$<smiles>[R]c1cc(C(c2c(O)c3ccccc3oc2=O)c2c(O)c3ccccc3oc2=O)ccc1Oc1nc(Oc2ccc(C(c3c(O)c4ccccc4oc3=O)c3c(O)c4ccccc4oc3=O)cc2[R])nc(Oc2ccc(C(c3c(O)c4ccccc4oc3=O)c3c(O)c4ccccc4oc3=O)cc2[R])n1</smiles>

373a-c

a, $\mathrm{R}=\mathrm{H}, p$-isomer

b, $\mathrm{R}=\mathrm{H}, m$-isomer

c, $\mathrm{R}=\mathrm{MeO}, p$-isomer

Scheme 101 Synthesis of tris[bis(4-hydroxycoumarinyl)methanes] 373a-c

2,4,6-tri-p-tolyl-1,3,5-triazine $\mathbf{3 3 4}$ and subsequent chromic oxide mediated oxidation (Scheme 89). In general, a decrease of the chain length of the alkoxy groups led to enhancement of corecore interaction and subsequently, stabilizing both $\mathrm{Col}_{\mathrm{r}}$ and $\mathrm{Col}_{\mathrm{h}}$ phases and improving the thermal range. The SSMs 338 fluoresced blue-green light either in solution or in the solid state according to the type of peripheral chains. The persistence of fluorescene in the solid state was attributed to the columnar assembly of the star molecules. Cyclic voltammograms of $\mathbf{3 3 8}$ implied that these molecules have lower LUMO and band gaps making them potential electron-transporting candidates for OLEDs.

4.3.3.10. 1,4-Dihydropyridine. Tripodal 1,4-dihydropyridines 341a-d were synthesized in good yields through Hantzsch reaction of tris-aldehydes 288 and 339 with $\beta$-keto esters 340 in the presence of $\mathrm{NH}_{4} \mathrm{~F}$ (Scheme 90). ${ }^{131}$
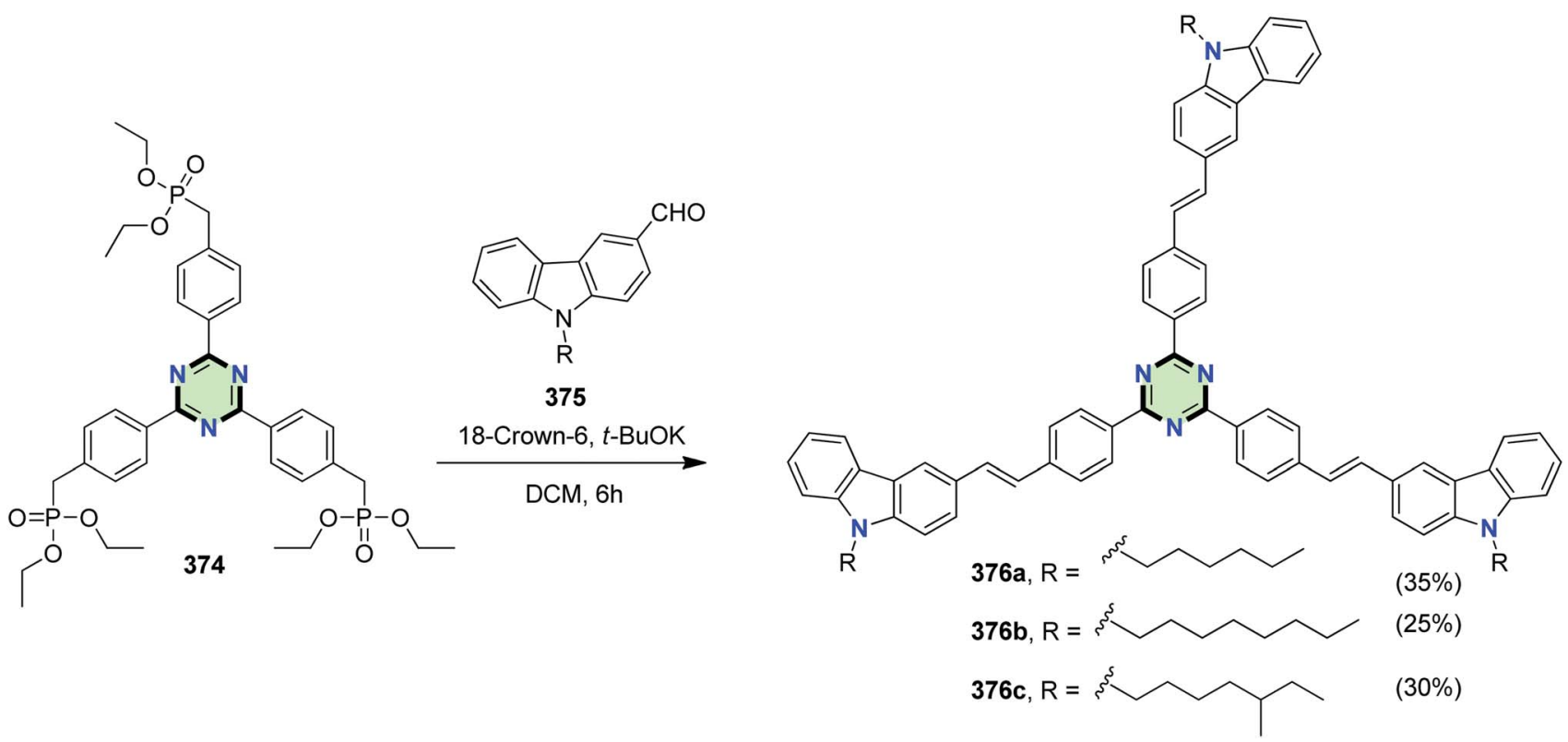

Scheme 102 Synthesis of SSMs 376a-c with 1,3,5-triazine core linked to three carbazole units. 

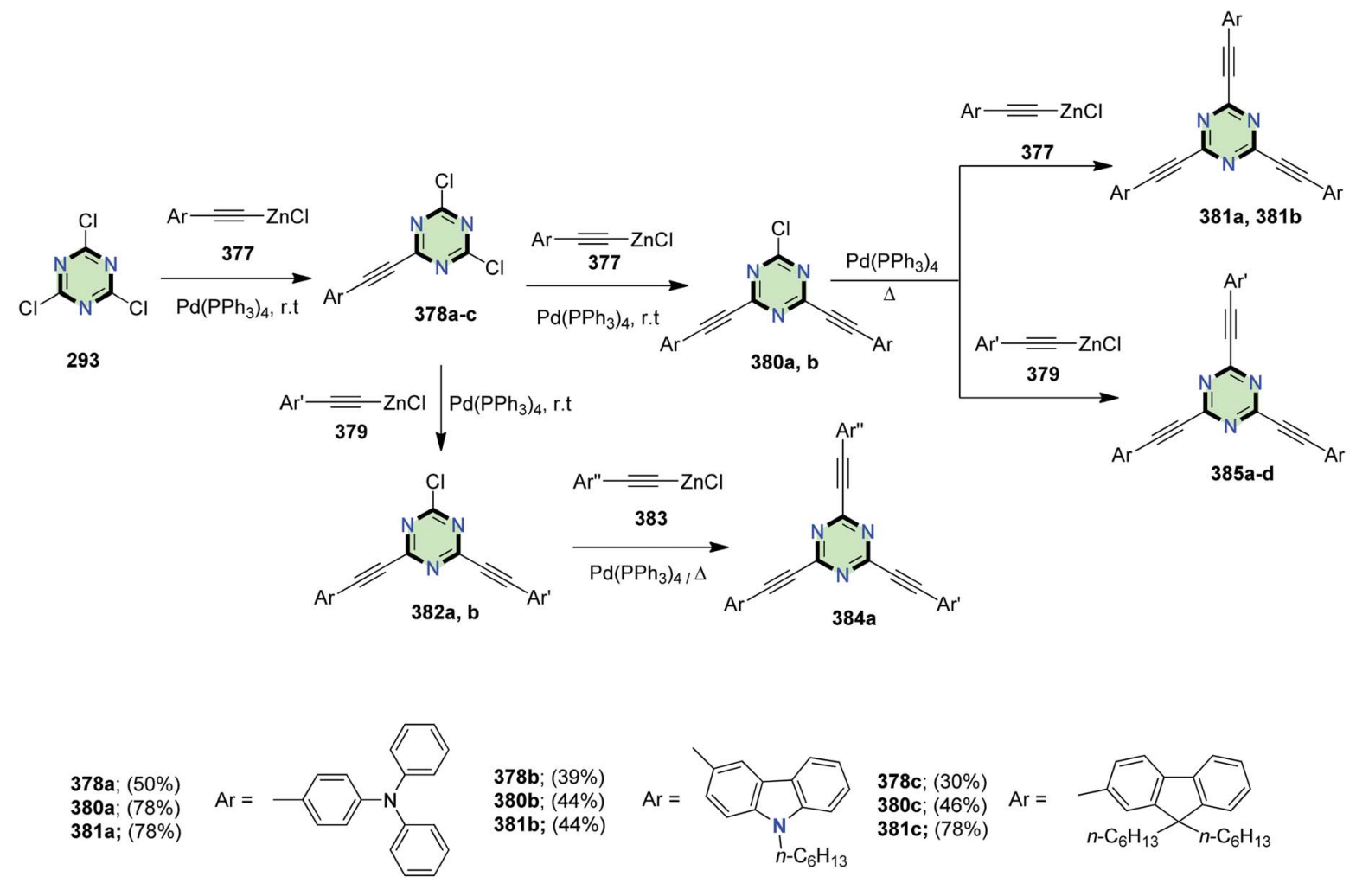<smiles>Cc1ccc(N(c2ccccc2)c2ccccc2)cc1</smiles><smiles>Cc1ccc2c(c1)c1ccccc1n2[14CH2][14CH2]</smiles><smiles>Cc1ccc(N(c2ccccc2)c2ccccc2)cc1</smiles><smiles>[Al]=[Ti]</smiles><smiles>CCCCCCC1(C)c2ccccc2-c2ccc(C)cc21</smiles>

385c; $(36 \%) \quad \mathrm{Ar}=$

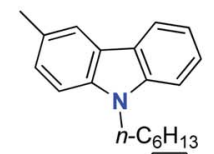

382a; $(46 \%) \mathrm{Ar}=$<smiles>Cc1ccc(N(c2ccccc2)c2ccncc2)cc1</smiles>
382c; $(45 \%) \mathrm{Ar}=$

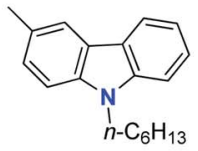

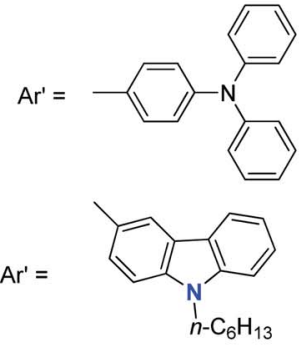

385d; (53\%) $\mathrm{Ar}=$

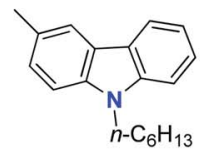
$\operatorname{Ar}^{\prime}=$<smiles>CCCCCCC1(C)c2ccccc2-c2ccc(C)cc21</smiles>
382b; (59\%) $\mathrm{Ar}=$<smiles>Cc1ccc(N(c2ccccc2)c2ccccc2)cc1</smiles>

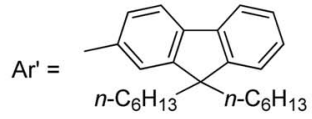

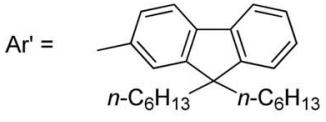

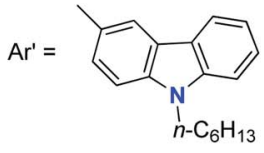<smiles>Cc1ccc(N(c2ccccc2)c2ccccc2)cc1</smiles>
$\operatorname{Ar"~=~}$<smiles>CCCCCC1(C)c2ccccc2-c2ccc(C)cc21</smiles>

Scheme 103 Synthesis of symmetrical and asymmetrical 2,4,6-tris(arylethynyl)-1,3,5-triazines.

4.3.3.11. Pyrimidine. Karimi et al. ${ }^{132}$ reported the synthesis of tri[bis(6-aminopyrimidinyl)methanes] 344-346 in good yields by reaction of the appropriate trisaldehydes $342 a-c$ with 6amino-1,3-dimethyluracil 343 using sulfuric acid functionalized silica-coated magnetic nanoparticles (SSA-MNPs) as a catalyst (Scheme 91).

4.3.3.12. 1,3-Diazabicyclo[3.1.0]hex-3-ene. Mahmoodi et al. ${ }^{133}$ reported the synthesis of star shaped molecules with 1,3diazabicyclo[3.1.0]hex-3-enes side arms 348 and 349 in $72 \%$ and 
<smiles>N#CC[N+]#N</smiles>

339
386

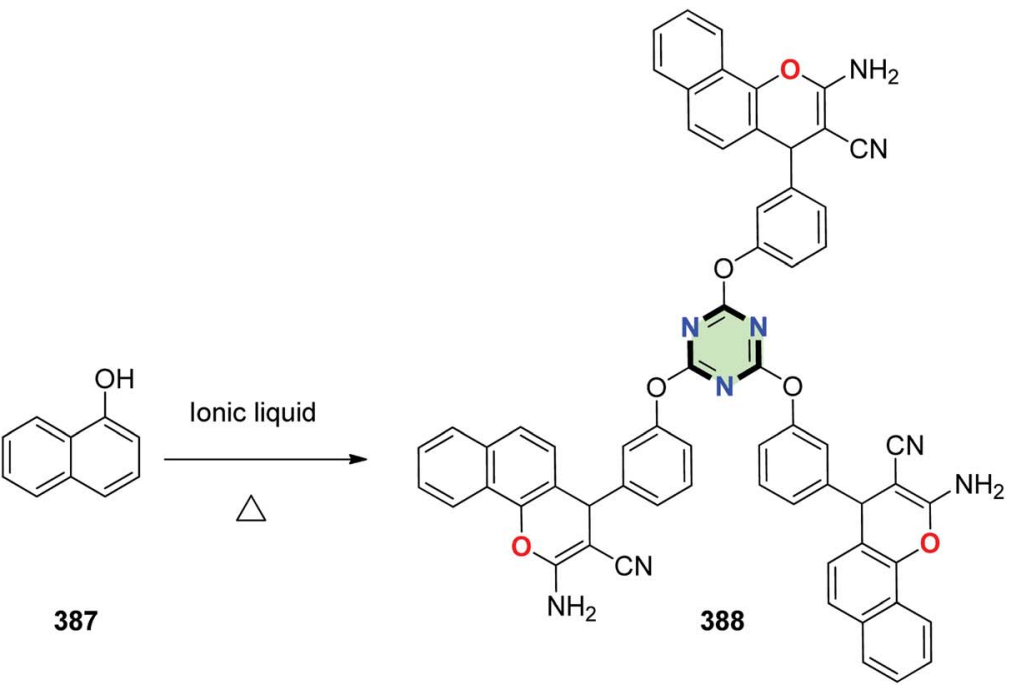

Scheme 104 Synthesis of tris(2-amino-4H-chromene) 388

$70 \%$ yields, respectively, through reaction of tris-aldehydes $\mathbf{2 8 8}$ and 339 with aziridinyl ketones $347 \mathbf{a}$ and $347 \mathbf{b}$, respectively, in dry EtOH in the presence of $\mathrm{AcONH}_{4}$ (Scheme 92).

4.3.3.13. Benzimidazole. A series of tripodal-benzimidazole derivatives 351a-d were synthesized in $63-74 \%$ yields by Schiff base reaction between 2,4,6-tris(p-formylphenoxy)-1,3,5triazine and $o$-phenylenediamine derivatives 350a-d in the presence of $\mathrm{NaHSO}_{3}$ (Scheme 93). ${ }^{134}$

2,4,6-Tris(4-(di(indol-3-yl)methyl)phenoxy)-1,3,5-triazines 353 and 355 were prepared in good yields by the Friedel-Crafts reaction of tris-aldehyde 288 with each of $1 H$-indole 352 and 1methyl- $1 H$-indole 354, respectively, in acetonitrile in the presence of silica sulfuric acid (Scheme 94). ${ }^{7,10}$

On the other hand, Shiri et al. ${ }^{135}$ reported the synthesis of 2,4,6-tris(3-(bis(3-methyl-1H-indol-2-yl)methyl)phenoxy)-1,3,5triazine 357 in good yields by Friedel-Crafts reaction of 3methyl- $1 H$-indole 356 with tris-aldehyde 339 catalyzed by silica sulfuric acid in acetonitrile (Scheme 95).

4.3.3.14. Dihydrotetrazolo[1,5-a]pyrimidine. Vaghei et al. ${ }^{136}$ reported the synthesis of tris-dihydrotetrazolo[1,5- $a]$ pyrimidines $360 \mathrm{a}$ and $360 \mathrm{~b}$ in $85 \%$ and $92 \%$ yield, respectively, through a multi-component reaction between tris-aldehyde 288, acetophenone derivatives $\mathbf{3 5 9}$ and 5-aminotetrazole $\mathbf{3 5 8}$ under solvent free conditions (Scheme 96).

4.3.3.15. 2,3-Dihydrothieno[3,4-b][1,4]dioxine. 2,4,6-Tris(2,3dihydrothieno[3,4- $b][1,4]$ dioxin-5-yl)-1,3,5-triazine 362 was synthesized in $90 \%$ yield by Stile coupling reaction between cyanuric chloride 293 and tributyl(2,3-dihydrothieno[3,4-b][1,4] dioxin-5-yl)stannane 361 in the presence of $\operatorname{Pd}\left(\mathrm{PPh}_{3}\right)_{4}(\mathrm{Scheme}$ 97). ${ }^{123}$

A star-shaped molecule with triazine core linked to thieno $[3,4-b][1,4]$ dioxine via thiophene moiety 363 was synthesized in $83 \%$ yield by the reaction of 2,4,6-tris(5-bromothiophen-2-yl)1,3,5-triazine 303 with tributyl(2,3-dihydrothieno[3,4-b][1,4] dioxin-5-yl)stannane 361 under similar conditions (Scheme 98). ${ }^{123}$ The effect of conjugation persisted in compounds 362 and 363. It was shown that increasing the number of thiophene moieties led to a remarkable red shift in their UV-vis absorption spectra and a decrease in their oxidation potential as evident from cyclic voltammetry.

4.3.3.16. Quinoline. Star-shaped conjugated molecules with quinolone side arms 367 and 368 were synthesized in good

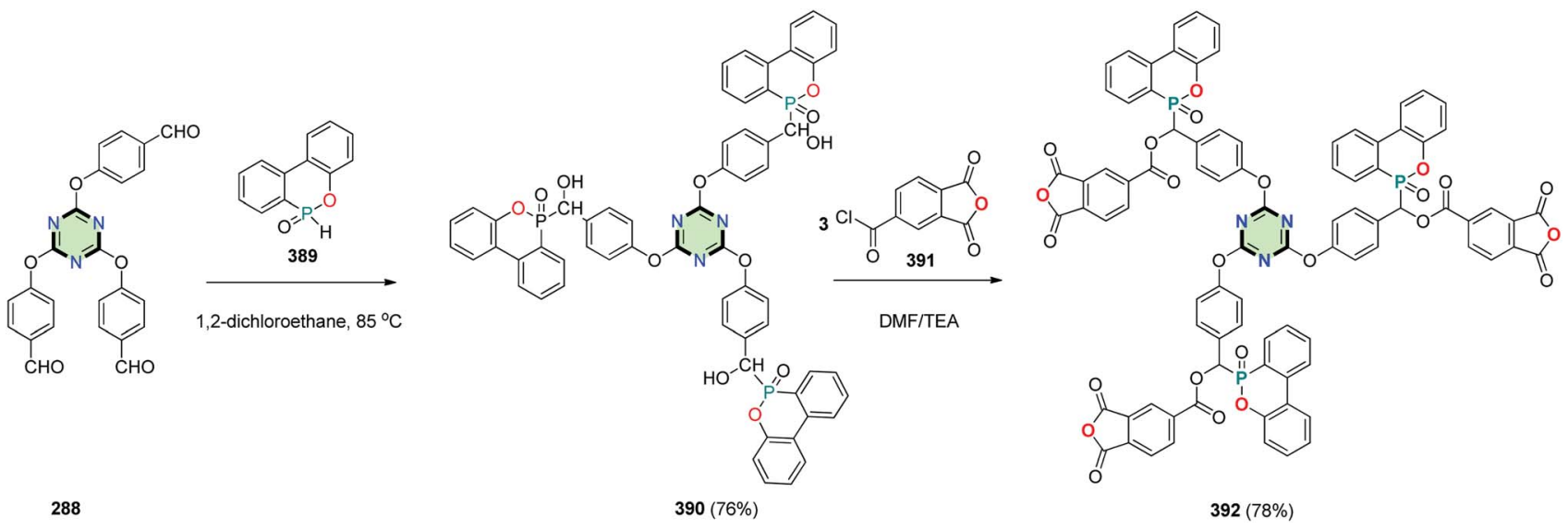

Scheme 105 Synthesis of tri(phosphaphenanthrenemethylphenoxyl)-1,3,5-triazine 390 and 392. 
<smiles>O=C1C=CC(=O)N1c1ccc(Oc2nc(Oc3ccc(N4C(=O)C=CC4=O)cc3)nc(Oc3ccc(N4C(=O)C=CC4=O)cc3)n2)cc1</smiles><smiles>C[R5](C)(C)C(C)(C)C</smiles>

Scheme 106 Synthesis of tris(3-(6-oxido-6H-dibenzo[c,e][1,2]oxaphosphinin-6-yl)pyrrolidine-2,5-dione) 394.

yields, using Suzuki coupling reaction of the appropriate boronic acid 364 with 5-bromo-8-methoxyquinoline 365 or 5bromo-8-methoxy-2-methylquinoline 366 in the presence of $\mathrm{Na}_{2} \mathrm{CO}_{3}$ and $\mathrm{Pd}\left(\mathrm{PPh}_{3}\right)_{4}$ (Scheme 99). ${ }^{112}$

Karatas and Ucan reported a synthesis of a tripodal Schiff base molecule with triazine core and quinoline side arms 370 in $70 \%$ yield through reaction of 5-aminomethyl-8hydroxylquinoline 369 with 2,4,6-tris( $p$-formylphenoxy)-1,3,5triazine 288 in the presence of acidic catalyst (Scheme 100). ${ }^{137}$

4.3.3.17. Coumarin.

Tris[bis(4-hydroxycoumarinyl) methanes] 373a-c were synthesized by condensation of 4hydroxy-2H-coumarin-2-one 372 with the appropriate trisaldehydes 288,339 or 371 . The reaction proceeded using alkanedisulfamic acid-functionalized silica-coated magnetic nanoparticles (ADSA-MNPs) as a catalyst (Scheme 101). ${ }^{138}$
4.3.3.18. Carbazole. Star-shaped molecules with 1,3,5triazine core linked to three carbazole units via ethenyl linkage 376a-c were synthesized in 35,25 and $30 \%$ yields via WittingHorner coupling reaction between the appropriate carbazole-3carbaldehydes 375 and 2,4,6-tris[4-(diethylphosphonomethyl) phenyl]-1,3,5-triazine 374 in the presence of $t$-BuOK (Scheme 102). The star-shaped molecules showed high optical properties, efficient fluorescence, AIE properties and also provide useful information for the further design of OLEDs and solar cell materials. ${ }^{139}$

Symmetrical and asymmetrical star-shaped 2,4,6tris(arylethynyl)-1,3,5-triazine 378a-c, 380a,b, 381a,b, 282a,b, 384a and 385a-d containing triphenylamine, fluorene, and/or carbazole moieties were synthesized in moderate yields (36$53 \%$ ) via step-by-step Negishi reactions of 2,4,6-trichloro-1,3,5-

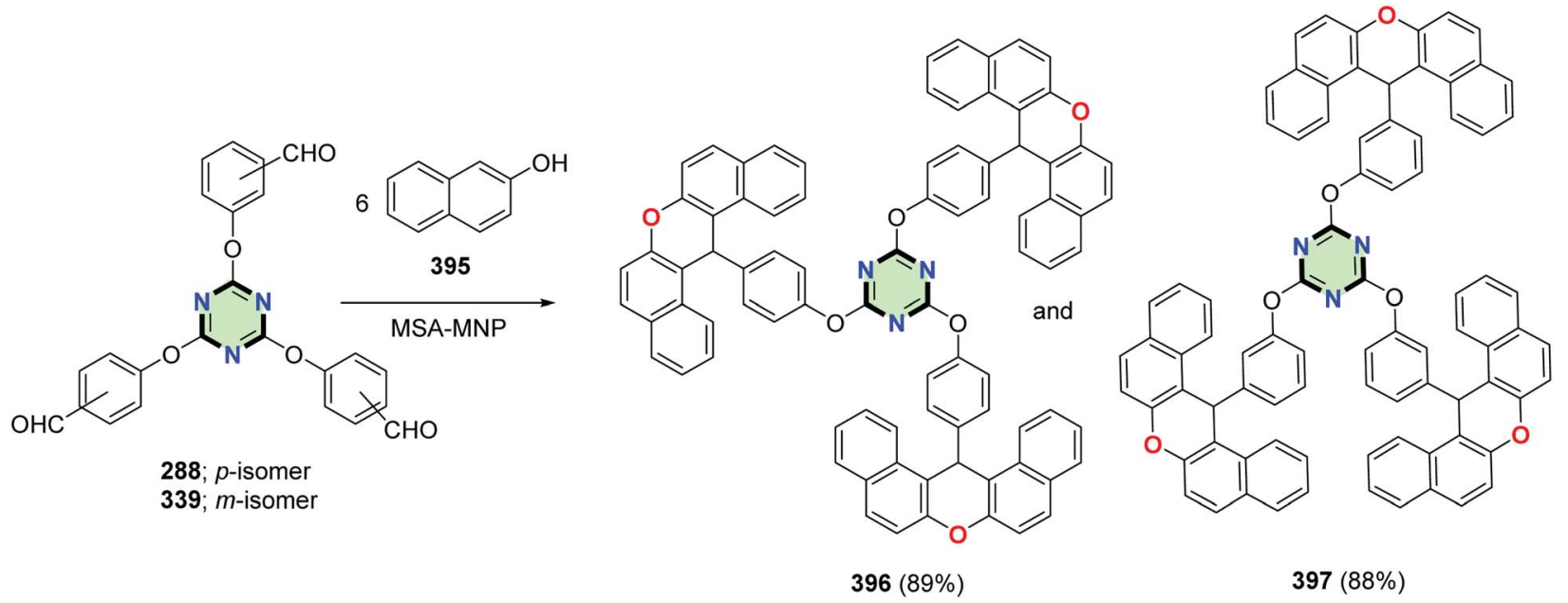

Scheme 107 Synthesis of tris-14H-dibenzo[a,j]xanthen-14-ylarenes 396 and 397. 

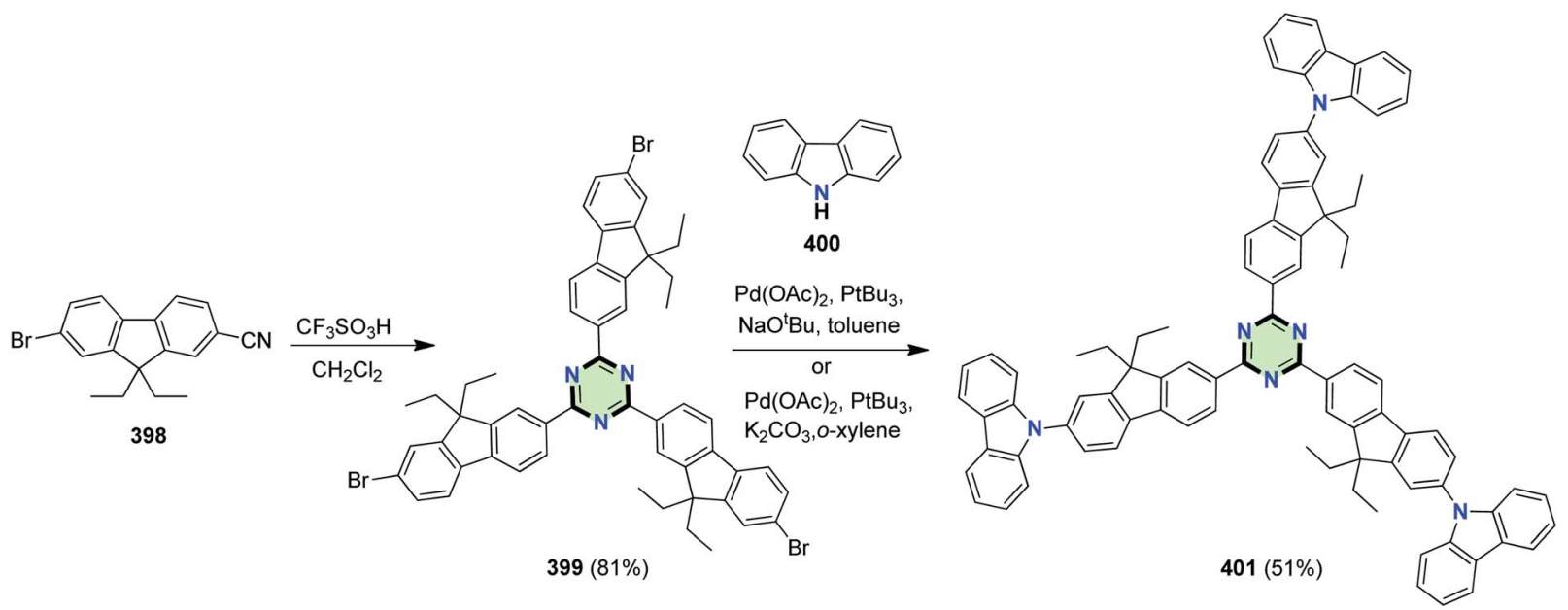

Scheme 108 Synthesis of SSM 401 containing triazine core and fluorine-carbazole arms.

triazine 293 with the appropriate arylethynylzinc chloride $\mathbf{3 7 7}$, 379 or 383 in the presence of $\mathrm{Pd}\left(\mathrm{PPh}_{3}\right)_{4}$ (Scheme 103). ${ }^{\mathbf{1 4 0}}$

4.3.3.19. 4H-Benzo[h]chromene. Tris(2-amino-4H-chromene) 388 has been developed using the reaction between tris(aldehyde) 339, malononitrile 386 and $\alpha$-naphthol 387 in the presence of $3,3^{\prime}$-(pentane-1,5-diyl)bis(1,2-dimethyl- $1 H^{-}$ imidazol-3-ium)bromide. The present methodology offers several advantages such as solvent-free conditions, excellent yields, simple procedure, mild conditions and reuse of the recovered ionic liquid (Scheme 104). ${ }^{\mathbf{1 4 1}}$

4.3.3.20. 6H-Dibenzo[c,e][1,2]oxaphosphinine 6-oxide. Tri(phosphaphenanthrenehydroxylmethylphenoxyl)-1,3,5triazine 390 was synthesized in $76 \%$ yield by the reaction of 2,4,6-tris( $p$-formylphenoxy)-1,3,5-triazine 288 with $6 H$ dibenzo[c,e][1,2] oxaphosphinine 6-oxide 389. ${ }^{\mathbf{1 4 2 , 1 4 3}}$ Reaction of 390 with 4-chloroformylphthalic anhydride 391 in DMF in the presence of TEA afforded SSM with triazine core and (6oxido-6H-dibenzo[c,e][1,2] oxaphosphinin-6-yl)methyl 1,3dioxo-1,3-dihydroisobenzofuran-5-carboxylate side arm 392 in $78 \%$ yield (Scheme 105). ${ }^{6}$

Tris(3-(6-oxido-6H-dibenzo[c,e][1,2] oxaphosphinin-6-yl) pyrrolidine-2,5-dione) linked to 1,3,5-triazine core 394 was prepared in $81 \%$ yield by the reaction of tris( $1 H$-pyrrole-2,5dione) 393 with $6 H$-dibenzo[ $c, e][1,2]$ oxaphosphinine-6-oxide 389 in diglyme (Scheme 106). ${ }^{\mathbf{1 4 4}}$

4.3.3.21. 14H-Dibenzo[a,j]xanthen. Tris-14H-dibenzo[a,j] xanthen-14-ylarenes 396 and 397 were synthesized in 89\% and $88 \%$ yields, respectively, by reacting 2-naphthol 395 with tris-aldehydes 288 and 339, respectively, under solvent free conditions using magnetite-sulfuric acid $\left(\mathrm{Fe}_{3} \mathrm{O}_{4} \cdot \mathrm{SO}_{3} \mathrm{H}\right)$ nanoparticles as a catalyst (Scheme 107). ${ }^{\mathbf{1 4 5}}$

\subsubsection{Miscellaneous arms}

4.3.3.22.1. Fluorene linked to carbazole, phenoxazine or phenothiazine. Omer et al. ${ }^{\mathbf{1 4 6}}$ reported the synthesis of C3symmetrical SSM 401 in a two-step procedure. The reaction starts with trifluoromethanesulfonic acid-catalyzed trimerization of 7-bromo-9,9-diethylfluorene-2-carbonitrile 398 to form triazine derivative 399 in $81 \%$ yield, followed by $\mathrm{C}-\mathrm{N}$ cross-coupling reaction with $9 H$-carbazole 400 to give 401 in
51\% yield (Scheme 108). Compound 401 with electronaccepting triazine core bridged by fluorene linked to electron-donating carbazolyl groups showed a high fluorescent activity. The carbazole moiety undergoes dimerization during the electrochemical oxidation producing a polymer film on the electrode surface which exhibits electrochromic behavior. ${ }^{\mathbf{1 4 6}}$

By analogy, a series of 1,3,5-triazine derivatives peripherally decorated with fluorene ring linked to carbazole 406, phenoxazine $\mathbf{4 0 8}$ or phenothiazine $\mathbf{4 1 0}$ moieties were designed and synthesized by Liu et al. ${ }^{\mathbf{1 4 7}}$

The reactions proceeded via initial cyanation of 2-bromo9,9-dihexyl-7-iodo-9H-fluorene $\mathbf{4 0 2}$ upon treatment with CuCN in the presence of Pd catalyst to give 7-bromo-9,9dihexyl-9H-fluorene-2-carbonitrile 403 Trifluoromethanesulfonic acid-catalyzed trimerization of $\mathbf{4 0 3}$ led to the formation of triazine derivative 404. Subsequent $\mathrm{C}-\mathrm{N}$ cross-coupling reaction with the appropriate $\mathrm{N}$ heterocyclic compounds 405, 407 and 409 yielding SSMs 406, 408 and 410, respectively, in good yields (Scheme 109).

The carbazolyl-, phenoxazinyl- and phenothiazinylgroups were selected as electron-donating substituents, which would not only extend the $\pi$-conjugation, but also build the donor- $\pi$-acceptor $(\mathrm{D}-\pi-\mathrm{A})$ architectures in the target molecules. Fluorenyl units are commonly used as building blocks in two-photon absorption (TPA) molecules, on which alkyl chains were introduced to reduce the intermolecular aggregation and consequently improve the solubility. In addition, termination by the $\mathrm{N}$-heterocyclic aromatic chromophores, which can rotate around the triazine-fluorene core, may causes aggregation-induced emission (AIE) feature based on the mechanism of restriction of intramolecular rotation (RIR). These compounds exhibit intense fluorescence, AIE and TPA features.

4.3.3.22.2. Di(thiophen-2-yl)ethene linked to triphenylamine or carbazole. 1,3,5-Triazine centered star-shaped molecules with thienylvinylene arms 413 and 415 connected to structurally similar triphenylamine or carbazole end group were 


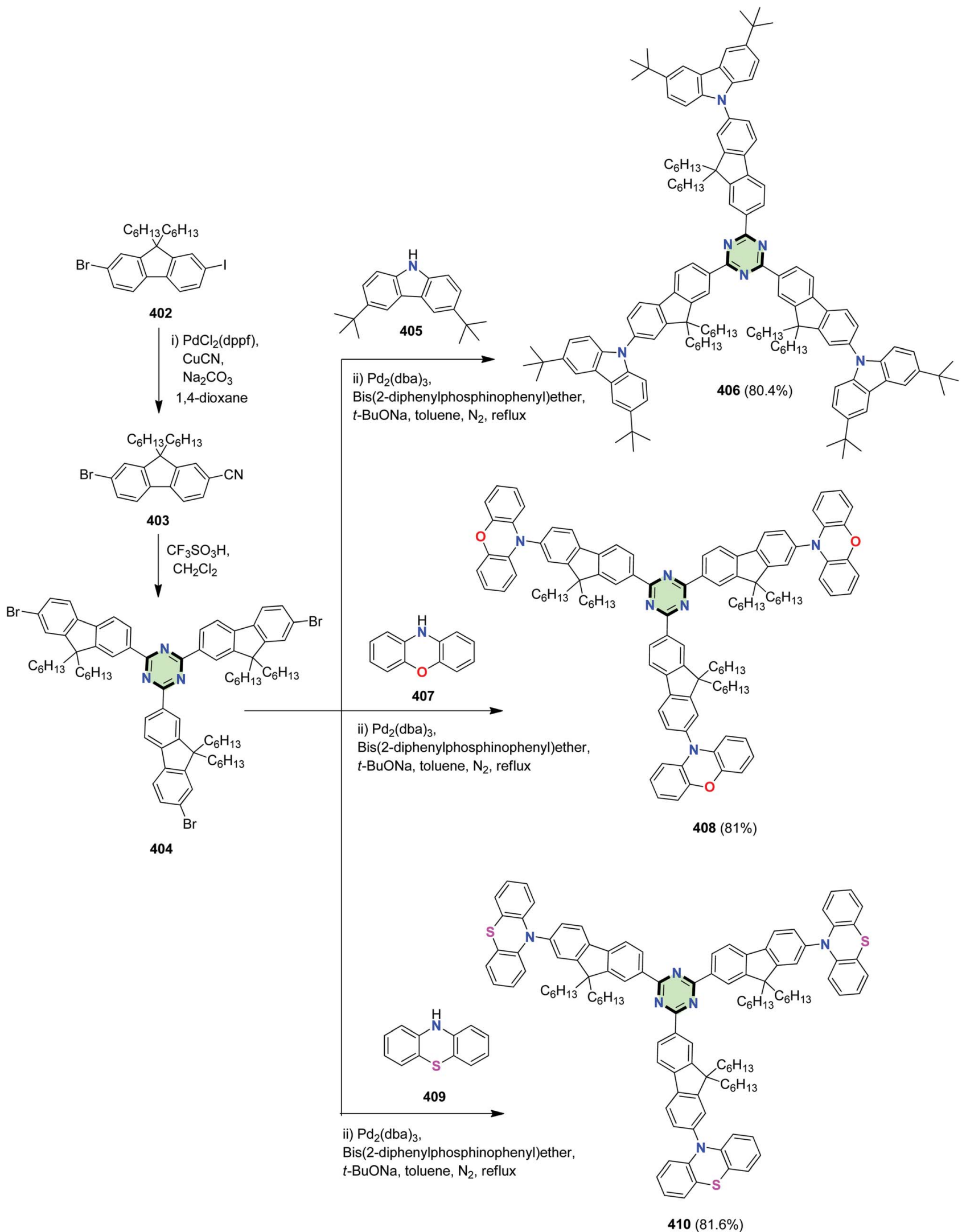

Scheme 109 Synthesis of SSMs with 1,3,5-triazine core with fluorene ring linked to carbazole 406, phenoxazine 408 and phenothiazine 410 


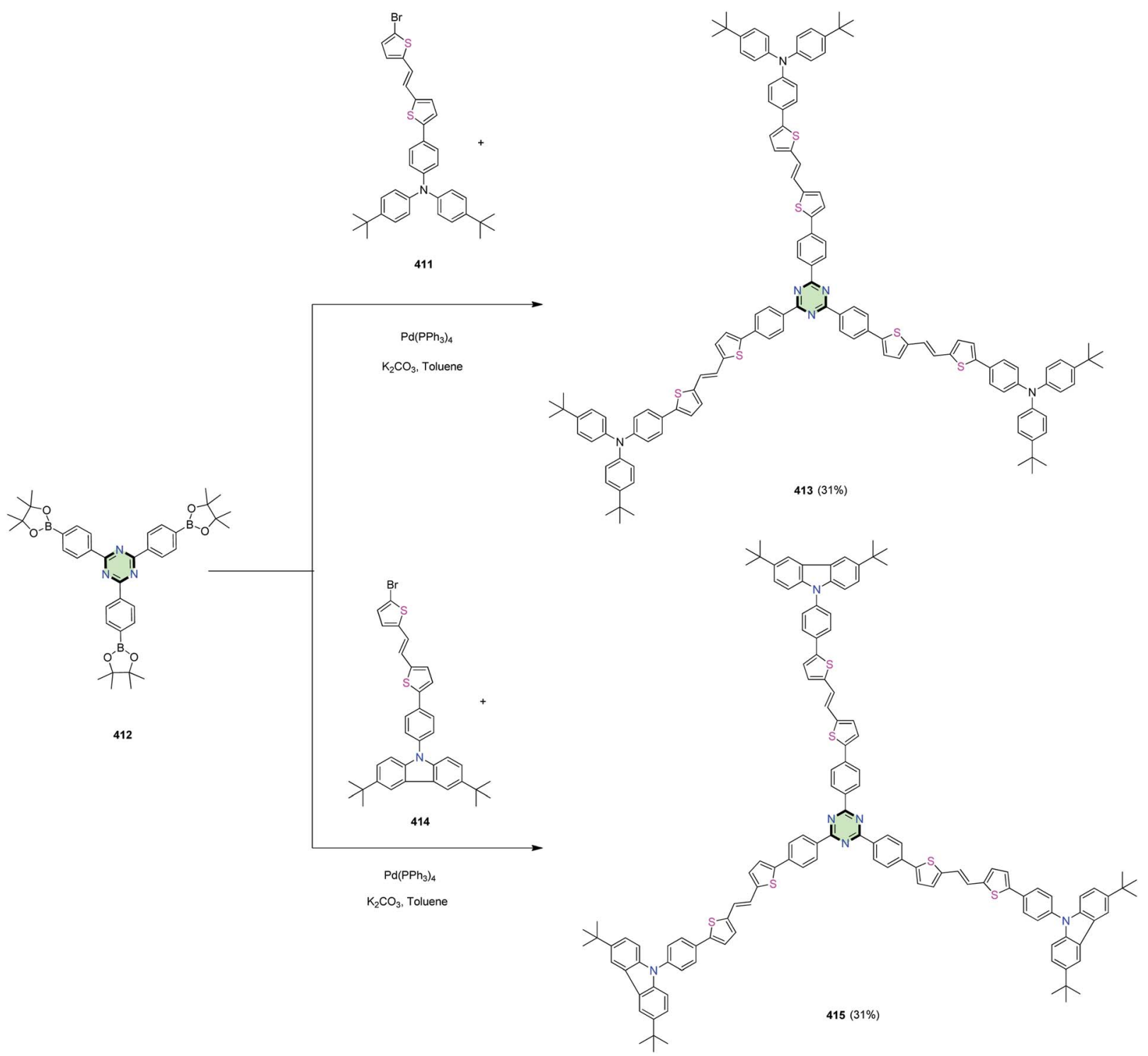

Scheme 110 Synthesis of SSMs with thienylvinylene arms connected to triphenylamine 413 or carbazole 415.

synthesized by Huang et al. ${ }^{\mathbf{1 4 8}}$ via Suzuki coupling reaction of 2,4,6-tris-boronic acid ester $\mathbf{4 1 2}$ with the appropriate bromo compounds $\mathbf{4 1 1}$ and $\mathbf{4 1 4}$, respectively, in the presence of $\mathrm{Pd}\left(\mathrm{PPh}_{3}\right)_{4}$ (Scheme 110). ${ }^{\mathbf{1 4 8}}$

4.3.3.22.3. Diketopyrrolo[3,4-c]pyrrole linked to triphenylamine, thiophene and/or carbazole. Shiau et al. ${ }^{\mathbf{1 4 9}}$ reported the synthesis of a series of star-shaped molecules with triazinecore 417, 419 and 421 in 69, 70 and 68\% yields, as a donor materials for organic solar cells, through Suzuki coupling reaction of tris(4-(4,4,5,5-tetramethyl-1,3,2-dioxaborolan-2yl)phenyl)-1,3,5-triazine $\mathbf{4 1 2}$ with the appropriate bromo derivatives 416, 418 and 420, respectively, in the presence of $\mathrm{Pd}\left(\mathrm{PPh}_{3}\right)_{4}$ in refluxing toluene (Schemes 111-113).

4.3.4. Miscellaneous heterocyclic-cored SSMs with different arms

4.3.4.1. Thieno[3,2-b]thiophene. Magnan et al. ${ }^{113}$ reported the synthesis of star shaped molecules 424 and 427 in 63 and
$62 \%$ yields, respectively, by fourfold Negishi coupling between tetrabromothieno[3,2- $b]$ thiophene 422 with each of 2-hexylthiophene $\mathbf{4 2 3}$ and 2-hexylthieno[3,2- $b$ ] thiophene $\mathbf{4 2 6}$. Subsequent oxidative cyclodehydrogenation of the latter compounds using anhydrous ferric chloride gave tetra(5hexylthieno)benzothieno[3,2- $b]$ benzothiophene 425 and tetra(5-hexylthieno[3,2- $b]$ thieno)benzo thieno[3,2- $b]$ benzothiophene $\mathbf{4 2 8}$ in 30 and 53\% yield, respectively (Scheme 114).

4.3.4.2. Benzo[1,2-b:4,5- $\left.b^{\prime}\right]$ dithiophene. Sheng et al. ${ }^{150}$ reported the synthesis of a star shaped molecule with benzo[1,2$\left.b: 4,5-b^{\prime}\right]$ dithiophene core and terthiophene side arm 431 in good yield, by Stille coupling reaction between tributyl $\left(5,5^{\prime \prime}\right.$ didodecyl-[2,2' $: 3^{\prime}, 2^{\prime \prime}$-terthiophen]-5'-yl)stannane 430 with the dibromo compound 429 in the presence of $\mathrm{Pd}\left(\mathrm{PPh}_{3}\right)_{4}$ (Scheme 115). Compound 431 showed high thermal stability with decomposition temperature $\left(447^{\circ} \mathrm{C}\right)$, low-lying HOMO level 


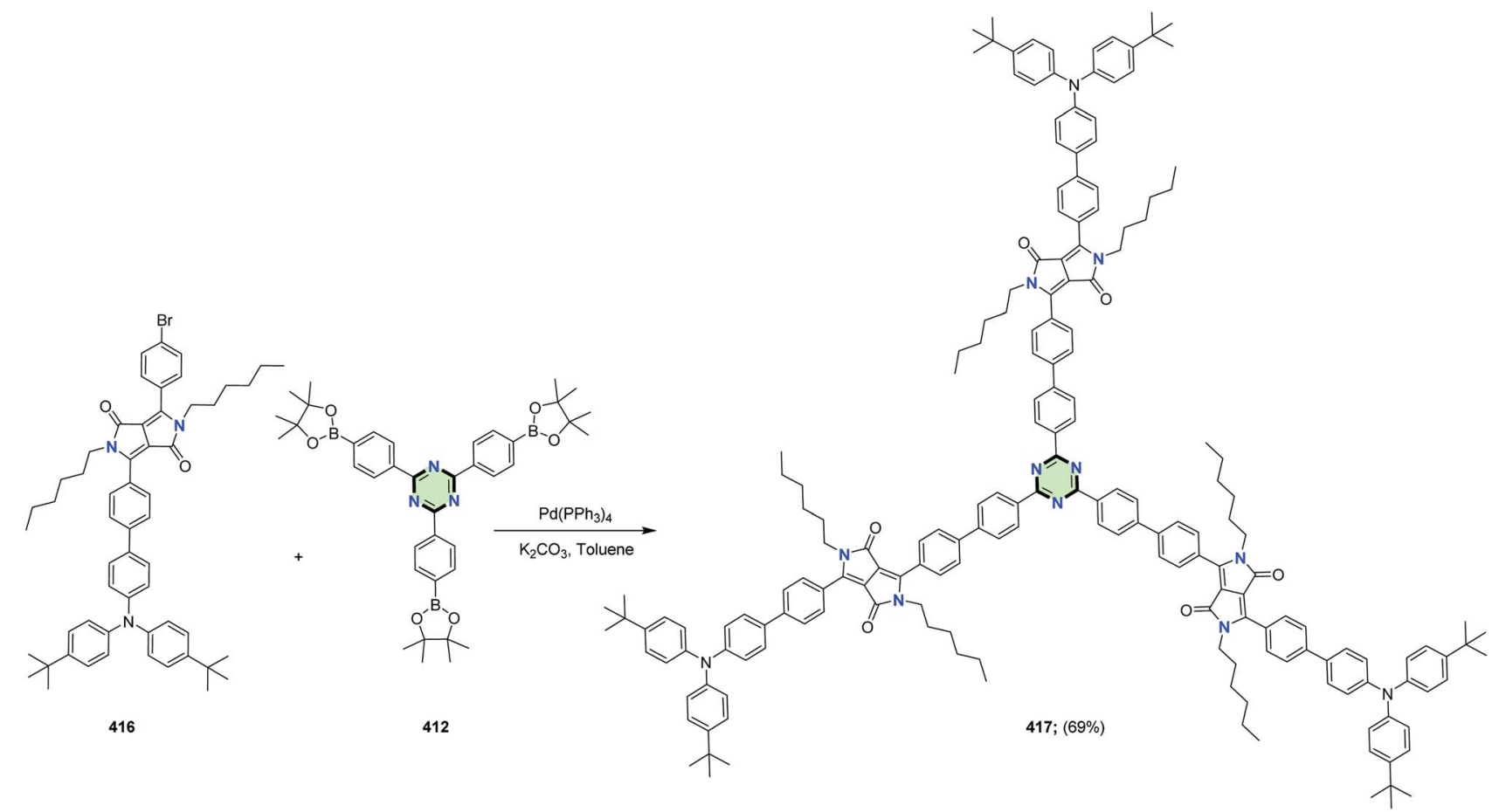

Scheme 111 Synthesis of SSM with triazine-core linked to diketopyrrolo[3,4-c]pyrrole and triphenylamine 417.

$(-5.52 \mathrm{eV})$, and wide UV-vis absorption between 300 and $530 \mathrm{~nm}\left(E_{\mathrm{g}}=2.36 \mathrm{eV}\right)$.

4.3.4.3. Benzo[1,2-b:4,5-b']difuran. The Suzuki crosscoupling reaction of 2,3,6-tris(4-bromophenyl)-4,8-didecyl-7- phenylbenzo[1,2- $\left.b: 4,5-b^{\prime}\right]$ difuran $\quad \mathbf{4 3 2}$ with 1,3,6,2dioxazaborocane-4,8-diones $\mathbf{4 3 3}$ afforded different SSMs with benzo[1,2-b:4,5- $\left.b^{\prime}\right]$ difuran core $\mathbf{4 3 4 a - c}$ in $37-99 \%$ yields (Scheme 116). ${ }^{151}$

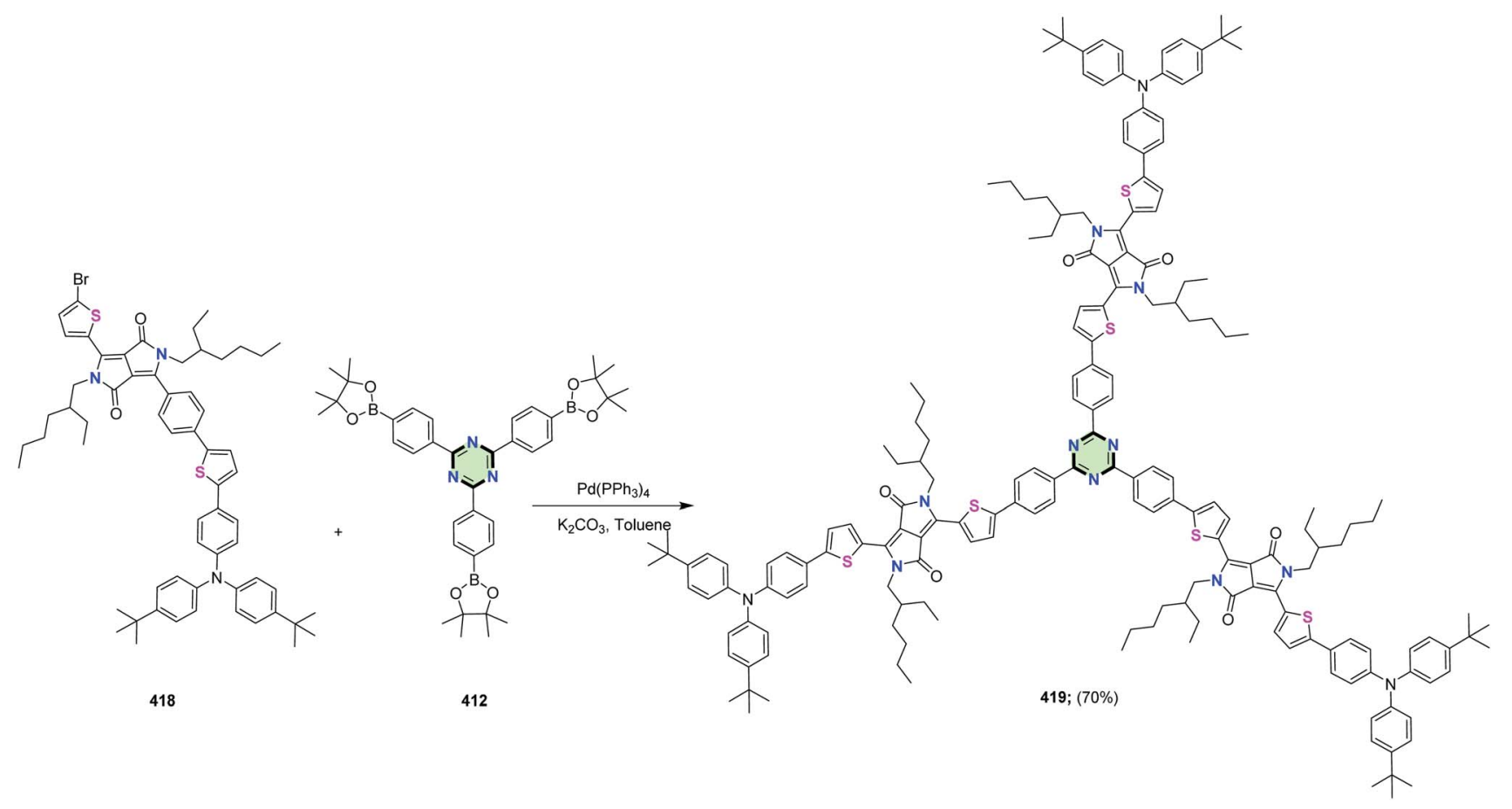

Scheme 112 Synthesis of SSM with triazine-core linked to diketopyrrolo[3,4-c]pyrrole and thiophene 419. 


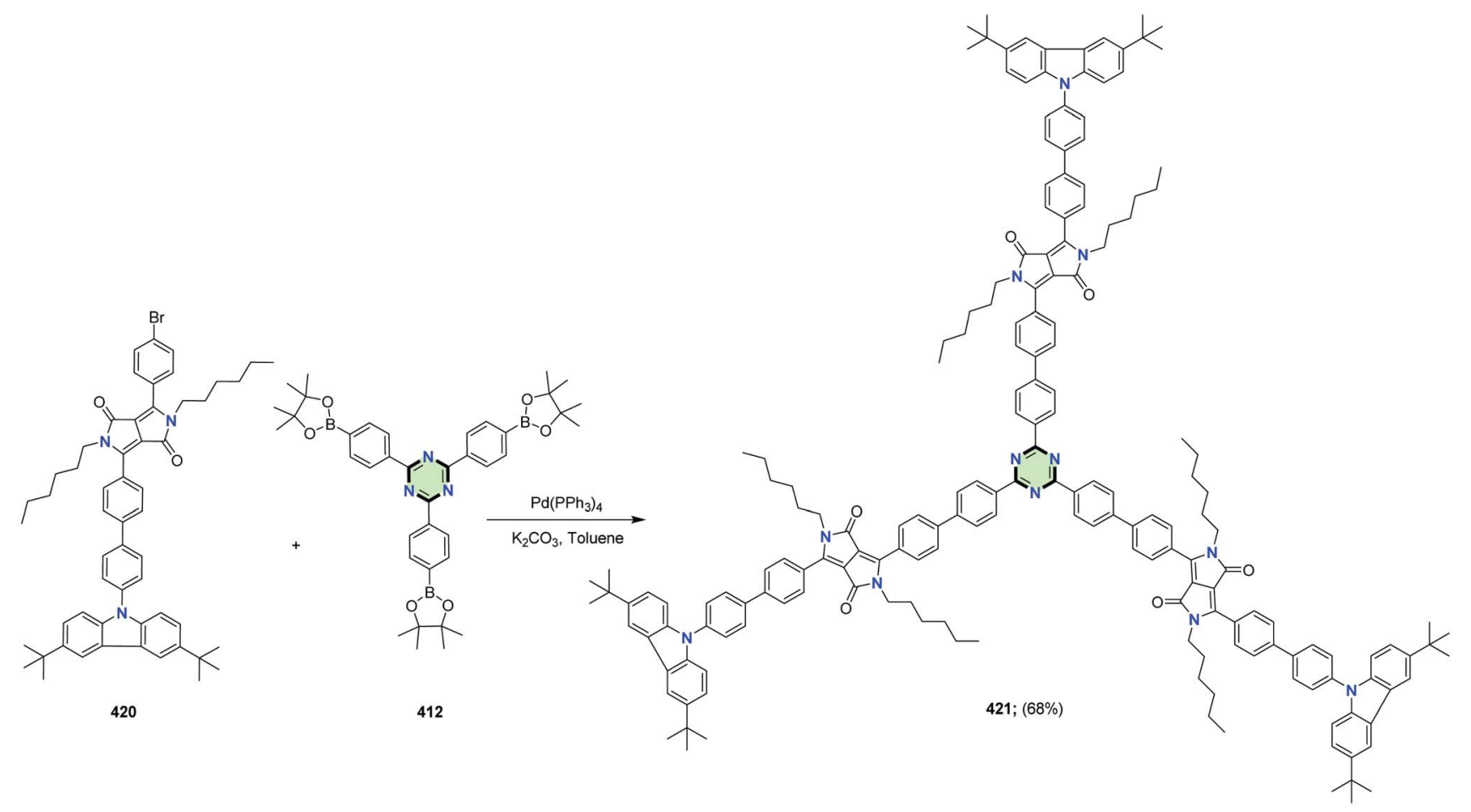

Scheme 113 Synthesis of SSM with triazine-core linked to diketopyrrolo[3,4-c]pyrrole and carbazole 421.

4.3.4.4. 9H-Carbazole. Tribromo compound 436 was obtained via the bromination of 9-(4-bromophenyl)-9H-carbazole 435 with $n$-bromosuccinimide. Lithiation of 436 followed by treatment with fluorodimesitylborane yielded SSM with carbazole core 437 (Scheme 117). The latter compound showed excellent thermal stability $\left(T_{\mathrm{d}}=234{ }^{\circ} \mathrm{C}\right)$, electrochemical stability and high $\Phi(0.95)$ as well as high triplet energy $(2.83 \mathrm{eV}){ }^{\mathbf{1 5 2}}$
4.3.4.5. Naphthothiophene. Tan et al. ${ }^{153}$ reported the synthesis of two molecules 440 and 442 having 4,9-di(thiophen-2-yl)naphtho $[2,3-b]$ thiophene core and diketopyrrolopyrrole arms 440 and 442 in $62 \%$ and $73 \%$ yields, respectively. The formation of the latter compounds proceeded through Stille coupling reaction of $\left(5,5^{\prime}\right.$ (6,7-dimethoxy-2-(trimethylstannyl)naphtha[2,3- $b]$ thiophene-4,9diyl)bis(thiophene-5,2-diyl))bis(trimethylstannane) 438 with each

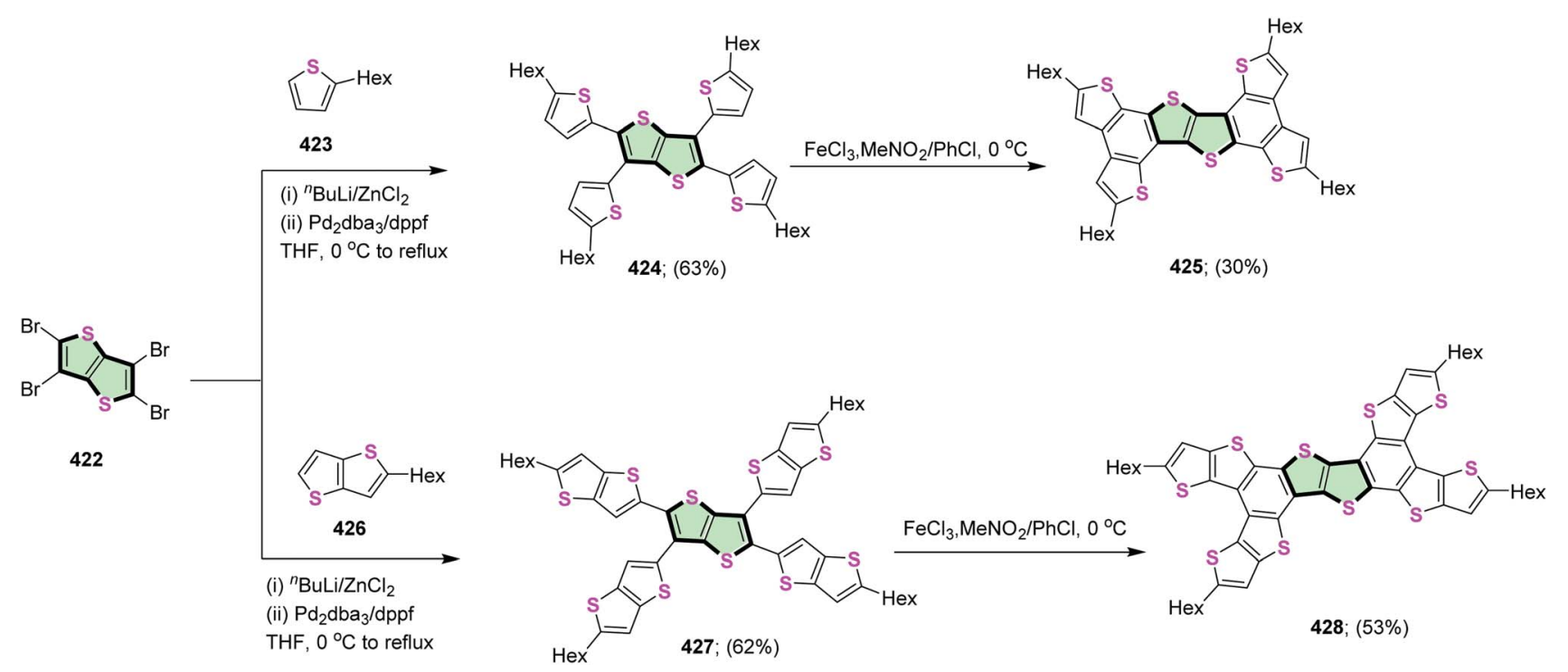

Scheme 114 Synthesis of SSMs 425 and 428 with thieno[3,2-b]thiophene core and their oxidized derivatives 425 and 428. 


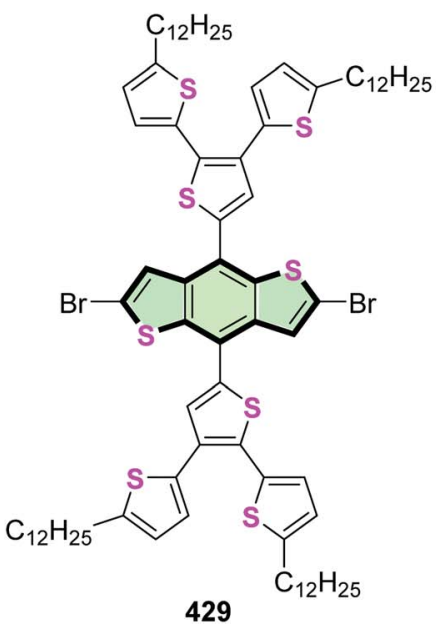

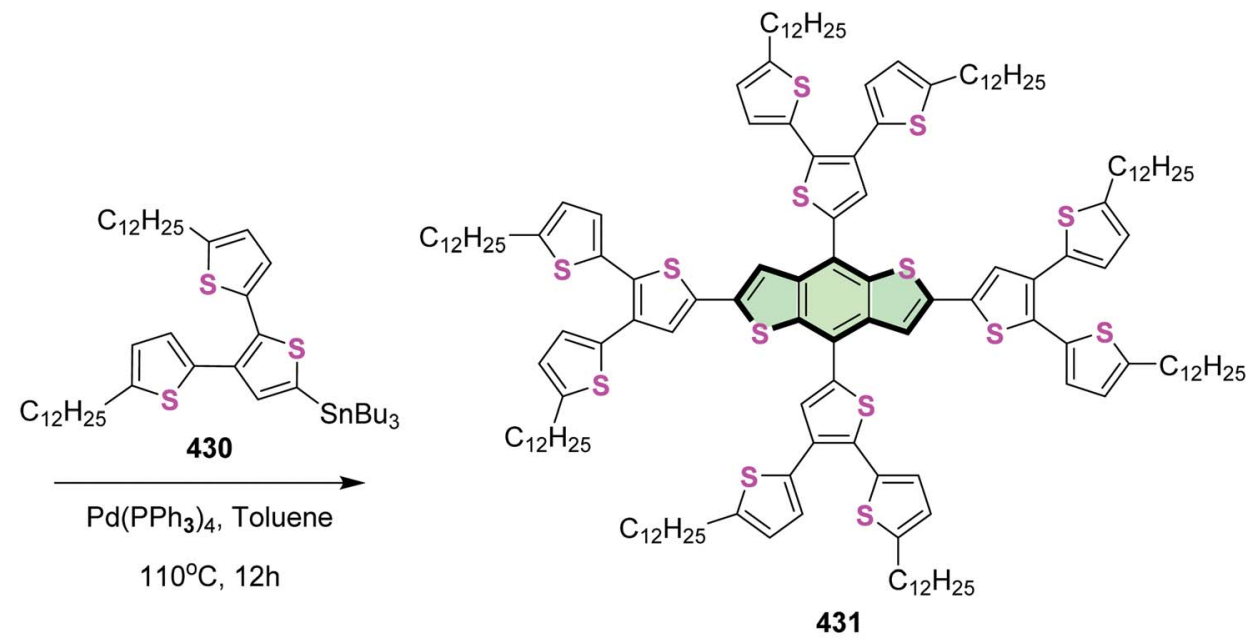

Scheme 115 Synthesis of SSMs with benzo[1,2-b:4,5- $\left.b^{\prime}\right]$ dithiophene core 431.<smiles>CCc1c2oc(-c3ccc(Br)cc3)c(-c3ccc(Br)cc3)c2c(C)c2oc(-c3ccc(Br)cc3)c(C(=O)c3ccccc3)c12</smiles>

432

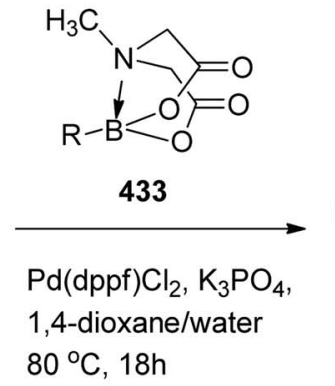

$80^{\circ} \mathrm{C}, 18 \mathrm{~h}$

Scheme 116 Synthesis of SSMs with benzo[1,2-b:4,5- $b^{\prime}$ ]difuran core $434 a-c$.
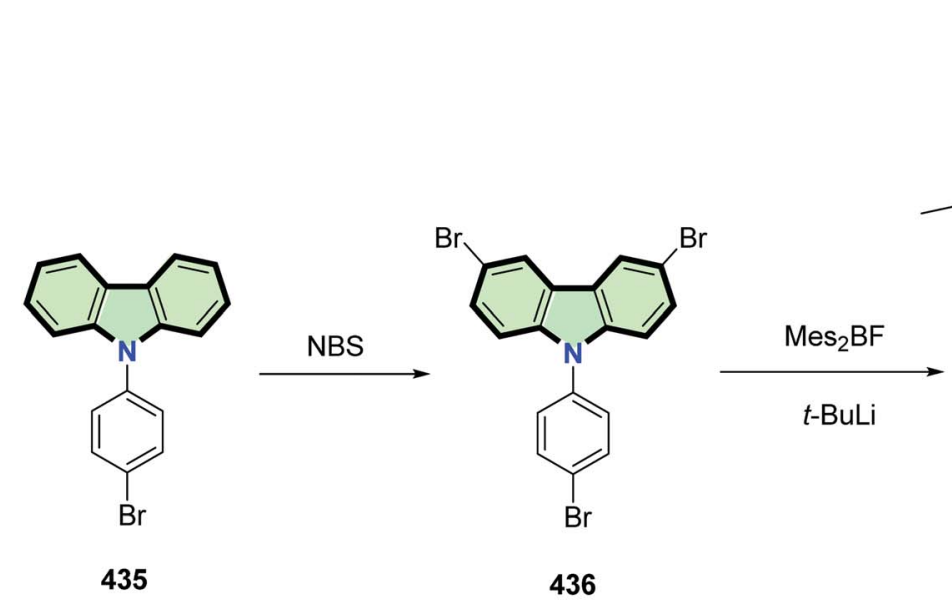

434a-c

$\mathrm{R}=4$-Pyridyl $\quad(42 \%)$

$\mathrm{R}=3$-Quinolinyl (99\%)

$\mathrm{R}=3$-Furyl

$(49 \%)$ 

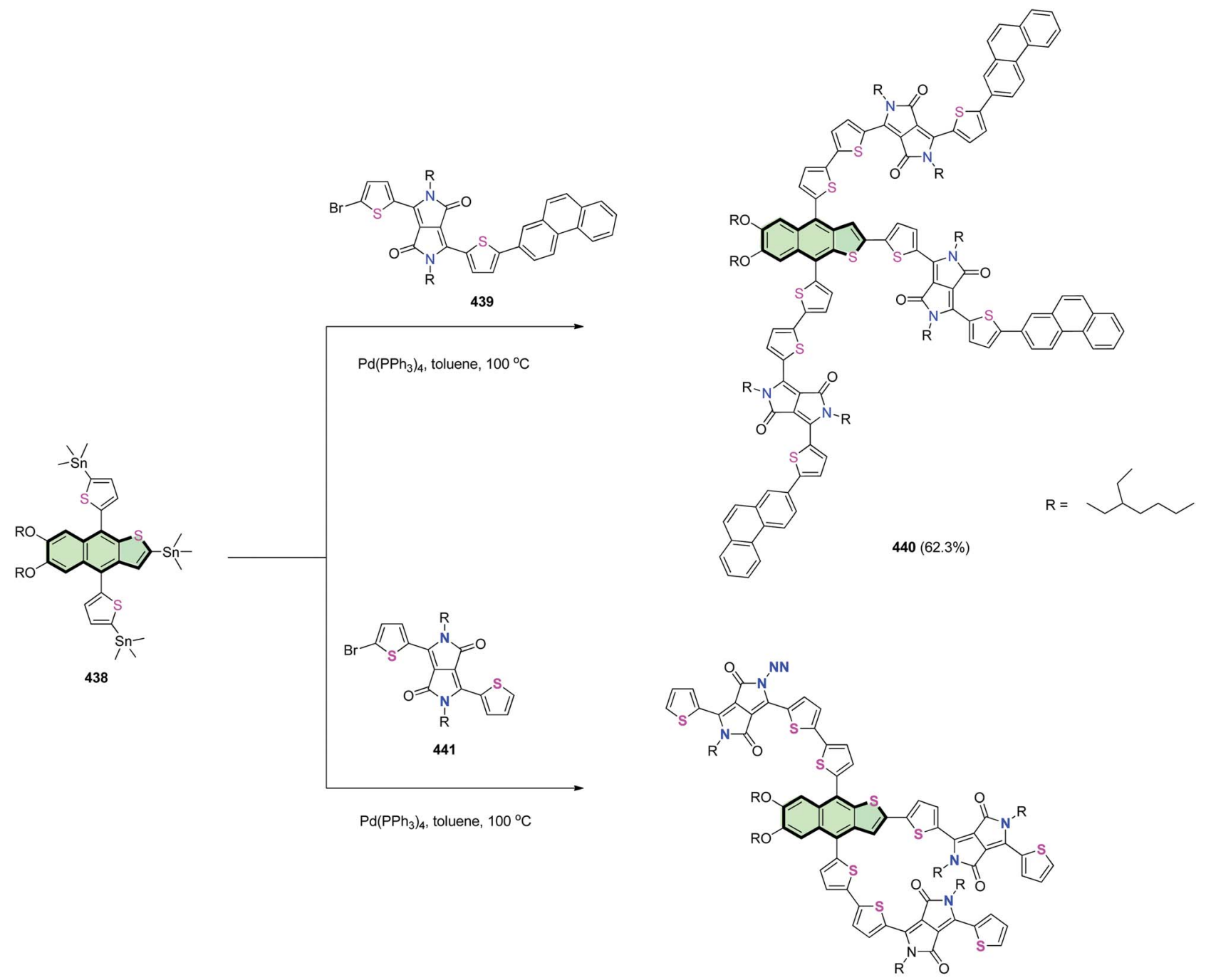

$442(73 \%)$

Scheme 118 Synthesis of SSMs with naphtho[2,3-b]thiophene core 440 and 442.

of 3-(5-bromothiophen-2-yl)-6-(5-(phenanthren-2-yl)thiophen-2-yl) pyrrolo[3,4-c]pyrrole-1,4(2H,5H)-dione 439 and 3-(5-bromothiophen-2-yl)-2,5-dimethyl-6-(thiophen-2-yl)pyrrolo[3,4-c]pyrrole1,4(2H,5H)-dione 441, respectively (Scheme 118). ${ }^{153}$

4.3.4.6. Benzo[1,2-b:3,4- $\left.b^{\prime}: 4,6-b^{\prime \prime}\right]$ trithiophene. Star-shaped molecule with benzotrithiophene core and diketopyrrolo[3,4-c] pyrrole unit arms 445 was synthesized in $47 \%$ yield via Stille coupling of 2,5,8-tris(trimethylstannyl)benzo[1,2- $\left.b: 3,4-b^{\prime}: 5,6-b^{\prime \prime}\right]$ trithiophene $\mathbf{4 4 3}$ with bromo(thieophen-2-yl)pyrrolo[3,4-c] pyrrole derivative 444 in the presence of $\mathrm{Pd}\left(\mathrm{PPh}_{3}\right)_{4}$ (Scheme 119). ${ }^{20,154}$

Similarly, Stille coupling of $\mathbf{4 4 3}$ with bromo derivatives 446a-c afforded SSMs with benzotrithiophene core and (oligo)thiophene-benzo[ $c][1,2,5]$ thiadiazole-thiophene side arms 447a-c in good yields (44-70\%) (Scheme 120). The starshaped molecule $447 \mathrm{c}$ with enlarged $\pi$-can be delocalization used in photovoltaic applications as increasing the number of thiophene connecting units elevates the HOMO energy level of the based molecule. ${ }^{155}$

4.3.4.7. Benzo[9,1]quinolizino[3,4,5,6,7-defg]acridine. Paek et al. ${ }^{156}$ managed to synthesize SSM 450 with benzo[9,1]quinolizino[3,4,5,6,7-defg]acridine core and trithiophene as a side arm via Suzuki coupling of the trithiophene boronic acid 448 with tribromo compound 449 in the presence of $\mathrm{Pd}\left(\mathrm{PPh}_{3}\right)_{4}$ (Scheme 121). Compound 450 with $\pi$-conjugated bridge undergoes photovoltaic performances in solutionprocessed organic solar cells OSCs.

Lim et al. ${ }^{157}$ reported the synthesis of SSM 453 which contain benzo[9,1]quinolizino[3,4,5,6,7-defg]acridine core and 4-(silylene-2,2'-bithiophen-5-yl)-7-(2,2', $2^{\prime \prime \prime}$-terthiophen-5yl)-[1,2,5]thiadiazolo[3,4-c]pyridine as a side arm via Stille coupling reaction of bromo compound 451 with 4,4,8,8,12,12-hexamethyl-2,6,10-tris(trimethylstannyl)-8,12dihydro-4H-benzo[1,9]quinolizino[3,4,5,6,7-defg]acridine 452 (Scheme 122). This star-shaped molecule has optical and 


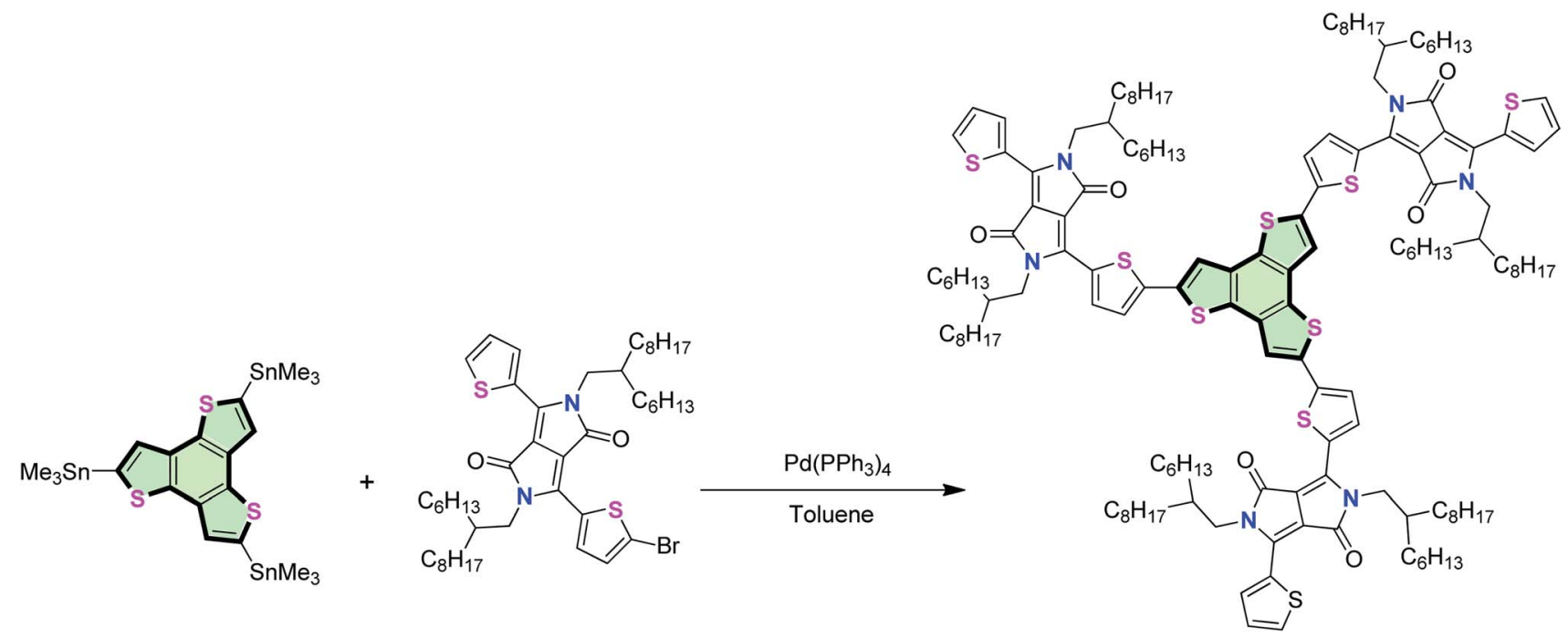

443

444

$445 ;(47 \%)$

Scheme 119 Synthesis of SSM with benzotrithiophene core 445

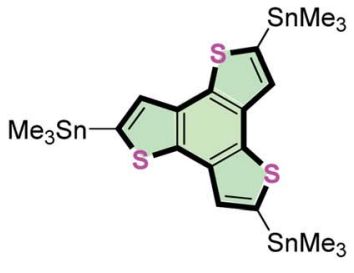

443
$\mathrm{R}=$ 2-hexyldecyl

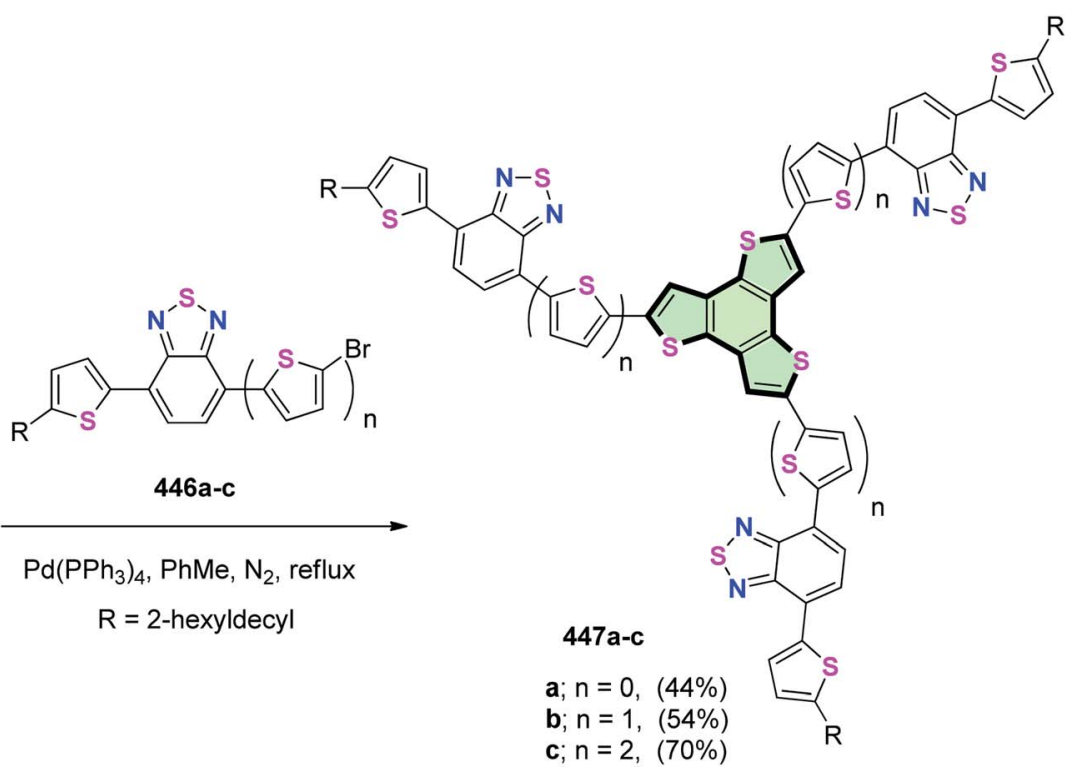

Scheme 120 Synthesis of SSMs with benzotrithiophene core 447 .

electrochemical properties and can be used as donor components in solution-processed organic solar cells.

4.3.4.8. Diindolo[3,2-a:3', $2^{\prime}$-c]carbazole. SSMs 456 and 458 with diindolo[3,2-a:3',2'-c]carbazole core were synthesized in $85 \%$ and $84 \%$ yields by Shao et al. ${ }^{158}$ via the Horner-Wadsworth-Emmons reaction of the trialdehyde 454 with phosphonate esters 455 and 457, respectively (Scheme 123).

$2,2^{\prime}, 2^{\prime \prime}-\left(\left(5,5^{\prime}, 5^{\prime \prime}-((5,10,15\right.\right.$-Tridodecyl-10,15-dihydro-5H-diindolo [3,2-a:3', $\left.2^{\prime}-c\right]$ carbazole-3,8,13-triyl)tris(ethene-2,1-diyl))tris(thiophene-5,2-diyl))tris(ethene-2,1-diyl))tris(benzo[d]thiazole) 462 was synthesized in $82 \%$ yield by Shao et al. ${ }^{158}$ via the Horner-
Wadsworth-Emmons reaction of the tris(thiophene-2carbaldehyde) 460 with diethyl (benzo[d]thiazol-2-ylmethyl) phosphonate 461 . The trialdehyde $\mathbf{4 6 0}$ was obtained in $93 \%$ yield by formylation of tris(-2-(thiophen-2-yl)vinyl)-10,15-dihydro-5Hdiindolo $\left[3,2-a: 3^{\prime}, 2^{\prime}-c\right]$ carbazole 459 upon treatement with $\mathrm{POCl}_{3}$ in DMF (Scheme 124). Compound 462 showed good thermal and photo stabilities. It can be used as chromophore with significant bathochromic shift of the emission spectra together with a larger Stokes shift in polar solvents due to intramolecular charge transfer.

Lu et al. ${ }^{159}$ reported the synthesis of triindole-cored starshaped molecules 465 in $70 \%$ yield by heating a mixture of 


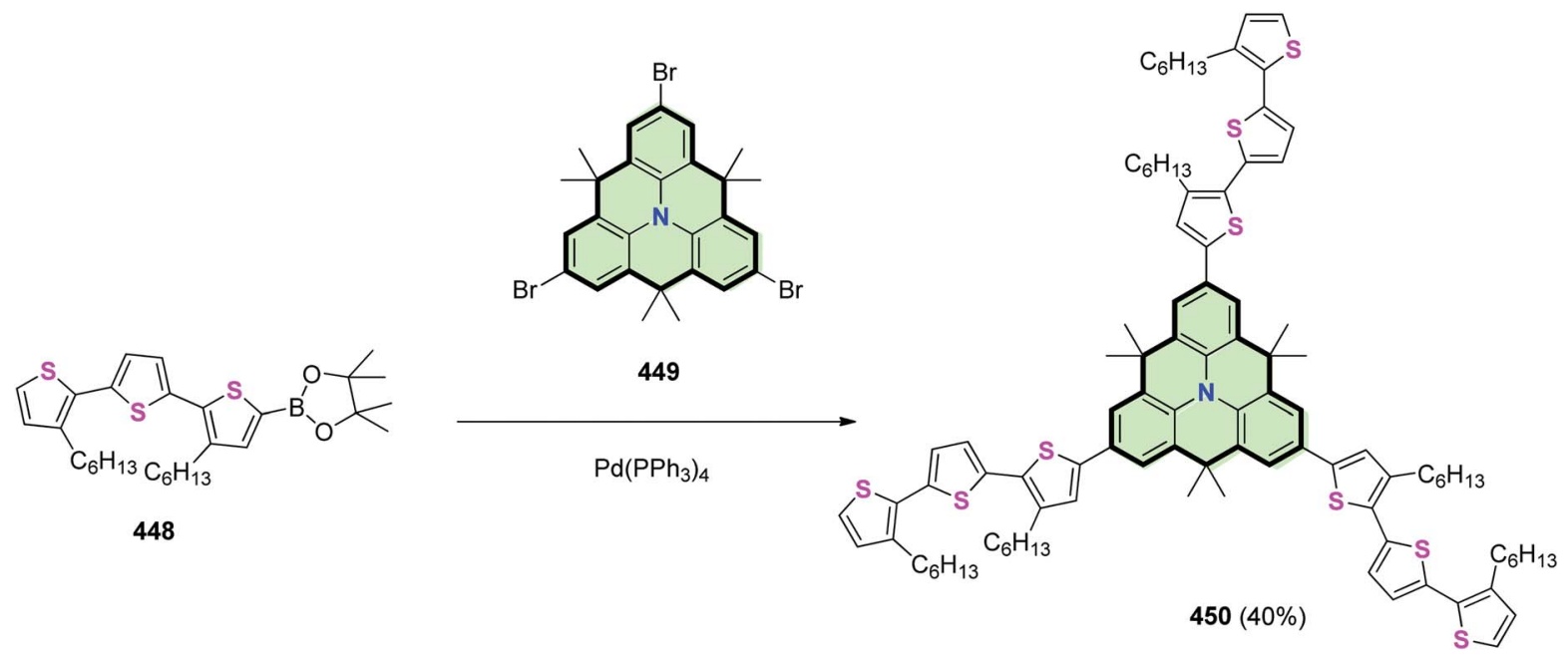

Scheme 121 Synthesis of SSM 450 with benzo[9,1]quinolizino[3,4,5,6,7-defg]acridine core.

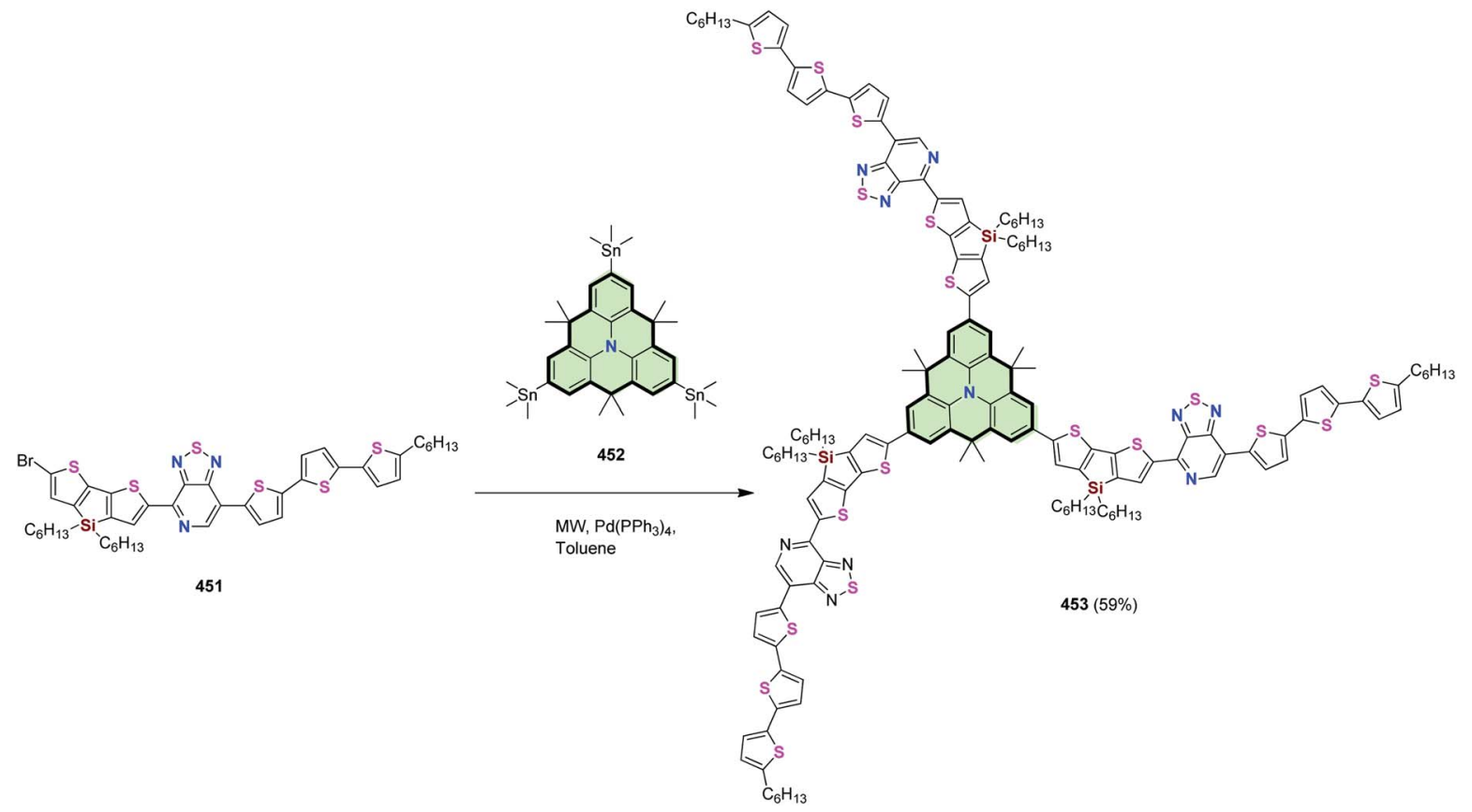

Scheme 122 Synthesis of SSM 453 with benzo[9,1]quinolizino[3,4,5,6,7-defg]acridine core.

5,10,15-trihexyltriindole-2,7,12-triboronic ester 463 and 5-(5bromothiophen-2-yl)thiophene-2-carbaldehyde 464 in the presence of $\mathrm{K}_{2} \mathrm{CO}_{3}$ and $\mathrm{Pd}\left(\mathrm{PPh}_{3}\right)$. On the other hand, heating compound 463 with 4-(5-(4-(5-bromothiophen-2-yl)benzo[c] $[1,2,5]$ thiadiazol-7-yl)-thiophen-2-yl)- $N, N$-diphenylbenzenamine 466 in the presence of $\mathrm{Bu}_{4} \mathrm{NBr}$ and $\mathrm{Pd}\left(\mathrm{PPh}_{3}\right)_{4}$ at reflux afforded triindole-cored star-shaped compound 467 in $75 \%$ yield. The two star-shaped molecules 465 and 467 showed good thermal stability, intensive absorption in a broad region, relatively high hole mobility and high efficiency as organic solar cells (Scheme 125).
4.3.4.9. Anthra[1,2-b:4,3- $\left.b^{\prime}: 5,6-b^{\prime \prime}: 8,7-b^{\prime \prime \prime}\right]$ tetrathiophene. Komiyama et al. ${ }^{\mathbf{1 6 0}}$ reported the synthesis of a star shaped molecule 470 in $44 \%$ yield by the reaction of 2,5,9,12-tetrabromoanthra[1,2- $\left.b: 4,3-b^{\prime}: 5,6-b^{\prime \prime}: 8,7-b^{\prime \prime \prime}\right]$ tetrathiophene $\mathbf{4 6 8}$ with stannyl(thiophen-2-yl)pyrrolo[3,4-c]pyrrole derivative 469 in dry DMF and in the presence of $\mathrm{Pd}\left(\mathrm{PPh}_{3}\right)_{4}($ Scheme 126).

4.3.4.10. Diquinoxalino[2,3-a:2', $3^{\prime}$-c]phenazine. Zhao et al. ${ }^{\mathbf{1 6 1}}$ reported the synthesis of SSM 473 containing hexaazatriphenylene cored fused with perylene-3,4,9,10tetracarboxylic acid bisimides, as conjugated n-type semi- 
Review

View Article Online

RSC Advances

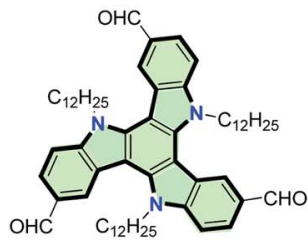

454

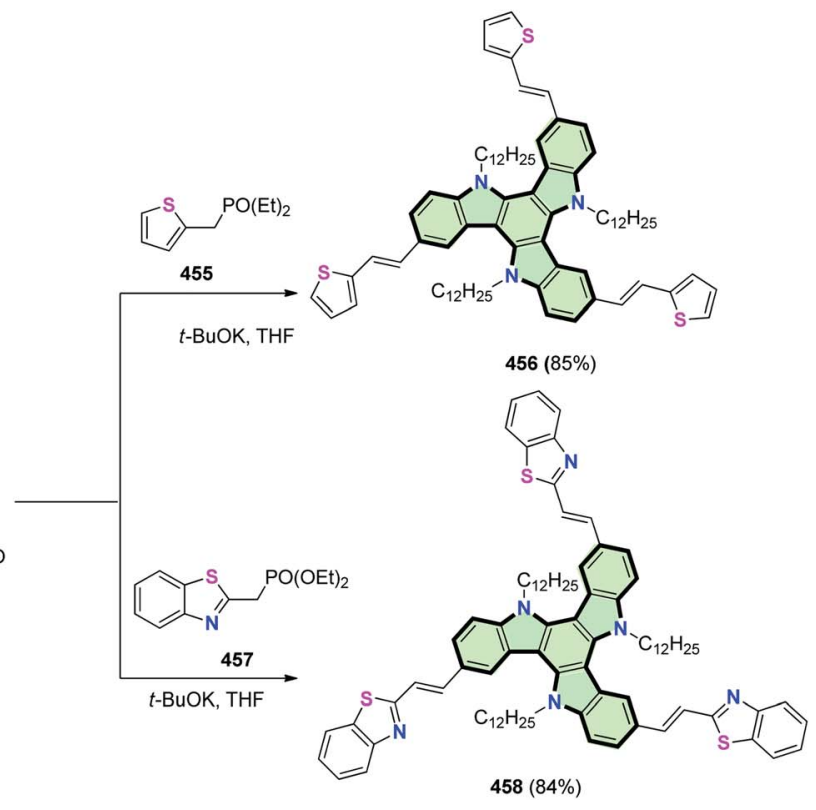

Scheme 123 Synthesis of SSM 456 and 458 with diindolo[3,2-a: $\left.3^{\prime}, 2^{\prime}-c\right]$ carbazole core.
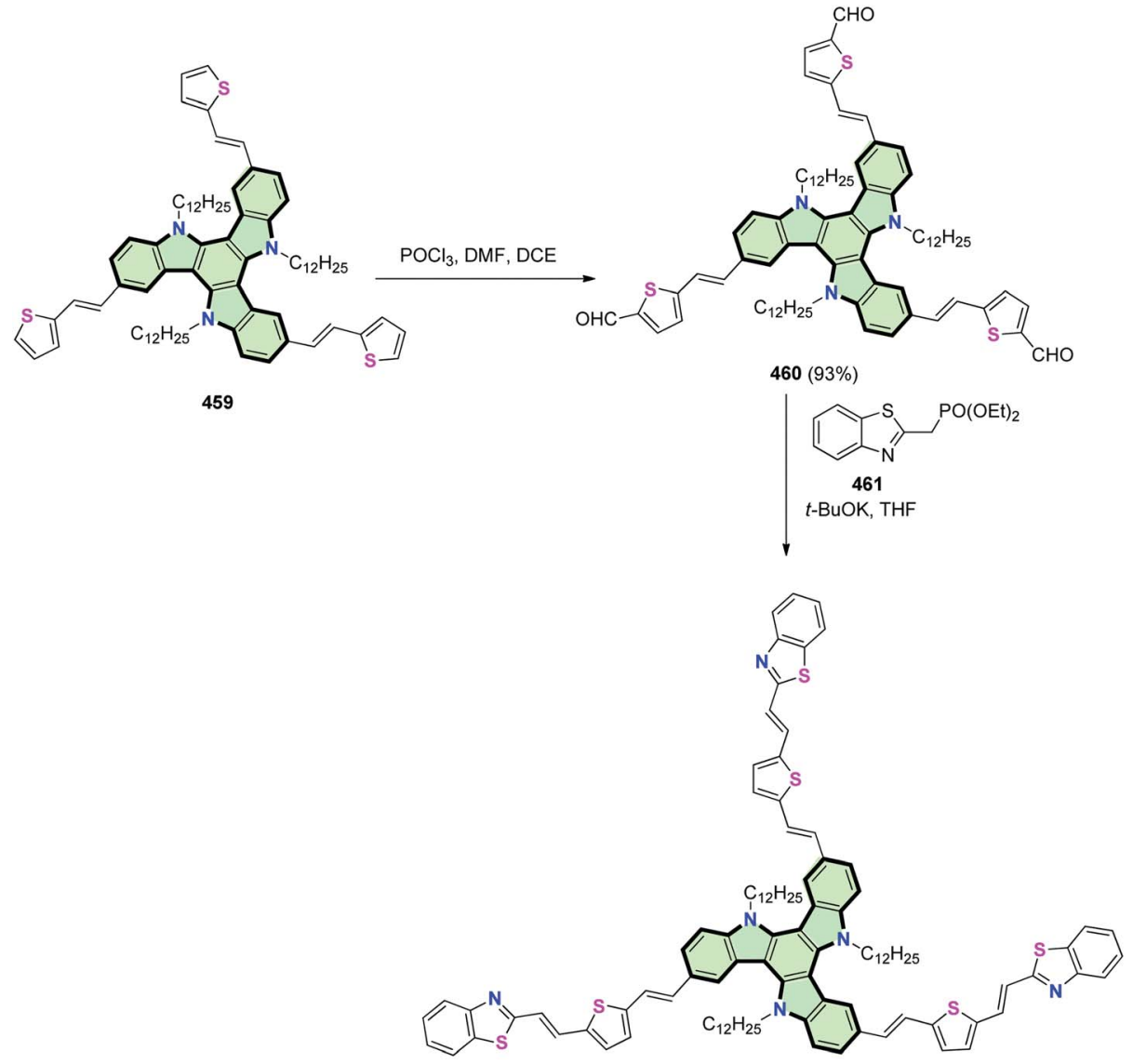

$462(82 \%)$

Scheme 124 Synthesis of SSM 462 with diindolo[3,2-a:3', $\left.2^{\prime}-c\right]$ carbazole core.

This journal is @) The Royal Society of Chemistry 2019

RSC Adv., 2019, 9, 16606-16682 | 16677 


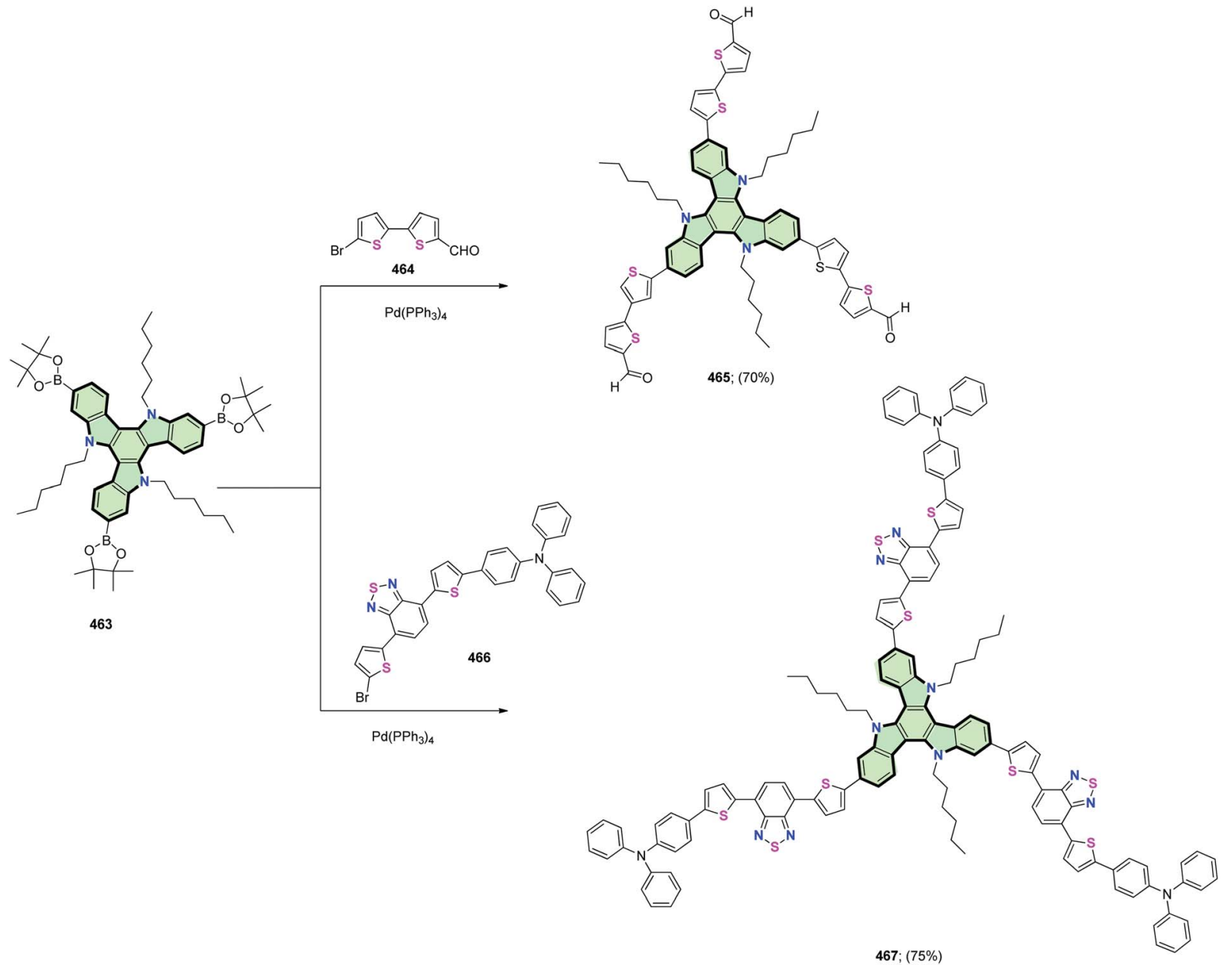

Scheme 125 Synthesis of triindole-cored star-shaped molecules 465 and 467.

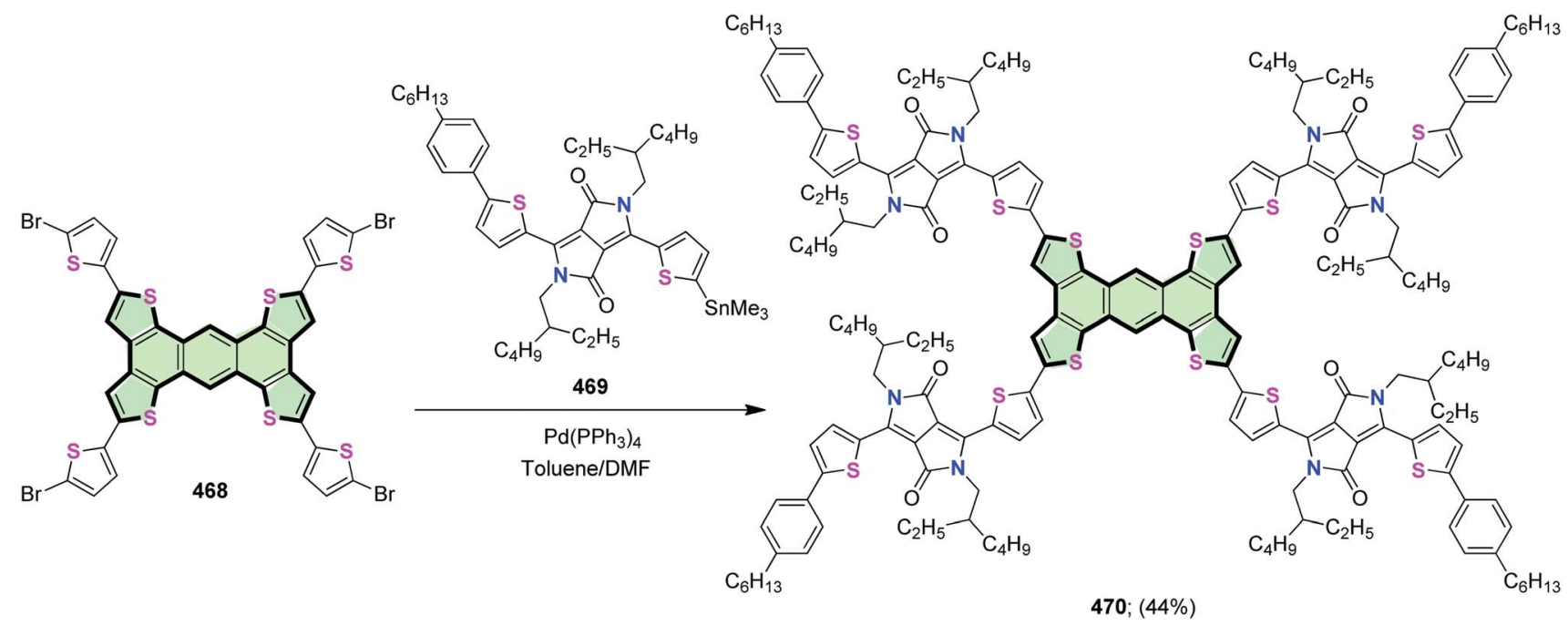

Scheme 126 Synthesis of SSM 470 with anthra[1,2-b:4,3- $\left.b^{\prime}: 5,6-b^{\prime \prime}: 8,7-b^{\prime \prime \prime}\right]$ tetrathiophene core. 

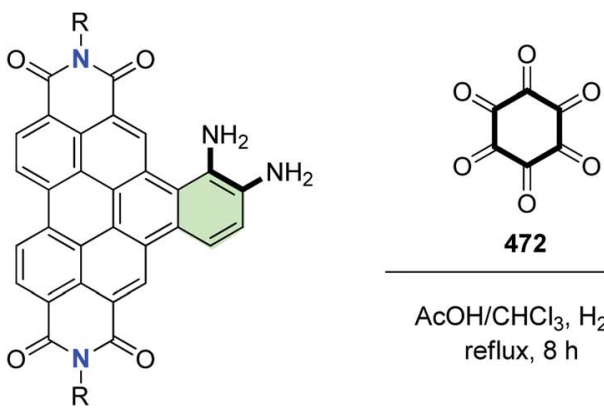

$\mathrm{AcOH} / \mathrm{CHCl}_{3}, \mathrm{H}_{2} \mathrm{O}$

reflux, $8 \mathrm{~h}$

471

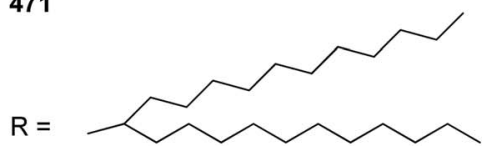

Scheme 127 Synthesis of SSM 473 with hexaazatriphenylene core

conductor in $43 \%$ yield by fusion of 9,10-diaminonaphtho [1,2,3,4-ghi]perylene $\mathbf{4 7 1}$ with cyclohexane-1,2,3,4,5,6hexaone 472 (Scheme 127).

\section{Conclusions}

This review gives an overview of the new developments over the last decades in the synthesis of star-shaped molecules especially those containing heterocyclic core and/or heterocyclic arms. The physical properties of these compounds are markedly different to their linear analogues. These molecules are considered as versatile building blocks for the formation of liquid crystals, dendrimers as well supramolecular host-guest compounds. Their applications in organic solar cells OSCs and as promising candidates for organic semiconducting materials are recently studied. The star-shaped molecules mentioned in this review are arranged in an organized manner with respect to the type of the core as well as the side arms.

The methods described for the synthesis of such compounds includes a variety of synthetic methodologies, among which the $O$-, $S$ - and $\mathrm{N}$-alkylation, condensation and cyclocondensation, cyclotrimerization reactions, and palladium-catalyzed $\mathrm{C}-\mathrm{C}$ and $\mathrm{C}-\mathrm{N}$ bond formation via Heck, Negishi, Sonogashira, Stille and Suzuki cross-coupling reactions seem to be the most interesting strategies.

From a synthetic chemist's perspective, it is extremely challenges to develop new strategies to synthesize novel structures of these molecules.

We hope that this review will be useful not only for organic synthetic chemists, but also for Physicists as well as for those who are interested in the field of industrial applications.

\section{Conflicts of interest}

There are no conflicts to declare.

\section{Notes and references}

1 J. R. Schaefgen and P. J. Flory, J. Am. Chem. Soc., 1948, 70, 2709-2718.

2 M. Morton, T. E. Helminiak, S. D. Gadkary and F. Bueche, J. Polym. Sci., 1962, 57, 471-482.

3 B. Walker, C. Kim and T.-Q. Nguyen, Chem. Mater., 2011, 23, 470-482.

4 J. Roncali, Acc. Chem. Res., 2009, 42, 1719-1730.

5 Y. Lin, Y. Li and X. Zhan, Chem. Soc. Rev., 2012, 41, 4245.

6 H. Muraoka, M. Mori and S. Ogawa, Phosphorus, Sulfur Silicon Relat. Elem., 2015, 190, 1382-1391.

7 J. Cremer and C. A. Briehn, Chem. Mater., 2007, 19, 41554165.

8 Z. Luo, W. Xiong, T. Liu, W. Cheng, K. Wu, Y. Sun and C. Yang, Org. Electron., 2016, 41, 1-7.

9 J. X. Qiu, Y. X. Li, J. L. Miao, Z. W. Zhang and Z. H. Chen, Synth. Met., 2015, 199, 353-359.

10 X. Cheng, J. Zhao, C. Cui, Y. Fu and X. Zhang, J. Electroanal. Chem., 2012, 677-680, 24-30.

11 W. Li, Q. Li, C. Duan, S. Liu, L. Ying, F. Huang and Y. Cao, Dyes Pigm., 2015, 113, 1-7.

12 R. Misra, R. Maragani, C. P. Singh and R. Chari, Dyes Pigm., 2016, 126, 110-117.

13 K. Karon, M. Lapkowski, A. Dabuliene, A. Tomkeviciene, N. Kostiv and J. V. Grazulevicius, Electrochim. Acta, 2015, 154, 119-127.

14 Z. Hao, Y. Liu, Y. Huang, F. Meng, Y. Wang, H. Tan, S. Su and W. Zhu, J. Organomet. Chem., 2017, 835, 52-59.

15 W. Li, L. Chen, Y. Pan, S. Yan, Y. Dai, J. Liu, Y. Yu, X. Qu, Q. Song, M. Ouyang and C. Zhang, J. Electrochem. Soc., 2017, 164, 84-89.

16 A. Irfan, S. Muhammad, A. R. Chaudhry, A. G. Al-Sehemi and R. Jin, Optik, 2017, 149, 321-331. 
17 Y. N. Luponosov, J. Min, A. N. Solodukhin, O. V. Kozlov, M. A. Obrezkova, S. M. Peregudova, T. Ameri, S. N. Chvalun, M. S. Pshenichnikov, C. J. Brabec and S. A. Ponomarenko, Org. Electron., 2016, 32, 157-168.

18 F. A. Olate, M. L. Parra, J. M. Vergara, J. Barberá and M. Dahrouch, Liq. Cryst., 2017, 44, 1173-1184.

19 S. K. Pathak, S. Nath, J. De, S. K. Pal and A. S. Achalkumar, New J. Chem., 2017, 41, 4680-4688.

20 X. Wu, Z. Zhang, H. Hang, Y. Chen, Y. Xu, H. Tong and L. Wang, Macromol. Rapid Commun., 2017, 38, 1-8.

21 N. V. Usol, O. B. Akopova, A. I. Smirnova, I. Maria, N. V. Bumbina, N. V. Zharnikova, N. V. Usol, O. B. Akopova, A. I. Smirnova, I. Maria, N. V. Bumbina and N. V. Zharnikova, Phase Transitions, 2017, 90, 800-807.

22 R. Sharma, R. Maragani and R. Misra, New J. Chem., 2018, 42, 882-890.

23 A. Rananaware, R. S. Bhosale, K. Ohkubo, H. Patil, L. A. Jones, S. L. Jackson, S. Fukuzumi, S. V. Bhosale and S. V. Bhosale, J. Org. Chem., 2015, 80, 3832-3840.

24 A. L. Kanibolotsky, I. F. Perepichka and P. J. Skabara, Chem. Soc. Rev., 2010, 39, 2695-2728.

25 S. K. Pathak, B. Pradhan, R. K. Gupta, M. Gupta, S. K. Pal and A. S. Achalkumar, J. Mater. Chem. C, 2016, 4, 65466561.

26 A. S. Achalkumar, U. S. Hiremath, D. S. S. Rao, S. K. Prasad and C. V. Yelamaggad, J. Org. Chem., 2013, 78, 527-544.

27 E. Westphal, M. Prehm, I. H. Bechtold, C. Tschierske and H. Gallardo, J. Mater. Chem. C, 2013, 1, 8011-8022.

28 P. J. Stackhouse, A. Wilson, D. Lacey and M. Hird, Liq. Cryst., 2010, 37, 1191-1203.

29 P. V. Dmitryakov, M. A. Shcherbina, S. M. Peregudova, G. V. Cherkaev, S. N. Chvalun, J. Brabec and S. A. Ponomarenko, J. Mater. Chem. C, 2016, 4, 7061-7076.

30 S. K. Pathak, S. Nath and J. De, New J. Chem., 2017, 41, 99089917.

31 S. K. Pathak, R. K. Gupta, S. Nath, D. S. S. Rao, S. K. Prasad and A. S. Achalkumar, J. Mater. Chem. C, 2015, 3, 29402952.

32 D. Astruc, E. Boisselier and C. Ornelas, Chem. Rev., 2010, 110, 1857-1959.

33 P. Rajakumar and S. Raja, Tetrahedron Lett., 2008, 49, 65396542.

34 D. L. Reger, R. F. Semeniuc and M. D. Smith, Inorg. Chem., 2003, 42, 8137-8139.

35 W. Zhang and Y. Jin, Dynamic covalent chemistry: principles, reactions, and applications, John Wiley \& Sons, New York City, USA, 2017.

36 M. Grillaud and A. Bianco, J. Pept. Sci., 2015, 21, 330-345.

37 S. Roquet, A. Cravino, P. Leriche, O. Ale, P. Fre, J. Roncali, B. La and V. F. Angers, J. Am. Chem. Soc., 2006, 128, 34593466.

38 C. He, Q. He, Y. Yi, G. Wu, F. Bai, Z. Shuai and Y. Li, J. Mater. Chem., 2008, 18, 4085-4090.

39 K. Rundel, S. Maniam, K. Deshmukh, E. Gann and C. R. Mcneill, J. Mater. Chem. A, 2017, 5, 12266-12277.

40 C. Lu, I. T. Choi, J. Kim and H. K. Kim, J. Mater. Chem. A, 2017, 5, 20263-20276.
41 T. Aytun, P. J. Santos, C. J. Bruns, D. Huang, A. R. Koltonow, M. Olvera De La Cruz and S. I. Stupp, J. Phys. Chem. C, 2016, 120, 3602-3611.

42 K. Lin, B. Xie, Z. Wang, R. Xie, Y. Huang and C. Duan, Org. Electron., 2018, 52, 42-50.

43 V. A. Online, L. Chen and Y. Xiao, RSC Adv., 2015, 5, 3228332289.

44 Y. Zhou, W. Chen, Z. Du, D. Zhu, D. Ouyang, L. Han and R. Yang, Sci. China: Chem., 2015, 58, 357-363.

45 Y. C. Chao, C. H. Chuang, H. L. Hsu, H. J. Wang, Y. C. Hsu, C. P. Chen and R. J. Jeng, Sol. Energy Mater. Sol. Cells, 2016, 157, 666-675.

46 P. Zhou, D. Dang, Q. Wang, X. Duan, M. Xiao, Q. Tao, H. Tan, R. Yang and W. Zhua, J. Mater. Chem. A, 2015, 3, 13568-13576.

47 J. Zhang, L. Xu, J. Chen, P. Shen, M. Ye, N. Y. Yuan and J. N. Ding, Thin Solid Films, 2018, 645, 129-133.

48 C. He, Q. He, X. Yang, G. Wu, C. Yang, F. Bai, Z. Shuai, L. Wang and Y. Li, J. Phys. Chem. C, 2007, 111, 8661-8666.

49 C. He, Q. He, G. Wu, F. Bai and Y. Li, Proc. SPIE, 2007, 6656, $66560 \mathrm{Z}$.

50 G. Wu, G. Zhao, C. He, J. Zhang, Q. He, X. Chen and Y. Li, Sol. Energy Mater. Sol. Cells, 2009, 93, 108-113.

51 C. He, Q. He, Y. He, Y. Li, F. Bai, C. Yang, Y. Ding, L. Wang and J. Ye, Sol. Energy Mater. Sol. Cells, 2006, 90, 1815-1827.

52 J. Roncali, P. Leriche and A. Cravino, Adv. Mater., 2007, 19, 2045-2060.

53 D. Wang and Z. GENG, Can. J. Chem., 2015, 93, 1181-1190.

54 R. Jin, C. R. Chim., 2015, 18, 1-6.

55 R. Jin, J. Mol. Model., 2015, 21, 1-9.

56 F. Goubard and F. Dumur, RSC Adv., 2015, 5, 3521-3551.

57 K. H. Park, W. Kim, J. Yang and D. Kim, Chem. Soc. Rev., 2018, 47, 4279-4294.

58 N. O. Mahmoodi and M. Mohammadi, J. Iran. Chem. Soc., 2018, 15, 311-336.

59 M. Lehmann, Chem.-Eur. J., 2009, 15, 3638-3651.

60 C. Viñas, F. Teixidor and R. Núñez, Inorg. Chim. Acta, 2014, 409, 12-25.

61 H. Zhang, D. Wu, H. Liu and J. Yin, Curr. Org. Chem., 2012, 16, 2124-2158.

62 P. Gale, Chem. Soc. Rev., 2009, 38, 1551-1561.

63 E. De Jesu and J. C. Flores, New J. Chem., 2007, 31, 11611191.

64 M. Thelakkat, Macromol. Mater. Eng., 2002, 287, 442-461.

65 C. Tschierske, Annu. Rep. Prog. Chem., Sect. C: Phys. Chem., 2001, 97, 191-267.

66 P. Agarwala and D. Kabra, J. Mater. Chem. A, 2017, 5, 13481373.

67 A. S. Santra, A. F. Khasanov, A. Mukherjee, M. Rahman, I. S. Kovalev, D. S. Kopchuk, V. Zyryanov, A. Majee, O. N. Chupakhin and N. Charushin, Eur. J. Org. Chem., 2018, 2018, 4351-4375.

68 M. Ishikawa, H. Teramura, K. K. Lee, W. Schneider, A. Naka, H. Kobayashi, Y. Yamaguchi, M. Kikugawa, J. Ohshita, A. Kunai, H. Tang, Y. Harima, T. Yamabe and T. Takeuchi, Organometallics, 2001, 20, 5331-5341. 
69 Y. N. Luponosov, S. A. Ponomarenko, N. M. Surin and A. M. Muzafarov, Org. Lett., 2008, 10, 2753-2756.

70 Y. N. Luponosov, S. A. Ponomarenko, N. M. Surin, O. V. Borshchev, E. A. Shumilkina and A. M. Muzafarov, Chem. Mater., 2009, 21, 447-455.

71 M. Halik, H. Klauk, U. Zschieschang, G. Schmid, W. Radlik, S. Ponomarenko, S. Kirchmeyer and W. Weber, J. Appl. Phys., 2009, 93, 2977-2981.

72 N. P. Yevlampieva, A. P. Khurchak, Y. N. Luponosov and E. A. Kleimyuk, Russ. J. Appl. Chem., 2013, 86, 747-755.

73 Z. Lin, J. Bjorgaard, A. G. Yavuz and E. K. Muhammet, J. Phys. Chem. C, 2011, 115, 15097-15108.

74 H. F. T. Klare and M. Oestreich, Dalton Trans., 2010, 39, 9176-9184.

75 J. Ohshita, Y. Hatanaka, S. Matsui, Y. Ooyama, Y. Harima and Y. Kunugi, Appl. Organomet. Chem., 2010, 24, 540-544.

76 M. F. Mohamed, A. F. Darweesh, A. H. M. Elwahy and I. A. Abdelhamid, RSC Adv., 2016, 6, 40900-40910.

77 F. Cheng, N. Tang, J. Chen, F. Wang and L. Chen, Inorg. Chem. Commun., 2011, 14, 852-855.

78 J. Lellouche, Z. Pomerantz, R. Persky, H. E. Gottlieb and S. Ghosh, Synth. Met., 2011, 161, 2378-2383.

79 Z. Xu, T. Yu, Y. Zhao, H. Zhang, G. Zhao, J. Li and L. Chai, J. Fluoresc., 2016, 26, 149-154.

80 S. Kotha, D. Kashinath, K. Lahiri and R. B. Sunoj, Eur. J. Org. Chem., 2004, 2004, 4003-4013.

81 S. Kotha, S. Todeti, M. B. Gopal and A. Datta, ACS Omega, 2017, 2, 629-6297.

82 J. Luo, Z. Xie, J. W. Y. Lam, L. Cheng, H. Chen, C. Qiu, H. S. Kwok, X. Zhan, Y. Liu, D. Zhu and B. Z. Tang, Chem. Commun., 2001, 1740-1741.

83 Q. Niu, Y. Lu, H. Sun and X. Li, Spectrochim. Acta, Part A, 2013, 107, 377-385.

84 D. Suresh, C. S. B. Gomes, P. S. Lopes, C. A. Figueira, B. Ferreira, P. T. Gomes, E. Di Paolo, A. L. Maåanita, M. T. Duarte, A. Charas, J. Morgado, D. Vila-Viåosa and M. Josø, Chem.-Eur. J., 2015, 21, 1-18.

85 P. Rajakumar, S. Raja and A. Thirunarayanan, Synlett, 2010, 1669-1673.

86 M. E. Salem, A. F. Darweesh, A. M. Farag and A. H. M. Elwahy, J. Heterocycl. Chem., 2017, 54, 586-595.

87 M. Al-Smadi and S. Mohammad, J. Heterocycl. Chem., 2009, 46, 201-206.

88 X. He, L. Chen, Y. Zhao, S. C. Ng, X. Wang, X. Sun and X. M. Hu, RSC Adv., 2015, 5, 15399-15406.

89 S. Nath, S. K. Pathak, J. De, S. K. Pal and A. S. Achalkumar, Mol. Syst. Des. Eng., 2017, 2, 478-489.

90 C. Yang, X. Chen, X. Lu, Q. Zhou and Y. Yang, Chem. Commun., 1997, 2041-2042.

91 M. Al-Smadi and S. Ratrout, J. Heterocycl. Chem., 2004, 41, 887-891.

92 A. H. M. Elwahy, R. M. Sarhan and M. A. Badawy, Curr. Org. Synth., 2013, 10, 786-790.

93 K. Rajesh, B. P. Reddy and V. Vijayakumar, Can. J. Chem., 2011, 89, 1236-1244.

94 I. A. Abdelhamid, A. F. Darweesh and A. H. M. Elwahy, Tetrahedron Lett., 2015, 56, 7085-7088.
95 X. Yin and M. Tan, Synth. Commun., 2003, 33, 1113-1119.

96 D. A. McMorran and P. J. Steel, Tetrahedron, 2003, 59, 37013707.

97 N. A. Abd El-Fatah, A. F. Darweesh, A. A. Mohamed, I. A. Abdelhamid and A. H. M. Elwahy, Tetrahedron, 2017, 73, 1436-1450.

98 X. Yin, J. Miao, Y. Xiang, H. Wu and Y. Cao, Macromol. Rapid Commun., 2015, 36, 1658-1663.

99 D. Shi, Y. Wang, Y. Liu, Z. Zhang, J. Luo, J. He, Q. Chen, G. Lei and W. Zhu, Chem.-Asian J., 2012, 7, 2096-2101.

100 C. Aubert, C. Dallaire, G. Pèpe, E. Levillain, G. Félix and M. Gingras, Eur. J. Org. Chem., 2012, 2012, 6145-6154.

101 J. Pang, E. J. P. Marcotte, C. Seward, R. S. Brown and S. Wang, Angew. Chem., 2001, 4166-4169.

102 Y. Xiang, Q. Wang, G. Wang, X. Li and D. Zhang, Tetrahedron, 2016, 72, 2574-2580.

103 J. X. Qiu, Y. X. Li, X. F. Yang, Y. Nie, Z. W. Zhang, Z. H. Chen and G. X. Sun, J. Mater. Chem. C, 2014, 2, 5954-5962.

104 J. Qiu, Y. Li, J. Miao, Z. Zhang and Z. Chen, Synth. Met., 2015, 199, 353-359.

105 K. Jiang, Y. C. Wu, H. Q. Wu, S. L. Li, S. H. Luo and Z. Y. Wang, J. Photochem. Photobiol., A, 2018, 350, 52-58.

106 Y. Wu, J. Huo, L. Cao, S. Ding, L. Wang, D. Cao and Z. Wang, Sens. Actuators, B, 2016, 237, 865-875.

107 W. White, Z. M. Hudson, X. Feng, S. Han, Z. H. Lu and S. Wang, Dalton Trans., 2010, 39, 892-899.

108 F. Wei and G. X. Yu, J. Lumin., 2013, 134, 710-717.

109 M. R. A. Al-Mandhary, C. M. Fitchett and P. J. Steel, Aust. J. Chem., 2006, 59, 307-314.

110 P. Singh and S. Kumar, Tetrahedron Lett., 2006, 47, 109-112.

111 P. Taylor, S. Kumar, S. Kaur and G. Singh, Supramol. Chem., 2010, 200, 37-40.

112 Y. Cui and S. Wang, J. Org. Chem., 2006, 71, 6485-6496.

113 F. Magnan and J. L. Brusso, RSC Adv., 2016, 6, 97420-97429.

114 M. H. Hoang, M. J. Cho, D. C. Kim, K. H. Kim, J. W. Shin, M. Y. Cho, J. soo Joo and D. H. Choi, Org. Electron., 2009, 10, 607-617.

115 K. Kotwica, A. S. Kostyuchenko, P. Data, T. Marszalek, L. Skorka, T. Jaroch, S. Kacka, M. Zagorska and A. Pron, Chem.-Eur. J., 2016, 22, 1-13.

116 K. Madasamy and M. Kathiresan, ChemistrySelect, 2016, 1, 354-359.

117 A. Brzeczek, P. Ledwon, P. Data, P. Zassowski, S. Golba, K. Walczak and M. Lapkowski, Dyes Pigm., 2015, 113, 640-648.

118 W. Jiang, Z. Ge, P. Cai, B. Huang, Y. Dai, Y. Sun, J. Qiao, L. Wang, L. Duan and Y. Qiu, J. Mater. Chem., 2012, 22, 12016-12022.

119 L. Hu, J. Li, J. Huang and J. Yin, Chin. J. Chem., 2017, 35, 9397.

120 W. Hung, P. Chiang, S. Lin, W. Tang, S. Liu, P. Chou, Y. Hung and K. Wong, ACS Appl. Mater. Interfaces, 2016, 8, 4811-4818.

121 L. Peng, C. Chen, C. R. Gonzalez and V. Balogh-Nair, Int. J. Mol. Sci., 2002, 3, 1145-1161.

122 M. Ak, M. S. Ak and L. Toppare, Macromol. Chem. Phys., 2006, 207, 1351-1358. 
123 P. Leriche, F. Piron, E. Ripaud, P. Frère, M. Allain and J. Roncali, Tetrahedron Lett., 2009, 50, 5673-5676.

124 L. Zou, Z. Liu, X. Yan, Y. Liu, Y. Fu, J. Liu, Z. Huang, X. Chen and J. Qin, Eur. J. Org. Chem., 2009, 2009, 5587-5593.

125 N. O. Mahmoodi and M. Mohammadi, Res. Chem. Intermed., 2017, 43, 2641-2651.

126 H. Duan, L. Wang, D. Qin, X. Li, S. Wang and Y. Zhang, Synth. Commun., 2011, 41, 380-384.

127 J. A. Seijas, M. Carracedo-Taboada, X. Feás and M. P. Vázquez-Tato, Int. Electron. Conf. Synth. Org. Chem., 15th, 2011, 15, 1-30.

128 E. Beltra, L. Serrano, T. Sierra and R. Gime, Org. Lett., 2010, 12, 2649-2652.

129 E. Beltrán, J. L. Serrano, T. Sierra and R. Giménez, J. Mater. Chem., 2012, 22, 7797-7805.

130 B. Pradhan, S. K. Pathak, R. K. Gupta, M. Gupta, S. K. Pal and A. S. Achalkumar, J. Mater. Chem. C, 2016, 4, 61176130.

131 M. Ali, Z. Eskandar, A. Abdoli and M. Shiri, Mol. Diversity, 2010, 14, 809-813.

132 A. R. Karimi, Z. Dalirnasab, M. Karimi and F. Bagherian, Synthesis, 2013, 45, 3300-3304.

133 N. Mahmoodi, K. Tabatabaeian and H. Kiyani, Helv. Chim. Acta, 2012, 95, 536-542.

134 Z. Erdem, H. Bingol, A. O. Saf, E. Torlak and A. Coskun, J. Hazard. Mater., 2010, 183, 251-255.

135 M. Shiri, A. Zol and A. Shamsian, J. Heterocycl. Chem., 2012, 49, 1429-1433.

136 R. Ghorbani-Vaghei, Z. Toghraei-Semiromi, M. Amiri and R. Karimi-Nami, Mol. Diversity, 2013, 17, 307-318.

137 E. Karatas and H. I. Ucan, J. Heterocycl. Chem., 2016, 54, 692-698.

138 A. R. Karimi, Z. Eftekhari, M. Karimi and Z. Dalirnasab, Synthesis, 2014, 46, 3180-3184.

139 G. Sathiyan and P. Sakthivel, Dyes Pigm., 2017, 143, 444454.

140 L. Zhang, L. Zou, J. Xiao, P. Zhou, C. Zhong, X. Chen, J. Qin, I. F. A. Mariz and E. Maçôas, J. Mater. Chem., 2012, 22, 16781-16790.

141 M. Nikpassand, L. Zare Fekri, H. Badri and L. Asadpour, Synthesis and Antimicrobial Activity of Mono, Bis and Tris 2Amino-4H Chromenes, 2015, vol. 12.

142 L. Qian, Y. Qiu, J. Liu, F. Xin and Y. Chen, J. Appl. Polym. Sci., 2014, 131, 1-8.
143 Z. Bai, L. Song, Y. Hu, X. Gong and R. K. K. Yuen, J. Anal. Appl. Pyrolysis, 2014, 105, 317-326.

144 S. Yang, J. Wang, S. Huo, M. Wang and L. Cheng, Synthesis of a Phosphorus/Nitrogen-Containing Additive with Multifunctional Groups and Its Flame-Retardant Effect in Epoxy Resin, 2015, vol. 54.

145 A. R. Karimi, Z. Dalirnasab and M. Karimi, Synthesis, 2014, 46, 917-922.

146 K. M. Omer, S. Ku, Y. Chen, K. Wong and A. J. Bard, J. Am. Chem. Soc., 2010, 10944-10952.

147 R. Liu, M. Shu, J. Hu, S. Zhu, H. Shi and H. Zhu, Dyes Pigm., 2017, 137, 174-181.

148 C. Y. Huang, W. H. Lee and R. H. Lee, $R S C A d v ., 2014$, 4, 48150-48162.

149 S. Shiau, C. Chang, W. Chen, H. Wang, R. Jeng and R. Lee, Dyes Pigm., 2015, 115, 35-49.

150 R. Sheng, Q. Liu, M. Qiu, C. Gu, Y. Zhou, J. Ren, M. Sun and R. Yang, Chem. Lett., 2015, 44, 291-293.

151 M. J. Bosiak, P. Trzaska, D. Kędziera and J. Adams, Dyes Pigm., 2016, 129, 199-208.

152 H. Shi, D. Xin, X. Dong, J. X. Dai, X. Wu, Y. Miao, L. Fang, H. Wang and M. M. F. Choi, J. Mater. Chem. C, 2014, 2, 2160-2168.

153 H. Tan, W. Peng, H. Liu, Y. Luo, Y. Chen and L. Duan, Eur. J. Org. Chem., 2016, 2016, 5127-5135.

154 A. Riaço, I. Arrechea-Marcos, M. J. Mancheço, M. Burrezo, A. De Peça, S. Loser, A. Timalsina and A. Facchetti, Chem.-Eur. J., 2016, 22, 6374-6381.

155 Y. Jiang, D. Yu, L. Lu, C. Zhan, D. Wu, W. You, Z. Xie and S. Xiao, J. Mater. Chem. A, 2013, 1, 8270-8279.

156 S. Paek, H. Choi, J. Sim, K. Song, J. K. Lee and J. Ko, J. Phys. Chem. C, 2014, 118, 27193-27200.

157 K. Lim, S. Y. Lee, K. Song, G. D. Sharma and J. Ko, J. Mater. Chem. C, 2014, 2, 8412-8422.

158 J. Shao, Z. Guan, Y. Yan, C. Jiao, Q. Xu and C. Chi, J. Org. Chem., 2011, 76, 780-790.

159 Z. Lu, C. Li, T. Fang, G. Li and Z. Bo, J. Mater. Chem. A, 2013, 1, 7657-7665.

160 H. Komiyama, C. Adachi and T. Yasuda, Beilstein J. Org. Chem., 2016, 12, 1459-1466.

161 H. W. Zhenbo Zhao and Y. Xiao, RSC Adv., 2013, 3, 2137321376. 